\title{
The ground thermal regime of the Peel Plateau, Northwest Territories, Canada
}

\author{
by \\ Hugh Brendan O’Neill, B.Sc., M.Sc. \\ A dissertation submitted to the \\ Faculty of Graduate and Postdoctoral Affairs \\ in partial fulfillment of the requirements for the degree of
}

Doctor of Philosophy in Geography

Department of Geography and Environmental Studies

Carleton University

Ottawa, Ontario

December, 2016

(C) Copyright

Hugh Brendan O'Neill, 2016 



\section{Abstract}

The near-surface ground thermal regime of continuous permafrost was investigated on Peel Plateau, Northwest Territories, Canada. Extensive road maintenance has been necessary on the Plateau due to the thaw of ground ice near the Dempster Highway road embankment. This thesis examines permafrost conditions in undisturbed terrain and in disturbed ground at the road embankment.

Field data from 2010-15 provided a systematic examination of permafrost temperatures in forest and tundra vegetation on Peel Plateau and of the thermal disturbance from snow accumulation at the highway. Ground temperatures and measurements of associated controlling factors were used to characterize permafrost conditions across an elevational treeline in undisturbed settings. Permafrost conditions were also examined at the embankment toe and at a snow fence near the road to characterize disturbed ground thermal regimes in the region. Numerical simulations were calibrated with field measurements to assess the influence of varying snow accumulation characteristics (depth, density, rate, timing) on the evolution of ground temperatures at disturbed sites.

Annual mean permafrost temperatures increased across treeline from about $-2.5{ }^{\circ} \mathrm{C}$ in lowland forest to about $-1.5^{\circ} \mathrm{C}$ in tundra, coinciding with higher air temperatures due to winter inversions, and earlier snow accumulation at tundra sites. Rapid and deep snow accumulation at the road embankment toe has resulted in annual mean 
ground temperatures typically just below $0{ }^{\circ} \mathrm{C}$, thaw depths in excess of $5 \mathrm{~m}$, and the development of perennially unfrozen zones (taliks). Numerical simulations of the ground thermal regime closely reproduced measured temperatures near the road. This enabled the effect of limiting snow depth and increasing density to be investigated as a potential method to mitigate permafrost thaw. The simulations indicated that ground temperatures and thaw depths may thereby be significantly reduced at the embankment toe. The long-term disturbance to permafrost was then investigated in the field and simulated numerically in two-dimensions at a snow fence near the road embankment. A talik developed under the fence after 25 years in the simulation. Permafrost thaw in the simulation continued for several decades without reaching equilibrium, demonstrating the sensitivity of warm permafrost to changes in surface conditions that initiate thermokarst. 
To "the few" 


\section{Acknowledgments}

The completion of this thesis would not have been possible without the support of many individuals and organisations.

The research was funded by the Northwest Territories Cumulative Impacts Monitoring Program, The Natural Science and Engineering Research Council (NSERC), Transport Canada, The W. Garfield Weston Foundation, and the Northern Scientific Training Program of Aboriginal Affairs and Northern Development Canada. The research is a contribution from the NSERC Frontiers Arctic Development and Adaptation to Permafrost in Transition programme and Transport Canada's Network of Expertise in Northern Transportation Infrastructure Research. The research was supported by the the Tetlit Gwich'in Renewable Resources Council and the Aurora Research Institute.

I thank the many field assistants and guides from Fort McPherson who helped with field data collection: Abe Snowshoe, Steven Tetlichi, Christine Firth, John Itsi, Clifford Vaneltsi, Jeff Moore, Adrian Gaanderse, Emily Cameron, Krista Chin, Marcus Phillips, Blair Kennedy, and Dominique Hill. Thank you to Steven, Abe, Christine, John, and Clifford for sharing their intimate knowledge of their home, and making me feel welcome in the community. Thanks to Jeff, Adrian, Emily, Krista, Marcus, and Blair for all the memories we made while sipping the malty delights of Yukon and Scotland. The residents of Fort McPherson were very helpful 
in a number of logistical matters, from helping me to find accommodation, to fixing drilling equipment and flat tires. Mahsi-cho.

I am grateful for constructive conversations over the last many years with Pascale Roy-Léveillée, Peter Morse, Marcus Phillips, Jeff Moore, Adrian Gaanderse, Stephan Gruber, Kumari Karunaratne, Caroline Duschene, Mark Ednie, Simon Dumais, Loriane Périer, and certainly many others that I am forgetting.

Thank you to my supervisor, Chris Burn, for being supportive, available, and critical (always in the good way), and constantly challenging me throughout my Master's and Ph.D. research. Also thanks for all the chats that expanded my understanding of permafrost and the world in general, and the "soft drinks", cookies, and tea shared around the A330 table. I am also very appreciative of my committee members, Steve Kokelj and Steve Wolfe, who have helped me greatly throughout the research process.

Finally, thank you to my family and friends for everything you have done for me over the past five years. You know who you are, and I am truly lucky to have you all in my entourage. 


\section{Preface}

\section{Integrated manuscripts}

Chapters 4-6 of this thesis are drawn directly or developed from manuscripts that are published or are in preparation for publication at the time of thesis submission. Changes were made to the published versions as follows: (1) study area description and methods (e.g., instrumentation and measurement equipment) were removed from all manuscripts and included in the introductory chapters to eliminate redundancy; (2) a numerical modeling component, not included in the original manuscript, was added to Chapter 5; (3) Chapter 6 is a combination of two manuscripts (see below). The original citations for these articles are:

Chapter 4: Permafrost conditions across tree line on Peel Plateau. published as: O’Neill, H.B., Burn C.R., Kokelj S.V., and Lantz T.C. (Accepted 30 Jan 2015), 'Warm' tundra: atmospheric and near-surface ground temperature inversions across an alpine treeline in continuous permafrost, western Arctic, Canada. Permafrost and Periglacial Processes, 26(2): 103-118.

Chapter 5: The anthropogenic thermal regime: permafrost conditions at the Dempster Highway road embankment. Developed from the manuscript published as: O’Neill, H.B., Burn, C.R., and Kokelj, S.V. (2015), Field measurements of permafrost 
conditions beside the Dempster Highway embankment, Peel Plateau, NWT. Paper 380. Proceedings, 68th Canadian Geotechnical Conference and 7th Canadian Permafrost Conference, 21-23 September 2015, Québec City, QC, Canadian Geotechnical Society, Richmond, BC. 7 p. Available at: http://carleton.ca/permafrost/canadianpermafrost-conference/

Chapter 6: Permafrost degradation at snow fences. published as: O'Neill H.B., and Burn C.R. (Accepted 17 March 2016), Talik formation at a snow fence in continuous permafrost, western Arctic Canada. Permafrost and Periglacial Processes. DOI: 10.1002/ppp.1905

and

O'Neill, H.B., and Burn, C.R. (2015), Permafrost degradation adjacent to snow fences along the Dempster Highway, Peel Plateau, NWT. Paper 219. Proceedings, 68th Canadian Geotechnical Conference and 7th Canadian Permafrost Conference, 21-23 September 2015, Québec City, QC, Canadian Geotechnical Society, Richmond, BC. 7 p. Available at: http://carleton.ca/permafrost/canadianpermafrost-conference/

Additional refereed and non-refereed research contributions related to this thesis are listed in Appendix B.

\section{Statements of co-authorship}

Chapters 4-6 of this thesis are drawn from papers that have been published in refereed journals or in conference proceedings. The authors of each article have read 
and signed the following three statements outlining the role of Hugh Brendan O'Neill as principal investigator and main author on each publication:

(1) I, Christopher R. Burn, as co-author of "'Warm' tundra: atmospheric and nearsurface ground temperature inversions across an alpine treeline in continuous permafrost, western Arctic, Canada", published in the peer-reviewed journal Permafrost and Periglacial Processes, of "Talik formation at a snow fence in continuous permafrost, western Arctic Canada" published in Permafrost and Periglacial Processes, of "Permafrost degradation adjacent to snow fences along the Dempster Highway, Peel Plateau, NWT", in the Proceedings of the 68th Canadian Geotechnical Conference and 7th Canadian Permafrost Conference, 21-23 September 2015, Québec City, $Q C$, and of "Field measurements of permafrost conditions beside the Dempster Highway embankment, Peel Plateau, NWT", in the Proceedings of the 68th Canadian Geotechnical Conference and 7th Canadian Permafrost Conference, 21-23 September 2015, Québec City, QC, acknowledge Hugh Brendan O’Neill as the lead contributing author of these manuscripts. Brendan designed and performed the field studies, obtained and analyzed all data, and wrote and revised the manuscripts.

I, Christopher R. Burn, have contributed to the published papers in this thesis as supervisor of Hugh Brendan O’Neill during the doctoral program in geography. This has entailed discussion, criticism, advice, and editorial contributions to the design, field investigations, analysis, and writing of this thesis. These activities are entirely consistent with the role of thesis supervisor.

(2) I, Steve V. Kokelj, as co-author of "'Warm' tundra: atmospheric and near-surface ground temperature inversions across an alpine treeline in continuous permafrost, western Arctic, Canada" and "Field measurements of permafrost conditions beside 
the Dempster Highway embankment, Peel Plateau, NWT", acknowledge Hugh Brendan O'Neill as the manuscripts' lead contributing author. Brendan designed and performed the studies, obtained and analyzed all data, and wrote and revised the manuscripts.

I, Steve V. Kokelj, have contributed to the published papers in the role of thesis committee member and principal investigator in the Northwest Territories Cumulative Impacts Monitoring Program (NWT CIMP) project, the community-driven research programme to which the papers in this thesis contribute. This involvement has included contributions to the design and implementation of field data collection, the supply of field instrumentation, discussion, criticism, and editorial revisions of the manuscripts. These activities have been entirely consistent with the roles of thesis committee member and principal investigator of the NWT CIMP project.

(3) I, Trevor C. Lantz, as co-author of "Warm' tundra: atmospheric and near-surface ground temperature inversions across an alpine treeline in continuous permafrost, western Arctic, Canada", acknowledge Hugh Brendan O'Neill as the manuscript's lead contributing author. Brendan designed and performed the study, obtained and analyzed all data, and wrote and revised the manuscript.

I, Trevor C. Lantz, have contributed to the published paper in the role of a research partner and an investigator in the NWT CIMP project. This involvement has included assistance in the field, discussion, editorial revisions of the manuscript, and the contribution of ten data points to Figure 4.8 in the thesis (Figure 8 in the published paper). These activities have been entirely consistent with the roles of a research partner and investigator in the NWT CIMP project.

Signed statements are included in Appendix A. 


\section{Copyrighted material}

The copyright for most figures from Chapters 4 and 6 is held by John Wiley \& Sons, Inc. Permission for reproduction was obtained for these figures. The figures in question are Figures 4.1-4.11, and Figures 6.3-6.6 and 6.9. Proof of permission is included in Appendix C, and so is not listed for each figure. Copyright to the Canadian Permafrost Conference papers is held by the authors, because no assignment has been made to the Canadian Geotechnical Society, the organization that produced the proceedings.

\section{Citing material in this thesis}

Wherever possible, material from this thesis should be cited by referring to the published journal articles (references listed above). Otherwise, the theis may be cited as:

O'Neill, H.B. (2016), The ground thermal regime of the Peel Plateau, Northwest Territories, Canada. Ph.D. Thesis, Carleton University, Ottawa, ON. 


\section{Table of Contents}

Abstract

Acknowledgments $\quad$ vi

Preface viii

Table of Contents xiii

List of Tables $\quad$ xix

List of Figures $\quad$ xxiii

Nomenclature $\quad$ xxxiv

1 Overview 1

1.1 Introduction . . . . . . . . . . . . . . . . . 1

1.2 Peel Plateau . . . . . . . . . . . . . . . . . . . 3

1.3 Research objectives . . . . . . . . . . . . . . . . 7

1.4 Thesis structure . . . . . . . . . . . . . . . . . . 8

2 Background $\quad 10$

2.1 Introduction . . . . . . . . . . . . . . . . . 10

2.2 The thermal regime of permafrost . . . . . . . . . . . 11 
$2.2 .1 \quad$ Permafrost. . . . . . . . . . . . . . . . . . . . . 11

2.2.2 The climate-permafrost relation . . . . . . . . . . . . 13

2.2 .3 The surface offset . . . . . . . . . . . . . . . . . . . 13

2.2.4 The annual thermal regime of permafrost . . . . . . . . 15

2.2 .5 Conductive heat flow . . . . . . . . . . . . . . 15

2.2 .6 Ground thermal properties . . . . . . . . . . . . . . 17

2.2.7 The thermal offset . . . . . . . . . . . . . . . . . . 19

2.2 .8 Non-conductive heat flow . . . . . . . . . . . . . . . 20

2.2.9 Latent heat and unfrozen water content . . . . . . . . . . . . 21

2.3 Environmental influences on permafrost temperatures . . . . . . . 23

2.3 .1 Vegetation . . . . . . . . . . . . . . . . . . 23

2.3.2 Surface organic layer . . . . . . . . . . . . . . . . . 24

2.3 .3 Snow . . . . . . . . . . . . . . . . . . 26

2.3.4 Permafrost conditions across treeline . . . . . . . . . . 28

2.4 Study area: Peel Plateau region, Northwest Territories _ . . . . . . . 30

2.4.1 Physiography and research context . . . . . . . . . 30

2.4 .2 Climate . . . . . . . . . . . . . . . . . . 31

2.4.3 Geology and surficial materials . . . . . . . . . . . . 32

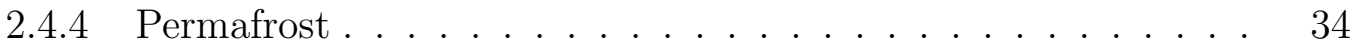

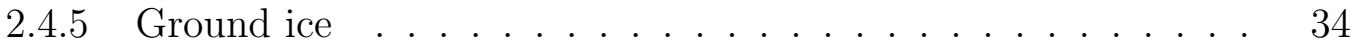

2.4 .6 Vegetation .................... 35

2.4.7 The Dempster Highway _. . . . . . . . . . . . . . 37

3 Methods 42

3.1 Introduction . . . . . . . . . . . . . . . . . 42

3.2 Study design and site selection . . . . . . . . . . . . . 43 
3.2.1 Ground temperatures across tree line . . . . . . . . . . . . . 44

3.2.2 Ground temperatures at the road embankment toe . . . . . . 45

3.2.3 Disturbance at snow fences . . . . . . . . . . . . . . . . 46

3.3 Logistics . . . . . . . . . . . . . . . . . . . . . . . 47

3.4 Key field data collection methods . . . . . . . . . . . . . . . 47

3.4.1 Ground and air temperatures . . . . . . . . . . . 47

3.4.2 Snow surveys . . . . . . . . . . . . . . . . . 52

3.4.3 Active-layer thickness and thaw depths . . . . . . . . . . . 54

3.4.4 Soil moisture content determination . . . . . . . . . . . . 55

3.4.5 Excess-ice content determination . . . . . . . . . . . 56

3.5 Study design limitations . . . . . . . . . . . . . . . . . 58

3.6 Data collection limitations . . . . . . . . . . . . . . 60

3.7 Field observations and modelling . . . . . . . . . . . . . . . 61

3.7.1 Numerical simulations . . . . . . . . . . . . . . . . 63

3.8 Summary ......................... 66

4 Permafrost conditions across tree line on Peel Plateau 68

4.1 Introduction . . . . . . . . . . . . . . . . . . 68

4.2 Study sites . . . . . . . . . . . . . . . . . . . . . . 71

4.2.1 Lowland spruce forest $(\mathrm{LSF})$. . . . . . . . . . . . . . 73

4.2.2 Upland spruce forest (USF) . . . . . . . . . . . . . . . 73

4.2.3 Tall-shrub tundra $(\mathrm{TST}) \ldots \ldots$. . . . . . . . . . . . . . . 73

4.2.4 Dwarf-shrub tundra (DST) . . . . . . . . . . . . 74

4.2.5 Site-scale topography and moisture contents . . . . . . . . . . 74

4.3 Methods . . . . . . . . . . . . . . . . . . . 75

4.3.1 Air and ground temperatures ............. . . 75 
4.3.2 Snow surveys and iButton arrays . . . . . . . . . . . . 76

4.3.3 Vegetation heights . . . . . . . . . . . . . . 77

4.3.4 Statistical analyses . . . . . . . . . . . . . . . . 78

4.4 Results . . . . . . . . . . . . . . . . . . . . . 78

4.4.1 Air temperature regime . . . . . . . . . . . 78

4.5 Snow conditions . . . . . . . . . . . . . . . . . . . . . 79

4.5.1 Permafrost conditions across tree line . . . . . . . . . . . 85

4.5.2 Ground temperatures and snow cover . . . . . . . . . . . . 85

4.5.3 Active-layer thicknesses . . . . . . . . . . . . . . . . . 90

4.6 Discussion . . . . . . . . . . . . . . . . . . . . . . . . . . 94

4.6.1 Air temperatures ................... 94

4.6.2 Active-layer thicknesses . . . . . . . . . . . . . . . 95

4.6.3 Snow conditions . . . . . . . . . . . . . . . . . . . . . . . 98

4.6.4 Permafrost conditions . . . . . . . . . . . . . . . . . . . . 99

4.7 Conclusions . . . . . . . . . . . . . . . . . . . . 102

5 The anthropogenic thermal regime: permafrost conditions at the $\begin{array}{ll}\text { Dempster Highway road embankment } & 104\end{array}$

5.1 Introduction . . . . . . . . . . . . . . . . . . . . . 104

5.2 Background . . . . . . . . . . . . . . . . 106

5.3 Study area . . . . . . . . . . . . . . . . . . . . . 108

5.4 Field methods . . . . . . . . . . . . . . . . . . . . . . . . . . . 111

5.4 Site selection . . . . . . . . . . . . . . 111

5.4.2 Measurements . . . . . . . . . . . . . . . . 111

5.5 Numerical simulations . . . . . . . . . . . . . . . . . . . . 114

5.5.1 Ground materials and element spacing . . . . . . . . . . 114 
5.5.2 Initial temperature profile . . . . . . . . . . . . 115

5.5.3 Transient simulations . . . . . . . . . . . . . . . . . . . . . . 119

5.6 Results . . . . . . . . . . . . . . . . . . . . . . . . . . . . . . 125

5.6 .1 Field measurements . . . . . . . . . . . . . . . . . 125

5.6.2 Simulation results . . . . . . . . . . . . . . . . . . . . . . . 129

5.7 Discussion . . . . . . . . . . . . . . . . . . . . . . . . . . . . . . . . 141

5.7 .1 Field conditions . . . . . . . . . . . . . . . . . . . . . . 141

5.7 .2 Simulations of field conditions . . . . . . . . . . . . . 146

5.7 .3 Simulation limitations . . . . . . . . . . . . . . . . 148

5.7.4 Snow cover simulation vs. the $n_{f}$ approach . . . . . . . 152

5.7.5 Implications and future directions . . . . . . . . . . 156

5.8 Summary and conclusions $\ldots \ldots \ldots \ldots \ldots$

6 Permafrost degradation at snow fences 160

6.1 Introduction . . . . . . . . . . . . . . . . . . 160

6.2 Study design and sites . . . . . . . . . . . . . . . 163

6.3 Field measurements and analyses $\ldots \ldots \ldots \ldots \ldots$

6.4 Numerical simulations . . . . . . . . . . . . . . . . . . . 165

6.5 Results . . . . . . . . . . . . . . . . . . . . . 167

6.5 .1 Fence $1 \ldots \ldots \ldots \ldots \ldots \ldots \ldots$

6.6 Active-layer thickness and topography $\ldots \ldots \ldots \ldots$

6.7 Vegetation . . . . . . . . . . . . . . . . . 176

6.8 Discussion . . . . . . . . . . . . . . . . . . . . . . . . . . . 179

6.8.1 Long-term permafrost degradation at Fence $1 \ldots \ldots$

6.9 Active-layer thickness, topography, and vegetation response . . . . . . 183

6.10 Conclusions . . . . . . . . . . . . . . . . . . . . . . . . 184 
7.1 Introduction . . . . . . . . . . . . . . . . 186

7.2 Key findings . . . . . . . . . . . . . . . . . . . . 187

7.2.1 Permafrost conditions across treeline on Peel Plateau . . . . . 187

7.2.2 The anthropogenic thermal regime: permafrost conditions at the Dempster Highway road embankment . . . . . . . . . . . 188

7.2.3 Permafrost degradation at snow fences . . . . . . . . . . . . . 189

7.3 Peel Plateau evolution . . . . . . . . . . . . . . . . . . . . 191

7.4 Directions for future research . . . . . . . . . . . . . . . . 192

7.4.1 Permafrost across treeline . . . . . . . . . . . . . . 193

7.4 .2 Infrastructure . . . . . . . . . . . . . . . . . 193

7.4.3 Thermokarst initiation . . . . . . . . . . . . . . . 194

List of References $\quad 196$

$\begin{array}{ll}\text { Appendix A Signed co-author statements } & 212\end{array}$

Appendix B Other publications and presentations related to this re$\begin{array}{ll}\text { search } & 215\end{array}$

$\begin{array}{ll}\text { Appendix C Copyright permissions } & 217\end{array}$ 


\section{List of Tables}

2.1 Thermal properties of soil constituents. Reproduced from Burn (2004). Data from Williams (1982); Williams and Smith (1989). . . . . . . . 18

2.2 Climate data for sites at different distances along the Dempster Highway, 2004. Annual mean air temperature $\left(T_{a}\right)$, and precipitation are available for this year (Table modified from Burn et al., 2015, Table 2) 39

2.3 Annual mean ground temperatures $\left(T_{g}\right)$ and active-layer thicknesses in undisturbed terrain at sites along the Dempster Highway, Yukon and NWT. Data are from various sources, and are indicated in the table. Sites in the boreal forest or taiga are marked by *. The km post values in brackets indicate the distance along the Northwest Territories portion of the highway. Table modified from Table 3 in Burn et al. (2015). 41

4.1 Annual mean air temperatures $\left(T_{a}\right)$ and the number of freezing/thawing degree-days (FDD/TDD) from three monitoring sites. Asterisks denote mean daily temperatures estimated using regressions of dwarf-shrub tundra (DST) and upland spruce forest (USF) temperatures from 2011-2012. . . . . . . . . . . . . . . . . . 80

4.2 Mean annual temperatures at the permafrost surface $\left(T_{p s},{ }^{\circ} \mathrm{C}\right)$ and ground surface $\left(T_{s},{ }^{\circ} \mathrm{C}\right)$, late winter snow depths, and the estimated dates of snow arrival. . . . . . . . . . . . . . . 
4.3 Upper: Wilcoxon rank-sum results for 2012-2014 snow depths from transects; Lower: Wilcoxon rank-sum results for 2011-13 active-layer thicknesses from transects. $\mathrm{X}$ indicates significant $\mathrm{p}$-values between the sites in all years, while 1, 2, 3, and 4 refer to significant p-values in 2011, 2012, 2013, and 2014 respectively. The upper right quadrant is a summary of the data pooled for 2011-13. The numbers indicate the difference in the 3-year median values between the sites $(\mathrm{cm})$. Underlined values indicate significant results in the pooled years. No snow depths were measured at LSF in $2012 \ldots \ldots \ldots \ldots$

5.1 Embankment height (High $>2 \mathrm{~m}$, Low $<2 \mathrm{~m}$ ), presence of standing water, and occurrence of Equisetum spp. at each road site. . . . . . 110

5.2 Properties of materials used in the simulations. $\lambda_{f}$ and $\lambda_{t}$ are the frozen and thawed thermal conductivities $\left(\mathrm{W} \mathrm{m}^{-1} \mathrm{~K}^{-1}\right)$ calculated using Kersten's method (e.g., Farouki, 1981) and an equation developed by Johansen (1977). $\theta_{v}$ is volumetric water content $\left(\mathrm{m}^{3} \mathrm{~m}^{-3}\right)$; the value for the mineral soil is the porosity for Mayo silty clay from Smith and Tice (1988), while the value for peat is from Smith and Riseborough (2010). The value for the embankment is representative of dry conditions within the coarse material. $C_{f}$ and $C_{t}$ are the frozen and thawed heat capacities $\left(\mathrm{J} \mathrm{m}^{-3} \mathrm{~K}^{-1}\right)$, and are based on an arithmetic mean of the soil constituent heat capacities (e.g., Burn, 2004, eq. 3.3.5).118

5.3 Snow parameters and $n$-factors from field measurements used to simulate present ground thermal conditions at the embankment toe sites, undisturbed (control) tundra, and the road centreline. Snow initiation refers to the number of days between the onset of freezing surface temperatures and snow cover commencement. . . . . . . . . . . . . 122 
5.4 Parameterizations for six snow accumulation simulations. Snow initiation refers to the number of days after freezing air temperatures that snow accumulation commences. Resulting $T_{g}$ (5 $\mathrm{m}$ depth), $T_{s}$, and thaw depths from year 35 of the simulations are also presented. . . . 123

5.5 Parameterizations for six snow management simulations that varied snow density $\left(\mathrm{kg} \mathrm{m}^{-3}\right)$. Snow initiation refers to the number of days after freezing air temperatures that snow accumulation commences. All $n_{t}$ values were 0.7, as in S1-S6. The initial temperature profile for M1M3 is from the undisturbed simulation (Und., Figure 5.7). Resulting $T_{g}$ (5 $\mathrm{m}$ depth), $T_{s}$, and active-layer thicknesses (ALT) from the final year of the simulations are also presented. . . . . . . . . . .

5.6 Annual mean ground temperatures near $5 \mathrm{~m}$ depth $\left(T_{g}\right)$, at the surface $\left(T_{s}\right)$, and active-layer thickness (ALT) or thaw depth, late-winter snow depth (March), snow thermal resistance, and snow arrival dates (written as $\mathrm{S} / \mathrm{O}$ dd; where $\mathrm{S}=$ Sept., $\mathrm{O}=$ Oct., dd = day) at the seven field sites. The $T_{s}$ ranges and snow arrival dates reported for the control sites are from nearby sites in undisturbed tundra (O'Neill et al., 2015), as there were no shallow cables at the control sites. . . . . . . . .

5.7 Root mean square error ( $\left.\mathrm{RMSE},{ }^{\circ} \mathrm{C}\right)$, mean absolute error $\left(\mathrm{MAE},{ }^{\circ} \mathrm{C}\right)$, and mean error $\left(\mathrm{ME},{ }^{\circ} \mathrm{C}\right)$ of modeled daily ground surface temperatures (0.05 $\mathrm{m}$ depth) at four sites at the Dempster Highway embankment toe. All indices are based on $n=730$ (2 years) daily measurements. The calculations were conducted using the hydroGOF package in $\mathrm{R}$ (http://www.rforge.net/hydroGOF/ . . . . . . . . . . . . . 150 
5.8 Root mean square error ( $\left.\mathrm{RMSE},{ }^{\circ} \mathrm{C}\right)$, mean absolute error (MAE, ${ }^{\circ} \mathrm{C}$ ), and mean error $\left(\mathrm{ME},{ }^{\circ} \mathrm{C}\right)$ between freezing season ground surface temperatures modeled by TONE and those measured in the field, and the same error indices (in brackets) for ground surface temperatures calculated using site-specific $n_{f}$ and those measured in the field. The indices were calculated for ground temperatures measured over 2 freezing seasons. The calculations were conducted using the hydroGOF package in R (http://www.rforge.net/hydroGOF / . . . . . . . . . . . . . . 155

6.1 Properties of peat and silty clay used in model simulations. . . . . . . 169

6.2 Late-summer thaw depth and late-winter snow depths along the transect at the fence, 2012-15. The + symbols indicate when the maximum length of the probe was attained, or when friction prevented the probe from reaching the frost table. Locations of the control $(\mathrm{C})$, north $(\mathrm{S})$, and south (S) instruments are indicated in the distance column. . . . 170

6.3 Annual mean ground temperatures $\left(T_{g}\right)$ at 0.05 and $1 \mathrm{~m}$ at the snow fence and control site in 2012-15. Minimum temperatures are shown in brackets beside the annual means. Annual period for most data begins near 15 August. For values marked with asterisks, the annual period begins on 1 May. . . . . . . . . . . . . . . . . . . . . 174 


\section{List of Figures}

1.1 (upper) Map of the study area on Peel Plateau near Fort McPherson, Northwest Territories. Permafrost zones of northwest Canada are shown in the inset (after Heginbottom et al. (1995)). A and B indicate equivalent locations along the highway on the map and in the (lower) image (Quickbird image, 2010). The Dempster Highway is traced in white on the image. Tundra at higher elevation, forest at lower elevation, and a large thaw slump are labeled. Peel River divides Peel Plateau from the Peel Plain lowlands. . . . . . . . . . . . . . .

1.2 Photograph of the Dempster Highway road embankment on Peel Plateau in March 2013. Note the rolling topography, shrub growth, and snow accumulation along the embankment. . . . . . . . . . .

2.1 Distribution of permafrost in the northern hemisphere north of $50^{\circ} \mathrm{N}$, retrieved 25 May 2016 from: https://nsidc.org/sites/nsidc.org/files/ images//permafrost_distribution_in_the_arctic.jpg . . . . . . . .

2.2 The climate-permafrost relation and the annual thermal regime of permafrost (after Fig 1, Riseborough et al., 2008; Burn, 2004, Fig 3.3.2) .

2.3 Unfrozen water content of soils below $0{ }^{\circ} \mathrm{C}$ (Reproduced with permission from Roy-Léveillée, 2014, Figure 4, originally in Burt and Williams (1976), Figure 1) . . . . . . . . . . . . . . . 
2.4 Late-winter snow depths and ground surface temperatures measured in March 1970 in the central Mackenzie Delta (modified from Smith, 1975, Figure 9) . . . . . . . . . . . . . .

2.5 Annual mean air temperature at Inuvik 1926-2014 (modified from Burn and Kokelj, 2009, Figure 4). The data for 1957-2006 are from Inuvik, and the data for 1926-57 are a composite series based on measurements at Aklavik. The running mean air temperature for the previous 10 years is plotted as a line for 1935-2014. Data are from Environment

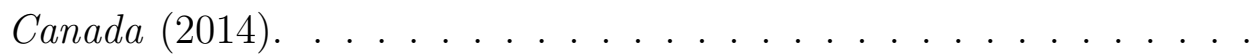

2.6 Massive retrogressive-thaw slump on Peel Plateau in August 2013. Note the person in the left foreground for scale. . . . . . . . . . .

2.7 Placement of fill material at the roadside to control the thaw of ground ice and deformation of the road surface. Cracks in the road surface are visible near near the flagging. Photo from summer 2012. . . . . . .

3.1 Examples of (a) shallow ground temperature cable installation, (b) deep ground temperature cable, and (c) air temperature sensor in radiation shield. . . . . . . . . . . . . . . . .

3.2 Ground temperatures over two months from a depth of $7.86 \mathrm{~m}$ at a deep cable located at the toe of the Dempster Highway road embankment showing the pronounced, but short-lived, disturbance from water jet drilling. . . . . . . . . . . . . . . . . .

3.3 (a) Volumetric water content (VWC) and (b) gravimetric water content (GWC) plotted vs. dry bulk density for 44 active-layer soil samples. The samples are from depths of either 30 or $50 \mathrm{~cm} . \quad . . . . . .$. 
4.1 Location of study sites, and elevation profile between points A and B along the Dempster Highway [Elevation profile modified from Google Earth (2013)]. Symbols are as follows: $\boldsymbol{\Delta}$ shallow $(1 \mathrm{~m})$ thermistor array; $\diamond$ deep $(4-7 \mathrm{~m})$ thermistor array; ${ }^{*}$ air temperature sensor; $\mathrm{X}$ iButton array; M meteorological station. The locations of instruments are approximate. The inset is modified from Fig.1 in Burn (1994) and permafrost zones are after Heginbottom et al. (1995). The Dempster Highway begins near Dawson City and runs through Fort McPherson to Inuvik. . . . . . . . . . . . . . . . . . 70

4.2 Study sites across the forest-tundra ecotone. . . . . . . . . . . 72

4.3 Plots showing a) air temperatures on Peel Plain (LSF $30 \mathrm{~m}$ ) and near the top of Peel Plateau (DST $492 \mathrm{~m}$ ), b) daily surface lapse rates between $30 \mathrm{~m}$ and $492 \mathrm{~m}$, and c) relations between freezing degreedays and elevation. The question mark indicates where missing data were estimated for USF using regression (see text). . . . . . . . .

4.4 a) Box-whisker plot of snow depths from transects for winters 20122014. The whiskers indicate extreme values, the top and bottom of the box represent the upper and lower quartiles, respectively, and the line in the center of the box is the median. The number of points measured along each transect is in parentheses. The shaded grey areas represent the range of individual snow depth measurements from transects and shallow thermistor sites (Table 4.2). Snow depths were not measured at LSF in 2012 due to logistical constraints; b) average snow density and snow cover thermal resistance determined from 2013 and 2014 snow pits. 82 
4.5 a) iButton temperatures (grey lines) and inferred snow depth in forest on Peel Plateau; b) iButton temperatures and inferred snow depth adjacent to snow fence in tundra. The blue lines in a) and b) are air temperatures from the USF and DST air temperature sensors, respectively. Daily maximum wind speeds from the meteorological (MET) station are plotted as black bars, and the grey shading represents wind speeds at which snow transport is possible under cold, dry conditions (Li and Pomeroy, 1997). Question marks indicate the limit of inferred snow depths (when snow is $\geq 90 \mathrm{~cm}$ ), and missing wind data from the MET station. . . . . . . . . . . . . . . .

4.6 Mean annual temperature near the permafrost surface $\left(T_{p s}\right)$ across the forest-tundra ecotone for 2010-13. The solid black lines represent the median $T_{p s}$ from instruments in mineral soil for each vegetation unit, and the dashed line is the median for the DST peatland instrument. . 88

4.7 Mean ground temperatures for September 2012 to August 2014. The symbols on each line represent the thermistor locations. . . . . . . . 
4.8 Relations between late-winter snow depth and a) mean annual permafrost surface temperature $\left(T_{p s}\right)$ and b) ground surface temperature $\left(T_{s}\right)$ for 2012 and 2013. Tundra (M) and Tundra (P) denote sites in mineral and peatland soils, respectively. Asterisks in the legend denote additional data collected on Peel Plateau by Gill et al. (2014). The dashed line is the regression relation for tundra sites $\left[T_{p s}=0.04(\mathrm{LWSD})\right.$ $\left.4.79, \mathrm{r}^{2}=0.72, \mathrm{n}=19, \mathrm{p}<0.01\right]$, and the dotted line is for forest sites $\left[T_{p s}=0.03(\mathrm{LWSD}) \quad 4.56, \mathrm{r}^{2}=0.43, \mathrm{n}=8, \mathrm{p}=0.14\right]$. There are fewer points for $T_{s}$ than $T_{p s}$ because subsidence at DST-3 caused the $5 \mathrm{~cm}$ thermistor to be exposed after 2011-12, and because TST-3 did not have a surface thermistor. . . . . . . . . . . . . . .

4.9 Ground temperatures at a) a peatland at the base of a slope where thick snow accumulates $\left(T_{s}=1.3{ }^{\circ} \mathrm{C} ; T_{p s}=-0.5^{\circ} \mathrm{C}\right)$, and b) an exposed peatland where little snow accumulates $\left(T_{s}=-0.8{ }^{\circ} \mathrm{C} ; T_{p s}=-2.3{ }^{\circ} \mathrm{C}\right)$.

4.10 Active-layer thicknesses across the forest-tundra ecotone from the four transects in mineral soil, and around instrumented sites in the DST and TST peatland (pooled values from the TST and DST peatland). The number of individual points measured is in parentheses. . . . .

4.11 Relation between latitude and average freezing degree-days (1981-2010) at 7 weather stations (Environment Canada, 2014). The study area on Peel Plateau is at about $67.2^{\circ} \mathrm{N}$, and there were 3968 and 4257 freezing degree-days at DST in 2011-12 and 2012-13, respectively. These data are not plotted here, as they are not similar to the long-term averages. The least-squares regression line is plotted as dashes. . . . . . . . . . 96 
5.1 Location of study sites in dwarf-shrub tundra (DST) and tall shrub tundra (TST) on Peel Plateau. Snow depth transects are marked by white lines. . . . . . . . . . . . . . . . . . . . . . 109

5.2 The DST2 and TST2 instrument locations. DST2 is the least disturbed, located near a low embankment and exposed to winds that carry snow away. TST2 is adjacent to a high embankment where vegetation and moisture conditions have changed as a result of deep snow accumulation. . . . . . . . . . . . . . . .

5.3 Thermal conductivity and unfrozen water content characteristic curves for the three materials in the simulations. The frozen thermal conductivity of the coarse embankment material is less than the unfrozen conductivity because of the very low moisture content (e.g., Farouki,

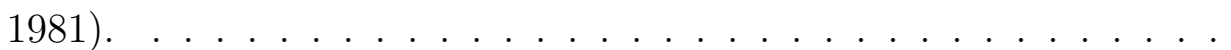

5.4 Schematic diagram of the numerical simulations showing timelines for (a) sites at the embankment toe, (b) the embankment centreline, (c) the DST control site, (d) the S1 to S6 simulations examining snow timing parameterizations, (e) the M1-M3 simulations examining longterm snow management since embankment construction, and (f) the 10-year M4-M6 simulations of snow management following 35 years of disturbance at the embankment toe. $t_{0}$ indicates embankment construction and the beginning of the transient simulations from the initial temperature profile (spin up), $t_{p}$ indicates the present, and $t_{f}$ the end of the M4-M6 simulations. Note that snow depth is different for each embankment toe site, and that the snow depths on the diagram are not to scale. . . . . . . . . . . . . . . . . 
5.5 Temperature envelopes from the deep cables in 2013-14 at embankment toe sites and control sites. The dots on the lines indicate the position of thermistors. Note that DST3 is not plotted here. . . . . . . . . . . 126

5.6 Snow accumulation measured in March 2015 at (a) six tundra and (b) six forest transects. The dots are the median depths from the transects, and the vertical lines represent the interquartile ranges. . . . . . . . . 130

5.7 Temperature envelope for the equilibrium spin-up used as the initial condition in subsequent 35-year transient simulations. Measured air temperatures on Peel Plateau were reduced based on the record from Inuvik to represent cooler conditions in the late 1970s, when the road was constructed. The annual mean temperature at $5 \mathrm{~m}$ depth was -2.9 ${ }^{\circ} \mathrm{C}$, and thaw depth was $1.0 \mathrm{~m} . \ldots \ldots \ldots$

5.8 Measured (dots) and modeled (solid lines) annual mean ground temperatures for the five sites at the embankment toe (a to e), at the embankment centreline (f) (measured values from Idrees et al. (2015)), and for the DST control site (g). The solid horizontal line is the modeled thaw depth after 35 years of disturbance, and the dashed horizontal lines are the measured values from Table 5.6. Maximum snow depths used in the simulations are shown under each site label. . . . . 133

5.9 Measured (solid) and modeled (dashed) ground surface temperatures (0.05 $\mathrm{m}$ depth) between 2012-2015 for sites at the embankment toe. Note that DST3 is not plotted here. . . . . . . . . . . . . . . 134 
5.10 (a) simulated ground surface temperatures (0.05 m depth), (b) positions of the $0{ }^{\circ} \mathrm{C}$ isotherm, and (c) temperature envelopes for simulations $\mathrm{S} 1$ and $\mathrm{S} 2$. In $\mathrm{S} 1$, snow began to accumulate on the first day of freezing conditions; in $\mathrm{S} 2$, snow accumulation began 14 days after freezing conditions. In both simulations, snow reached its maximum depth $(1.0 \mathrm{~m})$ after 30 days of accumulation. The simulations commence on August 1 and results are shown for year 35. . . . . . . . . . . . . . 137

5.11 (a) simulated ground surface temperatures (0.05 m depth), (b) positions of the $0{ }^{\circ} \mathrm{C}$ isotherm, and (c) temperature envelopes for simulations $\mathrm{S} 3$ and $\mathrm{S} 4$. In $\mathrm{S} 3$, the maximum snow depth $(1.0 \mathrm{~m})$ is reached after 90 days; in $\mathrm{S} 4$, the maximum snow depth $(1.0 \mathrm{~m})$ is reached after 120 days. Snow commenced on the first day of freezing conditions in both simulations. The simulations commence on August 1 and results

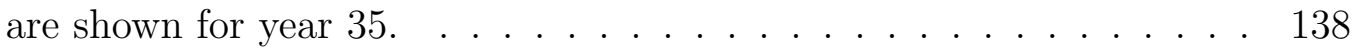

5.12 (a) simulated ground surface temperatures (0.05 m depth), (b) positions of the $0{ }^{\circ} \mathrm{C}$ isotherm, and (c) temperature envelopes for simulations S5 and S6. In these simulations, snow commenced 14 days following freezing conditions; in S5, the maximum snow depth $(1.0 \mathrm{~m})$ is reached after 90 days, and in $\mathrm{S} 6$, the maximum snow depth $(1.0 \mathrm{~m})$ is reached after 120 days. The simulations commence on August 1 and results are shown for year 35. . . . . . . . . . . . . . . . . 140

5.13 Simulated annual mean ground temperatures for year 35 of the M1-M3 snow manipulation scenarios (see Table 5.5). The initial temperature conditions in the simulations were the undisturbed conditions in Figure 5.7. The results are plotted with simulated conditions after 35 years for the DST control site (e.g., Figure 5.8g) . . . . . . . . . . . . . . . 142 
5.14 Simulated annual mean ground temperatures for year 10 of the M4-M6 snow manipulation scenarios (see Table 5.5). The initial temperature conditions in the simulations were from year 35 of the TST2 embankment toe simulation in Figure 5.8e . . . . . . . . . . . . . . . . . 143

5.15 Simulated annual mean ground temperatures for years 2, 5, and 8 of the M6 snow manipulation scenario (see Table 5.5). The initial temperature conditions in the simulations were from year 35 of the TST2 embankment toe simulation in Figure 5.8e . . . . . . . . . . . . 144

5.16 Simulated thaw depths $\left(0^{\circ} \mathrm{C}\right.$ isotherm $)$ over ten years for the M4-M6 snow manipulation scenarios (see Table 5.5). The initial temperature conditions in the simulations were from year 35 of the TST2 embankment toe simulation in Figure 5.8e . . . . . . . . . . . . . . . 145

5.17 Modeled vs measured ground surface temperatures $(0.05 \mathrm{~m}$ depth $)$ at sites near the embankment toe between 2012-15 (same data as Figure 5.9). The ellipse in (a) encompasses values when the modeled snowpack was still ablating but the ground was free of snow in the field. Note that DST3 is not plotted here. . . . . . . . . . . . . . . . 149

5.18 An example of air and calculated ground surface temperatures for four different $n_{f}$ values representative of different snow covers. As air temperature decreases and $n_{f}$ increases, lower ground surface temperatures are produced, which may underestimate ground temperatures during freezeback under a snow cover. . . . . . . . . . . . . . . . . . . 154

6.1 Location of study sites. Fences 2 and 4 are at $67.18^{\circ} \mathrm{N} 135.78^{\circ} \mathrm{W}$ and 67.10N 136.10W, respectively, in Richardson Mountains. Permafrost zones of northwest Canada are shown in the inset. . . . . . . . . . . . 162 
6.2 Field sites in summer 2014. Locations of the transect (line) and shallow thermistor arrays (dots) are shown for Fence 1. . . . . . . . . . . 164

6.3 Thermal conductivity and unfrozen water content characteristic curves for mineral and peat used in modeling simulations. . . . . . . . . 168

6.4 Cross-section of Fence 1 transect showing late-winter snow depths, ground relief, and August thaw depths from 2013 field measurements and the numerical simulation. The 2013 thaw depth data are shown because this is when the deepest probing near the fence was possible. Capital letters indicate the instrument locations. The shaded area represents wet, sedge-dominated ground, which prescribed the disturbed conditions in the simulation. . . . . . . . . . . . . . . . 171

6.5 (a) Ground surface temperatures for the control site at Fence 1 calculated from air temperatures on Peel Plateau corrected to account for the cooler 1951-80 climate (see text), and $\mathrm{n}$-factors for the site $\left(\mathrm{n}_{f}=\right.$ $0.21 ; \mathrm{n}_{t}=0.36$ ) used for the model spin up; (b) measured temperatures in 2013-14 at 0.05-m depth near the fence (south instrument) and at the control site, used as the surface boundary conditions in the disturbance simulation; and (c) excess-ice contents from the core drilled near the control site in undisturbed tundra. The symbols represent the average depth of the retrieved core sections. . . . . . . . . . . 173 
6.6 Numerical simulation of: (a) ground below $0{ }^{\circ} \mathrm{C}$ (white) and thawed ground (grey) at the end of June of year 35; maximum talik thickness $(t)$ is determined at this point, after winter upfreezing has ceased; $w=$ talik width; (b) late-summer thaw depth; $d=$ maximum thaw depth; (c) depth of seasonal freezing (on 1 May) above the talik, maximum talik thickness on 1 July (see a) and maximum thaw depth on 1 September (see b). The scalloped-shaped progression in the simulation of thaw depth is discussed by Riseborough (2008). (d) Talik width on 1 July (see a). Talik width was the maximum horizontal extent of the main thaw bulb. Isolated thawed zones adjacent to the main bulb were excluded. . . . . . . . . . . . . . . . . . . 177

6.7 Active-layer thicknesses along transects at all fences in 2014. The blue data points are from sites on flat ground and the red points are from sites on slopes. . . . . . . . . . . . . . . . . . . . . . . . . 178

6.8 Vegetation heights along transects at Fences 2-4. The blue data are from the sites in flat ground and the red data are from sites on slopes. 180

6.9 Simulated annual mean ground temperature profiles during the 35-year disturbance. . . . . . . . . . . . . . . . . . . 182 


\section{Nomenclature}

$A_{s} \quad$ Amplitude of ground surface temperature oscillation $\left({ }^{\circ} \mathrm{C}\right)$

$\begin{array}{ll}\text { ALT } & \text { Active-layer thickness }(\mathrm{m}) \\ C & \text { Soil specific heat capacity }\left(\mathrm{J} \mathrm{kg}^{-1}{ }^{\circ} \mathrm{C}^{-1}\right) \\ C_{a} & \text { Soil apparent heat capacity }\left(\mathrm{J} \mathrm{kg}^{-1}{ }^{\circ} \mathrm{C}^{-1}\right) \\ \text { DST } & \text { Dwarf-shrub tundra } \\ E_{i} & \text { Excess-ice content (\%) } \\ \text { FDD, TDD } & \text { Freezing, thawing degree-days } \\ \kappa & \text { Thermal diffusivity }\left(\mathrm{m}^{2} \mathrm{~s}^{-1}\right) \\ L & \text { Latent heat of fusion (e.g., }\left(334 \mathrm{~kJ} \mathrm{~kg}^{-1}\right) \\ \lambda & \text { Soil thermal conductivity }\left(\mathrm{W} \mathrm{m}{ }^{-1} \mathrm{~K}^{-1}\right) \\ \lambda_{s} & \text { Snow thermal conductivity }\left(\mathrm{W} \mathrm{m} \mathrm{m}^{-1} \mathrm{~K}^{-1}\right) \\ \mathbf{L S F} & \text { Lowland spruce forest } \\ m, w, a, i & \text { Volumetric fractions of mineral, water, air, and ice in soil } \\ n_{f} & \text { Freezing season n-factor } \\ n_{t} & \text { Thawing season n-factor } \\ \theta_{g} & \text { Gravimetric water content }\left(\mathrm{g} \mathrm{g}^{-1}\right)\end{array}$




\begin{tabular}{|c|c|}
\hline$\theta_{u}$ & Unfrozen water content $\left(\mathrm{g} \mathrm{g}^{-1}\right)$ \\
\hline$\theta_{v}$ & Volumetric water content $\left(\mathrm{m}^{3} \mathrm{~m}^{-3}\right)$ \\
\hline$p, q, r$ & Volumetric fractions of pore space, air, and ice in soil \\
\hline$Q^{*}$ & Net radiation at the ground surface $\left(\mathrm{W} \mathrm{m}^{-2}\right)$ \\
\hline$Q_{G}$ & Ground heat flux $\left(\mathrm{W} \mathrm{m}^{-2}\right)$ \\
\hline$Q_{H}$ & Sensible heat flux $\left(\mathrm{W} \mathrm{m}^{-2}\right)$ \\
\hline$Q_{L}$ & Latent heat flux $\left(\mathrm{W} \mathrm{m}^{-2}\right)$ \\
\hline$R_{s}$ & Snow cover thermal resistance $\left(\mathrm{m}^{2} \mathrm{~K} \mathrm{~W}^{-1}\right)$ \\
\hline$S P$ & Subsidence potential from thaw of excess ice $(\mathrm{m})$ \\
\hline$t$ & Time $(\mathrm{s})$ \\
\hline$T$ & Temperature $\left({ }^{\circ} \mathrm{C}\right)$ \\
\hline$T_{a}$ & Annual mean air temperature $\left({ }^{\circ} \mathrm{C}\right)$ \\
\hline$T_{g}$ & Annual mean ground temperature $\left({ }^{\circ} \mathrm{C}\right)$ \\
\hline$T_{p s}$ & Annual mean temperature at the permafrost surface $\left({ }^{\circ} \mathrm{C}\right)$ \\
\hline$T_{s}$ & Annual mean ground surface temperature $\left({ }^{\circ} \mathrm{C}\right)$ \\
\hline$T_{\max }$ & Annual maximum temperature $\left({ }^{\circ} \mathrm{C}\right)$ \\
\hline$T_{\min }$ & Annual minimum temperature $\left({ }^{\circ} \mathrm{C}\right)$ \\
\hline TST & Tall-shrub tundra \\
\hline USF & Upland spruce forest \\
\hline$\omega$ & angular velocity $\left(\mathrm{rad} \mathrm{s}^{-1}\right)$ \\
\hline$z$ & Depth $(\mathrm{m})$ \\
\hline
\end{tabular}




\section{Chapter 1}

\section{Overview}

\section{$1.1 \quad$ Introduction}

This thesis is concerned with ground thermal conditions on Peel Plateau, an extensive glacially-formed upland in Northwest Territories and Yukon. The research investigates the ground thermal regime in undisturbed terrain across an elevational (alpine) tree line, and at disturbed locations near the Dempster Highway road embankment. Snow-vegetation-permafrost relations across the forest-tundra ecotone, and long-term (multi-decadal) effects of transportation infrastructure operation on ground temperatures are investigated. These two topics are of contemporary relevance due to the roles of permafrost in the global carbon cycle, and as a foundation upon which northern infrastructure integrity relies. The portion of Peel Plateau crossed by the Dempster Highway is ideal for this research because of the range of vegetation communities represented, and because the permafrost is characteristically ice rich, so the region is representative of Arctic locales sensitive to disturbance from climate warming and infrastructure effects (Nelson et al., 2002).

Permafrost, ground that remains at or below $0{ }^{\circ} \mathrm{C}$ for at least two consecutive years, underlies about $24 \%$ of the North American landmass and $50 \%$ of Canada (Brown et al., 1997). Permafrost research in Canada has historically been focused in

lowlands. This is partly because northern settlements, and thus infrastructure, are 
situated in valley bottoms and plains, and because of limited historical use of mountainous regions in Canada (Gruber et al., 2015). As a result, monitoring networks are biased towards settlements and infrastructure corridors in gentle terrain at low elevation (Smith et al., 2010, Figure 1).

Recent evidence however suggests that climate warming is amplified with elevation (Mountain Research Initiative EDW Working Group, 2015). This, combined with the disproportionate warming observed over the past several decades at high latitudes, suggests that permafrost and the infrastructure upon it may be particularly sensitive to climate amelioration and disturbance in upland regions. In undisturbed settings, there are important and complex relations between air temperature, snow, vegetation, and permafrost conditions (e.g. Smith, 1975; Sturm et al., 2001a; Morse et al., 2012). Ground temperatures decline with air temperatures northward across latitudinal treeline, as snow depths decrease from forest to tundra (Smith et al., 1998; Palmer et al., 2012). However, the situation is complicated at elevational (alpine) treeline due to frequent winter air temperature inversions at high latitudes (Burns, 1973; Wahl et al., 1987), making the changes in ground temperatures across treeline less clear (Lewkowicz et al., 2012).

Relations between climate, vegetation, snow, and permafrost have been topics of considerable research due to potential feedbacks that may contribute to the release of greenhouse gases from frozen or previously frozen ground (Sturm et al., 2001a; Christensen et al., 2004; Schuur et al., 2008; Jorgenson et al., 2010). In particular, thaw of permafrost may promote the formation of thermokarst depressions, shifting the landscape from a carbon sink to a source (Natali et al., 2014; Nauta et al., 2015), triggering feedbacks that contribute to increasing air temperatures.

Recent climate warming has increased the thickness of the active layer, leading to the thaw of ground ice at the top of permafrost in ice-rich terrain (Brown et al., 
2000). At infrastructure, permafrost degradation may occur independently of climate warming because structures trap windblown snow, thereby limiting winter ground cooling (Andersland and Ladanyi, 2004). Thaw subsidence, due to enhanced snow accumulation, may further exacerbate the thermal perturbation if moisture ponds in the depressions, because this water must freeze before ground cooling below $0{ }^{\circ} \mathrm{C}$ can occur. Thermokarst ponds are common along linear transportation infrastructure and may be a concern for embankment stability (Niu et al., 2014). Consequently, thaw of near-surface ground ice and associated settlement of the ground surface at infrastructure has garnered significant attention in permafrost regions around the world (e.g., Anisimov and Reneva, 2006; Wu and Zhang, 2008; Bommer et al., 2010; Darrow, 2011; Fortier et al., 2011; Streletskiy et al., 2012). The effects are anticipated to be widespread and costly in the circumpolar North (Nelson et al., 2001).

This thesis examines permafrost conditions on Peel Plateau in undisturbed terrain and anthropogenically altered settings near infrastructure. The specific research objectives seek to (1) characterize ground temperatures in undisturbed terrain across the forest-tundra ecotone on Peel Plateau, (2) determine the effect on permafrost of deep snow accumulation at the toe of the Dempster Highway road embankment, and (3) examine, through numerical modelling, the timing and geometry of talik formation where infrastructure has caused permafrost to degrade.

\subsection{Peel Plateau}

Peel Plateau is a nearly $60,000 \mathrm{~km}^{2}$ upland formed by multiple advances and retreats of the Laurentide Ice Sheet. The region is characterized by rolling topography incised by steep river valleys (Figure 1.1, 1.2). The region has a subarctic, continental climate with long, cold winters and short, cool summers. The mean annual air temperature 
at Fort McPherson, the nearest meteorological station, was $-7.0{ }^{\circ} \mathrm{C}$ in $1987-2006$ (Environment Canada, 2014). Total annual precipitation (1987-2006) averages 295 $\mathrm{mm}$, with $148 \mathrm{~mm}$ falling as rain (Environment Canada, 2014). Precipitation is typically heaviest in late summer and early fall.

The Laurentide Ice Sheet retreated from the region about 13,500 years ago (Zazula et al., 2009). The surficial sediments on Peel Plateau are predominantly glacial till (Fulton, 1995). The plateau includes an ecotone with vegetation transitioning from forest communities to alpine tundra at higher elevation. The portion of Peel Plateau examined in this thesis is underlain by continuous permafrost (Figure 1.1). The permafrost on Peel Plateau is characteristically ice rich. Geotechnical drilling on the plateau found ice-rich ground in the upper $18.3 \mathrm{~m}$ of permafrost (Yukon Ecoregions Working Group, 2004). Numerous large retrogressive-thaw slumps expose ice-rich ground over $20 \mathrm{~m}$ in depth, comprising segregated ground ice near the surface and buried glacier ice at depth (e.g., Lacelle et al., 2015). The thaw of ice-rich permafrost on Peel Plateau poses challenges for road maintenance, and sections of the Dempster Highway have required significant remediation to maintain the driving surface.

Prior to this study, there was little data available on permafrost temperatures from Peel Plateau. Mean annual ground temperatures of about -2.0 to $-3.0{ }^{\circ} \mathrm{C}$ have been reported (Mackay, 1967; Burn et al., 2015). In nearby Richardson Mountains at higher elevation, ground temperatures are closer to $-4.0^{\circ} \mathrm{C}$, the lowest reported from along the entire length of the Dempster Highway (Burn et al., 2015, Table 3).

The Peel River watershed, which includes Peel Plateau, is one of the largest intact wilderness areas in North America. The study region is within the traditional territory of the Gwich'in First Nation. The Protect the Peel movement has received significant attention in the past several years due to concerns about potential resource 

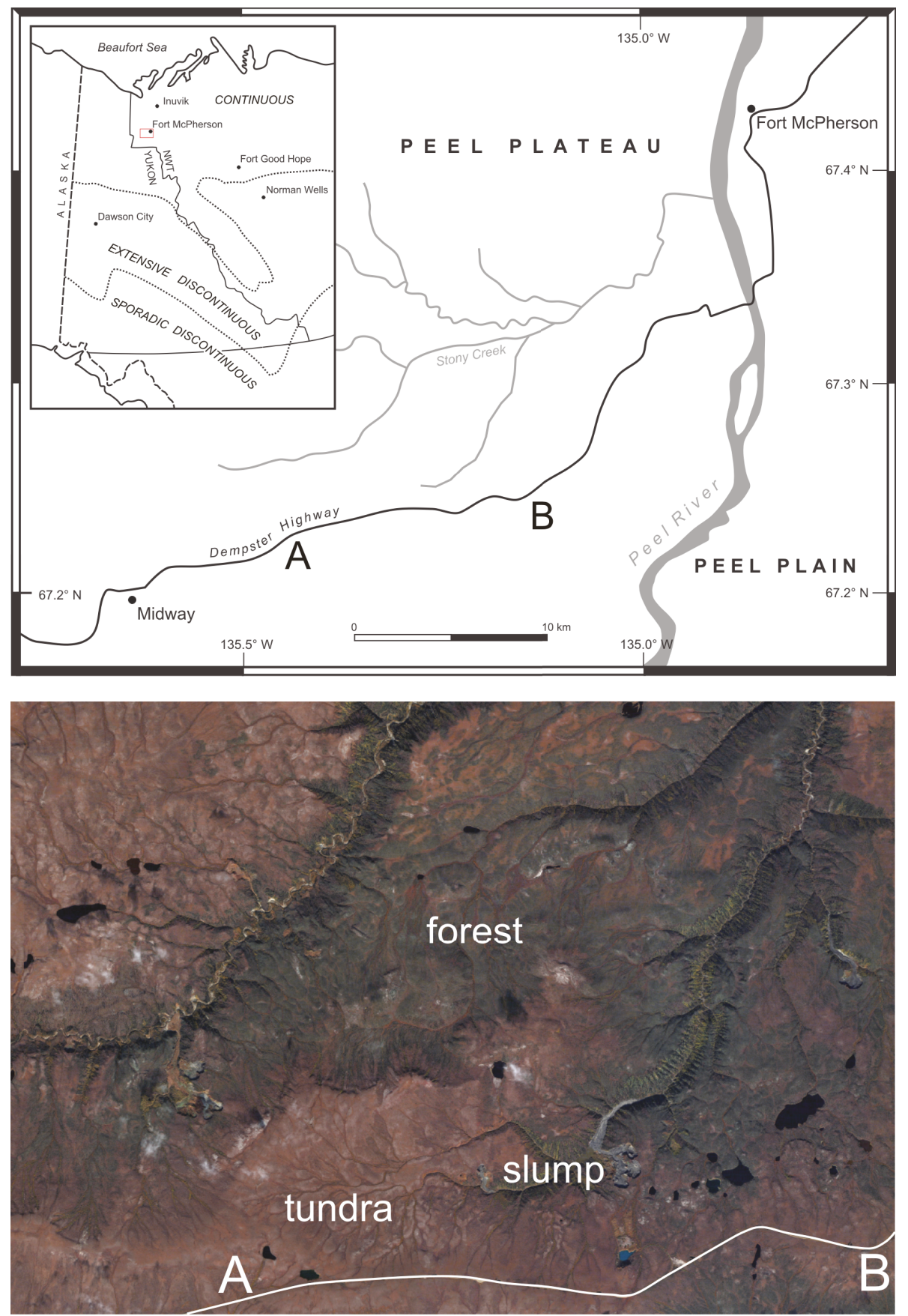

Figure 1.1: (upper) Map of the study area on Peel Plateau near Fort McPherson, Northwest Territories. Permafrost zones of northwest Canada are shown in the inset (after Heginbottom et al. (1995)). A and B indicate equivalent locations along the highway on the map and in the (lower) image (Quickbird image, 2010). The Dempster Highway is traced in white on the image. Tundra at higher elevation, forest at lower elevation, and a large thaw slump are labeled. Peel River divides Peel Plateau from the Peel Plain lowlands. 


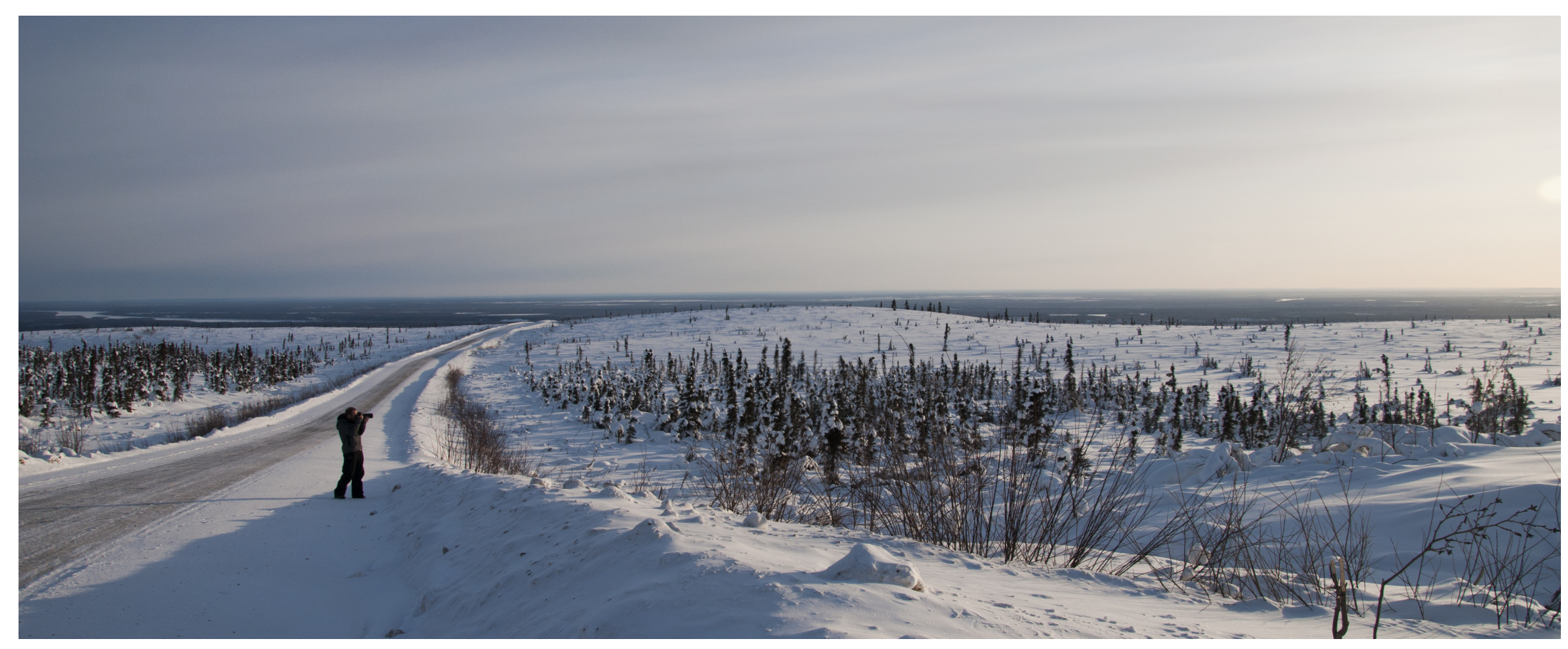

Figure 1.2: Photograph of the Dempster Highway road embankment on Peel Plateau in March 2013. Note the rolling topography, shrub growth, and snow accumulation along the embankment. 
exploration and development (see protectpeel.ca, accessed 21 April 2016). This research was part of a Northwest Territories Cumulative Impacts Monitoring Program (NWT CIMP) project based in Fort McPherson, which was guided by the community to monitor landscape changes in the region.

This thesis addresses a significant knowledge gap by reporting permafrost conditions in forest and tundra environments in the region, and by examining the effect of infrastructure on ground thermal conditions. The Dempster Highway is the only road to communities in the western Canadian Arctic. The highway has recently increased in importance because the route is being extended north of Inuvik to Tuktoyaktuk, and will thus connect the national road network to the Beaufort Sea Coast. In addition, Inuvik relies on tanker truckloads of propane transported by road for power generation. Peel Plateau is a critical area for this research due to the sensitivity of the ice-rich substrate to disturbance and future climate warming, but the results from this study may be pertinent to management of other highway sections, since thaw settlement has also been identified as the primary hazard in Richardson Mountains and Blackstone Uplands (Burn et al., 2015).

\subsection{Research objectives}

The research presented in this thesis focuses on addressing the following:

The first objective (1) is to characterize ground temperatures in undisturbed terrain characteristic of Peel Plateau. This is accomplished by instrumenting specific vegetation types across the forest-tundra ecotone, from forest at low elevation, to tall-shrub and dwarf-shrub tundra at higher elevations. Initially, it was anticipated that ground temperatures may not decline as drastically between forest and tundra as at the nearby latitudinal treeline north of Inuvik, due to persistent air temperature 
inversions in winter between Peel Plateau and the surrounding lowlands.

The second objective (2) is to characterize the ground thermal regime near the toe of the Dempster Highway road embankment, where thick snow accumulates annually. Extensive road maintenance has been required due to ground subsidence at the embankment toe, and thermokarst ponds have formed in some locations. Consequently, it is hypothesized that the increased snow accumulation at the roadway has caused taliks - zones of perenially unfrozen ground - to develop in some locations. One-dimensional numerical simulations that incorporate the accumulation and ablation of a snow pack are used to examine permafrost conditions near the road embankment and the effect of the snow accumulation regime and snow density on the ground thermal regime.

The third objective (3) is to simulate, in two dimensions, the disturbance to permafrost from snow accumulation beside the roadway, and the spatial and temporal dimensions of thermokarst initiation. This is accomplished with a field-based case study of conditions at a long-standing snow fence near the embankment. Field data are used to parameterize a two-dimensional finite-element model to characterize the timing and geometry of talik formation at the site. Active-layer thicknesses and vegetation conditions are measured at additional snow fences in the region to examine multi-decadal response to the increase in snow cover in different topographic settings.

\subsection{Thesis structure}

Three primary research papers comprise the bulk of the thesis, and are presented in Chapters 4 to 6 . These integrated manuscripts address the objectives outlined above. Chapter 2 reviews the literature pertinent to the research presented in Chapters 4 to

6. The review chapter situates this thesis in the broader literature and is divided into 
sections on (1) the immanent processes governing heat flow between permafrost and the atmosphere, (2) the effect of environmental conditions on ground temperatures, and (3) the physiographic configuration of the study region. Chapter 3 presents the methodological approach and details instrumentation and sampling techniques. The specific application of methods is included in Chapters 4 to 6 . Chapter 7 follows the integrated chapters and summarizes key conclusions, implications, and suggests directions for future research. During the compilation of this thesis, considerate effort was taken to avoid repitition. For this reason, the chapters presented are not verbatim reproductions of the publications on which they are based. 


\section{Chapter 2}

\section{Background}

\section{$2.1 \quad$ Introduction}

This thesis examines the thermal regime across the forest-tundra ecotone on Peel Plateau in undisturbed terrain and along the Dempster Highway where infrastructure has disturbed the ground. The thermal regime of permafrost may be considered as the integrated response of immanent (nonhistorical) and configurational (historical) processes (Simpson, 1963). More specifically, the surficial materials on Peel Plateau are the result of erosive and depositional processes associated with the advance and retreat of the Laurentide Ice Sheet (Fulton, 1995). These glacial processes laid down the sediment and buried ice that underlies the present landscape. The ultimate retreat of the ice sheet from the region about 13,500 years ago (Zazula et al., 2009) has controlled the time available for subsequent periglacial processes and vegetation growth and succession, while climatic conditions have broadly controlled permafrost temperatures. In addition, the construction of the Dempster Highway in the late 1970s changed the natural landscape and affected thermal conditions near the road. These historical conditions and immanent processes govern the present thermal state of the ground.

This chapter provides a review of literature on: (1) the immanent processes governing permafrost and heat flow between the ground and atmosphere, (2) the effect 
of environmental conditions on ground temperatures, and (3) the physiographic configuration of the study region.

\subsection{The thermal regime of permafrost}

\subsubsection{Permafrost}

Permafrost refers to ground that remains at or below $0{ }^{\circ} \mathrm{C}$ for at least two consecutive years (Harris et al., 1988). Permafrost may consist of a variety of earth materials, including bedrock, mineral soils, organic deposits, ice, air, and unfrozen water. Permafrost underlies about 50\% of the Canadian landmass (Heginbottom et al., 1995), and about $24 \%$ of the northern hemisphere's landmass (Brown et al., 1997, Figure $2.1)$.

The thermal state of permafrost is of scientific and practical relevance because it governs important mechanical and biological processes. First, permafrost in finegrained mineral soil commonly contains a significant volume of ground ice, which, upon thawing, causes thaw settlement and initiation of thermokarst processes. Degradation of ice-rich permafrost presents a significant hazard to infrastructure in the circumpolar North (e.g. Nelson et al., 2002). The effects of permafrost thaw at infrastructure is an ongoing challenge (Nelson et al., 2001; Yu et al., 2002; Fortier et al., 2011), and will likely continue because the climate is expected to warm in the coming decades. Permafrost contains significant pools of carbon (Tarnocai et al., 2009), which may be mobilized by microbial activity and released as greenhouse gases when permafrost warms or degrades (Schuur et al., 2008). The specific magnitude and timing of the carbon release is uncertain, and the topic remains a principal catalyst for current permafrost research (Schuur et al., 2015). 


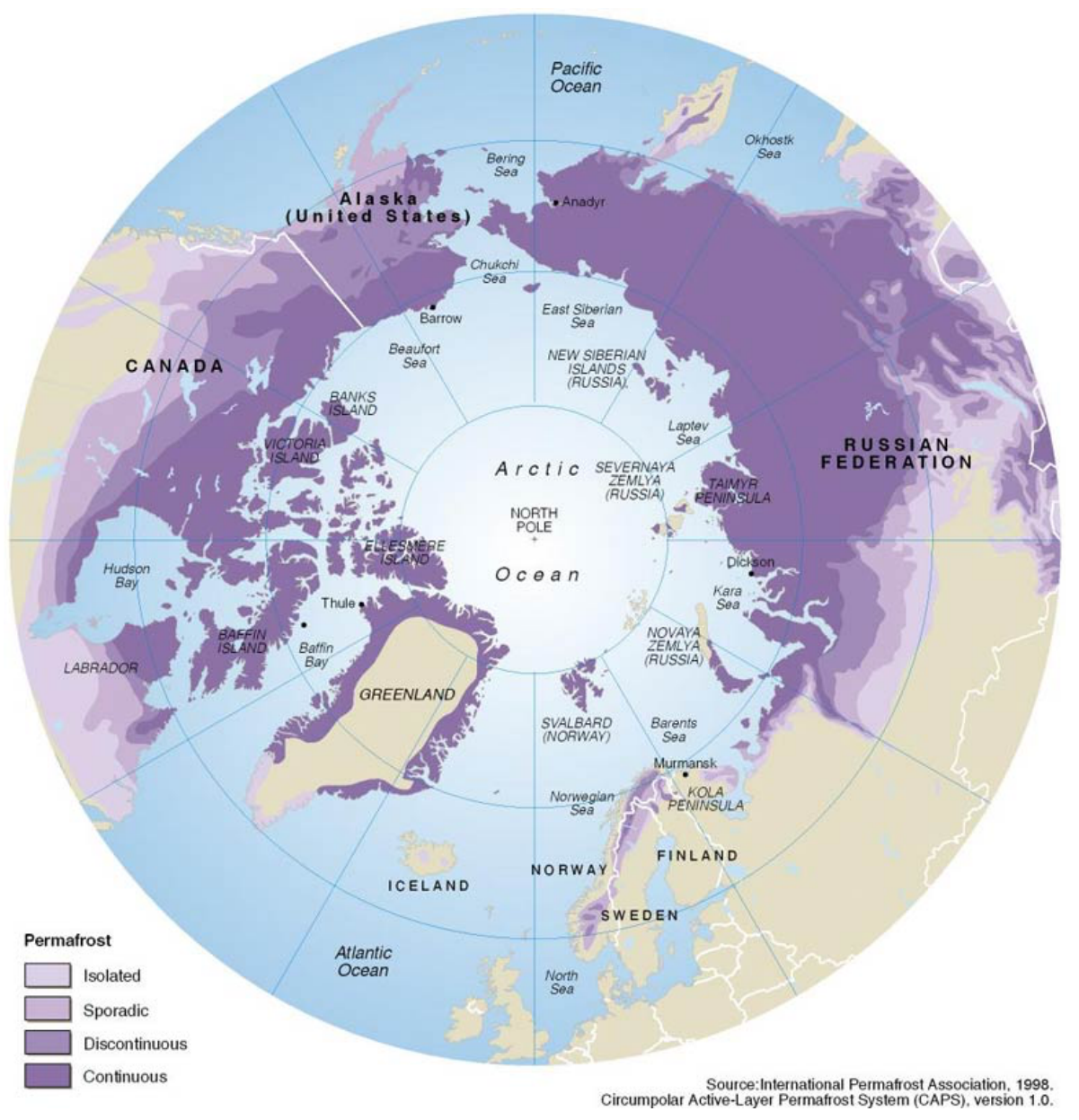

Figure 2.1: Distribution of permafrost in the northern hemisphere north of 50 ${ }^{\circ} \mathrm{N}$, retrieved 25 May 2016 from: https://nsidc.org/sites/nsidc.org/files/images/ /permafrost_distribution_in_the_arctic.jpg 
This thesis presents research on the thermal regime of permafrost in the Peel Plateau region in natural and anthropogenically-disturbed locations near infrastructure, and thus contributes to the broader literature.

\subsubsection{The climate-permafrost relation}

Lachenbruch et al. (1988) conceptualized the climate-permafrost system by relating the mean annual air temperature $\left(T_{a}\right)$, ground surface temperature $\left(T_{s}\right)$, and temperature at the permafrost surface $T_{p s}$ (Figure 2.2). Following this conceptual model, the difference between the mean annual ground surface and air temperatures has been termed the surface offset (Henry and Smith, 2001), while the difference between $T_{s}$ and $T_{p s}$ is referred to as the thermal offset (Burn and Smith, 1988; Williams and Smith, 1989).

\subsubsection{The surface offset}

The surface offset is a result of the surface energy balance, controlled by the effects of snow, vegetation, and the surface organic layer (Luthin and Guymon, 1974, Fig. $4)$. The net radiation at the surface $\left(Q^{*}\right)$ depends on the three flux components of the surface energy balance:

$$
Q^{*}=Q_{H}+Q_{L}+Q_{G}
$$

where $Q_{H}, Q_{L}$, and $Q_{G}$ are the sensible, latent, and ground heat fluxes $\left(W m^{-2}\right)$, respectively $(O k e, 1978)$. The buffer zone of snow, vegetation, and organic matter is critical to the surface offset and permafrost temperatures as it controls the transfer of heat to the underlying ground (Luthin and Guymon, 1974). The thermal influence of 


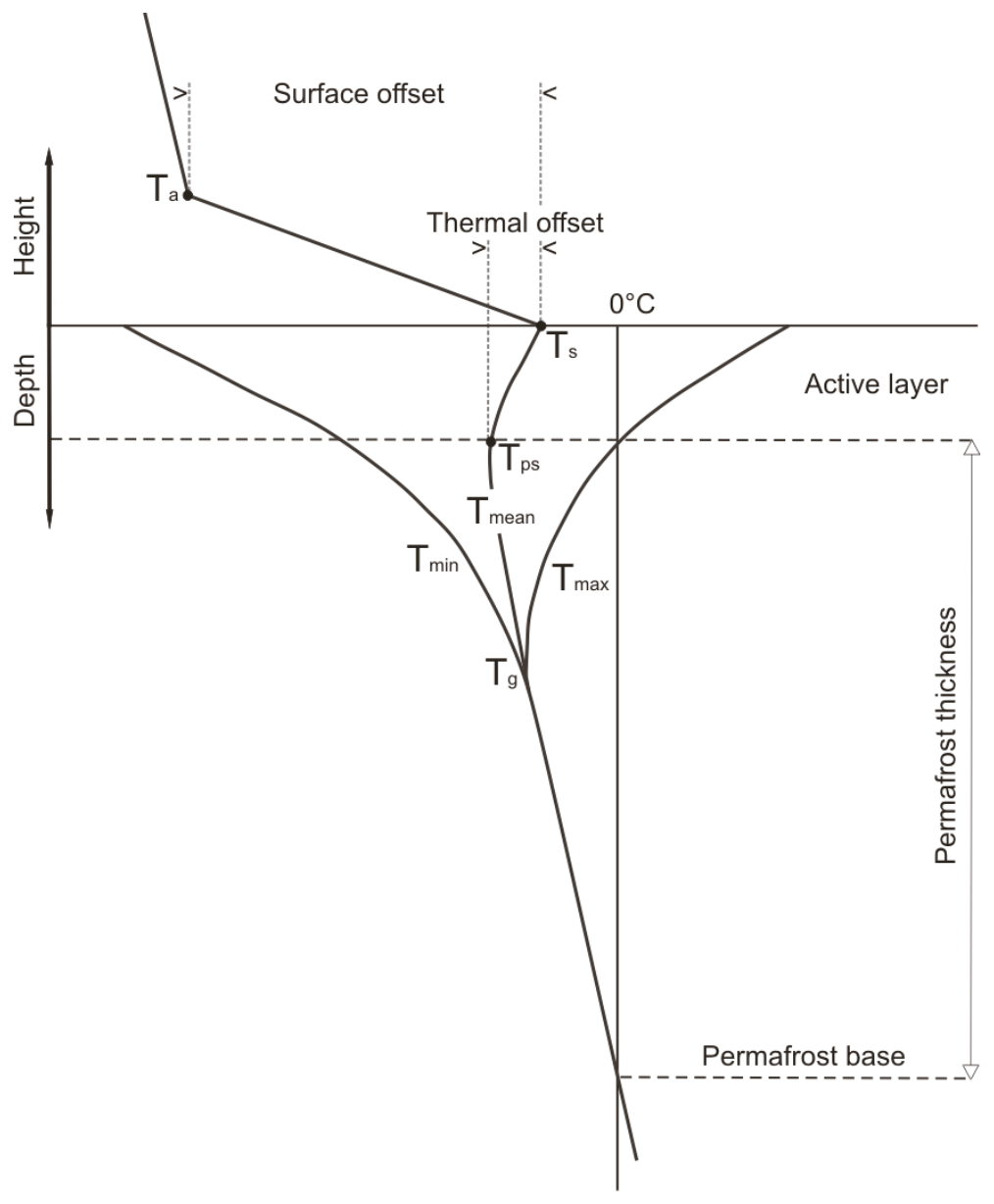

Figure 2.2: The climate-permafrost relation and the annual thermal regime of permafrost (after Fig 1, Riseborough et al., 2008; Burn, 2004, Fig 3.3.2) 
the surface conditions, particularly that of winter snow cover, causes $T_{s}$ to commonly be higher than $T_{a}$ (Brown, 1969), resulting in a surface offset of several degrees.

\subsubsection{The annual thermal regime of permafrost}

The thermal regime of permafrost under equilibrium conditions is shown in Figure 2.2. The lines $T_{\max }$ and $T_{\min }$ represent the annual maximum and minimum permafrost temperatures at depth. The depth at which the temperature envelope converges and annual temperature fluctuations are $<0.1{ }^{\circ} \mathrm{C}$ represents the depth of zero annual amplitude (Williams and Smith, 1989). The temperature increases below this depth due to the geothermal gradient. The base of permafrost occurs when the profile reaches $0{ }^{\circ} \mathrm{C}$.

\subsubsection{Conductive heat flow}

Conductive heat flow is the main mechanism of heat transfer in soil. Heat flows by conduction through all soil constituents: mineral solids, organic matter, water in all three phases, and air in the soil pores (Farouki, 1981). The ground heat flux may be expressed by (Lunardini, 1981, p. 41):

$$
Q_{G}=\lambda\left(\frac{d T}{d z}\right)
$$

where $Q_{G}$ is the ground heat flux $\left(\mathrm{W} \mathrm{m}^{-2}\right), \lambda$ is the thermal conductivity ( $\mathrm{W} \mathrm{m}^{-1}$ $\left.\mathrm{K}^{-1}\right), T$ is temperature and $z$ is depth in the ground. Therefore, the ground heat flux increases with the thermal conductivity and temperature gradient.

The change in soil temperature over time is expressed by the heat conduction equation Carslaw and Jaeger (1959): 


$$
\frac{d T}{d t}=\frac{\lambda}{C} \frac{d^{2} T}{d z^{2}}
$$

where $C$ is the specific heat capacity of the soil $\left(\mathrm{J} \mathrm{kg}^{-1} \mathrm{~K}^{-1}\right)$, the amount of energy required to raise the temperature of a unit mass or volume by $1{ }^{\circ} \mathrm{C}$. The fraction $\frac{\lambda}{C}$ represents the thermal diffusivity $\left(\mathrm{m}^{2} \mathrm{~s}^{-1}\right)$, the soils ability to propagate a temperature change. Therefore, soils with high thermal diffusivity change temperature rapidly and propagate a temperature wave effectively.

As a temperature wave propagates into the soil, two effects are observed. First, the amplitude of the wave decreases, and second, the wave is progressively offset. The thermal diffusivity is responsible for these effects as it controls the speed of the temperature wave through the ground and the depth to which temperature changes occur $($ Oke, 1978). The temperature wave may be described by (Carslaw and Jaeger, 1959):

$$
T(z, t)=T_{s}+A_{s} e^{-z \sqrt{\frac{\omega}{2 \kappa}}} \sin \left(\omega t-z \sqrt{\frac{\omega}{2 \kappa}}\right)
$$

where $A_{s}$ is the amplitude of the temperature oscillation at the ground surface, $\omega$ is the angular velocity ( $\left.2 \pi \mathrm{rad} \mathrm{a}^{-1}\right)$ and $\kappa$ is the thermal diffusivity. From this equation, we see that the thermal diffusivity is an important component of the ground thermal regime because it controls both the attenuation of the surface temperature wave and the offset at depth. Equations 2.1-2.3 demonstrate the importance of the soil thermal conductivity, diffusivity, and heat capacity for the ground thermal regime, and thus the importance of site-specific conditions that influence these thermal properties. 


\subsubsection{Ground thermal properties}

\section{Thermal conductivity}

The thermal conductivity of the soil controls heat flow and temperature changes in the ground [Eq. 2.1-2.3]. The thermal conductivity of a soil may be estimated using (Johansen, 1977):

$$
\lambda=\left(\lambda_{m}{ }^{1-p}\right)\left(\lambda_{w}^{p-q-r}\right)\left(\lambda_{a}^{q}\right)\left(\lambda_{i}^{r}\right)
$$

where $\lambda$ is the thermal conductivity of the ground, and $\lambda_{m}, \lambda_{w}, \lambda_{a}, \lambda_{i}$ are the thermal conductivities of the mineral, water, air, and ice fractions of the soil, respectively. The superscripts $p, q$, and $r$ are the porosity and volumetric fractions of air and ice, respectively. An important consideration in permafrost soils is the near-fourfold increase in thermal conductivity when water changes phase from liquid to pure ice (Table 2.1). The result is that once pore water begins to freeze, the soil can cool more quickly due to the increased ability to conduct heat out of the ground. Conversely, the rate of thaw decreases over the summer as the thaw front progresses deeper and heat must travel through a thickening layer of ground with a relatively low thermal conductivity.

\section{Specific heat capacity}

Temperature changes in the ground also depend on the soil's specific heat capacity. The overall heat capacity of the soil $(C)$ is a weighted average of the heat capacities of all the soil constituents (Burn, 2004):

$$
C=(1-p) C_{m}+(p-q-r) C_{w}+q C_{a}+r C_{i}
$$


Table 2.1: Thermal properties of soil constituents. Reproduced from Burn (2004). Data from Williams (1982); Williams and Smith (1989).

\begin{tabular}{llll}
\hline Material & $\begin{array}{l}\text { Thermal conductivity } \\
\left(\mathrm{W} \mathrm{m}^{-1} \mathrm{~K}^{-1}\right)\end{array}$ & $\begin{array}{l}\text { Heat capacity } \\
\left(\mathrm{J} \mathrm{m}^{-3} \mathrm{~K}^{-1}\right)\end{array}$ & $\begin{array}{l}\text { Thermal Diffusivity } \\
\left(\mathrm{m}^{2} \mathrm{~s}^{-1}\right)\end{array}$ \\
\hline Air & $2.2 \times 10^{-2}$ & $8.6 \times 10^{2}$ & $2.6 \times 10^{-5}$ \\
Water & $5.6 \times 10^{-1}$ & $4.2 \times 10^{6}$ & $1.3 \times 10^{-7}$ \\
Ice & $2.2 \times 10^{0}$ & $1.9 \times 10^{6}$ & $1.2 \times 10^{-7}$ \\
Quartz & $8.0 \times 10^{0}$ & $2.1 \times 10^{6}$ & $3.8 \times 10^{-6}$ \\
Peat (dry) & $6.0 \times 10^{-2}$ & $5.8 \times 10^{6}$ & $1.0 \times 10^{-7}$ \\
Peat (wet) & $5.0 \times 10^{-1}$ & $4.0 \times 10^{6}$ & $1.2 \times 10^{-7}$ \\
Peat (wet,frozen) & $1.1 \times 10^{0}$ & $1.6 \times 10^{6}$ & $6.8 \times 10^{-7}$ \\
\hline
\end{tabular}


where the subscripts $m, w, a$, and $i$ represent the mineral, water, air, and ice fractions respectively. The specific heat capacity of water is high $\left(4180 \mathrm{~J} \mathrm{~kg}^{-1} \mathrm{~K}^{-1}\right)$ compared to the other soil constituents, and the heat capacity of soil increases linearly with moisture content Oke (1978). The specific heat capacity of thawed soils is commonly greater than for frozen soils, because ice has a significantly lower heat capacity than water (Table 2.1).

\section{Thermal diffusivity}

Thermal diffusivity is necessarily affected by the same soil properties as the conductivity and heat capacity, and particularly by soil moisture (Oke, 1978). The diffusivity increases with thermal conductivity, and decreases with a higher heat capacity. The addition of moisture to a dry soil initially results in a pronounced increase in diffusivity as the conductivity increases. However, a decrease is observed beyond about $20 \%$ moisture content due to the continual increase in heat capacity and the reduced increase in thermal conductivity (Oke, 1978). Because the thermal conductivity is increased during freezing and the heat capacity is reduced, the thermal diffusivity of ice is much greater than water (Table 2.1). Therefore, once frozen, the ground is able to propagate a temperature change more rapidly than when thawed.

\subsubsection{The thermal offset}

The thermal offset, which is the difference between $T_{s}$ and $T_{p s}$, is a result of the seasonal differences in soil thermal conductivity. When the frozen conductivity is greater than the thawed conductivity, thermal equilibrium is maintained by a greater temperature gradient in summer than in winter (Burn, 2004). As a result, the mean annual ground temperature decreases with depth toward the base of the active layer, 
where the thermal properties vary little seasonally. The thermal offset increases as the difference between the frozen and thawed conductivities increases. In bedrock and dry soils, the thermal offset is minimal due to low moisture contents and consequently small variation in seasonal thermal properties. However, in soils with higher porosity and greater moisture contents, the thermal offset may be significant. Burn and Smith (1988) observed thermal offsets up to $1.7^{\circ} \mathrm{C}$ near Mayo, YK. The existence of the thermal offset allows the presence of permafrost where the mean annual ground surface temperature is $>0{ }^{\circ} \mathrm{C}$. In very dry soils, a reverse thermal offset may exist ( Lin et al., 2015).

\subsubsection{Non-conductive heat flow}

Non-conductive modes of heat transfer involve the coupled movement of heat and mass by the migration of water through the soil. Particularly, the transfer of latent heat from one location to another may significantly influence local temperatures. (Kane et al., 2001) suggested that non-conductive heat transfer is important near the ground surface during the spring and fall periods when phase changes are occurring. For example, Outcalt et al. (1990) found that active-layer freeze back was influenced by vapour transport and the coupled advection of latent heat from evaporation and condensation. Non-conductive heat transfer is believed to maintain the zero curtain effect during freeze back, when little conduction occurs due to negligible temperature gradients in the soil profile (Outcalt et al., 1990; Kane et al., 2001). During the thaw period, melt water from snow may infiltrate into the frozen ground and refreeze, causing rapid warming of the ground near to $0{ }^{\circ} \mathrm{C}$.

Though non-conductive heat transfer may cause significant temperature changes in the active layer, the effect is typically short-lived and does not significantly alter the overall thermal regime of the ground. Vapour transport and convection of water may 
be important in porous organic, sandy, or gravel soil, but in fine-grained soils, conductive heat flow models accurately predict active-layer temperatures during freezeback and thaw, provided that latent heat effects due to unfrozen water content are taken into account (Romanovsky and Osterkamp, 2000). In this thesis, non-conductive heat flow is not considered as the sediments in the region are predominantly fine-grained.

\subsubsection{Latent heat and unfrozen water content}

Water in fine-grained soils composed mainly of silt and clay freezes over a range of temperatures below $0{ }^{\circ} \mathrm{C}$, due to its restriction in small soil pores, ion concentration, and adsorption to soil particles (Williams and Smith, 1989). The unfrozen water content characteristic curve of the soil demonstrates this effect (Patterson and Smith, 1981), and can normally be described with the equation (Burn, 2004):

$$
\theta_{u}=a T^{-b}
$$

where $\theta_{u}$ is the unfrozen water content, and $a$ and $b$ are fitting parameters (e.g., Burn, 1998a, Eq. 1). The unfrozen water content curve characterizes the latent heat released or absorbed over a range of temperatures as the soil freezes or thaws. The latent heat causes the soil to exhibit an apparent heat capacity $\left(C_{a}\right)$ (Burn, 2004):

$$
C_{a}=C+L \frac{d \theta_{u}}{d T}
$$

where $L$ is the heat of fusion $\left(334 \mathrm{~kJ} \mathrm{~kg}^{-1}\right)$. For example, during freeze back if the change in unfrozen water with temperature is large, a significant amount of heat is released, and the apparent heat capacity increases. The change in apparent heat capacity necessarily changes the apparent thermal diffusivity. As a result, a ground 


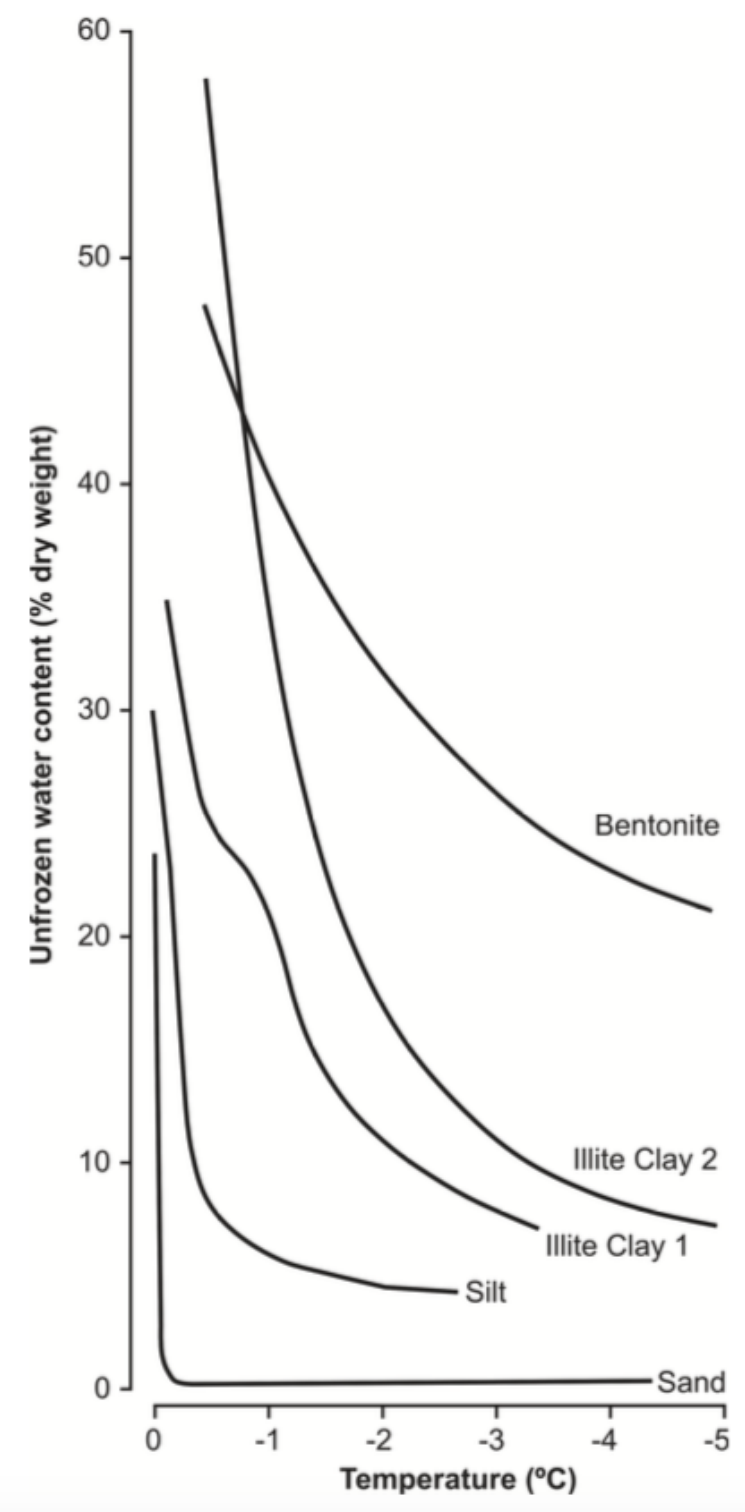

Figure 2.3: Unfrozen water content of soils below $0{ }^{\circ} \mathrm{C}$ (Reproduced with permission from Roy-Léveillée, 2014, Figure 4, originally in Burt and Williams (1976), Figure 1) 
temperature profile is associated with a corresponding profile of thermal properties (Riseborough, 1990). The thermal properties change most rapidly near $0^{\circ} \mathrm{C}$ (Farouki, 1981).

\subsection{Environmental influences on permafrost tem- peratures}

\subsubsection{Vegetation}

Vegetation has a direct influence on the ground thermal regime, and also exerts control on other environmental conditions that affect permafrost temperatures.

In summer, vegetation blocks incoming solar radiation from reaching the ground surface, reducing net radiation received at the surface (Luthin and Guymon, 1974; Smith, 1975). Solar radiation may be reduced by two orders of magnitude under a dense forest canopy compared to an open area (Brown, 1966). Smith (1975) found that decreases in radiation from vegetation cover accounted for variations of about $5^{\circ} \mathrm{C}$ in the daytime summer surface temperatures in the Mackenzie Delta, and that sun flecking at forest sites caused irregular variations of surface temperatures over the day. Chasmer et al. (2011) used a combination of remote sensing and field measurements to determine the effect of shading on permafrost temperatures on permafrost plateaus in the discontinuous permafrost zone near Fort Simpson, NWT. As the canopy cover decreased, more shortwave radiation reached the ground surface, evident by increased longwave radiation emitted from the surface. The reduction in net radation due to vegetation and reduced summer heat flux into the ground is partly responsible for the thinner active layers common under dense vegetation (e.g. Luthin and Guymon, 1974; Blok et al., 2010) 
The most important indirect effect of vegetation on the thermal regime is its ability to modify snow depths by trapping blowing snow in winter (Smith, 1975; Sturm et al., 2001a). Vegetation indirectly influences heat flux into the ground in several other ways, however it is difficult to isolate these effects (Brown, 1966; Luthin and Guymon, 1974). For example, the reduction in net radiation from shading results in lower evaporation rates and more moisture at the surface, which promotes cool conditions (Brown, 1966). However, vegetation also facilitates evaporative cooling after the surface has dried out, because roots enable latent heat transfer from the soil to atmosphere by transpiration. The structure of vegetation may also reduce wind speed, which lowers heat advection from the ground surface (Brown and Péwé, 1973).

In permafrost regions, the influences of vegetation are necessarily more important in forests of the discontinuous zone than in sparsely vegetated tundra areas, where vegetation plays little role in determining permafrost temperatures (Brown and Péwé, 1973). Shur and Jorgenson (2007) conceptualized climate and ecological effects into five classifications of permafrost. On one end of the classification, climate-driven permafrost forms in the continuous permafrost zone following the exposure of a bare surface, and is thus devoid of vegetation influences. In contrast, ecosystem-protected permafrost persists in patches at the southern limit of permafrost, maintained by the thermal offset associated with surface conditions of late-stage vegetation succession (Shur and Jorgenson, 2007).

\subsubsection{Surface organic layer}

The surface organic layer has a significant impact on the surface offset and heat flow into the ground below. The effects of the organic layer are strongly seasonal. In summer, surface organic matter is commonly dry due to evaporation. Since mosses, lichen, and peat are highly porous, the thermal conductivity of dry organic matter 
in summer is very low (Table 2.1). In autumn, the organic layer is typically wetter because of reduced evaporation rates and increased precipitation (Williams and Smith, 1989). When the surface layer freezes, the thermal conductivity of the organic layer increases significantly as the water turns to ice. For example, dry peat has a thermal conductivity of about $0.06 \mathrm{~W} \mathrm{~m}^{-1} \mathrm{~K}^{-1}$, whereas when wet and frozen, the conductivity may be greater $\left(1.1 \mathrm{~W} \mathrm{~m}^{-1} \mathrm{~K}^{-1}\right.$, Table 2.1$)$. The seasonal difference in thermal conductivity serves to inhibit heat flow into the ground in summer, and facilitate heat loss from the ground in winter. In addition, mosses and lichens can readily hold and absorb water, but evaporation from their surfaces is rapid, which cools the ground surface in summer (Brown, 1966; Harazono et al., 1995).

The importance of the organic layer is well illustrated when it is removed and the resulting ground temperature conditions are examined. For example, Smith (1975) removed $10 \mathrm{~cm}$ of organic matter from the surface in a spruce-covered area of the Mackenzie Delta, and compared ground temperatures at a depth of $10 \mathrm{~cm}$ to an undisturbed site $1 \mathrm{~m}$ away. The mean daily ground surface temperature increased by about $3{ }^{\circ} \mathrm{C}$ at the disturbed site (Smith, 1975, Figure 8). Forest fires destroy part of the organic layer, resulting in increased ground temperatures and active layer depths (Viereck, 1982; Mackay, 1995; Burn, 1998a). The ground surface warms in summer following disturbance of the organic layer due to reduced evaporative cooling and lower albedo at the surface. The reduction in thickness of the insulating material increases the heat flux into the ground and increases ground temperatures (Burn, 1998a). Active layer thicknesses respond to the increased heat flux, becoming up to four times thicker following fires (Viereck, 1982). The destruction of the organic layer from forest fires highlights the importance of the surface cover in maintaining ground temperatures that favour permafrost.

The organic layer is typically thinner in tundra, or may be absent entirely, in 
contrast to forest sites where significant peat, moss, or lichen layers accumulate. Therefore, the thermal influence of the organic layer is more important in the discontinuous permafrost zone and forested areas of the continuous permafrost zone than at higher latitudes. For example, the removal of the organic layer in the continuous permafrost zone results in more restricted permafrost thaw, and more rapid thermal stabilization $($ Mackay, 1995) than in the discontinuous zone, likely due to the lower prevailing air temperatures (Viereck, 1982). In the discontinuous permafrost zone, removal of the organic layer may result in the disappearance of permafrost (Brown and Péwé, 1973). Smith and Riseborough (2002) indicated that surface organic accumulation controls the presence or absence of permafrost at the southern limit of the discontinuous permafrost zone, due to the large thermal offsets associated with organic material.

\subsubsection{Snow}

Snow is highly porous and mostly composed of air. Consequently, it has a very low thermal conductivity that typically ranges between about 0.01 and $0.9 \mathrm{~W} \mathrm{~m}^{-1} \mathrm{~K}^{-1}$ (Sturm et al., 1997, Fig. 11). The low thermal conductivity inhibits heat loss from the ground in winter, and ground temperatures are typically higher where thicker snow cover accumulates (Mackay and MacKay, 1974; Smith, 1975) (Figure 2.4). The timing of snow arrival and melting control the overall thermal effect on the underlying ground (Goodrich, 1982a). Early snowfall during the fall leads to a greater warming effect, while persistence of snow cover in the spring may have a cooling effect on the ground, because the surface remains near $0{ }^{\circ} \mathrm{C}$ until the snow melts (Zhang, 2005).

In the continental continuous permafrost zone, snow cover is the most important surficial factor causing local ground temperature variations, and results in differences 


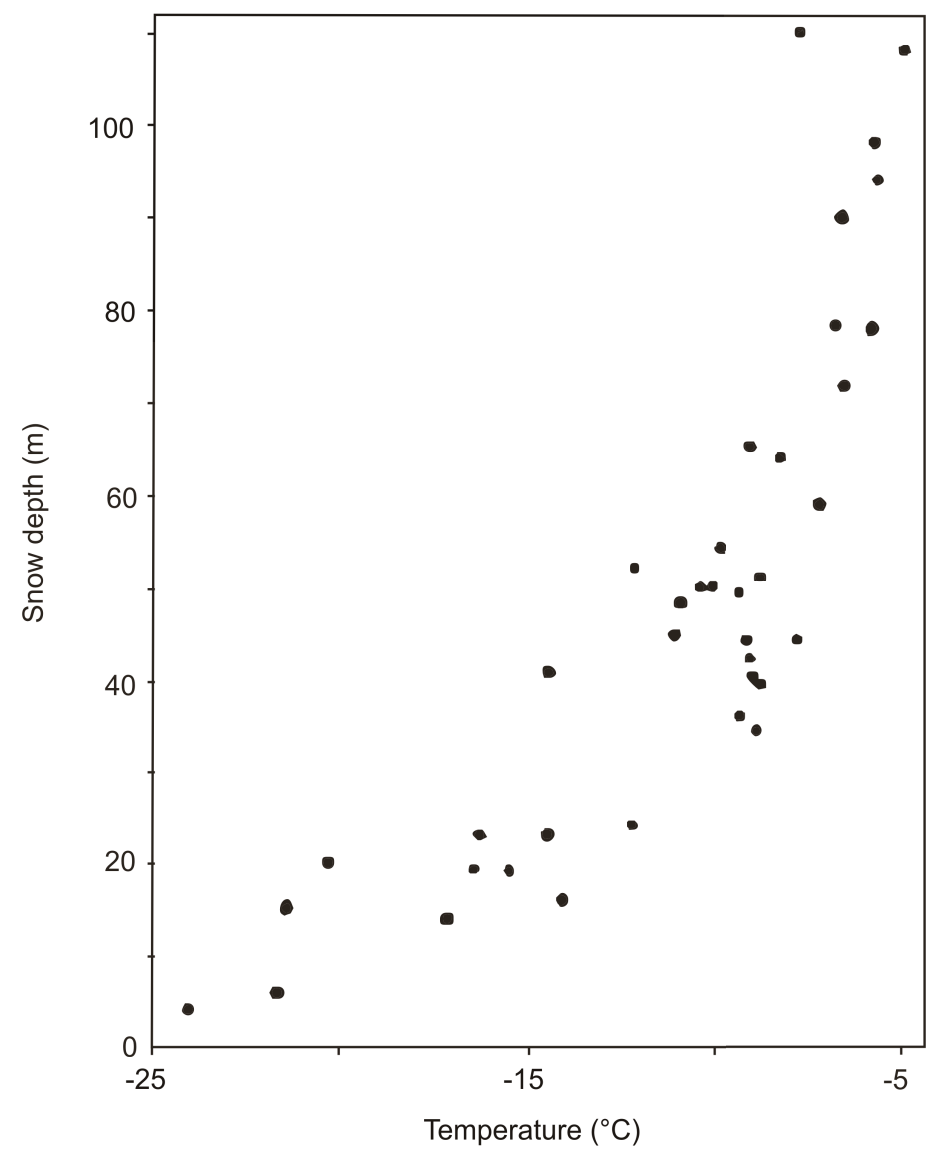

Figure 2.4: Late-winter snow depths and ground surface temperatures measured in March 1970 in the central Mackenzie Delta (modified from Smith, 1975, Figure 9) 
in the mean annual temperature near the top of permafrost of several degrees in the tundra (Mackay and MacKay, 1974; Burn and Zhang, 2009; Morse et al., 2012). Morse et al. (2012) performed a stepwise linear regression that suggested snow accounted for $69 \%$ of the variation in ground temperatures in upland tundra permafrost in the outer Mackenzie Delta area. Snow is also a critical environmental condition in some areas of the discontinuous zone, causing significant variations in permafrost temperatures (Goodrich, 1982a; Zhang, 2005), thickness, and distribution (Brown and Péwé, 1973).

\subsubsection{Permafrost conditions across treeline}

Permafrost conditions vary over relatively short distances across the forest-tundra ecotone due to important snow-vegetation interactions. The vegetation gradient across the ecotone at latitudinal treeline is commonly, from north to south: dwarf-shrub tundra, scrub tundra with taller shrubs, shrubby open woodlands, open woodlands, and finally closed-canopy woodland (e.g. Mackay, 1963). Snow cover is thinner and denser in tundra than in forest due to sublimation and packing during strong winter winds (Mackay and MacKay, 1974; Sturm et al., 2001a). It therefore offers low thermal resistance, facilitating ground heat loss. Palmer et al. (2012) reported thermal resistances from 2.4 to $9.5 \mathrm{~m}^{2} \mathrm{~K} \mathrm{~W}^{-1}$ in tundra and $11.0 \mathrm{~m}^{2} \mathrm{~K} \mathrm{~W}^{-1}$ in boreal forest north of Inuvik. Tundra snow depths are predominantly controlled by the topographic setting (Mackay and Burn, 2002; Burn and Zhang, 2009) and modified by vegetation structure as snow is redistributed by winter winds (Thompson et al., 2004; Sturm et al., 2001a; Palmer et al., 2012). Tundra in the continuous permafrost zone is generally associated with cold $\left(<5^{\circ} \mathrm{C}\right)$ permafrost temperatures for infrastructure management and engineering purposes (e.g. p. 34, Johnston, 1981; McGregor et al., 2010, p. 3). 
Larger shrubs reduce wind speed, allowing snow to accumulate and protecting the deposited snow from strong winds, reducing rates of sublimation (Sturm et al., 2001a). The height, density, and complexity of tundra shrubs control the amount of snow that is trapped by the vegetation (Thompson et al., 2004; Palmer et al., 2012). Consquently, ground temperatures in the transitional zone between dwarfshrub tundra and woodland are relatively high (Sturm et al., 2001a; Palmer et al., 2012).

In forest, wind distribution of snow is limited, so snow depths are more uniform and the snow cover density is lower (Burn, 2004; Palmer et al., 2012). However, snow wells may occur under trees, reducing snow depths immediately beneath branches (Brown and Péwé, 1973). In addition, closed forest canopies may intercept precipitation and reduce snow depths on the ground (Kokelj et al., 2007; Kanigan et al., 2009), resulting in cooler ground temperatures compared to open-canopy stands. The marked changes in snow conditions across the ecotone cause ground temperatures to be significantly lower in tundra than in forest. For example, mean annual permafrost temperatures in upland forests near Inuvik are -1 to $-3{ }^{\circ} \mathrm{C}$, but decline to around -6 ${ }^{\circ} \mathrm{C}$ in tundra north of latitudinal treeline (Burn and Kokelj, 2009, Figure 11).

Air temperatures also influence permafrost conditions across treeline. The northern limit of trees is predominantly determined by summer climate, but is also influenced by the availability of moisture (Elliott-Fisk, 2000). Treeline coincides with the $12{ }^{\circ} \mathrm{C}$ mean July isotherm in continental areas of North America, and is close to the $10{ }^{\circ} \mathrm{C}$ mean July isotherm in maritime locations (Walker, 2000). At latitudinal treeline near Inuvik, autumn and winter air temperatures are similar across the ecotone (Palmer et al., 2012). Summer air temperatures decline across the vegetation gradient due to differences in net radiation and onshore breezes blowing off ice and 
cold water in the Beaufort Sea (Burn, 1997). Summer air temperatures also theoretically decline across an alpine treeline, as temperatures decrease with elevation at the

environmental lapse rate (e.g. $-6.5^{\circ} \mathrm{C} \mathrm{km}-1$ ). However, air temperature inversions are common in winter at high latitudes and, in mountainous terrain, strong inversions may develop during calm periods with a clear sky (Burns, 1973; Burn, 1993; Taylor et al., 1998). For short periods in winter, valley temperatures in the Yukon may be -40 to $-50{ }^{\circ} \mathrm{C}$, and rise to $-15^{\circ} \mathrm{C}$ at $1000 \mathrm{~m}$ a.s.l. (Wahl et al., 1987). As a result, the number of freezing degree days may decline with elevation, reducing winter ground cooling in higher terrain (Taylor et al., 1998; Lewkowicz and Bonnaventure, 2011).

\subsection{Study area: Peel Plateau region, Northwest Territories}

\subsubsection{Physiography and research context}

The Peel River Plateau Ecoregion is an extensive, glacially-formed environment of the Taiga Plains Ecozone (Yukon Ecoregions Working Group, 2004). The plateau covers an area of $59,790 \mathrm{~km}^{2}$ in Yukon and Northwest Territories, bounded by Richardson Mountains to the west, Wernecke Mountains to the south, the scarp leading to the Mackenzie and Peel rivers to the east, and the Beaufort Sea to the north (Yukon Ecoregions Working Group, 2004). Elevation (m a.s.l.) in the ecoregion ranges from about $100 \mathrm{~m}$ in the Bonnet Plume Depression, up to $760 \mathrm{~m}$ in uplands (Yukon Ecoregions Working Group, 2004).

Topography along the Dempster Highway on Peel Plateau is characterized by rolling hills, incised by steep-sided canyons of Stony Creek to the north and Vittrekwa River to the south, draining east to Peel River. The elevation on Peel Plain at Fort 
McPherson is about $20 \mathrm{~m}$, rising to about $500 \mathrm{~m}$ on Peel Plateau where the highway reaches the Midway emergency airstrip. Over this elevation range, vegetation changes from open-canopy spruce forest, to tall-shrub tundra and low-shrub tundra at higher elevations (Kokelj et al., 2013).

The Peel Plateau near Fort McPherson is within the traditional territory of the Tetlit Gwich'in First Nation. In recent years there has been considerable research activity on Peel Plateau as part of a Northwest Territories Cumulative Impacts Monitoring Program project to monitor landscape changes in the region. This watershedscale project was developed to address community and land management concerns associated with the disturbance to infrastructure, water quality, and fisheries due to thawing of permafrost at large retrogressive thaw slumps on Peel Plateau. The Tetlit Renewable Research Council in Fort McPherson has been the logistics hub for the research activities, and the project has resulted in close collaboration with the community through meetings of the local steering committee and researchers, local involvement in field work, and outreach activities.

\subsubsection{Climate}

There are no climatic data from Peel Plateau, and the closest meteorological station at Fort McPherson airport in the Peel Plain lowlands closed in 2007. The broader region has a subarctic, continental climate with long, cold winters and short, cool summers. The mean annual air temperature at Fort McPherson in 1987-2006 was $7.0{ }^{\circ} \mathrm{C}$ (Environment Canada, 2014). Temperatures in February average -25 to $-30{ }^{\circ} \mathrm{C}$, with extreme minimums reaching $-55{ }^{\circ} \mathrm{C}$ (Yukon Ecoregions Working Group, 2004). However, winter air temperature inversions between Peel Plain and Peel Plateau cause air temperatures to be considerably warmer at higher elevation (O'Neill et al., 2015). July is the warmest month, averaging $15^{\circ} \mathrm{C}$. 
Total annual precipitation (1987-2006) averages $295 \mathrm{~mm}$, with $148 \mathrm{~mm}$ falling as rain (Environment Canada, 2014). Precipitation is typically heaviest in late summer and early fall. Snow accumulation in 2000-2007 at Fort McPherson began between 29 September and 14 October, and melt was complete by 12 and 31 May (Burn and Kokelj, 2009). Winds in the region are commonly light or moderate $(10-15 \mathrm{~km} / \mathrm{h})$, and are dominantly from the northwest and south (Yukon Ecoregions Working Group, 2004).

The Canadian western Arctic has experienced significant climate warming over the past several decades, with air temperatures increasing by about $2.5{ }^{\circ} \mathrm{C}$ since 1970 at Inuvik (Figure 2.5; Burn and Kokelj, 2009). Summer precipitation at Fort McPherson has increased in magnitude and intensity from 1986-2012 (Kokelj et al., 2015).

\subsubsection{Geology and surficial materials}

The region was affected by the Late Wisconsinan Laurentide Ice Sheet, which covered Peel Plateau and extended to the foothills of Richardson Mountains (Fulton, 1995; Yukon Ecoregions Working Group, 2004). There are three defined glacial limits in the

region. The maximum extent occurred ca. $30,000{ }^{14} \mathrm{C}$ years ago, with two later advances dated to ca. 22,000 and 13,000 14C years ago, respectively ( Yukon Ecoregions Working Group, 2004).

Bedrock outcrops are found only in some river valleys in the ecoregion, and none are visible within the study area along the Dempster Highway on Peel Plateau. Surficial deposits are underlain by Cretaceous marine shale and siltstone bedrock (Norris, 1984). The surficial deposits are mainly glacial in origin, consisting predominantly of 


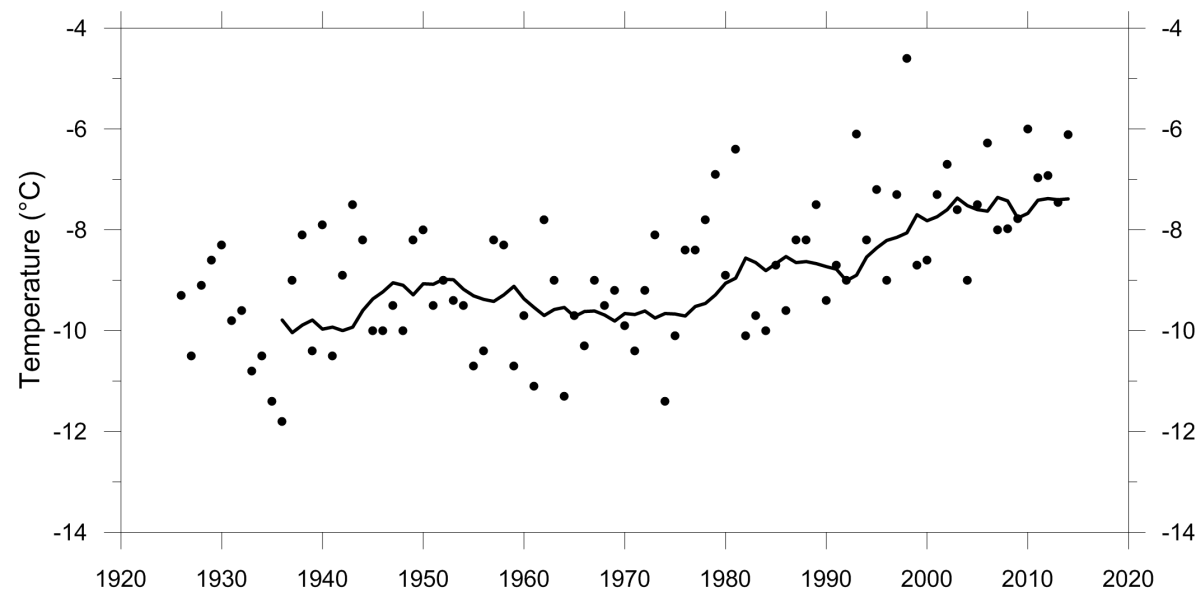

Figure 2.5: Annual mean air temperature at Inuvik 1926-2014 (modified from Burn and Kokelj, 2009, Figure 4). The data for 1957-2006 are from Inuvik, and the data for 1926-57 are a composite series based on measurements at Aklavik. The running mean air temperature for the previous 10 years is plotted as a line for 1935-2014. Data are from Environment Canada (2014). 
till (Fulton, 1995). Glaciofluvial deposits of sand and gravel are also present (DukRodkin and Hughes, 1992). Silt and/or organic deposits overlie the tills and glaciofluvial sediments in places (Duk-Rodkin and Hughes, 1992).

\subsubsection{Permafrost}

Permafrost on Peel Plateau has formed since the retreat of the Laurentide Ice sheet. Remains of steppe bison (Bison priscus) found near Tsiigehtchic (formerly Arctic Red River) indicate that the region was ice-free by $\sim 13,565$ to 13,811 cal yr BP (Zazula et al., 2009). Until recently, there has been little research on ground thermal conditions in the region. Mackay (1967) estimated that permafrost at an instrumented borehole site $22 \mathrm{~km}$ west of Fort McPherson was approximately $120 \mathrm{~m}$ thick, with mean annual ground temperatures about $-3.0{ }^{\circ} \mathrm{C}$ in the near-surface. Geophysical data collected at a high-elevation site near the Yukon/NWT border have indicated a thickness of about $625 \mathrm{~m}$, but at lower elevations on the plateau the thickness is likely closer to 300 m (Yukon Ecoregions Working Group, 2004). Near-surface ground tem-

peratures inferred on national-scale maps range between -2 and $-5{ }^{\circ} \mathrm{C}$ (Heginbottom et al., 1995; Henry and Smith, 2001).

\subsubsection{Ground ice}

Permafrost on Peel Plateau is characteristically ice rich. Geotechnical drilling by EBA Engineering near Midway Lake found ice-rich ground in the upper $18.3 \mathrm{~m}$ of permafrost (Yukon Ecoregions Working Group, 2004). Near-surface sediments are enriched with segregated ground ice in the form of lenses and veins. Below these uppermost deposits, large bodies of massive ice may be present. Headwalls of numerous retrogressive thaw slumps in the region indicate thicknesses of massive ice exceeding 
$20 \mathrm{~m}$ (Kokelj et al., 2013; Lacelle et al., 2015). Ice wedges are found on pediment slopes near Richardson Mountains, but are less common in the glaciated terrain on Peel Plateau proper and limited primarily to small patches of organic soils (Yukon Ecoregions Working Group, 2004).

\subsubsection{Vegetation}

Vegetation on Peel Plateau consists mainly of open stands of stunted black spruce (Picea mariana) and larch (Larix laricina) woodland at lower elevations. These woodlands exist near the limit of spruce growth, and trees become more prostrate as growing conditions deteriorate with elevation (e.g. Mackay, 1963). The forest cover transitions to low-shrub tundra communities at higher elevations (Yukon Ecoregions Working Group, 2004). Between the woodland and dwarf-shrub tundra, there is a transitional zone of scrub tundra characterized by taller willows, alders, and birch shrubs up to about $1 \mathrm{~m}$ in height (Mackay, 1963). The low-shrub tundra vegetation on Peel Plateau includes dwarf shrubs of willow, alder, and ground birch (Betula nana), sedges, grasses, and heaths.

Alders typically grow in moist soil where deep snow accumulates (e.g. Mackay, 1963), and on Peel Plateau these shrubs have recently proliferated along the Dempster Highway road embankment where conditions are favourable (Gill et al., 2014). In addition, tall alder shrubs $(\sim 3 \mathrm{~m})$ are present along water tracks. The vegetation gradient across the alpine treeline on Peel Plateau is similar to that observed at the latitudinal treeline in the Mackenzie Delta region, but shrubs on Peel Plateau may be larger (Mackay, 1963; Timoney et al., 1992). 


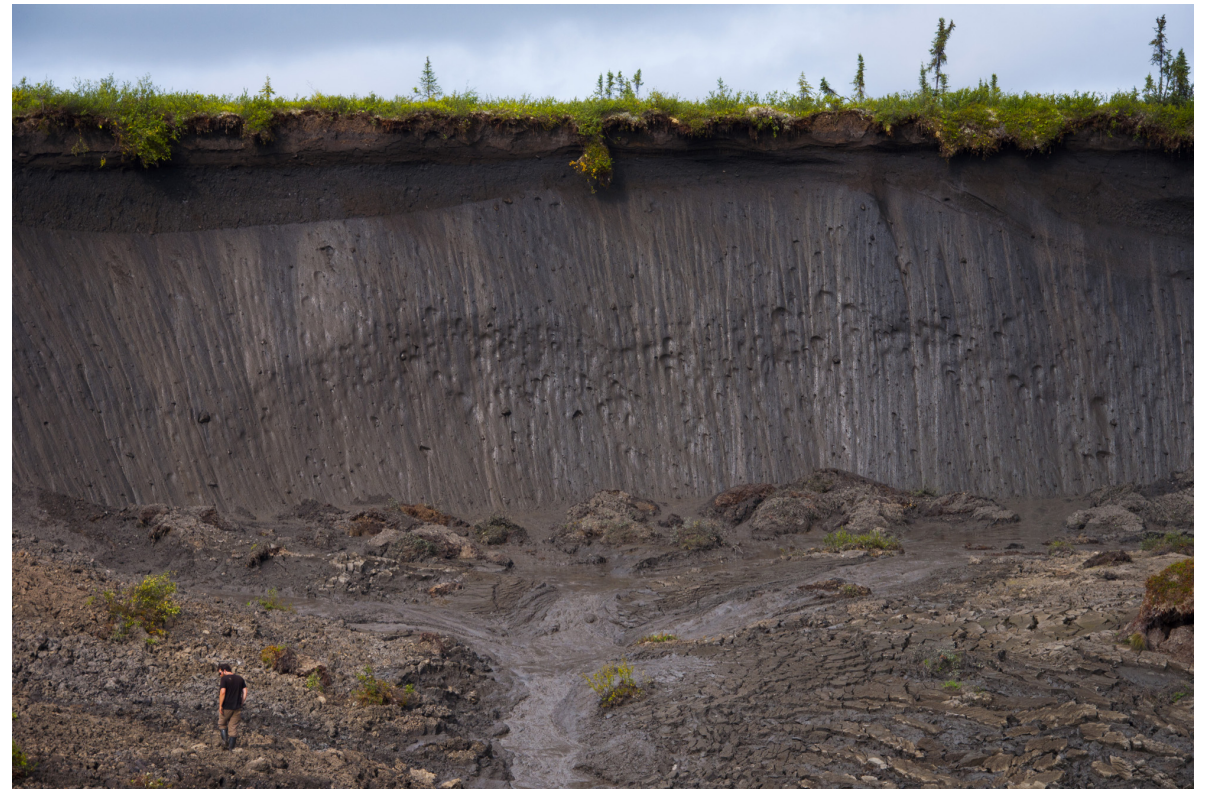

Figure 2.6: Massive retrogressive-thaw slump on Peel Plateau in August 2013. Note the person in the left foreground for scale. 


\subsubsection{The Dempster Highway}

The Dempster Highway is the only road to Canada's western Arctic. It is an allseason gravel road opened in 1979 between the Klondike Highway near Flat Creek, YK, and Inuvik, NWT. Continuous permafrost underlies the Dempster Highway for about $90 \%$ of its $732 \mathrm{~km}$ length. The road passes over discontinuous permafrost for the first $75 \mathrm{~km}$ of its route, north from the junction with Klondike Highway (Heginbottom et al., 1995). As a result, the road surface is built on an embankment that was designed to maintain permafrost and prevent thaw subsidence (Huculak et al., 1978). The embankment height ranges from about 1.0 to $2.5 \mathrm{~m}$ on flat ground, but may be significantly higher on uneven terrain. The embankment in the Peel Plateau region is constructed of quarried shale and sandstone, with a surface treatment of crushed limestone, sandstone, and dolomite (Huculak et al., 1978).

Communities in the Mackenzie Delta region rely on the highway for transportation, goods and services, and tourism. The highway has gained importance since 2011 because Inuvik relies for power generation on tanker truckloads of propane. In addition, construction of the $\$ 300 \mathrm{M}$ Inuvik-Tuktoyaktuk Highway, begun in 2013-14, is an important northern development project that will link the Dempster Highway with the Beaufort Sea at Tuktoyaktuk, NWT.

The climate along the Dempster Highway is subarctic, modified by the mountainous terrain of the region (Table 2.2). Temperatures generally decline northward, but very cold conditions exist in areas with topographic shading and cold-air drainage (e.g., Ogilvie Camp, Table 2.2). Air temperatures rise with elevation within atmospheric inversions, so that surface lapse rates are lower in winter than in summer (Lewkowicz and Bonnaventure, 2011). At a continental scale, precipitation is reduced by the rain shadow of St. Elias Mountains, but rainfall has been increasing 
recently near Peel Plateau (Kokelj et al., 2015).

Ground temperatures reported from sites in undisturbed settings along the highway indicate that $T_{g}$ within the boreal forest and taiga is $\geq-3.0^{\circ} \mathrm{C}$ (Table 2.3 ) (Lacelle et al., 2009). In taiga near Inuvik, $T_{g} \geq-2.0{ }^{\circ} \mathrm{C}$ have been measured in peatlands, where the zero curtain may be prolonged in some soils due to high porosity, wet ground, and deep snow accumulation (Burn et al., 2009).

Prior to the commencement of this thesis, little data were available on permafrost thermal conditions at the road. In 2013-14, a long-term permafrost monitoring site was installed beside the road embankment on Peel Plateau (Idrees et al., 2015). Preliminary data from a three-month period indicate that permafrost tempreatures near the toe of the embankment are about $-1.0^{\circ} \mathrm{C}$ (Idrees et al., 2015, Table 4).

The thaw of ice-rich permafrost on Peel Plateau has posed significant challenges to road maintenance. Ongoing work has been necessary to address thaw subsidence near the embankment toe in some locations (e.g., Figure 2.7). Over the duration of the fieldwork for this research, the highway on Peel Plateau underwent significant rehabilitation. The road was widened and re-surfaced in many sections, and new culverts were installed to improve drainage. 
Table 2.2: Climate data for sites at different distances along the Dempster Highway, 2004. Annual mean air temperature $\left(T_{a}\right)$, and precipitation are available for this year (Table modified from Burn et al., 2015, Table 2)

\begin{tabular}{llllll}
\hline Site & $\mathrm{km}$ post & $\begin{array}{l}\text { Elev. } \\
(\mathrm{m})\end{array}$ & $\begin{array}{l}T_{a} \\
\left({ }^{\circ} \mathrm{C}\right)\end{array}$ & $\begin{array}{l}\text { Rainfall } \\
(\mathrm{mm})\end{array}$ & $\begin{array}{l}\text { Snowfall } \\
(\mathrm{cm})\end{array}$ \\
\hline Dawson & 0 & 346 & -4.2 & 78.6 & 237.4 \\
Klondike Camp & 65 & 966 & -4.9 & 243.3 & 304.3 \\
Ogilvie Camp & 195 & 588 & -9.2 & 104.4 & 176.5 \\
Eagle Plains & 369 & 729 & -6.0 & 81.1 & 94 \\
Rock River & 457 & 735 & -6.8 & - & - \\
Fort McPherson & 550 & 22 & -8.7 & 67.8 & 117.6 \\
Inuvik & 732 & 15 & -9.4 & 83.4 & 246 \\
Tuktoyaktuk & - & 0 & -11.6 & 56 & 151.3 \\
\hline
\end{tabular}




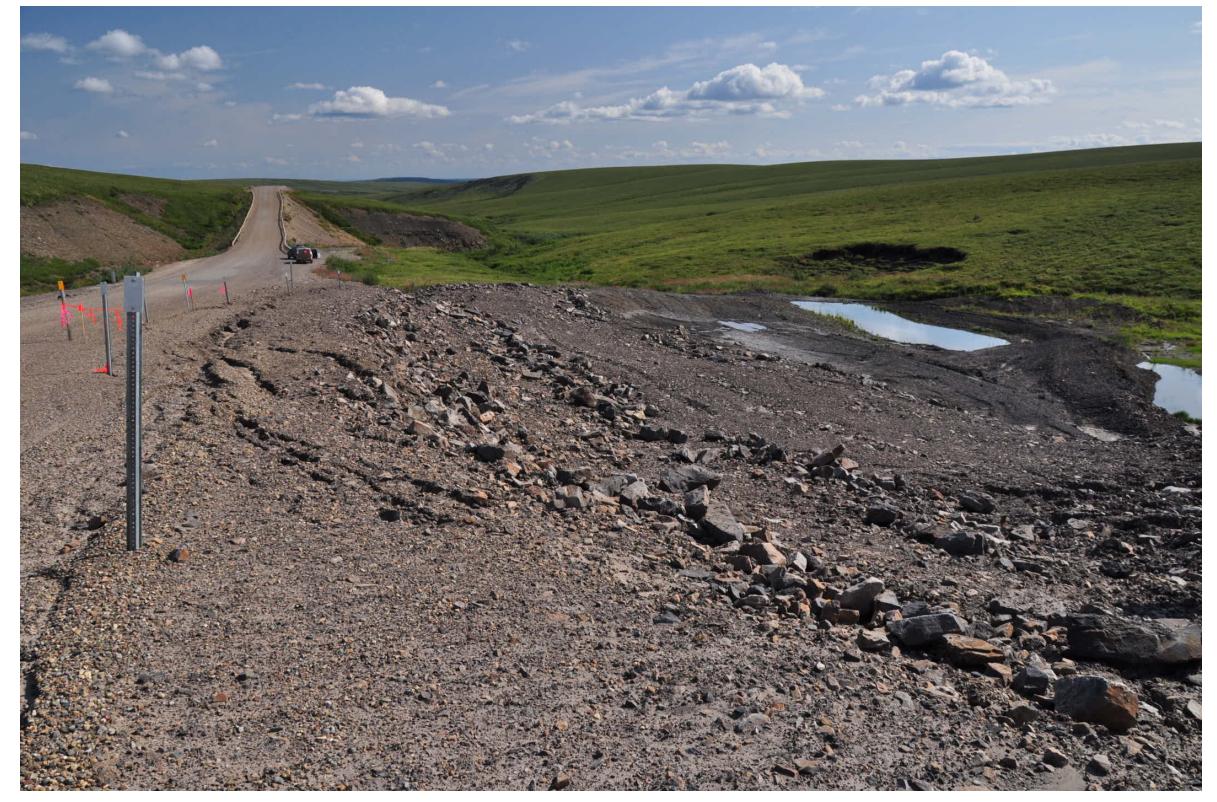

Figure 2.7: Placement of fill material at the roadside to control the thaw of ground ice and deformation of the road surface. Cracks in the road surface are visible near near the flagging. Photo from summer 2012. 
Table 2.3: Annual mean ground temperatures $\left(T_{g}\right)$ and active-layer thicknesses in undisturbed terrain at sites along the Dempster Highway, Yukon and NWT. Data are from various sources, and are indicated in the table. Sites in the boreal forest or taiga are marked by $*$. The $\mathrm{km}$ post values in brackets indicate the distance along the Northwest Territories portion of the highway. Table modified from Table 3 in Burn et al. (2015).

\begin{tabular}{|c|c|c|c|c|c|c|}
\hline Site & Region & $\begin{array}{l}\text { km post } \\
(\mathrm{NWT})\end{array}$ & $\begin{array}{l}\text { Depth } \\
(\mathrm{m})\end{array}$ & $\begin{array}{l}T_{g} \\
\left({ }^{\circ} \mathrm{C}\right)\end{array}$ & $\begin{array}{l}\text { Active layer } \\
(\mathrm{cm})\end{array}$ & Source \\
\hline North Fork & Blackstone Uplands & 98 & 10 & -3.7 & 75 & Northwestel (Burn et al., 2015) \\
\hline Chapman Airstrip & Blackstone Uplands & 124 & 1 & -2.7 & 80 & Idrees et al. (2015) \\
\hline *Red Creek & Engineer/Ogilvie River & 167 & 7 & -2.5 & 110 (est.) & Lacelle et al. (2009) \\
\hline *Ehnjuu Choo & Eagle Plain & 347 & 10 & -1.2 & 150 & Northwestel (Burn et al., 2015) \\
\hline Glacier Creek & Richardson Mountains & 421 & 8 & -3.6 & 40 & Idrees et al. (2015) \\
\hline North Vittrekwa & Richardson Mountains & 465 & 10 & -3.8 & 40 & Northwestel (Burn et al., 2015) \\
\hline Deep Water Lake & Peel Plain & $572(107)$ & 10 & -3.4 & 130 & Northwestel (Burn et al., 2015) \\
\hline Rengleng & Anderson Plain & $645(180)$ & 10 & -1.4 & 100 & Northwestel (Burn et al., 2015) \\
\hline Inuvik & Anderson Plain & $722(257)$ & 5 & -1.2 & 55 & Burn et al. (2009) \\
\hline
\end{tabular}




\section{Chapter 3}

\section{Methods}

\subsection{Introduction}

Characterization of the ground thermal regime on Peel Plateau requires measurements of permafrost temperatures under a range of environmental conditions represented in the region, and of factors controlling heat flow between the air and ground. Several field techniques were used in this thesis to investigate near-surface permafrost temperatures, active-layer thicknesses, and their relations with controlling factors such as air temperature, snow, vegetation, soil, and topography in undisturbed terrain, and near the road embankment. The specific implementation of these methods is described in the integrated chapters, but here the study rationale, key field techniques, and additional limitations not addressed in Chapters 4-6 are presented. In addition, the numerical modelling approach and programs are described in this chapter. Discussions of the modelling limitations are included in the integrated manuscripts of Chapters 5 and 6 , as these sections were important to present in context with the respective study results. For the same reason, secondary methods such as the measurement of vegetation heights and statistical tests, commonly unique within the thesis to one of the manuscripts, are also described in their respective chapters. 


\subsection{Study design and site selection}

There is a rich history of rigorous scientific observations of features and processes in the remote and logistically challenging Arctic (e.g., Leffingwell, 1915; Odell, 1943; Mackay, 1963). Recently, the need for long field expeditions has diminished as transportation to remote regions and data have become more accessible (Church, 2013). This has occurred along with the 'quantitative revolution', when geographic inquiry shifted to a quantitative approach, and the advent of more powerful computers enabled new analyses of problems in physical geography (Burton, 1963). However, fieldwork remains essential to geographic enquiry when existing data are limited or unavailable, and when hypotheses must be tested in the field (Lounsbury and Aldrich, 1986).

The research presented in this thesis was predominantly based on field observation, as no similar previous data were available from Peel Plateau, and detailed interest in the study area has only arisen since 2010 (Kokelj et al., 2013; Gill et al., 2014; Lacelle et al., 2015; Cameron and Lantz, 2016). Numerical modelling was used to examine the evolution of the thermal regime at disturbed sites, and to isolate the effect of changes to the snow accumulation regime and snow density on permafrost temperatures. This would not have been possible with an entirely field-based approach because of the lack of historical ground temperature data, and the difficulty of manipulating and isolating the effects of controlling factors in the field. Field measurements aimed to address the broad objectives of characterizing the thermal regime in natural and disturbed terrain on Peel Plateau. Since this project was part of a Northwest Territories Cumulative Impacts Monitoring Program (CIMP) to record landscape changes in the region, data collection was focussed towards providing baseline information on permafrost conditions, in addition to contributing to current research priorities in permafrost 
science.

Peel Plateau is an ideal setting to investigate permafrost conditions across tree

line and at infrastructure. This research program builds upon and its results may be compared with findings from past investigations on permafrost conditions across the nearby forest-tundra ecotone north of Inuvik (e.g., Mackay, 1963; Palmer et al., 2012). However, to the author's knowledge, there has been no previous investigation of ground temperatures across alpine tree line in continuous permafrost, where winter air temperature inversions may influence ground temperatures in tundra at higher elevation. In addition, there have been few studies to characterize the recent disturbance to permafrost from infrastructure installations in the western Canadian Arctic (Kokelj et al., 2010; Idrees et al., 2015; Burn et al., 2015). The research contributes to a growing body of literature on the disturbance to permafrost at infrastructure in northern regions (Darrow, 2011; Fortier et al., 2011; LeBlanc et al., 2014; Flynn et al., 2016). The observations presented in this thesis provide some of the first data on permafrost disturbance at the embankment toe of the Dempster Highway and at snow fences in the ice-rich environment of Peel Plateau, and on the nature and timing of talik formation near these installations. This is of practical relevance given the importance of the Dempster Highway as a transportation link to the Mackenzie Delta region, and the recent problems associated with permafrost thaw along the roadway.

\subsubsection{Ground temperatures across tree line}

Measurement sites were selected to capture a range of thermal conditions in undisturbed terrain on Peel Plateau and in surrounding lowlands to address objective (1). The approach was to determine relations between ground temperatures, active-layer thicknesses, and environmental conditions such as snow accumulation, vegetation 
cover, and soil materials across the forest-tundra ecotone. Four main sites were stratified by broad vegetation unit from the Peel Plain lowlands near Fort McPherson to the top of Peel Plateau. From lowest to highest elevation, these vegetation units included: lowland spruce forest (LSF), upland spruce forest (USF), tall-shrub tundra (TST), and dwarf-shrub tundra (DST). Ground temperatures, late-winter snow depths and snow cover densities, and active-layer thicknesses were recorded for several years (2010-14) at each site. Vegetation heights were measured to establish snow-vegetation relations, and surface organic-layer thicknesses were determined to examine the effect on summer thaw depth. Sensors were installed to characterize the air temperature regime and winter atmospheric inversions.

\subsubsection{Ground temperatures at the road embankment toe}

Sites were established near the toe of the Dempster Highway embankment to address objective (2) of characterizing the thermal regime where deep snow is trapped annually. The approach was to capture the range of snow conditions represented beside the roadway. Five sites were chosen during borehole drilling in summer 2012 based on the height of the embankment, as it was assumed that windblown snow accumulation would be related to the height of the structure (Tabler, 1991). Ground temperatures to $8 \mathrm{~m}$ depth were measured in 2012-15 to address the hypothesis that taliks have formed at some locations at the roadside. Ground surface temperatures were also recorded for the calibration and validation of one-dimensional numerical simulations used to investigate the effect of snow accumulation on the thermal regime. Snow depths and densities were measured at the instrumented sites, and along transects running perpendicular from the road to characterize snow accumulation near the embankment, and to obtain snow parameters for the numerical simulations. The total 
number of instrumented sites at the roadside was limited due to the cost and logistics of the installations. Site selection was spatially constrained due to the necessity of having a water source (pond) within about $200 \mathrm{~m}$ for operation of the water jet drill. In addition, there was ongoing construction to widen parts of the road on Peel Plateau, and sites had to be chosen outside of these sections. Nonetheless, the chosen sites represented a broad range of snow conditions at the embankment toe.

\subsubsection{Disturbance at snow fences}

Multidecadal (35 year) disturbance to permafrost was examined in a detailed case study of a snow fence near the highway embankment to address objective (3). The timing and geometry of talik formation were examined to investigate thermokarst initiation on Peel Plateau. The approach was to record shallow ground temperatures, snow cover, and active-layer thicknesses along a transect perpendicular to the fence, to compare the disturbed setting to undisturbed ground. Ground subsidence near the structure was estimated by surveying the surface along the transect with an optical level, and by estimating the subsidence potential from the excess-ice content of a permafrost core retrieved from nearby undisturbed tundra. Vegetation conditions were also described in disturbed and undisturbed ground. The site was chosen as a case study because the approximate year of fence construction was known, thus constraining the temporal scale of the disturbance at the fence. In addition, clear signs of subsidence indicated that permafrost had degraded at the site. This enabled a twodimensional numerical simulation to investigate the evolution of thermal conditions since the fence was constructed at the site. Active-layer thicknesses and vegetation

conditions were also recorded at three other snow fences in the region to examine the disturbance associated with the structures in different topographic settings. 


\subsection{Logistics}

Field work was conducted in summer and winter each year from 2011-15. Summer field campaigns took place in July and August, while winter trips were typically in mid-late March. Access to field sites was simplified as they were all within $1 \mathrm{~km}$ of the Dempster Highway, and within a 45 minute drive to the hamlet of Fort McPherson. Sites were accessed from the highway by snowshoe in winter, and by foot in summer. On most field days, a local wildlife monitor accompanied the field crew, employed through a contribution agreement as part of the NWT CIMP project. This assistance was valuable and enriching to the overall project, as the assistants were typically very knowledgeable about the landscape on Peel Plateau. In addition, this facilitated a greater connection with the community, and increased local communication of the research.

\subsection{Key field data collection methods}

\subsubsection{Ground and air temperatures}

\section{Shallow ground temperature cables}

Shallow ground temperature cables were used to characterize the thermal regime at the ground surface, in the active layer, and near the top of permafrost. The installations consisted of thermistors (TMC6-HD or -HA, Onset Computer Corporation, Bourne, MA, USA) attached to HOBO data loggers (U12-006 or H08-006-04). These thermistors have a reported accuracy of $\pm 0.25^{\circ} \mathrm{C}$ over a measurement range of -40 to $50{ }^{\circ} \mathrm{C}$, and a resolution of $\pm 0.03{ }^{\circ} \mathrm{C}$ at $20{ }^{\circ} \mathrm{C}$. When used with the U12-006 logger, the precision of measurements is approximately $\pm 0.02{ }^{\circ} \mathrm{C}$ and about $\pm 0.45{ }^{\circ} \mathrm{C}$ with the H08-006-04 logger. Given the range of temperature fluctuations in the upper 2 
$\mathrm{m}$ of the ground, the performance of the loggers was sufficient for assessing relative differences between sites. The loggers were housed in PVC cases that were attached to dowels or PVC pipes. Installation was by hand drill, and the holes were backfilled using the drill cuttings to prevent free convection within the instrumented borehole. Sensors were typically placed at 0.05 and $1.00 \mathrm{~m}$ depth, with temperatures recorded every two hours. These high-frequency measurements from 1.0 and $0.05 \mathrm{~m}$ were averaged to obtain daily temperatures and to calculate the annual mean temperature near the permafrost surface $\left(T_{p s}\right)$, and at the ground surface $\left(T_{s}\right)$, respectively.

\section{Deep ground temperature cables}

Deeper ground temperature cables were used to measure values less affected by seasonal variation than those at $1.0 \mathrm{~m}$. Measurements were made using thermistor cables with sensors (YSI44033, YSI Incorporated, Yellow Springs, CO, USA) spaced at 1-m intervals $(1.0-8.0 \mathrm{~m})$. The sensors have an accuracy of $\pm 0.1{ }^{\circ} \mathrm{C}$. The cables were manufactured and calibrated by M-Squared Instruments (Cochrane, AB, Canada) and were installed in holes drilled by water jet, with a 1 " or $3 / 4$ " steel pipe used to case the hole. The steel pipes were filled with silcone oil, a thermally stable fluid, to prevent convection within the casing. The thermistor cables were connected to RBR data loggers that are accurate to $\pm 0.002{ }^{\circ} \mathrm{C}$ (Model XR420 T8, Richard Brancker Research, Ottawa, ON, Canada), with measurements collected every 4 hours. The loggers were housed within a PVC pipe casing.

Readings from the first several weeks after installation were not included in subsequent analyses to allow the thermal disturbance from the drilling to dissipate (Figure $3.2)$.

The steel pipes were painted black by the manufacturer, so solar heating of the 

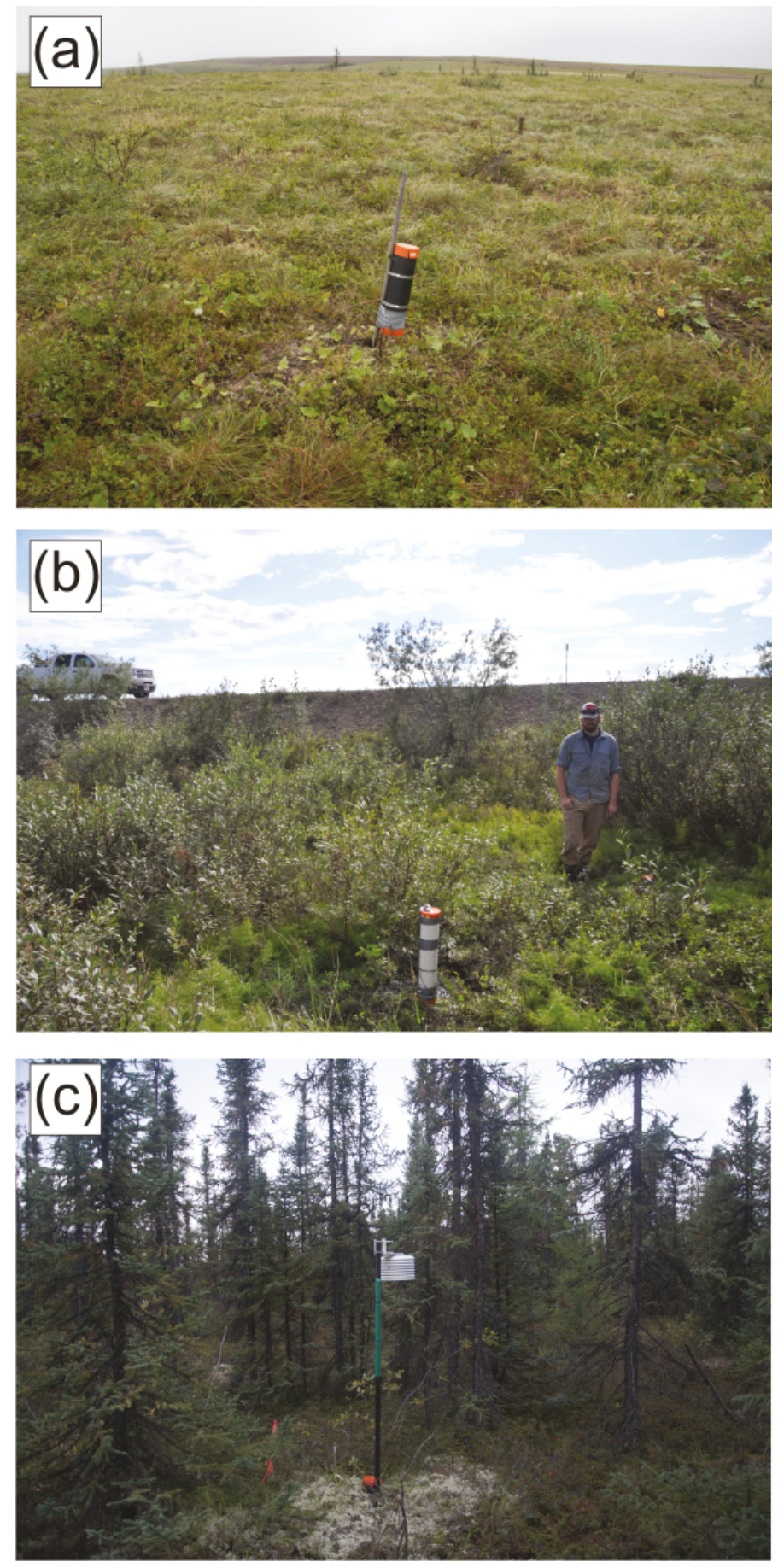

Figure 3.1: Examples of (a) shallow ground temperature cable installation, (b) deep ground temperature cable, and (c) air temperature sensor in radiation shield. 


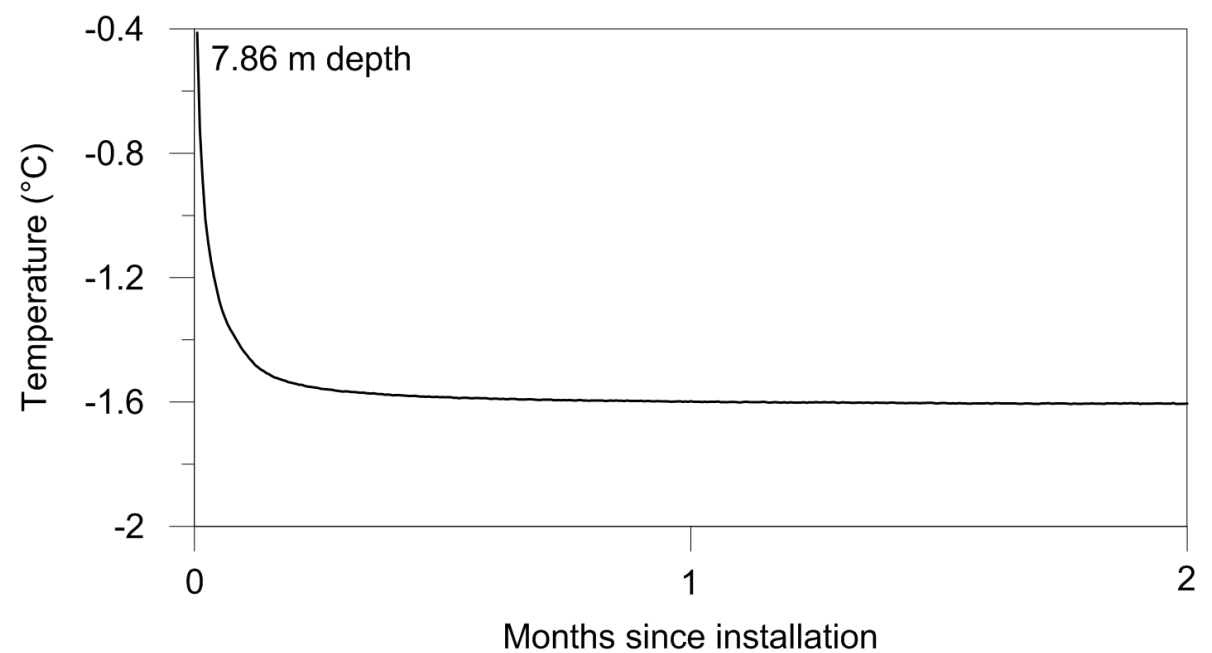

Figure 3.2: Ground temperatures over two months from a depth of $7.86 \mathrm{~m}$ at a deep cable located at the toe of the Dempster Highway road embankment showing the pronounced, but short-lived, disturbance from water jet drilling. 
pipe above ground may have contributed some heat to the sensors below ground via conduction. This effect was not quantifiable, but is anticipated to be negligible, as differences in annual mean ground temperature at $1.0-1.5 \mathrm{~m}$ between paired thermistors on wooden and metal supports have been found to be commonly $<0.1{ }^{\circ} \mathrm{C}$ (Morse, 2013, p. 76).

\section{Air temperatures}

Air temperatures were measured with a thermistor (TMC6-HD) attached to a HOBO U12-006 logger. The logger and sensor were placed inside an unventilated, multiplate radiation shield (either Onset $\mathrm{RS} 1$ or M-RSA) attached to a steel pipe driven into the ground. The radiation shield was approximately $1.5 \mathrm{~m}$ above the ground surface. Air temperatures were recorded every two hours. The hourly measurements were averaged to obtain daily temperatures and to calculate the annual mean air temperature $T_{a}$

Air temperatures measured within unventilated radiation shields are generally higher than in ventilated installations (Gill, 1983). Average nighttime and daytime differences of 0.3 and $1.3 \mathrm{~K}$, respectively, have been reported from a comparison in the Peruvian Cordillera by Georges and Kaser (2002). The differences were found to be greatest with the presence of snow cover and during periods with low wind speed. Differences between unventilated temperatures and actual air temperatures also vary with the sensor and radiation shield type (Gill, 1983).

In this study, the use of unventilated radiation shields is less problematic than in some cases. Since all sensors were in unventilated installations and the comparisons between sites were made on a relative basis, differences between sites are still meaningful even if the absolute values differ from the actual air temperatures. In addition, there is little solar radiation through much of the snow-covered season in the Arctic, 
so the differences observed by Gill (1983) at lower latitude are likely less pronounced on Peel Plateau.

\subsubsection{Snow surveys}

\section{Late-winter snow depths}

Late-winter snow depths were measured to characterize snow conditions at intrumented sites, along transects in each vegetation unit, and near the Dempster Highway road embankment. Measurements were made with a graduated avalanche probe or steel probe to the nearest $1.0 \mathrm{~cm}$.

\section{Snow pits}

Snow pits were excavated to characterize the snow stratigraphy and snow density, in order to calculate the thermal resistance of late-winter accumulation. For each pit, snow density was measured at $10 \mathrm{~cm}$ intervals by removing and weighing samples of $100 \mathrm{~cm}^{3}$. The snow samples were placed in a nylon bag attached to a calibrated spring scale (Homs Model 100g, Douglas Homs Corp., Belmont, CA, USA). The spring scale was tested over the range of mass values measured in the field using calibrated weights, and the accuracy was determined to be $\pm 0.5 \mathrm{~g}\left( \pm 5 \mathrm{~kg} \mathrm{~m}^{-3}\right)$.

Individual snow density measurements were averaged for each pit and the bulk snow pack thermal conductivity $\left(\lambda_{s}, \mathrm{~W} \mathrm{~m}^{-1} \mathrm{~K}^{-1}\right.$ ) was estimated using (Sturm et al., 1997, Eq. 7):

$$
\lambda_{s}=10^{(2.650 \rho-1.652)}
$$

where $\rho$ is the snow cover density in $\mathrm{g} \mathrm{cm}^{-3}$. Snow thermal resistance $\left(R_{s}, \mathrm{~m}^{2} \mathrm{~K}\right.$ $\mathrm{W}^{-1}$ ) was calculated as (Lunardini, 1981, p.42, Eq. 3.9): 


$$
R_{s}=H / \lambda_{s}
$$

where $(H, \mathrm{~m})$ is the snow thickness.

\section{iButton arrays}

Snow depth was also measured in 2012-13 and 2013-14 using arrays of iButton ${ }^{\circledR}$ miniature temperature sensors (Model DS1921G, Maxim Integrated, San Jose, CA, USA) to investigate the timing of deep snow cover development in forest and tundra. These sensors have a resolution of $0.5^{\circ} \mathrm{C}$ and accuracy of $\pm 1.0^{\circ} \mathrm{C}$ between -30 and $+70{ }^{\circ} \mathrm{C}$.

The iButtons were mounted on dowels; one sensor was located $5 \mathrm{~cm}$ above the ground surface, and the rest were spaced at 10-cm intervals $(10-100 \mathrm{~cm})$, so that snow cover development could be monitored to $\geq 90 \mathrm{~cm}$. The snow level was inferred semiquantitatively, similar to Lewkowicz (2008): if the temperature difference between two adjacent iButtons deviated persistently by $>1{ }^{\circ} \mathrm{C}$, this suggested the snow had covered the lower sensor. Plots of the iButton measurements from all sensors on the dowel were also compared visually with air temperatures to validate the patterns of temperature deviations with the inferred snow levels.

The utility of iButton arrays for monitoring snow pack development has been demonstrated by Lewkowicz (2008) in a field test at 20 sites in Yukon. Snow evolution was successfully monitored at 18 of the 20 sites. However, $13 \%$ of the deployed sensors failed over two years and clock inaccuracies also affected some instruments. In this thesis, a relatively high failure rate, especially during the second year of deployment, limited the precision of measurements at many sites. The iButton data presented in Chapter 4 are restricted to sites that experienced no sensor failure. In the future, the 
iButtons could be made more resistant using a silicone coating or other protective measure. Alternatively, time-lapse cameras and snow stakes could be used to directly record snow depths over winter.

\subsubsection{Active-layer thickness and thaw depths}

Active-layer thicknesses were estimated by probing in mid-late August using a 1-cm diameter graduated steel rod pushed to the depth of refusal. At disturbed sites near the Dempster Highway, probing was not always possible due to friction along the probe, and the maximum thaw penetration was determined by interpolation between annual maximum values from temperature sensors (e.g., Mackay, 1995). Riseborough (2008) determined that errors associated with this method are up to about $20 \%$. Since the deep cable sensors were typically spaced at $1.0 \mathrm{~m}$ increments, the maximum error in active-layer thicknesses for these sites may be about $0.2 \mathrm{~m}$.

The accuracy of active-layer thicknesses estimated by probing is affected by several factors. First, the weight and strength of the operator determines how far the probe can be pushed into soil (Burn, 1998b). Friction along the probe may prevent further penetration when thaw depths are $>1 \mathrm{~m}$, as was the case at the snow fence site in Chapter 6. In organic- and ice-rich soils, refusal is met very close to the $0{ }^{\circ} \mathrm{C}$ isotherm. However, in clay-rich soil, errors on the order of decimeters may occur because the high unfrozen water content causes refusal to be reached at temperatures below $0{ }^{\circ} \mathrm{C}$ (Mackay, 1977). The active-layer thickness may also be underestimated in late summer if upfreezing from the top of permafrost has commenced prior to probing (Osterkamp and Romanovsky, 1997). These sources of error are impossible to quantify without a direct comparison to the position of the $0{ }^{\circ} \mathrm{C}$ isotherm, which was not logistically possible during field data collection. At most locations on Peel Plateau, the depth of refusal was firmly met, but at a limited number of tundra 
sites where thaw depths were $\geq 1 \mathrm{~m}$, identifying the frost table was more difficult. Therefore, errors on the order of decimeters may be anticipated in limited instances.

Despite the potential errors associated with the method, probing remains widely used for active-layer measurements (e.g., Brown et al., 2000), and is appropriate when numerous measurements are required in a range of field settings (Burn, 1998b). The research presented in this thesis characterizes within-site variation in multiple vegetation units, so probing was the most suitable method.

\subsubsection{Soil moisture content determination}

Active-layer soil samples were collected in summer 2013 near most instrumented sites to characterize soil moisture content. Samples were carefully extracted from soil pits to yield a volume of $216 \mathrm{~cm}^{3}$, i.e. $6 \mathrm{~cm} \mathrm{x} 6 \mathrm{~cm} \mathrm{x} 6 \mathrm{~cm}$. A total of 44 samples, typically retrieved from depths of 30 and $50 \mathrm{~cm}$ in each pit, were collected. Samples were placed in plastic bags and transported to the Aurora Research Institute laboratory in Inuvik. The samples were weighed, oven-dried overnight at $105^{\circ} \mathrm{C}$, and weighed again to determine the mass of water. Volumetric water content $\left(\mathrm{m}^{3} \mathrm{~m}^{-3}\right)$ was defined as:

$$
\theta_{v}=\frac{m_{w}}{v}
$$

where $m_{w}$ is the mass of water $(\mathrm{g})$, assuming that $1.0 \mathrm{~g}$ water $=1.0 \mathrm{~cm}^{3}$, and $v$ is the sample volume $\left(\mathrm{cm}^{-3}\right)$. Gravimetric water content was defined as:

$$
\theta_{g}=\frac{m_{w}}{m_{d s}}
$$

where $m_{d s}$ is the mass of dried sediment $(\mathrm{g})$. Summary data are presented here since these data helped form the basis for the assignment of volumetric water content in the numerical simulations of Chapters 5 and 6 (Figure 3.3). Samples from mineral 
soil had dry bulk densities typically between about 1.0 and $1.8 \mathrm{~g} \mathrm{~cm}^{-3}$ (e.g., Phillips et al., 2015). Volumetric water contents of these mineral samples were commonly around $0.4 \mathrm{~m}^{3} \mathrm{~m}^{-3}$, suggesting that conditions in the active layer were near saturation given typical porosities for fine-grained soils (Smith and Tice, 1988). Samples of organic soil had dry bulk densities between about 0.2 to $0.5 \mathrm{~g} \mathrm{~cm}^{-3}$, and volumetric water contents from about 0.5 to $0.75 \mathrm{~m}^{3} \mathrm{~m}^{-3}$.

\subsubsection{Excess-ice content determination}

A core of near-surface permafrost was retrieved at the principal research site of Chapter 6 using a hand-held drilling unit attached to a concrete corer (e.g., Calmels et al., 2005) to estimate excess-ice content and subsidence potential. Several other boreholes were drilled as part of initial site investigations, but the data are not presented explicitly in the manuscripts within the thesis. The drilling depth was limited to 1.8 m. Below this depth, it became impossible to retrieve samples from the borehole with the equipment available, because the frozen cores could not be broken from the base of the hole. Core samples were photographed following retrieval, and the ice types within the samples were recorded. The samples were then double-bagged in plastic. The samples thawed subsequently in the field, as there was no way to keep them frozen.

The thawed samples were poured into beakers, mixed, weighed, and allowed to settle in the laboratory at the Aurora Research Institute in Inuvik. The beakers were sealed tightly to prevent evaporation, and weighed before and after settling to detect any moisture losses. Volumes of saturated sediment $\left(S_{v}\right)$ and supernatant water $\left(W_{v}\right)$ were recorded in order to calculate excess-ice content $\left(E_{i}, \%\right)$ using (Eq. 1, Kokelj and Burn, 2003): 

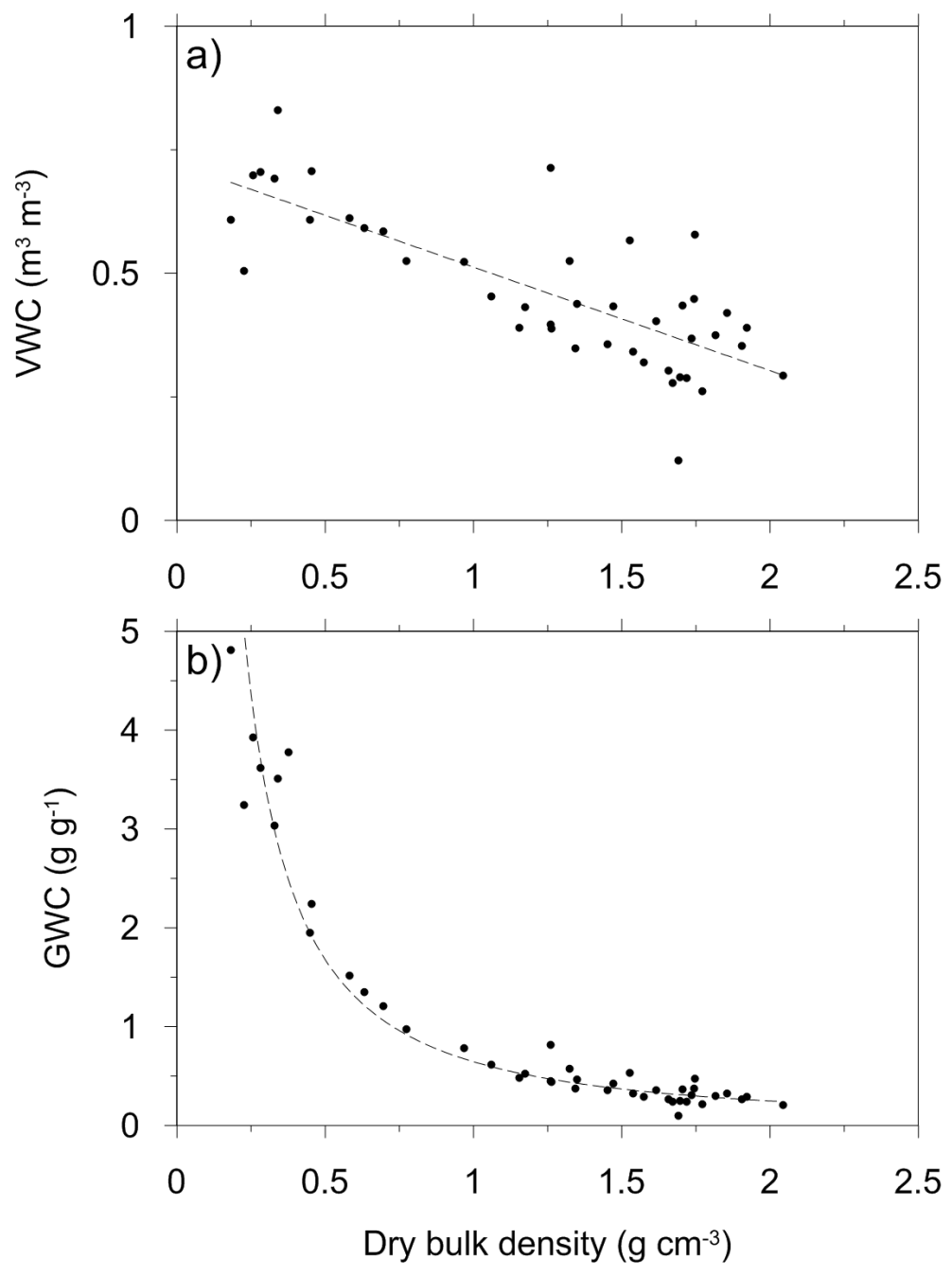

Figure 3.3: (a) Volumetric water content (VWC) and (b) gravimetric water content (GWC) plotted vs. dry bulk density for 44 active-layer soil samples. The samples are from depths of either 30 or $50 \mathrm{~cm}$. 


$$
E_{i}=\frac{W_{v} \cdot 1.09}{S_{v}+\left(W_{v} \cdot 1.09\right)} \times 100
$$

The mean excess-ice content from the samples obtained was used to estimate the potential subsidence at the snow fence site in Chapter 6 due to near-surface ground ice thaw. The estimated potential subsidence $(S P, \mathrm{~m})$ was determined using:

$$
S P=\frac{E_{i} \cdot \Delta A L T}{100}
$$

where $\triangle A L T$ represents the estimated change in active-layer thickness $(\mathrm{m})$ at the disturbed ground near the snow fence.

It was difficult to accurately partition $W_{v}$ and $S_{v}$ in samples with a significant clay content, despite allowing more than $48 \mathrm{hrs}$ for settling. In these cases, supernatant water, which necessarily contained some fine clay particles, was drawn carefully from these samples and measured using a syringe until the consistency of the remaining slurry blocked suction. As a result, the excess-ice content was underestimated, as a small amount of slurry was not accounted for. The amount of underestimation of $S P$ would not have changed the conclusion drawn in Chapter 6.

\subsection{Study design limitations}

The study design had some limitations due to the methods used. The full range of thermal conditions may not have been captured by the sampling scheme in the investigation of permafrost conditions across tree line (Chapter 4). In particular, the thermal regime in forest on Peel Plain and Peel Plateau was characterized with one 
shallow thermistor cable and one deep cable at each site. The limited number of instruments in forest was justified given the total number of loggers available and the need to deploy more in tundra where snow and ground thermal conditions are more variable. Nevertheless, the full range of thermal conditions in forest was likely not captured. Six shallow thermistor cables and one deep cable were installed in tundra. An attempt was made to install the shallow instruments in settings that represented the extremes in ground temperatures, with several in between. The extreme sites were located at the base of tundra slope where deep snow accumulated annually, and at a flat exposed site where most snow blew away. However, it is possible that warmer or colder conditions may be present in similar settings that were not instrumented.

The investigation of permafrost conditions at the embankment toe in Chapter 5 comprised five sites established in tundra on Peel Plateau. The sites represented a broad range of snow depths; one site adjacent to a low embankment had snow depths similar to undisturbed tundra, while over $2 \mathrm{~m}$ of snow accumulated at a site near a high embankment. The most disturbed settings, which were likely at thermokarst ponds beside the road, were not represented because the aim was to examine the effect of snow accumulation at the embankment rather than of associated thermokarst processes. Nonetheless, it should be noted that the measured disturbance at the embankment toe sites does not represent the full and most severe effects of the road on the ground thermal regime on Peel Plateau.

The research on permafrost degradation at snow fences in Chapter 6 used a casestudy approach to investigate the nature and timing of talik formation in tundra due to a step change in snow conditions. The primary snow fence site was chosen because there was noticeable subsidence around the structure. The case selection was opportunistic, and the results obtained are only applicable to other settings with similar site conditions. 
The use of case studies may be valuable when mechanisms and processes are already reasonably understood in later stages of a research project (Richards, 1996, p. 187-188). Since permafrost conditions in undisturbed settings on Peel Plateau were described by the study in Chapter 4, and the disturbed thermal regime from deep snow accumulation at infrastructure defined in Chapter 5 , the case study naturally built upon this by examining in greater detail the mechanism of permafrost degradation and talik formation with two-dimensional simulations. The selection of additional fences, though not instrumented for temperature measurements like the primary site, was intended to examine ALT and vegetation conditions in other topographic settings.

\subsection{Data collection limitations}

There were several problems encountered during temperature data collection. Rock clasts encountered during water jet drilling limited the depth of deep temperature cable installation at some sites to $<5 \mathrm{~m}$, despite a target depth of $8 \mathrm{~m}$. Wildlife destroyed several shallow thermistor cables, typically early in the summer. At one site, a shallow cable installation was destroyed two years in a row; it was later realized that this was likely because the PVC caps on the logger housing were the same colour as cloudberries (Rubus chamaemorus), and the instrument was located in a particularly productive berry patch. It was not always possible to replace the destroyed instruments, so the record at some sites is incomplete.

Flooding of instruments during the spring melt at the primary snow fence study site caused failure of the data loggers in some years. Battery failure at one of the air temperature measurement sites necessitated gap filling using regressions between the available data and measurements from the other air temperature sensors. 
The temperatures used to determine $T_{p s}$ at shallow cable installations were typically recorded at a depth of $1.0 \mathrm{~m}$. Therefore, this is an estimate of the true $T_{p s}$, as it was not possible to place the thermistor at the annually-varying boundary between permafrost and the active layer. At some sites, the permafrost table was below the sensor initially, but subsequently rose slightly above $1.0 \mathrm{~m}$.

The ground surface subsided by about $10 \mathrm{~cm}$ over one summer at a shallow cable installation, causing the sensor at $0.05 \mathrm{~m}$ to be pulled from the ground. Consequently, $T_{s}$ was not determined for the site in that year. At other instrumented sites, subsidence was typically $<5 \mathrm{~cm}$, and the surface sensors were unaffected. These issues and their implications are addressed specifically in the integrated manuscripts.

\subsection{Field observations and modelling}

Field observation and modelling are both fundamental to the modern practice of physical geography. Field observation has been described as an "empirical encounter" (Withers, 2011, p.44), which allows geographers to observe phenomena firsthand and results in the production of geographical knowledge through "travelling, dwelling, seeing, collecting, recording, and narrating" (Driver, 2000, p. 267). Geographical knowledge may be produced from field observation by directly observing or measuring system behaviour, testing hypotheses, or comparing the validity of different representations of reality (Withers, 2011).

Models may assume many different forms, but in general, they are a "conceptual or mathematical representation of a phenomenon" (Riseborough et al., 2008, p. 138). A model may be as simple as a preconceived idea of how components in a system

interact (i.e., a conceptual model), or as complex as a physically-based ensemble of computer algorithms. Commonly, the aim of modelling is to simulate the effect of a 
set of processes, and forecast potential outcomes (Kirkby et al., 1987). The creation of a model necessarily involves simplification of the system under consideration into key components that affect the system behaviour(s) of interest. The use of models is broad-ranging, but importantly, they allow the investigation of past events, predictions of future system behaviours, and predictions of conditions over broad spatial scales, which may not be possible with field observation alone.

Modelling and observation are essentially inseperable in modern physical geography. For example, conceptual models guide field observations, but the conceptual models themselves commonly originate from prior observations. Field data are typically used as parameters in both empirical and physically-based modelling to calibrate and validate simulations (Kirkby et al., 1987).

The numerical simulations in Chapter 5 and 6 were calibrated using field observations. Data collection in Chapters 4-6 was coordinated to include the most important variables (e.g., air temperature, snow depth, snow density, soil conditions) that govern heat flow between the atmosphere and ground. Therefore, the physically-based models in Chapters 5 and 6 are calibrated using 'process' parameters, which have real physical meaning within the system (Kirkby et al., 1987). The modelling objectives also build upon field observations from Chapters 4-6. For example, summer probing at sites with deep snow accumulation at the roadside indicated the presence of taliks; the simulations enriched the investigation of disturbed ground temperatures because they enabled the evolution of the ground thermal regime to be examined over several decades and in two dimensions, which was not possible in the field.

The following sections describe the links between field observations and simulations in this thesis, and present the modelling programs employed in Chapters 5 and 6. 


\subsubsection{Numerical simulations}

Numerical simulations were used to examine the evolution of the ground thermal regime under disturbed conditions beside the Dempster Highway and at adjacent snow fences.

A one-dimensional thermal model (TONE) was used to reproduce present ground thermal conditions at the Dempster Highway embankment toe, at the road centreline, and in undisturbed tundra (Chapter 5). Parameterization of the model was based on air, snow, and soil conditions at the field sites. The snow depth and density measurements from the field were used to initialize simulations that accounted for the accumulation and ablation of a seasonal snow cover. The initial dates of snow arrival from field sites in Chapters 4 and 6 informed the snow commencement dates used in the simulations. Model validation consisted of comparing measured values in 2013-15 to simulated values at the end of transient simulations of 1980-2015. The use of site-specific conditions to calibrate the model, and the resulting close agreement between modeled and measured ground temperatures provided confidence that the model accurately represents the system behaviour. This allowed subsequent simulations to investigate the effect of altering the snow accumulation regime characteristics, including limiting depth and increasing density to simulate potential management activities at the road embankment.

A two-dimensional finite-element thermal modelling software package (TEMP/W, GEO-SLOPE, Calgary, AB, Canada) was used to examine in greater detail the degradation of permafrost from the increase in snow depth following the installation of a snow fence near the embankment (Chapter 6). The disturbance at the fence was simulated as a step-change from conditions representative of undisturbed tundra. The upper boundary condition was driven by measured ground surface temperatures. Initially, the entire surface was assigned ground surface temperatures from a control site 
in tundra away from the fence. Then, the step-change was invoked by assigning surface temperatures measured beside the fence along part of the model geometry. The increases in ground temperature over time (1980-2015), the progression of the thaw front, and interactions between the warm ground at the fence and cooler surroundings were of particular interest. The longer-term (>100-year) effect of snow accumulation on thaw depth was also simulated.

\section{1-dimensional simulations (TONE)}

The TONE model is a one-dimensional heat conduction program that handles nonlinear (e.g., temperature dependent) material properties and solid-liquid phase change (Goodrich, 1982b). The model has been widely used in permafrost investigations (e.g., Oelke et al., 2003; Riseborough, 2007; Smith and Riseborough, 2010). TONE is similar to the model used in Goodrich (1982a), but provides improved accounting of total latent heat (Smith and Riseborough, 2010). Several different options are available in the model for assigning initial and boundary conditions in the model, but here the pertinent set up steps for the simulations in Chapter 5 are described.

The initial ground temperatures for transient simulations in TONE are input by the user, commonly from a spin-up simulation to equilibrium conditions. The upper boundary condition for transient simulations in Chapter 5 were daily air temperatures over a 365 day period. When air temperatures are positive, the temperature at the ground surface is calculated using an empirical transfer function (a thawing $n$-factor). When air temperatures are negative but no snow is present, a freezing $n$-factor is applied, commonly set to 1 so that the ground surface temperature is equal to the air temperature. The model includes a routine capable of specifying snow accumulation with user-designated parameters for density, snow commencement date, and the date that maximum snow depth is reached. The rate of snow pack ablation when the air 
temperatures rise above zero is specified by a melt factor $\left(\mathrm{kg} \mathrm{m}^{-2} \mathrm{TDD}^{-1}\right)$. When snow cover is present, the snow surface temperature is equal to air temperature and heat flow through the snow cover is calculated. The lower boundary condition is specified as a heat flux.

Node spacing is specified by the user for each ground material layer present in the simulation. The number of material layers is set by the user. The node spacing is specified for the top and bottom of each layer, and the grid routine in TONE generates the node positions, with separation increasing with depth following a geometric progression (Goodrich, 1982b). Temperature-dependent material properties including conductivity, heat capacity, and unfrozen water content are input for each material layer.

Further information on the TONE model, including all specific options available, may be found in Riseborough (2004), and Goodrich (1982b).

\section{2-dimensional simulations (TEMP/W)}

TEMP/W is a commercially available, two-dimensional finite-element thermal model produced by GEO-SLOPE International (Calgary, AB, Canada). The program can be used to model thermal changes in the ground, including freezing and thawing, due to conductive heat transfer in porous media composed of mineral particles, water, ice, and air. As a result, TEMP/W is commonly employed to model permafrost conditions (e.g., Smith and Riseborough, 2010; Darrow, 2011; Kokelj et al., 2014; Flynn et al., 2016).

TEMP/W simulations require four main inputs: (1) problem geometry, (2) meshing, (3) materials, and (4) boundary conditions. There are different options for each of these inputs, but here the modelling approach used in Chapter 6 is described. 
Setting the problem geometry involves inputting points, lines, and regions to represent the two-dimensional space being modelled. The horizontal and vertical extent, as well as any physical divisions between soil layers are decided prior to establishing regions based on the aims of the modelling exercise. Next, the meshing is defined for each simulation region by designating the horizontal and vertical element spacing. The materials are designated using a full thermal model for soils with temperaturedependent properties. The user provides thermal conductivity and unfrozen water content curves, in addition to thawed and frozen specific heat capacities and in situ water content. Finally, the boundary conditions are defined. In Chapter 6, the surface boundary conditions consisted of measured daily ground surface temperatures from instruments at the snow fence site. The lower boundary condition is specified as a flux representing geothermal heat.

\subsection{Summary}

The preceding chapters have described the objectives, background information, and various field and modelling methods necessary to investigate the ground thermal regime on Peel Plateau. The following three chapters comprise the integrated results manuscripts. Chapter 4 characterizes the ground thermal regime on Peel Plateau in undisturbed settings. Building upon this, Chapters 5 and 6 investigate disturbed conditions near the Dempster Highway road embankment. Together, these chapters provide (1) a comprehensive field-based examination of the natural and anthropogenic thermal regime in upland terrain of the continuous permafrost zone, and (2) modelling-based investigations into the timing and geometry of talik formation where infrastructure has caused permafrost to degrade. This thesis contributes to the broader literature on snow-vegetation-permafrost relations and the growing body of 
work characterizing the effects of human activity on permafrost temperatures. 


\section{Chapter 4}

\section{Permafrost conditions across tree line on Peel Plateau}

Modified from the paper published as:

O’Neill, H.B., Burn C.R., Kokelj S.V., Lantz T.C. (2015), Warm tundra: atmospheric and near-surface ground temperature inversions across an alpine treeline in continuous permafrost, western Arctic, Canada. Permafrost and Periglacial Processes, 26(2): 103-118.

\subsection{Introduction}

The forest-tundra ecotone presents significant variations in surface conditions that control the thermal regime of permafrost (Lewkowicz et al., 2012; Palmer et al., 2012; Roy-Léveillée et al., 2014). Changes to the ecotone are becoming apparent, as increases in shrub abundance have been observed near tree line (Sturm et al., 2001b; Mackay and Burn, 2011; Lantz et al., 2013). The interactions between physical and ecological conditions across tree line are likely to influence future changes in ground temperatures, which may in turn affect hydrology, terrain stability, ecosystem function, and northern infrastructure. 
The Dempster Highway in Canada's Northwest Territories crosses the foresttundra ecotone over $77 \mathrm{~km}$ from Peel Plain at about $30 \mathrm{~m}$ above sea level (a.s.l.) near Fort McPherson, to around 930 m a.s.l. at the Yukon/NWT border in Richardson Mountains (Figure 4.1). For $40 \mathrm{~km}$ the road traverses Peel Plateau, reaching about $500 \mathrm{~m}$ a.s.l. The shift in plant communities constitutes an alpine tree line, as vegetation changes with elevation from open-canopy forest on Peel Plain to tall- and dwarf-shrub tundra near the top of Peel Plateau. The vegetation gradient is similar to that at latitudinal tree line, which occurs in the western Arctic uplands to the northeast of Peel Plain (Mackay, 1963; Lantz et al., 2010).

Permafrost temperatures decline significantly across latitudinal tree line (e.g., Burn and Kokelj, 2009, Figure 11) due to reduced snow cover, higher snow density, and lower air temperatures over the tundra (Palmer et al., 2012). In similar fashion, Lewkowicz et al. (2012) observed that permafrost temperatures decline with elevation across alpine tree line in mountainous terrain of the Wolf Creek drainage, southern Yukon. Near Dawson City in central Yukon, the relations between permafrost temperatures and elevation are less clear due to the influence of more persistent atmospheric temperature inversions in winter (Lewkowicz et al., 2012, Figure 4), which are common at high latitudes (e.g., Burns, 1973; Wahl et al., 1987; Burn, 1993; Taylor et al., 1998; Bonnaventure and Lewkowicz, 2013). To the author's knowledge, no studies have examined permafrost conditions across an alpine tree line in the continuous permafrost zone.

This chapter investigates ground temperatures at four sites across the ecological transition between the forest in the Peel Plain lowlands and dwarf-shrub tundra on Peel Plateau. The influence of air temperature, vegetation, and snow conditions on the thermal regime of permafrost are assessed. The chapter determines whether 

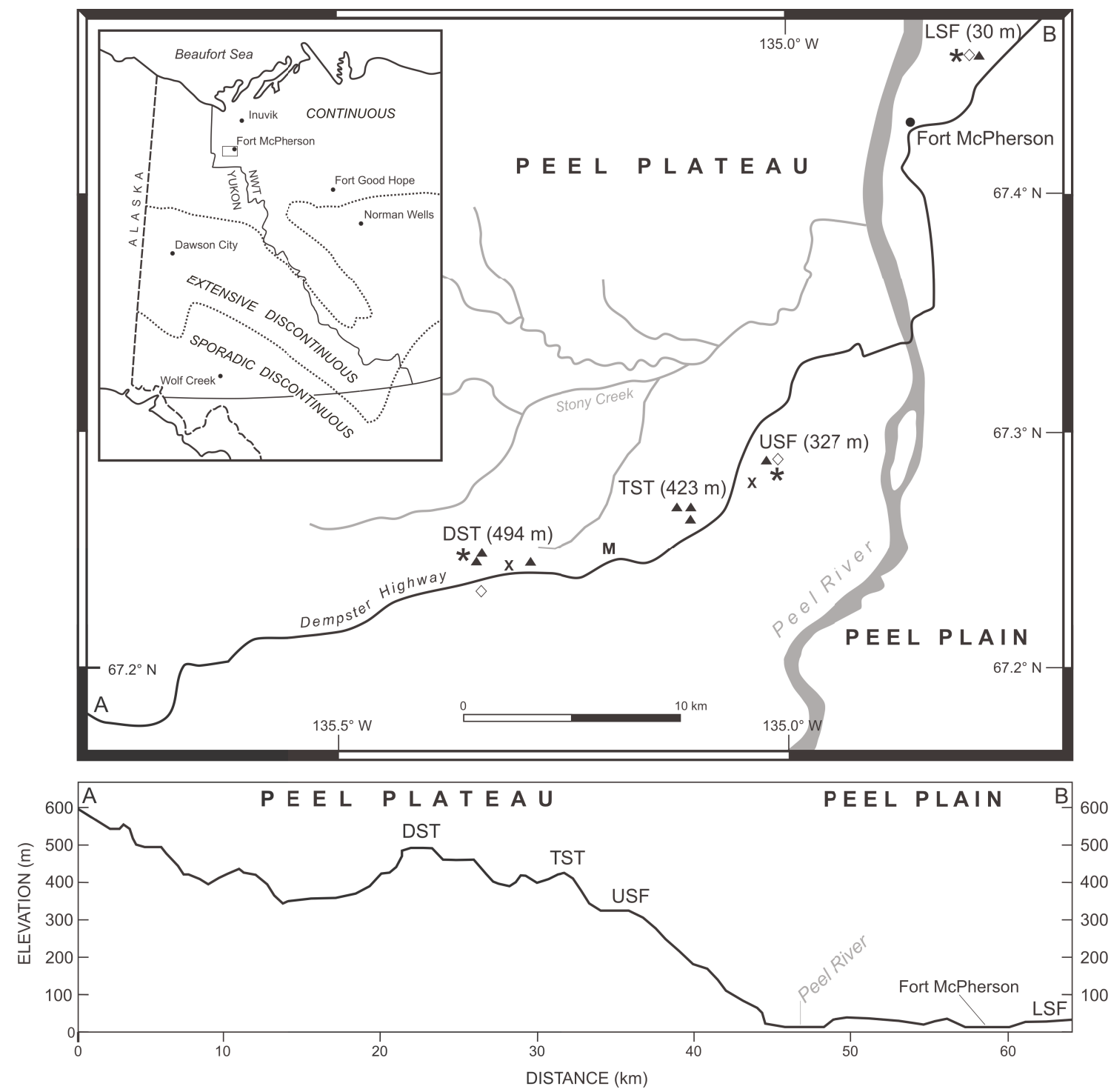

Figure 4.1: Location of study sites, and elevation profile between points $\mathrm{A}$ and B along the Dempster Highway [Elevation profile modified from Google Earth (2013)]. Symbols are as follows: $\boldsymbol{\Delta}$ shallow $(1 \mathrm{~m})$ thermistor array; $\diamond$ deep (4-7 m) thermistor array; * air temperature sensor; X iButton array; M meteorological station. The locations of instruments are approximate. The inset is modified from Fig.1 in Burn (1994) and permafrost zones are after Heginbottom et al. (1995). The Dempster Highway begins near Dawson City and runs through Fort McPherson to Inuvik. 
the pattern of declining ground temperatures across tree line observed by Palmer et al. (2012) and Lewkowicz et al. (2012) applies to the alpine tree line in the Peel Plateau region. Since the study region spans a considerable elevation range, it is predicted that permafrost temperatures will decrease less drastically from forest to tundra than at latitudinal tree line due to winter air temperature inversions. To test the prediction, this chapter: (1) characterizes environmental conditions at the study sites across an Arctic alpine tree line; (2) describes air and ground temperatures along this vegetation-elevation gradient; and (3) assesses relations between snow properties, vegetation, air temperature, and permafrost conditions at the sites.

\subsection{Study sites}

Instrumented sites (Figure 4.1) were established in four vegetation units (Figure 4.2) to describe conditions across the transition from subarctic boreal forest on Peel Plain to dwarf-shrub tundra at higher elevation on Peel Plateau. Active-layer $(n=42)$ and organic-layer thicknesses $(n=14)$ were measured along transects at each site. These data are summarized to provide the environmental context and are discussed later. Most of the instruments were installed in fine-grained mineral soil, though two were located in peatland on Peel Plateau. The substrate at mineral sites was predominantly ice-rich silt and clay, though stones, fine sand, and thin gravel layers were sometimes encountered during site installation. In peatland, the active layer and top of permafrost were composed of organic matter. 


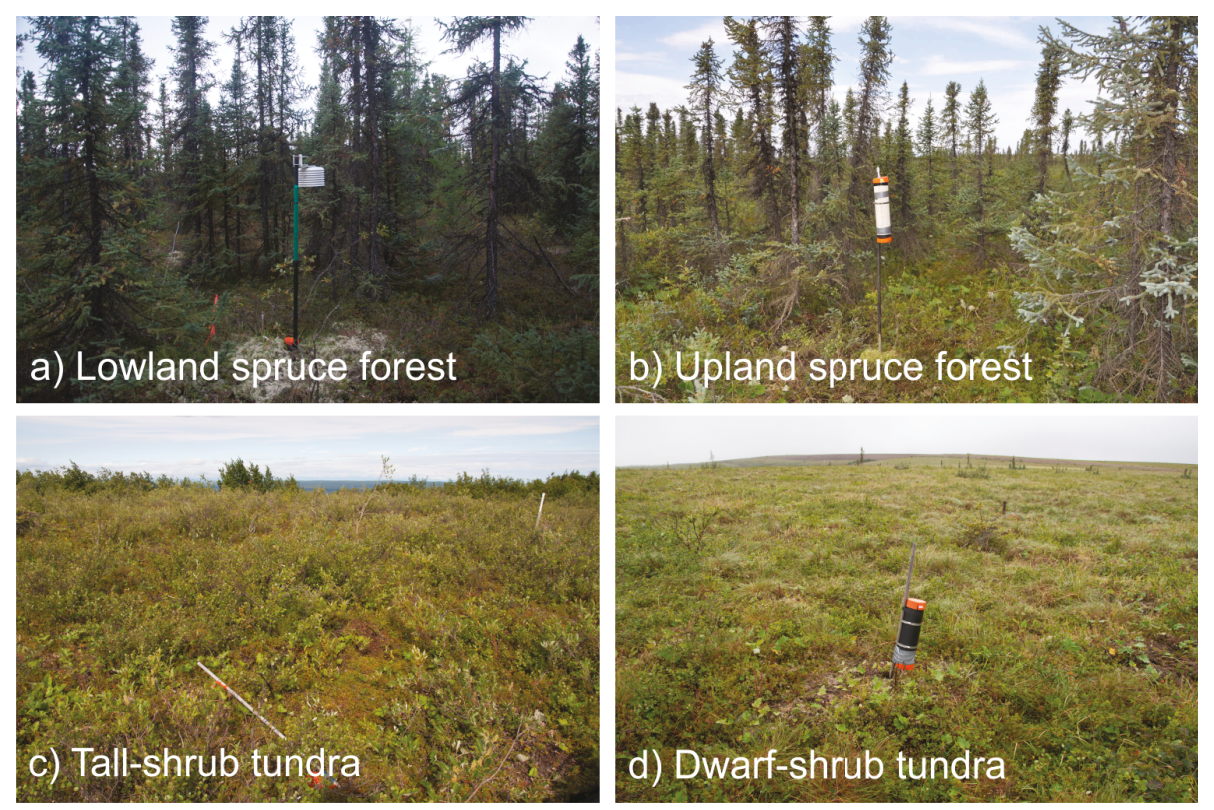

Figure 4.2: Study sites across the forest-tundra ecotone. 


\subsubsection{Lowland spruce forest (LSF)}

The first study site was located in flat ground at low elevation ( $\sim 30 \mathrm{~m}$ a.s.l.) on

Peel Plain. Vegetation consisted of an open canopy of black spruce (Picea mariana) and tamarack (Larix laricina) trees, with an understory of willow (Salix spp.) and dwarf birch (Betula glandulosa) shrubs, and lower-lying ericaceous shrubs of Labrador tea (Rhododendron subarcticum), cloudberry (Rubus chamaemorus), blueberry (Vaccinium uliginosum), and crowberry (Empetrum nigrum) (Figure 4.2a). The hummocky ground at the site was covered by a continuous $(10-30 \mathrm{~cm}$; median $18 \mathrm{~cm})$ layer of mosses and lichens. Active-layer thickness ranged between 28 and $55 \mathrm{~cm}$ (median $40 \mathrm{~cm})$.

\subsubsection{Upland spruce forest (USF)}

The USF site was located in flat ground at an intermediate elevation ( 330 m a.s.l.), in a broad valley on the eastern slopes of Peel Plateau, near the maximum elevation of forest growth. The forest at USF was composed exclusively of black spruce trees and the stand density was less than that at low elevation on Peel Plain (Figure 4.2b). The understory and ground cover were similar to that at LSF, consisting of willows, dwarf birch, Labrador tea, blueberry, cloudberry, and crowberry. The ground surface was hummocky and covered in a thinner, more variable layer of mosses and lichens (5-35 cm; median $9 \mathrm{~cm})$ than that at LSF. Active-layer thickness ranged between 30 and $88 \mathrm{~cm}$ (median $50 \mathrm{~cm}$ ).

\subsubsection{Tall-shrub tundra (TST)}

The TST site was in a transition zone of rolling topography above USF, at around $425 \mathrm{~m}$ a.s.l. The vegetation consisted of tall (typically $>40 \mathrm{~cm}$ ) willows, dwarf birch, 
and shrubs of Labrador tea, cranberry (Vaccinium vitis-idaea) and blueberry (Figure 4.2c). Some stunted spruce trees were present, and the ground was covered with a thin $(<10 \mathrm{~cm})$ surface organic layer of mosses and lichens, except in the troughs of poorly-defined hummocks, where the organic layer was thicker (up to $15 \mathrm{~cm}$ ). The median organic-layer thickness was $7 \mathrm{~cm}$. Active-layer thickness ranged between 32 and $140 \mathrm{~cm}$ (median $69 \mathrm{~cm})$.

\subsubsection{Dwarf-shrub tundra (DST)}

The DST site was located at higher elevation on Peel Plateau, between $\sim 470$ and $495 \mathrm{~m}$ a.s.l. The vegetation consisted of stunted willows, dwarf birch, and ericaceous shrubs, typically $<40 \mathrm{~cm}$ tall (Figure $4.2 \mathrm{~d}$ ). Well-defined earth hummocks and tussocks covered much of the gently rolling ground. The organic-layer was thin $(<10$ $\mathrm{cm}$ ) on hummock tops, but greater in hummock troughs (up to $\sim 30 \mathrm{~cm}$ ). The median organic layer thickness was $8 \mathrm{~cm}$. Active-layer thickness ranged between 41 and 100 cm (median: $67 \mathrm{~cm})$.

\subsubsection{Site-scale topography and moisture contents}

All sites were in flat or gently sloping $\left(\leq 5^{\circ}\right)$ ground, and had similar soil moisture conditions. Active-layer soil samples from $30 \mathrm{~cm}$ depth were collected from eight soil pits (in total) in mineral soil at USF, TST, and DST. At LSF the soil was organic material to below $30 \mathrm{~cm}$ depth. Volumetric water content $\left(\theta_{v}\right)$ was determined by oven drying the samples. $\theta_{v}$ was between 0.28 and 0.44 (mean 0.35 ; sd 0.05 ). The small variation in $\theta_{v}$ suggests that moisture differences between sites did not likely have a profound influence on the ground thermal regime in mineral soil. 


\subsection{Methods}

\subsubsection{Air and ground temperatures}

Air and near-surface ground temperatures across the alpine tree line were measured to characterize conditions across the vegetation gradient. Air temperature measurement sites were installed at LSF, USF, and DST. The air temperature sensors were in operation from August 2011 to August 2013, but the instrument at the USF site failed in autumn 2012. The annual values in Table 4.1 for 2012-13 were obtained by estimating daily air temperatures at USF using regression equations derived from 2011-12 DST and USF daily air temperatures for both the freezing and thawing seasons (thawing: USF $=0.98(\mathrm{DST})+1.20 ; \mathrm{r}^{2}=0.99$; freezing: $\mathrm{USF}=1.02(\mathrm{DST})-$ $\left.0.28 ; r^{2}=0.97\right)$. These estimated values are presented in summary form but were not used to quantify the inversions, which were characterized using data from the LSF and DST sensors.

Relations between air and ground temperatures and spatial variation in ground temperatures across the tree line were studied using shallow thermistor arrays with sensors typically at 5,20,50, and $100 \mathrm{~cm}$ depths. The $5 \mathrm{~cm}$ thermistor represents the temperature at the ground surface, and the $100 \mathrm{~cm}$ thermistor approximates the temperature at the permafrost surface. In total, 8 shallow thermistor arrays were installed (Table 4.2). Three arrays were located at DST, three at TST, and one each at LSF and USF. Snow depths were relatively uniform in the forest because the open canopy and stunted trees did not cause substantial tree wells, and wind distribution was minimal, so a single cable was deemed sufficient to describe ground thermal conditions at the LSF and USF sites. The shallow cables were installed in 2010 and 2011 (Table 2). In TST, two of the shallow thermistor arrays were located 
in flat ground on a ridge in mineral soil, and another at the base of a north-facing slope below the ridge in a flat peatland (Figure 4.1). In DST, two of the shallow thermistor arrays were located at around $495 \mathrm{~m}$ a.s.l., with one in a flat peatland and one on a gentle $\left(2^{\circ}\right)$ slope in mineral soil. Another was placed at $470 \mathrm{~m}$ a.s.l. in mineral soil, on a gentle $\left(\sim 5^{\circ}\right)$, north-facing slope. The shallow thermistor cables located in hummocky, mineral soil in TST and DST were placed on hummock tops.

Ground temperatures at depths of 5-8 m were measured with deep cables in order to obtain values less affected by seasonal variation than those at $1 \mathrm{~m}$. Gravel layers limited the penetration of the water jet drill. A deep cable was installed at LSF to a depth of $4.57 \mathrm{~m}$, at USF to $4.91 \mathrm{~m}$, and at DST, near the top of Peel Plateau, to $6.74 \mathrm{~m}$ depth. In this chapter, we report mean temperatures from the sensor nearest $5 \mathrm{~m}$ depth.

\subsubsection{Snow surveys and iButton arrays}

Snow surveys were conducted in March 2012, 2013, and 2014. Snow depths were measured in each vegetation unit with a graduated steel probe every $5 \mathrm{~m}$ along 70 to 75-m transects marked with PVC pipes to characterize snow cover in the vegetation units. The transects were located on flat or gently sloping ground. It was not possible to measure snow depths at LSF in 2012 due to logistical constraints. Snow depths were also measured at five points within a 1-m radius of shallow ground temperature sensors, and the average was used to estimate the snow depth at the sensor in order to examine the relation between the annual mean temperature at the permafrost surface $\left(T_{p s}\right)$ and late-winter snow depth. One snow pit was dug in each vegetation unit adjacent to the snow transects in 2013, and near each shallow thermistor cable in 2014 to determine snow densities and the thermal resistance of the snow cover.

Snow depth was also measured using iButton ${ }^{\circledR}$ arrays to investigate the influence 
of the timing of deep snow cover development in forest and tundra on ground thermal conditions. One iButton array was installed in forest in USF, and another was located near the Dempster Highway in DST, adjacent to a snow fence where a deep snowdrift forms. The snow fence iButton site is not representative of average snow conditions in the tundra, but is analogous to locations on the tundra where deep snow accumulates from wind redistribution, such as at the base of slopes, in depressions, or in areas with tall shrubs (Sturm et al., 2001a). Data from this iButton array were used solely to compare the timing of deep snow accumulation in the tundra with that in the forest. Water Resources Division (AANDC) established a meteorological (MET) station in 2010 on Peel Plateau, in forest dominated by tall shrubs, to measure air temperature, precipitation, net radiation, wind speed, and snow depths (Figure 4.1). Snow depths inferred from the USF iButton array were compared with depths measured at the MET station. Maximum daily wind speeds at the MET station were used to determine when wind-driven redistribution of snow may have occurred. Snow depths were measured using an acoustic sensor (Sonic Ranger SR50A, Campbell Scientific, Edmonton, AB, Canada) and wind speed was determined using an RM Young wind speed monitor (Model 05103). The data were recorded on a Campbell CRX1000 logger.

\subsubsection{Vegetation heights}

The ability of vegetation to trap snow depends on its height and structural complexity, which are closely correlated in shrub tundra (Thompson et al., 2004). Vegetation canopy heights were measured at ten randomly selected points within $3 \mathrm{~m}$ of the shallow thermistor arrays, as vegetation influences wind-distributed snow over distances of several metres (Sturm et al., 2001a). The ten canopy height measurements were averaged to obtain the mean-maximum vegetation height, which was used to examine 
the influence of vegetation on snow depths at the shallow thermistor cables.

\subsubsection{Statistical analyses}

The Wilcoxon rank-sum test was employed to examine differences in snow depths and active-layer thicknesses amongst the site transects for each year. This non-parametric test was used because the data violated the normality assumption for parametric tests. Least-squares linear regression was employed to examine relations between (1) snow depth and vegetation height at tundra sites, and (2) $T_{p s}$ and late-winter snow depths for forest and tundra sites, respectively. All statistical tests were conducted at the 0.05 significance level. TST-2 was not included in the regression between $T_{p s}$ and late-winter snow depth, due to damage at the site.

\subsection{Results}

\subsubsection{Air temperature regime}

$T_{a}$ from LSF, USF, and DST are summarized in Table 4.1. The $T_{a}$ at LSF for both years were lower $\left(-7.6\right.$ and $\left.-7.8^{\circ} \mathrm{C}\right)$ than the historical average at Fort McPherson $(-7.0$ ${ }^{\circ} \mathrm{C}$ ), but the instrument was in undisturbed forest, while the Environment Canada site, which was in operation until 2007, was at the Fort McPherson airport.

Strong air temperature inversions were observed between LSF and DST during the winter, and particularly during the coldest months (Figure 4.3a,b). Here, an inversion is considered to have occurred when the daily mean air temperature, calculated from measurements at 2-hr intervals, was higher in DST than in LSF. During the freezing season (Oct-Apr), when daily mean air temperatures in LSF were below $0{ }^{\circ} \mathrm{C}$, inversions occurred on $55 \%$ of the days. During the thawing season (May-Sep), 
normal surface lapse rates were persistent (Figure 4.3b), and inversions between LSF and DST occurred during only $8 \%$ of days.

The frequent and persistent temperature inversions caused the number of freezing degree-days to decline with elevation from LSF to DST (Figure 4.3b). The strength of the winter inversions, when positive surface lapse rates dominated, was enough cumulatively to outweigh the weaker normal surface lapse rates in summer, so that the $T_{a}$ was lowest at LSF in both years (Table 4.1). For example, the mean winter air temperature (Dec-Feb) in $2011-12$ was $-21.1^{\circ} \mathrm{C}$ at DST and $-25.1^{\circ} \mathrm{C}$ at LSF, while the mean summer temperatures in 2012 (Jun-Aug) were 13.4 and $14.5^{\circ} \mathrm{C}$, respectively.

\subsection{Snow conditions}

The annual start date of a continuous winter snow cover was estimated by examining ground temperatures from the thermistors at $5 \mathrm{~cm}$ depth. Snow was assumed to cover the ground when the diurnal variation in $T_{s}$ dropped below $1{ }^{\circ} \mathrm{C}$ (Burn and Zhang, 2009). At low elevation on Peel Plain, these conditions were recorded between September 24 and October 17 in 2010-13 (Table 4.2). On Peel Plateau, the arrival of snow occurred between September 21 and October 17.

In each year, median late-winter snow depth was greater in the forest than on the tundra (Figure 4.4a).

The rank order of snow depth in the forest has been USF > LSF, but it has not been consistent between TST and DST over the period of study. Variation in latewinter snow depth increased with elevation across the ecotone. On Peel Plain in LSF, snow depths were the least variable $(47-95 \mathrm{~cm})$. At USF, variation in snow depth was greater $(50-132 \mathrm{~cm})$ than at LSF. Snow depth along the transects varied 
Table 4.1: Annual mean air temperatures $\left(T_{a}\right)$ and the number of freezing/thawing degree-days (FDD/TDD) from three monitoring sites. Asterisks denote mean daily temperatures estimated using regressions of dwarf-shrub tundra (DST) and upland spruce forest (USF) temperatures from 2011-2012.

\begin{tabular}{llllllll}
\hline & \multicolumn{9}{c}{ 2011-2012 } & \multicolumn{5}{c}{ 2012-2013 } \\
Site & Elev. $(\mathrm{m})$ & $T_{a}\left({ }^{\circ} \mathrm{C}\right)$ & FDD & TDD & $T_{a}\left({ }^{\circ} \mathrm{C}\right)$ & FDD & TDD \\
\hline LSF (Peel Plain) & 30 & -7.6 & 4418 & 1755 & -7.8 & 4645 & 1782 \\
USF (Peel Plateau) & 326 & -6.8 & 4092 & 1782 & $-7.5^{*}$ & $4361^{*}$ & $1619^{*}$ \\
DST (Peel Plateau) & 492 & -6.8 & 3968 & 1327 & -7.6 & 4257 & 1485 \\
\hline
\end{tabular}



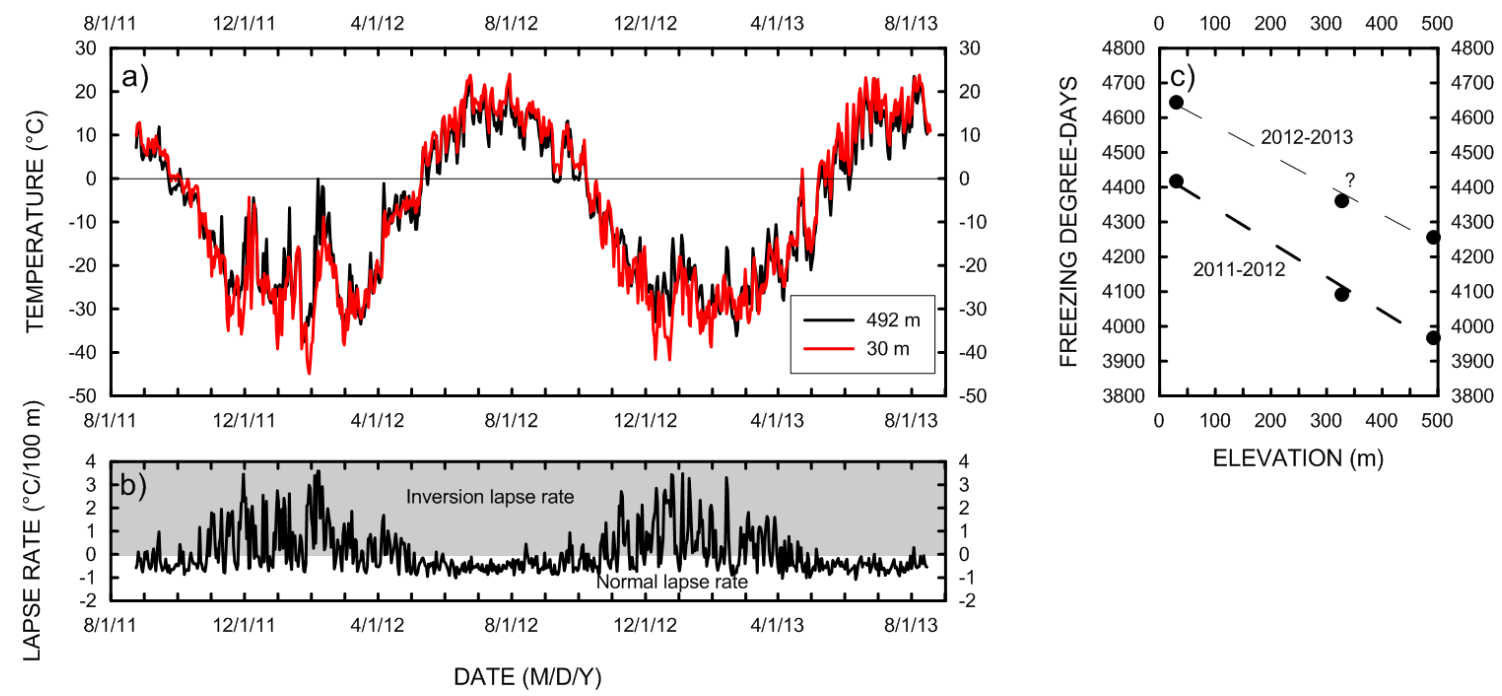

Figure 4.3: Plots showing a) air temperatures on Peel Plain (LSF $30 \mathrm{~m}$ ) and near the top of Peel Plateau (DST $492 \mathrm{~m}$ ), b) daily surface lapse rates between $30 \mathrm{~m}$ and $492 \mathrm{~m}$, and c) relations between freezing degree-days and elevation. The question mark indicates where missing data were estimated for USF using regression (see text). 

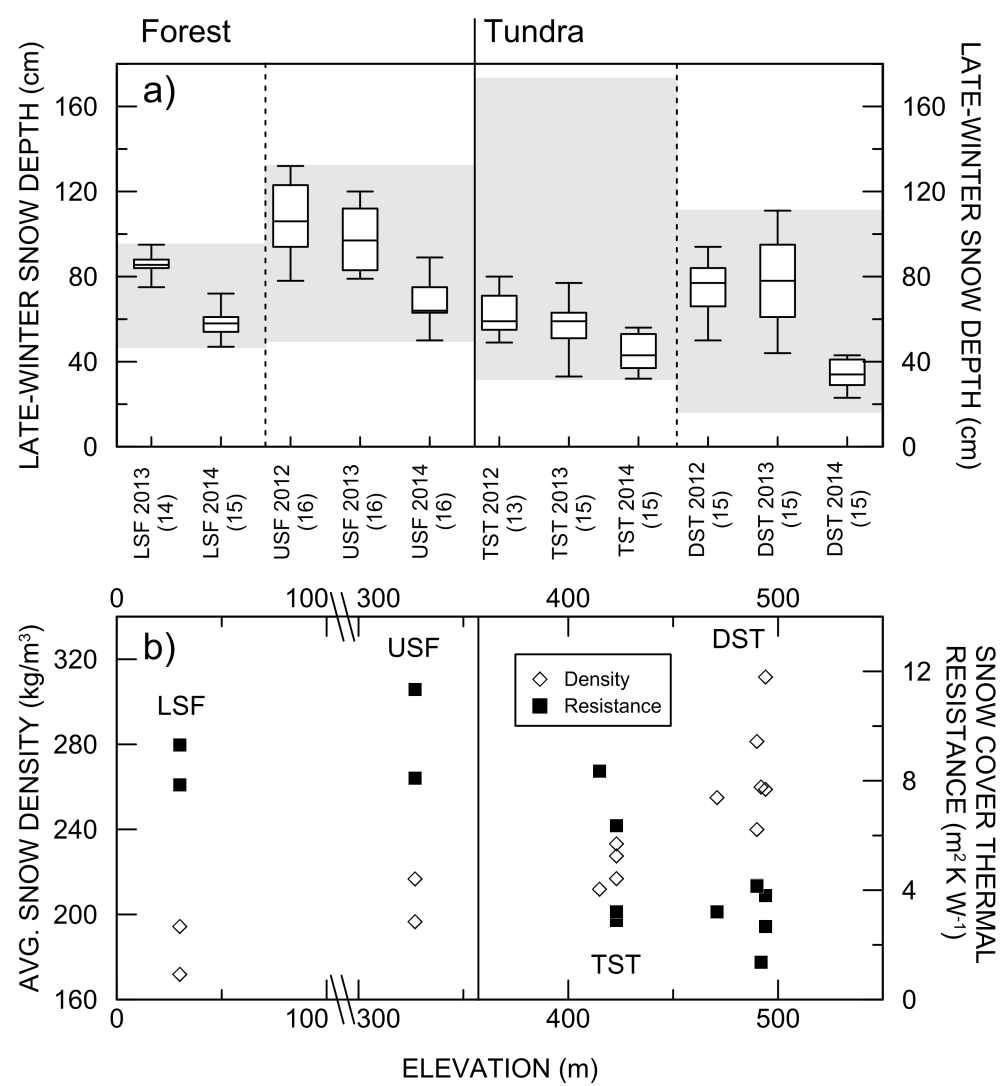

Figure 4.4: a) Box-whisker plot of snow depths from transects for winters 20122014. The whiskers indicate extreme values, the top and bottom of the box represent the upper and lower quartiles, respectively, and the line in the center of the box is the median. The number of points measured along each transect is in parentheses. The shaded grey areas represent the range of individual snow depth measurements from transects and shallow thermistor sites (Table 4.2). Snow depths were not measured at LSF in 2012 due to logistical constraints; b) average snow density and snow cover thermal resistance determined from 2013 and 2014 snow pits. 
Table 4.2: Mean annual temperatures at the permafrost surface $\left(T_{p s},{ }^{\circ} \mathrm{C}\right)$ and ground surface $\left(T_{s},{ }^{\circ} \mathrm{C}\right)$, late winter snow depths, and the estimated dates of snow arrival.

\begin{tabular}{|c|c|c|c|c|c|c|c|c|c|c|c|}
\hline Site & Elev. $(\mathrm{m})$ & $\begin{array}{l}2010-11 \\
\text { Snow arr. }\end{array}$ & $T_{p s}$ & $T_{s}$ & $\begin{array}{l}\text { 2011-12 } \\
\text { Snow arr. }\end{array}$ & Snow $(\mathrm{cm})$ & $T_{p s}$ & $T_{s}$ & $\begin{array}{l}\text { 2012-2013 } \\
\text { Snow arr. }\end{array}$ & Snow $(\mathrm{cm})$ & $T_{p s}$ \\
\hline LSF-1 & 30 & Sep. 24 & -2.6 & 0.1 & Oct. 9 & - & -2.8 & 0 & Oct. 17 & 75 & $-2.5-0.4$ \\
\hline USF-1 & 327 & Sep. 21 & -1.7 & 0 & Sep. 24 & $107^{1}$ & -1.7 & 0.4 & Oct. 17 & $99^{1}$ & $-2.7-0.8$ \\
\hline TST-1 & 423 & Sep. 21 & -2.1 & -1.9 & Sep. 24 & $62^{1}$ & -2.2 & -1.8 & Oct. 17 & 74 & $-1.7-1.9$ \\
\hline TST-2 (peatland) & 415 & Sep. 21 & -0.5 & 1.3 & - & $119^{2}$ & - & - & - & $97^{2}$ & $-\quad-$ \\
\hline TST-3 & 423 & - & - & - & $\mathrm{n} / \mathrm{a}$ & 62 & -1.8 & $\mathrm{n} / \mathrm{a}$ & $\mathrm{n} / \mathrm{a}$ & 73 & $-1.4 \mathrm{n} / \mathrm{a}$ \\
\hline$\overline{\text { DST-1 }}$ & 494 & Sep. 21 & -1.4 & -0.5 & Sep. 24 & 68 & -1.2 & 0.2 & Oct. 17 & 67 & $-1.5-1.1$ \\
\hline DST-2 (peatland) & 492 & Sep. 21 & -2.3 & -0.8 & Sep. 24 & 37 & -3.7 & -2.5 & Oct. 17 & 20 & $-4.4-3.4$ \\
\hline DST-3 & 479 & - & - & - & Sep. 24 & 52 & -2 & -0.3 & Oct. 17 & 48 & $-2.4 \mathrm{n} / \mathrm{a}$ \\
\hline
\end{tabular}


less in TST $(32-80 \mathrm{~cm})$ than in USF, but had the greatest variability overall due to deep snow accumulation at the TST-2 thermistor (Figure 4.4a). Snow depth variation was relatively high along the DST transect $(23-111 \mathrm{~cm})$. The Wilcoxon rank-sum tests indicated that snow depths measured along the transects at each site were significantly different from all other sites in individual years, except between LSF and DST in 2013 (Table 4.3). When the data for all years were pooled, there were significant differences between all vegetation units except DST and TST, and DST and LSF (Table 4.3).

Snow density increased, and snow thermal resistance decreased with elevation from forest to tundra (Figure 4.4b). Density was lowest at LSF $\left(172-194 \mathrm{~kg} \mathrm{~m}^{-3}\right.$ ), and increased with elevation to DST (233-311 $\left.\mathrm{kg} \mathrm{m}^{-3}\right)$. In LSF and USF, the snowpack mainly comprised powder and hoar fractions. In tundra, the depth-hoar fraction was smaller, and dense (300-400 $\left.\mathrm{kg} \mathrm{m}^{-3}\right)$ wind slab layers were present at some sites, contributing to the higher densities. The thermal resistance of snow was higher at the forest sites (7.9-11.4 $\left.\mathrm{m}^{2} \mathrm{~K} \mathrm{~W}^{-1}\right)$ than in tundra (1.4-8.3 $\left.\mathrm{m}^{2} \mathrm{~K} \mathrm{~W}^{-1}\right)$ (Figure $\left.4.4 \mathrm{~b}\right)$, due to lower densities and deeper cover in the forest. However, at TST-2, the thermal resistance was comparable to forest sites due to snowdrift accumulation at the slope base.

iButton thermistor arrays were employed to characterize the timing of deep snow accumulation in forest and tundra. Snow accumulation inferred from the iButton array in forest at USF suggests that snow accumulates gradually, coincident with precipitation events (Figure 4.5a). The inferred iButton snow depths closely agree with those measured at the MET station located in forest approximately $6 \mathrm{~km}$ to the west (Figure 4.1). The similarity of the plots suggests that snow accumulation is relatively uniform in forest on Peel Plateau and that wind distribution is minimal. In 
contrast, snow accumulation occurred rapidly at the iButton array located beside the snow fence in dwarf-shrub tundra, presumably due to redistribution by wind (Figure $4.5 b)$.

\subsubsection{Permafrost conditions across tree line}

Near-surface ground temperatures in 2010-13 generally increased with elevation across the forest-tundra ecotone (Figure 4.6). The $T_{p s}$ in LSF on Peel Plain ranged between -2.5 and $-2.8^{\circ} \mathrm{C}$ in $2010-13$ (Table 2 ). These data are corroborated by a mean temperature of $-2.5^{\circ} \mathrm{C}$ near $5 \mathrm{~m}$ depth from the LSF deep cable in 2012-2014. In forest on Peel Plateau (USF-1), $T_{p s}$ was between -1.7 and $-2.7^{\circ} \mathrm{C}$, and was $-1.0{ }^{\circ} \mathrm{C}$ near $5 \mathrm{~m}$ depth at the deep cable in 2012-2014. At TST, $T_{p s}$ at sites with mineral soil ranged from -1.4 to $-2.2{ }^{\circ} \mathrm{C}$ in $2010-13$. At DST, $T_{p s}$ was between -1.2 and $-2.4{ }^{\circ} \mathrm{C}$ at sites with mineral soils in the same period. The mean temperature near $5 \mathrm{~m}$ at the deep cable in DST was $-2.2{ }^{\circ} \mathrm{C}$ in $2012-2014$. In peatland, $T_{p s}$ was $-0.5^{\circ} \mathrm{C}$ at TST-2, and between -2.3 and $-4.4{ }^{\circ} \mathrm{C}$ at DST-2 (Figure 4.6). The majority of $T_{p s}$ values at TST and DST (12 of 14) were higher than those observed in forest on Peel Plain (Figure 4.6). The data from deep thermistor cables also indicate that permafrost on Peel Plateau is relatively warm, with higher temperatures at both USF and DST than at LSF (Figure 4.7).

\subsubsection{Ground temperatures and snow cover}

Strong associations were registered between late-winter snow depth and both $T_{p s}$ and $T_{s}$ at tundra sites (Figure 4.8). Linear regression indicated that late-winter snow depth (LWSD) accounted for the majority of variation in $T_{p s}\left[T_{p s}=0.04(\mathrm{LWSD})\right.$ 

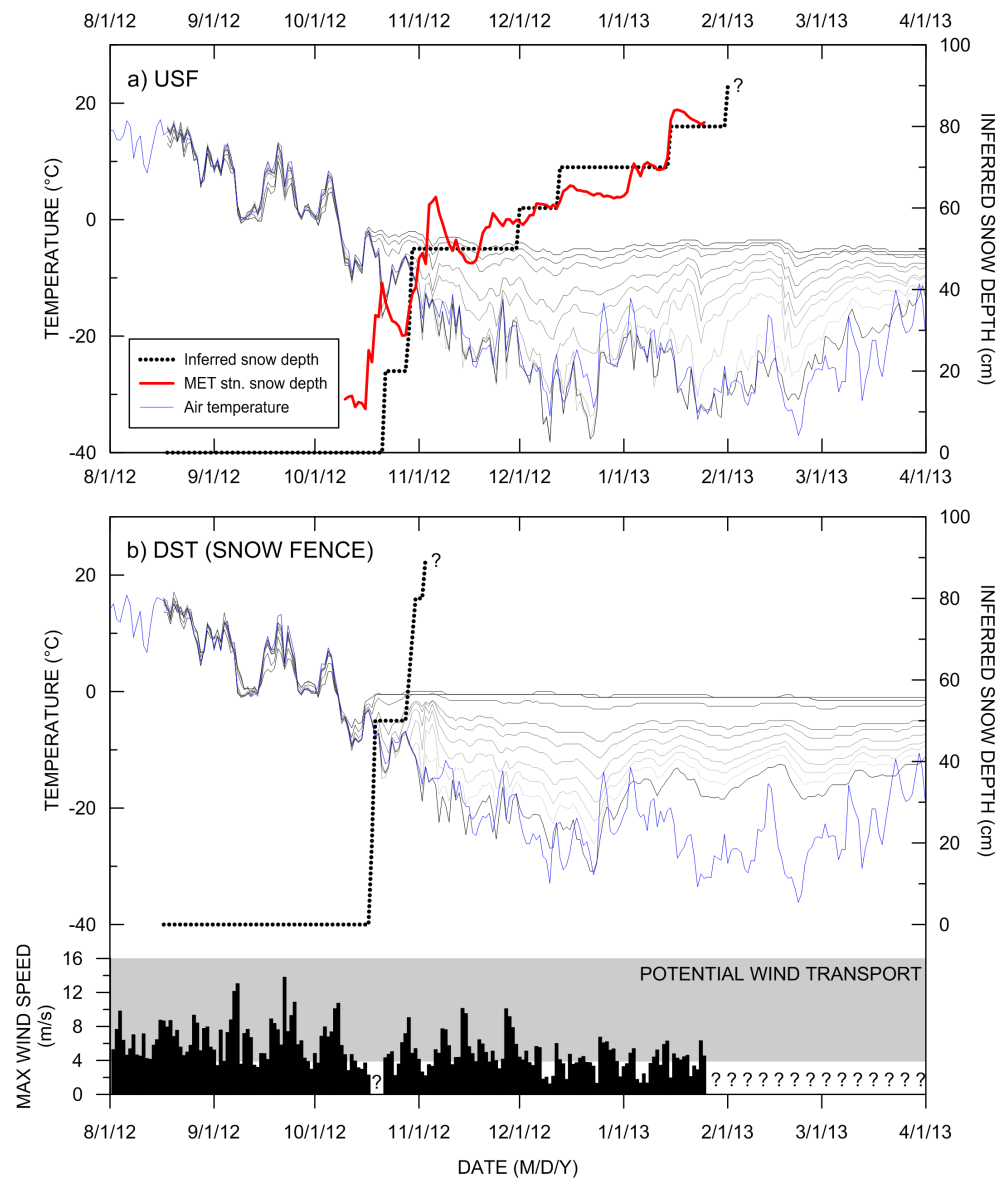

Figure 4.5: a) iButton temperatures (grey lines) and inferred snow depth in forest on Peel Plateau; b) iButton temperatures and inferred snow depth adjacent to snow fence in tundra. The blue lines in a) and b) are air temperatures from the USF and DST air temperature sensors, respectively. Daily maximum wind speeds from the meteorological (MET) station are plotted as black bars, and the grey shading represents wind speeds at which snow transport is possible under cold, dry conditions ( $\mathrm{Li}$ and Pomeroy, 1997). Question marks indicate the limit of inferred snow depths (when snow is $\geq 90 \mathrm{~cm}$ ), and missing wind data from the MET station. 
Table 4.3: Upper: Wilcoxon rank-sum results for 2012-2014 snow depths from transects; Lower: Wilcoxon rank-sum results for 2011-13 active-layer thicknesses from transects. X indicates significant p-values between the sites in all years, while 1, 2, 3, and 4 refer to significant p-values in 2011, 2012, 2013, and 2014 respectively. The upper right quadrant is a summary of the data pooled for 2011-13. The numbers indicate the difference in the 3 -year median values between the sites $(\mathrm{cm})$. Underlined values indicate significant results in the pooled years. No snow depths were measured at LSF in 2012.

\begin{tabular}{lllll}
\hline Site & LSF & USF & TST & DST \\
\hline LSF & - & $\underline{20}$ & $\underline{18}$ & 9 \\
USF & $\mathrm{X}$ & - & $\underline{38}$ & $\frac{29}{9}$ \\
TST & $\mathrm{X}$ & $\mathrm{X}$ & - & - \\
DST & 4 & $\mathrm{X}$ & $\mathrm{X}$ & - \\
\hline
\end{tabular}

\begin{tabular}{|c|c|c|c|c|c|}
\hline Site & LSF & USF & TST & DST & PEATLAND \\
\hline LSF & - & 10.5 & 29 & 27.5 & 5.5 \\
\hline USF & 1,2 & - & $\overline{18.5}$ & 17 & 5 \\
\hline TST & $\mathrm{X}$ & 2,3 & - & $\overline{1.5}$ & 23.5 \\
\hline DST & $\mathrm{X}$ & None & None & - & $\overline{22}$ \\
\hline PEATLAND & $\mathrm{X}$ & None & $\mathrm{X}$ & $\mathrm{X}$ & - \\
\hline
\end{tabular}




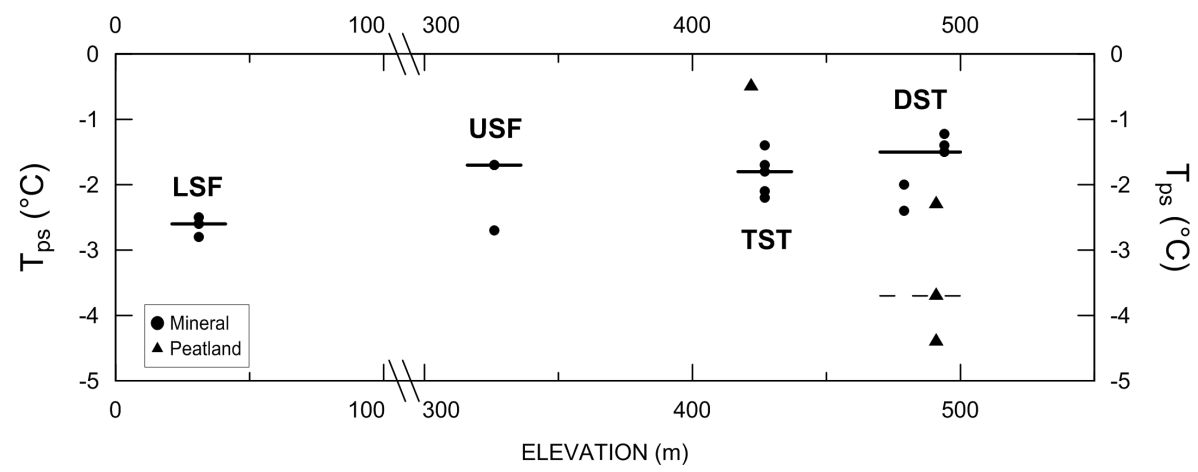

Figure 4.6: Mean annual temperature near the permafrost surface $\left(T_{p s}\right)$ across the forest-tundra ecotone for 2010-13. The solid black lines represent the median $T_{p s}$ from instruments in mineral soil for each vegetation unit, and the dashed line is the median for the DST peatland instrument. 


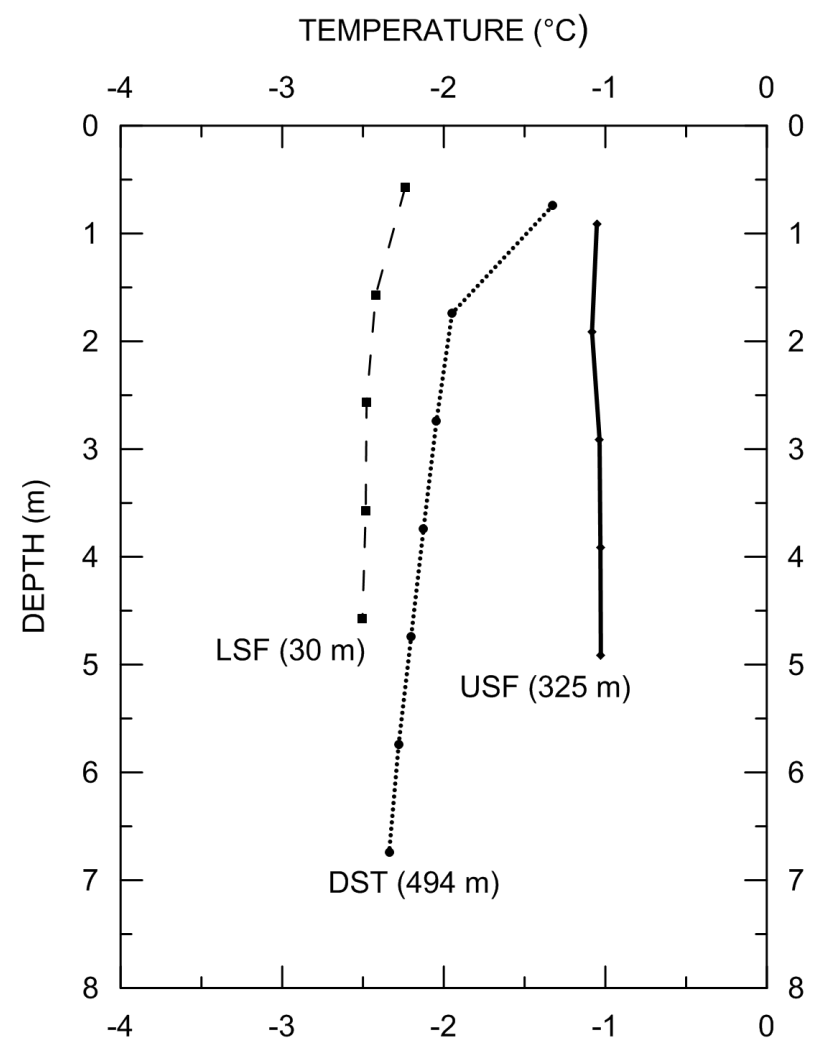

Figure 4.7: Mean ground temperatures for September 2012 to August 2014. The symbols on each line represent the thermistor locations. 
4.79, $\left.\mathrm{r}^{2}=0.72, \mathrm{n}=19, \mathrm{p}<0.01\right]$. The relation for forest sites was not statistically significant $\left[T_{p s}=0.03(\mathrm{LWSD}) 4.56, \mathrm{r}^{2}=0.43, \mathrm{n}=8, \mathrm{p}=0.14\right]$, and all the points were offset from the tundra regression line (Figure 4.8).

The thermal effect of snow was also apparent when comparing TST-2 and DST2. Both sites were in peatland, and had similar late-summer thaw depths $(45 \mathrm{~cm}$ in 2011-12). Only $77 \mathrm{~m}$ of elevation separated the sites, so their air temperatures were also similar. However, TST-2 was at the base of a north-facing slope, where deep snow accumulated annually, whereas DST-2 was exposed and most snow blew away. In 2012 and 2013, late-winter snow depths at TST-2 were 119 and $97 \mathrm{~cm}$, while there were 37 and $20 \mathrm{~cm}$ of snow at DST-2. At TST-2, the surface temperature was decoupled from the air temperature in autumn, indicating the early accumulation of deep snow (Figure 4.9). As a result, freezeback was delayed significantly at TST2. Between 2010 and 2013, $T_{p s}$ at DST-2 was between -2.3 and $-4.4 \mathrm{C}$, and freeze back in 2010-11 occurred nearly two months earlier than at TST-2 (Figure 4.9). The 2010-11 data suggest that, if all other environmental conditions are similar, snow may account for at least $1.8^{\circ} \mathrm{C}$ of the variation in $T_{p s}$ on Peel Plateau where snow can be redistributed (Table 4.2). This magnitude may only apply at peatland sites, as variation of $T_{p s}$ resulting from snow cover in mineral soil likely differs due to the different thermal properties of the substrates (Kokelj et al., 2014).

\subsubsection{Active-layer thicknesses}

Active-layer thicknesses and variability generally increased with elevation from forest to tundra (Figure 4.10), except in peatland. Median active-layer thicknesses from 2011 to 2013 were between 36 and $40 \mathrm{~cm}$ in LSF on Peel Plain, and in individual 

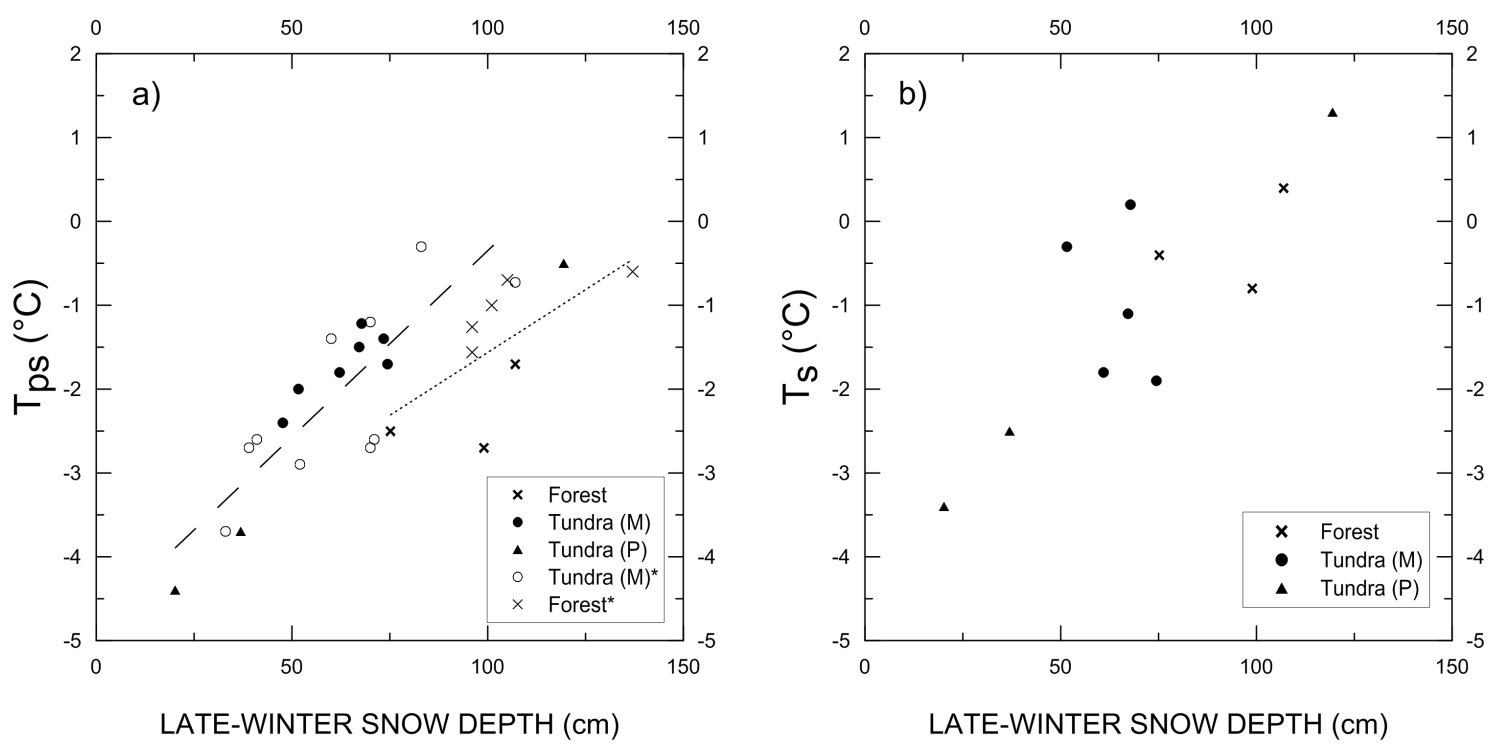

Figure 4.8: Relations between late-winter snow depth and a) mean annual permafrost surface temperature $\left(T_{p s}\right)$ and b) ground surface temperature $\left(T_{s}\right)$ for 2012 and 2013. Tundra (M) and Tundra (P) denote sites in mineral and peatland soils, respectively. Asterisks in the legend denote additional data collected on Peel Plateau by Gill et al. (2014). The dashed line is the regression relation for tundra sites $\left[T_{p s}=0.04(\mathrm{LWSD}) 4.79, \mathrm{r}^{2}=0.72, \mathrm{n}=19, \mathrm{p}<0.01\right]$, and the dotted line is for forest sites $\left[T_{p s}=0.03(\mathrm{LWSD}) 4.56, \mathrm{r}^{2}=0.43, \mathrm{n}=8, \mathrm{p}\right.$ $=0.14]$. There are fewer points for $T_{s}$ than $T_{p s}$ because subsidence at DST-3 caused the $5 \mathrm{~cm}$ thermistor to be exposed after 2011-12, and because TST-3 did not have a surface thermistor. 


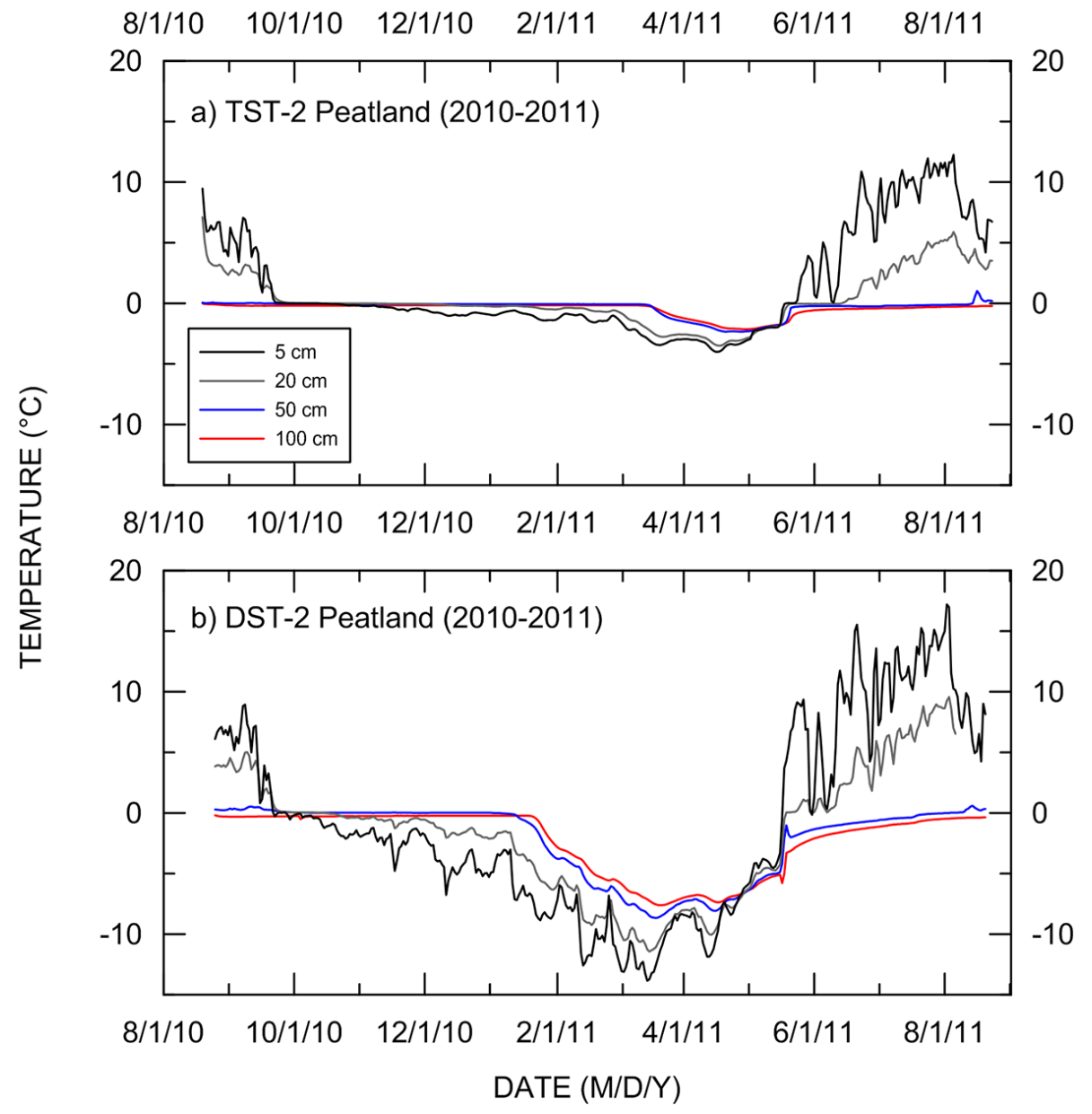

Figure 4.9: Ground temperatures at a) a peatland at the base of a slope where thick snow accumulates $\left(T_{s}=1.3^{\circ} \mathrm{C} ; T_{p s}=-0.5{ }^{\circ} \mathrm{C}\right)$, and b) an exposed peatland where little snow accumulates $\left(T_{s}=-0.8^{\circ} \mathrm{C} ; T_{p s}=-2.3^{\circ} \mathrm{C}\right)$. 


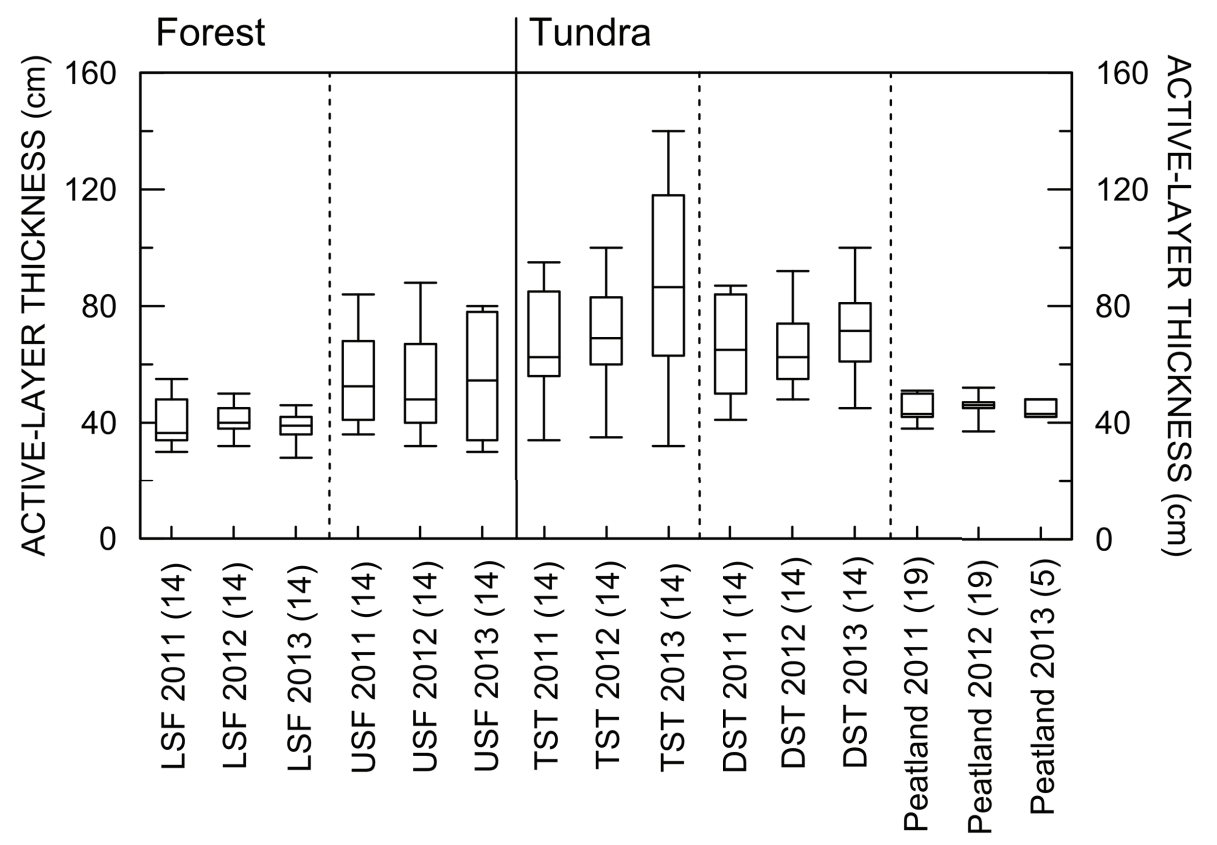

Figure 4.10: Active-layer thicknesses across the forest-tundra ecotone from the four transects in mineral soil, and around instrumented sites in the DST and TST peatland (pooled values from the TST and DST peatland). The number of individual points measured is in parentheses. 
years, the Wilcoxon rank-sum tests indicated that the thicknesses were statistically different than those at all other sites, except USF in 2013 (Table 4.3). In USF, the 2011-13 median thicknesses were between 48 and $55 \mathrm{~cm}$. TST had the greatest median active-layer thicknesses, between 63 and $87 \mathrm{~cm}$, and in individual years, the thicknesses differed statistically from all sites except DST (Table 4.3). In DST, median thicknesses were between 63 and $72 \mathrm{~cm}$, and the active-layer thicknesses were statistically different from those in LSF and the peatlands (Table 4.3. The peatland active-layer thicknesses in TST and DST were relatively uniform and varied little from 2011 to 2013, with median values from 43 to $46 \mathrm{~cm}$. Peatland active-layer thicknesses were significantly different from those measured along the transects at all sites except USF, which had similar median values (Table 4.3).

\subsection{Discussion}

\subsubsection{Air temperatures}

The air temperature regimes at LSF and DST revealed strong and persistent temperature inversions in winter. The inversion frequencies are similar to results presented by Burns (1973), who reported that between December and February, inversions occurred in Inuvik for $67 \%$ of the time at 11 GMT (3 am) and $58 \%$ at 23 GMT (3 pm) the two moments of radiosonde releases. In the Peel Plateau region, daily winter temperature inversions may occur more frequently than the $55 \%$ reported, because inversions below $492 \mathrm{~m}$, the elevation of the DST air temperature sensor, may not have been captured. The magnitudes of surface lapse rates observed during inversions in this study were similar in Dec-Feb (mean: $1.1^{\circ} \mathrm{C} / 100 \mathrm{~m}$ ) to those reported by Lewkowicz et al. (2012) in Yukon, where temperatures increased at about $1.0{ }^{\circ} \mathrm{C} / 100$ 
$m$ to the elevation of tree line in the coldest months. On individual days, increases of up to about $3.5^{\circ} \mathrm{C} / 100 \mathrm{~m}$ were recorded between Peel Plain and Peel Plateau.

Figure 4.11 shows the strong relation $\left[\mathrm{FDD}=223\right.$ (Latitude) 10,$752 ; \mathrm{r}^{2}=0.99$ ] between latitude and average freezing degree-days (1981-2010) for seven weather stations in the Northwest Territories and Nunavut. The number of freezing degree-days in DST was 450 less than in LSF in 2011-12 and 388 less in 2012-2013. Figure 4.11 shows that the effect of temperature inversions on freezing degree-days on Peel Plateau is equivalent to that observed with a southward shift in latitude of nearly $2^{\circ}$. Winter air temperatures on Peel Plateau are similar in aggregate to those observed in lowlands nearly $200 \mathrm{~km}$ to the south, between Fort Good Hope and Norman Wells, near the boundary of the continuous and discontinuous permafrost zones.

In summer, air temperature decreased with elevation. The mean July temperature in LSF was 17.7 and $15.4{ }^{\circ} \mathrm{C}$ in 2012 and 2013, while in DST it was 15.0 and $12.7^{\circ} \mathrm{C}$. The 2012 mean July temperature in LSF $\left(17.7^{\circ} \mathrm{C}\right)$ was higher than the 1981-2010 average mean July temperature $\left(15.2^{\circ} \mathrm{C}\right)$ recorded at the Fort McPherson airport (Environment Canada, 2014), indicating that July 2012 was considerably warmer than normal. The 2013 temperature in $\operatorname{LSF}\left(15.4^{\circ} \mathrm{C}\right)$ was similar to the long-term average, and corresponded with a $12.7^{\circ} \mathrm{C}$ temperature at DST, close to the $12{ }^{\circ} \mathrm{C}$ limit of tree line reported by Walker (2000) for continental areas. Therefore, we interpret that the position of tree line on the Peel Plateau is broadly controlled by the prevailing summer air temperature conditions.

\subsubsection{Active-layer thicknesses}

Active-layer thicknesses were predominantly associated with the thickness and variation of the surface organic layer at the four sites, while shading from the forest canopy 


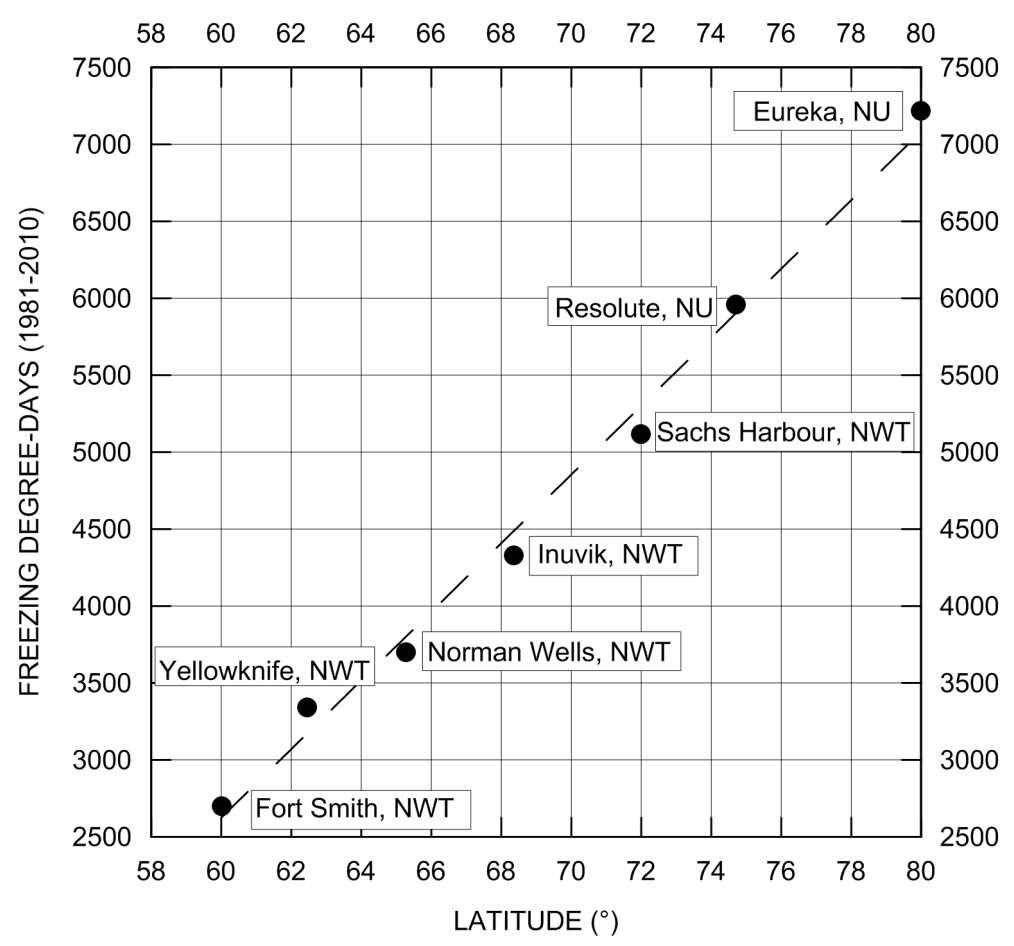

Figure 4.11: Relation between latitude and average freezing degree-days (1981-2010) at 7 weather stations (Environment Canada, 2014). The study area on Peel Plateau is at about $67.2^{\circ} \mathrm{N}$, and there were 3968 and 4257 freezing degree-days at DST in 2011-12 and 2012-13, respectively. These data are not plotted here, as they are not similar to the long-term averages. The least-squares regression line is plotted as dashes. 
and substrate composition were also important at some sites. Active-layer thickness is generally considered to be predominantly a function of summer temperature, surface conditions, and substrate composition (Smith, 1975), though conditions in winter are important in some settings (e.g., Burn and Zhang, 2010). Thawing degree-days declined with elevation on Peel Plateau due to the persistent normal surface lapse rates in summer (Table 4.1), but active-layer thicknesses generally increased from the forest up to the tundra (Figure 4.10).

Active-layer thicknesses were relatively shallow and uniform at LSF (Figure 4.10), likely because a thick, continuous surface organic layer was present, and shading from the canopy decreased incident radiation on the surface (Smith, 1975). The lower permafrost temperatures at LSF may have also contributed to shallower active-layer depths, due to the heat required to thaw the colder ground. The median activelayer thicknesses at USF were greater than at LSF (Figure 4.10), and depths were more variable, likely due to the sparser forest canopy and variable surface organiclayer thickness at the higher elevation site. TST had the greatest and most variable active-layer thicknesses (Figure 4.10). The deepest measurements were from sandy areas, where it was difficult to ascertain the position of the frost table due to friction along the probe, while the shallow measurements were in troughs of poorly-defined hummocks where there was a thicker surface organic layer. DST had less variable active-layer thicknesses than TST (Figure 4.10), due to the absence of sandy substrata, but the differences were not statistically significant (Table 4.3). The variation at DST was related to the differences in organic cover on hummock tops and troughs. Peatlands had uniform and thin $(\sim 45 \mathrm{~cm})$ active layers, similar to LSF, due to the thick and continuous organic cover. However, the active-layer thicknesses in peatland and LSF were statistically different, because LSF had consistently shallower depths, likely due to shading in the forest. 
In summary, the effects of surface and subsurface conditions obscured any relation between thawing degree-days and active-layer thicknesses across the ecotone.

\subsubsection{Snow conditions}

Snow depths generally declined with elevation from forest to tundra and were more variable in tundra (Figure 4.4a), but the pattern is not as clearly defined as at latitudinal tree line (Palmer et al., 2012, Figure 5). Snow depths from the transects in DST exceeded those in TST in 2012 and 2013 (Figure 4.4a), in contrast with the typically observed relation of increasing snow depth with vegetation height (Thompson et al., 2004; Palmer et al., 2012). Linear regression showed no apparent relation between mean-maximum vegetation height and late-winter snow depth at instrumented sites in tundra, suggesting that vegetation is a secondary control of snow accumulation at the site scale. This observation suggests that mesoscale topographic/wind effects may be important in the rolling terrain of Peel Plateau.

Snow cover was thin on Peel Plateau in winter 2013-14 (Figure 4.4a), due to low snowfall in early winter, and strong winds that removed snow from the tundra (S. Tetlichi and C. Firth, personal communications, March 2014). Mesoscale topographic effects may explain the deep snow observed in forest at USF (Figure 4.4a), which is located in a broad valley. Forested valleys in the Peel Plateau region may be sinks for snowfall blown from nearby tundra (e.g., Roy-Léveillée et al., 2014), but further investigation is required on this topic, since the study did not control for these effects.

Snow depths in LSF were similar to those observed in forest near Inuvik, but average tundra snow depths were typically deeper on Peel Plateau than has been observed recently north of tree line in the Mackenzie Delta area ( 50-60 cm vs. 20-50 cm) (Morse et al., 2012; Palmer et al., 2012). Snow is likely deeper in tundra on Peel Plateau than tundra further north because more precipitation falls in the former than 
has been measured north of latitudinal tree line (Burn and Kokelj, 2009, Figure 3).

Snow cover density increased with elevation, and tundra snow cover densities were much greater than those in forest. Aggregate snow densities from tundra snow pits were higher than those observed north of latitudinal tree line to the northeast. On Peel Plateau, the snow densities from pits in TST and DST were between 233 and $311 \mathrm{~kg} \mathrm{~m}^{-3}$, whereas upland shrub-tundra sites in the Mackenzie Delta area have reported average densities of $120-230 \mathrm{~kg} \mathrm{~m}^{-3}$ (Palmer et al., 2012) and $238 \mathrm{~kg} \mathrm{~m}^{-3}$ (Morse et al., 2012). In LSF and USF, snow cover densities were 172-194 and 197-217 $\mathrm{kg} \mathrm{m}^{-3}$, respectively, similar to the value of $190 \mathrm{~kg} \mathrm{~m}^{-3}$ reported by Palmer et al. (2012) from forest near Inuvik.

The thermal resistance of the snow covers observed in this study were within the range of those observed at latitudinal tree line, but the average resistance from snow pits in DST $\left(3.2 \mathrm{~m}^{2} \mathrm{~K} \mathrm{~W}^{-1}, \mathrm{n}=6\right)$ was greater than that reported by Palmer et al. (2012) (2.4 $\left.\mathrm{m}^{2} \mathrm{~K} \mathrm{~W}^{-1}\right)$ for a site north of latitudinal tree line in dwarf-shrub tundra, even though five of the six snow pits were dug in 2014, when snow cover was thinnest on Peel Plateau. The high thermal resistance of the snow cover in tundra on Peel Plateau may contribute to the warm permafrost conditions.

\subsubsection{Permafrost conditions}

Ground temperatures did not decline substantially across tree line, in contrast to observations by Lewkowicz et al. (2012) and Palmer et al. (2012). The majority of tundra sites had higher $T_{p s}$ than those at LSF (Figure 4.6). Ground temperatures at $5 \mathrm{~m}$ depth were also greater on Peel Plateau than those on the lower-lying Peel Plain (Figure 4.7). Tundra permafrost temperatures were several degrees higher than those typically observed north of latitudinal tree line (e.g., Burn and Kokelj, 2009; Palmer et al., 2012), and higher than those reported for the study region on national 
scale maps (Heginbottom et al., 1995; Henry and Smith, 2001). The combined effects of strong winter temperature inversions and relatively deep snow contribute to the warm permafrost conditions observed at tundra sites. We emphasize that our results apply to the elevation range examined, but that in higher terrain, which may have thinner snow cover and experience the effects of inversions less frequently, ground temperatures may be lower than at LSF.

Air temperature data show that the number of freezing degree-days on Peel Plateau is similar to that of lower latitudes such as the area between Fort Good Hope and Norman Wells, NWT. Burgess and Smith (2000) reported mean annual ground temperatures at sites near Fort Good Hope between -2 and $0{ }^{\circ} \mathrm{C}$. The average mean annual ground temperature from 17 sites near Norman Wells, reported in the Ground Temperature Database for Northern Canada (Smith and Burgess, 2000) is about $-2.7{ }^{\circ} \mathrm{C}$, lower than the median temperature on Peel Plateau, but with a similar range $\left(-0.8\right.$ to about $\left.-4.5^{\circ} \mathrm{C}\right)$. Therefore, the similar winter air temperature conditions on Peel Plateau and between Fort Good Hope and Norman Wells likely lead to similar permafrost temperatures.

Typically, higher permafrost temperatures in forest than tundra are attributed to deep snow covers (e.g., Smith et al., 1998; Burn and Kokelj, 2009; Palmer et al., 2012). However, on Peel Plateau, where snow in tundra may also be deep, the timing of snow accumulation may be an important factor contributing to lower ground temperatures at forest sites. Data from the iButtons in DST suggested that $>90 \mathrm{~cm}$ of snow may accumulate by early November, whereas the snow cover in the forest accumulated more gradually over several months, only surpassing $90 \mathrm{~cm}$ depth in early February (Figure 4.5). The more gradual snow accumulation in forest may partly explain why the relation between $\left(T_{p s}\right)$ and late-winter snow depth for forest sites is distinctive from that for tundra sites (Figure 4.8). This is supported by a shorter duration of 
freezeback at forest sites. For 2010-13, LSF had a mean freezeback duration of 116 days, while the mean at USF was 118 days; at tundra sites, freezeback averaged 140 days. The shorter freezeback period at forest sites is likely due, in part, to thinner snow cover early in the freezing season compared to tundra sites where wind-blown snow accumulates, and because active layers are thinner in the forest.

In summary, the warm permafrost temperatures observed on Peel Plateau are likely an integrated response to the higher air temperatures in winter caused by atmospheric temperature inversions, relatively deep snow in the tundra, and rapid snow accumulation in some areas due to wind redistribution. These conditions may apply over large spatial extents in the continuous and discontinuous permafrost zones, in areas with alpine tree lines and air temperature inversions.

The results from this chapter are also relevant to infrastructure planning, as it is apparent that the presence of tundra in the continuous permafrost zone does not necessarily imply cold $\left(<-5.0{ }^{\circ} \mathrm{C}\right)$ permafrost conditions, in contrast with common understanding (e.g., Johnston, 1981; McGregor et al., 2010). The vegetation gradient at tree line is controlled by summer air temperatures (Walker, 2000), but here, the role of winter conditions are emphasized, which do not govern the broad-scale vegetation assemblages across the ecotone, but largely define the ground thermal regime and $T_{p s}$.

The high $T_{p s}$ values measured on Peel Plateau and their association with snow depth suggest that the ice-rich permafrost is particularly susceptible to degradation following perturbations that increase snow cover. Precipitation in northern regions is likely to increase in the future (Collins et al., 2013), which may cause permafrost to warm and degrade if snow cover increases.

The relation between $T_{p s}$ and snow depth may also have important consequences for the ground thermal regime along the Dempster Highway, where the embankment and roadside shrubs that have proliferated since its construction enhance snow depth 
(Gill et al., 2014). In 2013, the Government of the Northwest Territories installed two permanent permafrost monitoring sites beside the highway in the study region. Continued research should focus on the thermal regime of permafrost where snow accumulates adjacent to the highway embankment. The compaction or removal of snow should be explored as methods to facilitate freezeback of the active layer given the strong relation between late-winter snow depth and $T_{p s}$ observed in this study. These topics are investigated in Chapter 5.

\subsection{Conclusions}

The results from the study area contrast with previous observations of permafrost temperatures declining markedly across the forest-tundra ecotone. Permafrost in the tundra environment was remarkably warm, contrary to common associations of the vegetation type with cold $\left(<-5{ }^{\circ} \mathrm{C}\right)$ ground temperatures in the continuous permafrost zone. The results of this investigation into air and ground temperatures and snow conditions across this elevational tree line allow the following conclusions to be drawn:

(1) Strong and persistent air temperature inversions in winter caused the number of freezing degree-days to vary inversely with elevation between Peel Plain and Peel Plateau, so that tundra sites were warmer than forest sites. The difference in freezing degree-days due to elevation is equivalent to a southwards shift in latitude of nearly $200 \mathrm{~km}$.

(2) Snow depths generally declined and snow cover density increased from forest to tundra, suggesting that vegetation controls regional-scale snow conditions across the ecotone. Variation in snow depth was greater at tundra sites than in the forest. Deep 
tundra snow is primarily related to topographic setting at the site scale, whereas vegetation height is a secondary factor. Tundra snow depths are greater on Peel Plateau than north of latitudinal tree line, likely due to greater precipitation in the study area.

(3) Snow may accumulate rapidly in tundra due to wind redistribution, and gradually in forest, coincident with snowfall events. This contributes to shorter freezeback duration and lower permafrost temperatures at forest sites in comparison with tundra sites with similar late-winter snow accumulation.

(4) Permafrost temperatures in tundra of Peel Plateau are remarkably high as a result of the combined effects of the winter air temperature inversions, relatively deep tundra snow depths, and rapid accumulation of snow in some tundra settings. Consequently, permafrost on Peel Plateau is more sensitive to disturbance than perennially frozen ground north of treeline in other parts of the western Arctic.

(5) An increase in $\mathrm{T}_{p s}$ with elevation may be common in Arctic mountain environments due to the prevalence of atmospheric temperature inversions in winter. In such contexts, although vegetation characteristics are governed by summer climate, permafrost conditions are critically influenced by the winter regime. 


\section{Chapter 5}

\section{The anthropogenic thermal regime: permafrost conditions at the Dempster Highway road embankment}

Developed in part from the manuscript published as:

O’Neill, H.B., Burn, C.R., and Kokelj, S.V. (2015), Field measurements of permafrost conditions beside the Dempster Highway embankment, Peel Plateau, NWT. Paper 380. Proceedings, 68th Canadian Geotechnical Conference and 7th Canadian Permafrost Conference, 21-23 September 2015, Québec City, QC. Available at: http://carleton.ca/permafrost/canadian-permafrost-conference/

\section{$5.1 \quad$ Introduction}

The western Arctic of North America has been one of the most rapidly warming environments on Earth over the past few decades (Serreze et al., 2000; Burn and Kokelj, 2009). Permafrost temperatures in the region have responded to rising air temperatures, increasing by more than $2{ }^{\circ} \mathrm{C}$ at some sites since the 1970s (Smith et al., 2010). This warming has led to increases in active-layer thickness and thaw of near-surface ground ice (Burn and Kokelj, 2009). Thaw of ice-rich permafrost causes ground subsidence and may damage infrastructure. Continued climate warming poses 
challenges to owners and operators of infrastructure in circumpolar regions (Nelson et al., 2002).

Permafrost degradation may occur irrespective of climate change near infrastructure that traps snow, thereby limiting winter ground cooling (e.g., Darrow, 2011; Fortier et al., 2011). Embankments underlying infrastructure may also disrupt natural drainage networks, causing water to accumulate, and increasing the amount of latent heat that must dissipate during freeze back of the active layer before further ground cooling may occur (Andersland and Ladanyi, 2004; de Grandpré et al., 2012). These problems may be particularly pronounced along northern highways, because the road embankments act as a windbreak, promoting snow accumulation (Auerbach et al., 1997). At the same time, the elevated permafrost table in the embankment may inhibit drainage, causing ponding at the embankment toe and increasing the potential for thaw subsidence there.

Despite the practical and political importance of the road transportation network in the western Arctic and significant investment by territorial and federal governments in maintenance and new construction projects, field measurements of permafrost conditions along the Dempster Highway have not been reported until recently (e.g., Gill et al., 2014; Burn et al., 2015; Idrees et al., 2015). Given the projected increases in air temperatures, baseline data on permafrost conditions near roads in the region are needed to calibrate modeling of the present conditions at the road and of the anticipated effects of climate change. Such modeling may inform effective maintenance.

In this chapter, ground temperatures measured at five tundra sites along the Dempster Highway on Peel Plateau are presented and compared with conditions at two sites in undisturbed tundra. The present ground thermal conditions at the sites are examined with transient numerical simulations and the effect of altering snow properties is investigated. The specific objectives are to (1) characterize permafrost 
conditions near the toe of the Dempster Highway road embankment on Peel Plateau, (2) recreate disturbed conditions near the road with a numerical model that allows the simulation of snow accumulation and ablation, (3) examine the sensitivity of the thermal model to changes in the snow accumulation regime, and (4) simulate the effect of active snow management, i.e., limiting snow depth and/or increasing snow density through mechanical compaction, to determine whether it may be an effective strategy to restrict or prevent permafrost degradation in sensitive areas. In addition, the utility of using freezing season $n$-factors to estimate ground surface temperatures for thermal modelling under snow cover at infrastructure is discussed.

\subsection{Background}

Numerous passive techniques have been developed to mitigate the disturbance to permafrost near embankments. These include thermosyphons, air convection embankments, heat drains, snow/sun sheds, and high-albedo surfaces (Doré et al., 2016). Field measurements and simulations of the effectiveness of these techniques have been widely reported from infrastructure in various regions (e.g., Lepage et al., 2012; Qin and Zhang, 2013; Darrow and Jensen, 2016; Dumais and Doré, 2016). There has been less investigation of active mitigation techniques, such as the removal of snow to increase the heat flux out of the ground in winter. Lepage et al. (2012) found that snow ploughing on a section of the Alaska Highway in Yukon, Canada, was effective in stabilizing the heat intake into the embankment toe after three years. In the first winter of ploughing, cooling of up to several degrees occurred in the embankment shoulder to a depth of about $3 \mathrm{~m}$ (Lepage and Doré, 2010). However, longer-term thermal effects of repeated snow manipulations at road embankments have not been 
reported. The technique has potential because it requires no construction of stationary infrastructure as with many passive techniques (Lepage and Doré, 2010), and thus may be targeted at sections of embankment in areas where the ground is ice rich and sensitive to degradation.

Prior to simulating snow clearing and/or compaction to address objective (4), it is necessary to reproduce present thermal conditions near the embankment in transient simulations that begin at the time of the construction. Relatively few investigations have simulated the transient disturbance to permafrost at infrastructure. Typically, these have focused on reproducing ground temperatures at and around road embankments, and projecting future degradation under climate warming scenarios (Alfaro et al., 2009; Fortier et al., 2011; Darrow, 2011; LeBlanc et al., 2014; Flynn et al., 2016). The ground surface boundary condition in these studies was defined using air temperatures modified by empirical transfer functions ( $n$-factors) for the freezing and thawing seasons. Freezing season $n$-factors summarize the effect of heat transfer through the snow cover over the entire freezing period, or at shorter time intervals (e.g., Karunaratne and Burn, 2003; LeBlanc et al., 2014). Using another approach, Kokelj et al. (2010) employed a one-dimensional surface energy balance model to define ground thermal conditions for transient simulations of northern drilling-mud sumps.

In contrast with the above studies, Smith and Riseborough (2010) used a model that allows the timing and physical properties of snow cover to be explicitly defined in a simulation of permafrost disturbance at a pipeline right-of-way in the Northwest Territories. This study uses the same modeling approach so that the snow cover properties (timing, density, depth) can be manipulated individually and their effects examined directly. The surface temperature of the ground or snow surface is determined by $n$-factors from the air temperature, but the heat flow through the snow 
pack is simulated numerically. In contrast, freezing season $n$-factors fix the surface temperature without detailed consideration of upward energy flow. Therefore, the aggregate nature of the seasonal $n$-factor may pose challenges when simulating conditions under snow cover, because the surface temperature is not only a product of air temperature and snow conditions, but of latent heat released from underlying ground, which may maintain the near-surface ground close to $0{ }^{\circ} \mathrm{C}$ in the beginning of the freezing season (e.g. Hinkel et al., 2001; O’Neill et al., 2015, Figure 9a).

\section{$5.3 \quad$ Study area}

Study sites were located along the Dempster Highway in continuous permafrost on Peel Plateau, west of Fort McPherson (Figure 5.1). The embankment height ranges from about 1 to $2.5 \mathrm{~m}$, but may be higher on sloping ground. Current permafrost conditions near the road reflect the effects of over 35 years of disturbance from road construction and operation. In many places along the embankment on Peel Plateau, large alder shrubs have established as a result of the modified snow conditions and fertilization from road dust (Gill et al., 2014; Cameron and Lantz, 2016). Due to the unsuitable fine-grained and ice-rich surface materials in the region, the embankment was built of relatively dry quarried sandstone and shale, which was packed to break down the large fractions before being topped with a gravel driving surface (Huculak et al., 1978). 


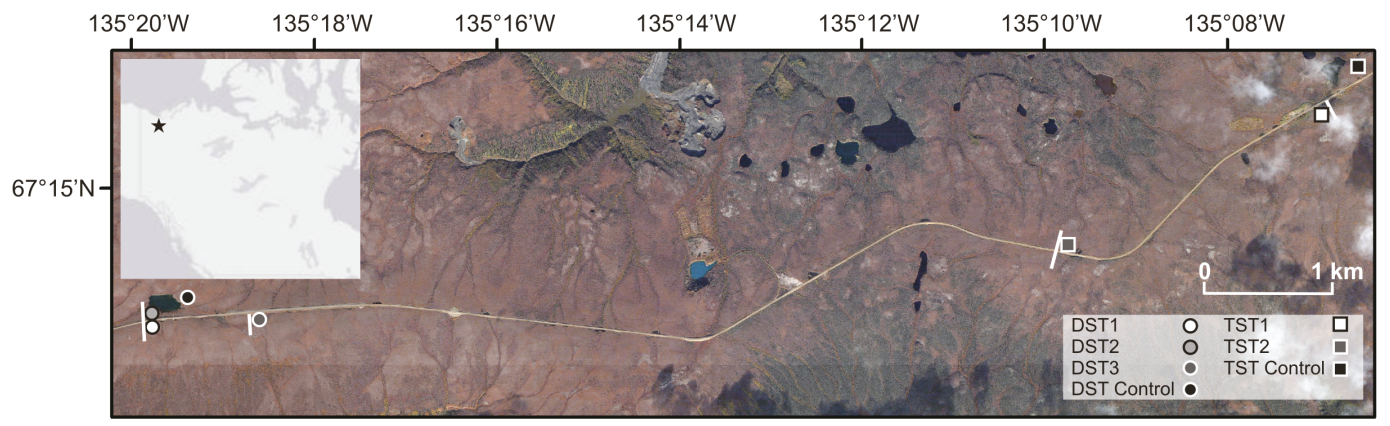

Figure 5.1: Location of study sites in dwarf-shrub tundra (DST) and tall shrub tundra (TST) on Peel Plateau. Snow depth transects are marked by white lines. 
Table 5.1: Embankment height (High $>2 \mathrm{~m}$, Low $<2 \mathrm{~m}$ ), presence of standing water, and occurrence of Equisetum spp. at each road site.

\begin{tabular}{llllll}
\hline & DST1 & DST2 & DST3 & TST1 & TST2 \\
\hline Embankment & High & Low & Low & Low & High \\
Ponding $(\mathrm{Y} / \mathrm{N})$ & $\mathrm{N}$ & $\mathrm{N}$ & $\mathrm{Y}$ & $\mathrm{N}$ & $\mathrm{N}$ \\
Equisetum $(\mathrm{Y} / \mathrm{N})$ & $\mathrm{Y}$ & $\mathrm{N}$ & $\mathrm{Y}$ & $\mathrm{Y}$ & $\mathrm{Y}$ \\
\hline
\end{tabular}




\subsection{Field methods}

\subsubsection{Site selection}

Five sites were selected for ground temperature measurements near the road and two were chosen as control sites in undisturbed terrain (Figure 5.1). Three of the road sites and one control site were in dwarf-shrub tundra (DST) on upper Peel Plateau. The two other road sites and the second control site were in tall-shrub tundra (TST) at slightly lower elevation. The road sites were selected to encompass a range of snow and moisture conditions. Therefore, road sites were placed adjacent to both low and high embankments, where the amount of snow trapping differed and moisture conditions appeared dissimilar. Areas of high moisture content were identified qualitatively by ponding within $5 \mathrm{~m}$, and the growth of Equisetum spp. Conditions at each road site are summarized in Table 5.1.

\subsubsection{Measurements}

\section{Ground temperatures}

Paired deep and shallow thermistor cables were installed at the five road sites in 2012 between 5 to $10 \mathrm{~m}$ from the embankment toe to characterize active-layer and permafrost temperatures (Figure 5.2). Two additional deep cables were installed at the control sites in 2013. Deep boreholes were drilled by water jet up to $8.5 \mathrm{~m}$ depth, but the maximum depth varied due to rock clasts encountered in the holes. The ground temperatures were recorded every four hours, and averaged to obtain daily values. Here we report annual mean ground temperature $\left(T_{g}\right)$ from the sensor nearest $5 \mathrm{~m}$ depth for 2013-14, when all instruments were in operation.

Shallow cables had two thermistors attached to a dowel and placed in the ground 
at $0.05 \mathrm{~m}$ (surface) and $1 \mathrm{~m}$ depths. Temperatures were recorded every two hours and averaged to obtain daily values. Data from the $0.05 \mathrm{~m}$ sensor were used to characterize the annual mean surface temperature $\left(T_{s}\right)$ at the road sites. $T_{s}$ was not determined for control sites because there were no shallow cables there, but are reported at a number of undisturbed sites in Chapter 4.

\section{Thaw depth}

The maximum annual thaw depth (i.e., depth to permafrost) was either estimated at each site in early-late August 2013-14 by probing with a graduated steel rod, or by examining the temperature envelope obtained from the deep cable if the thaw depth exceeded the length of the probe. For manual probing, five measurements were obtained within a radius of $1 \mathrm{~m}$ from the instrument and the average of these values is reported. Since the control sites were installed in summer 2013, thaw depths at the sites are only available from August 2014, although values from several similar sites are discussed in Chapter 4.

\section{Snow conditions}

Late-winter snow depths were measured at each site to characterize snow accumulation beside the road embankment and at control sites. Five snow depths were measured with a graduated probe within $1 \mathrm{~m}$ of each instrument in March 2013-15, and the five values were averaged to estimate snow depth at the instrument. Snow depths were also measured in 2015 along six 50-m transects perpendicular to the embankment, to examine spatial patterns of snow accumulation with distance from the road (Figure 5.1). Measurements were every metre within $15 \mathrm{~m}$ of the road, and every $2 \mathrm{~m}$ between 15 and $50 \mathrm{~m}$. Six additional transects were established along the road 

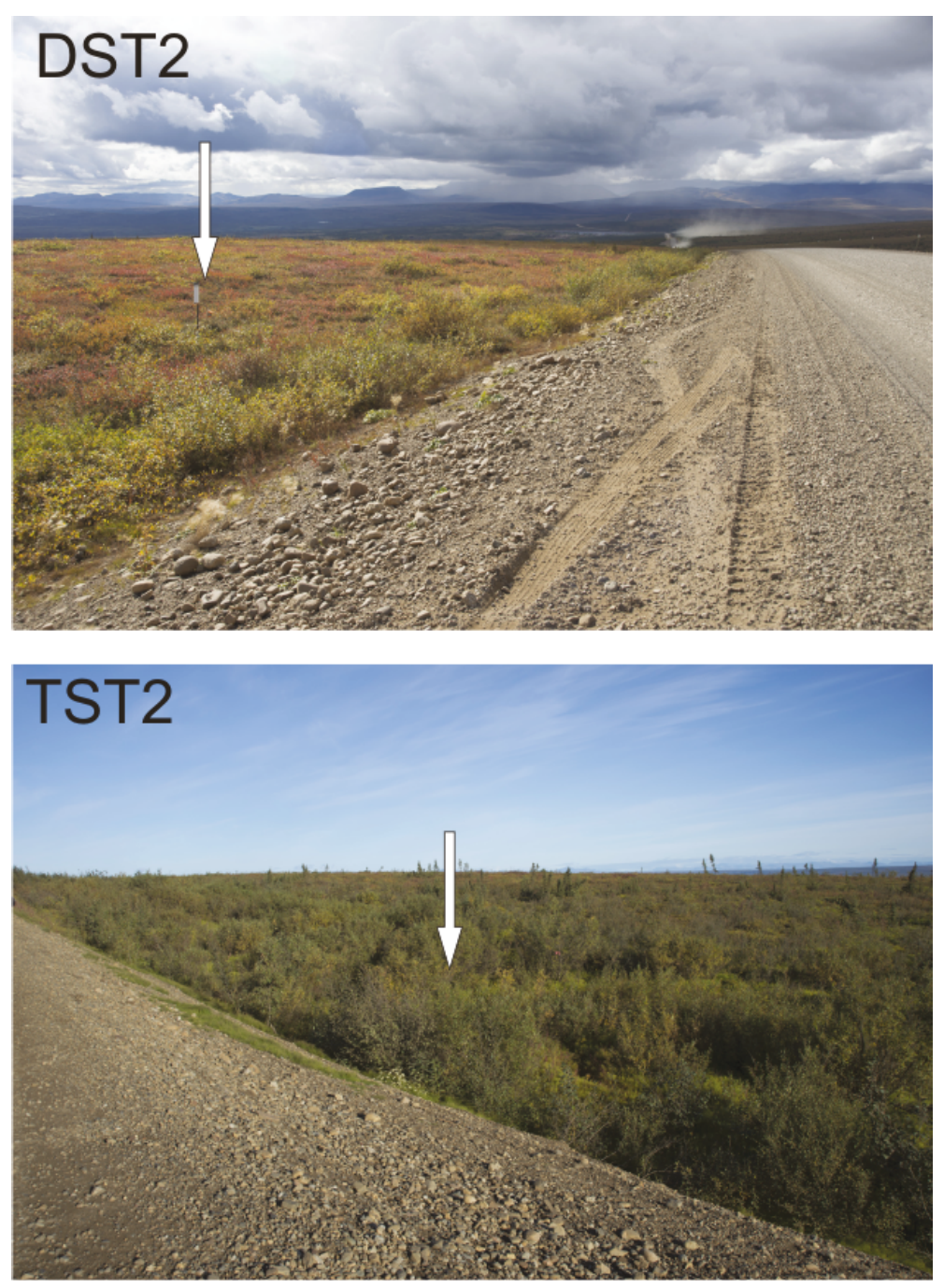

Figure 5.2: The DST2 and TST2 instrument locations. DST2 is the least disturbed, located near a low embankment and exposed to winds that carry snow away. TST2 is adjacent to a high embankment where vegetation and moisture conditions have changed as a result of deep snow accumulation. 
in 2015 in forest at lower elevation on Peel Plateau, to compare snow accumulation along the embankment between the vegetation types. Snow pits were excavated at most sites in March 2013 and 2014, and at all sites in 2015. The snow density was determined for each $0.1 \mathrm{~m}$ interval in the snow pit by weighing a $100 \mathrm{~cm}^{3}$ sample. The densities were averaged to obtain a value for the entire snowpack. The snow cover thermal conductivity $\left(\lambda_{s}, \mathrm{~W} \mathrm{~m}^{-1} \mathrm{~K}^{-1}\right)$ was estimated using Equation 3.1. Following this, the snow cover thermal resistance $\left(R_{s}, \mathrm{~m}^{2} \mathrm{~K} \mathrm{~W}^{-1}\right)$ was estimated with Equation 3.2. Snow depth in the $R_{s}$ calculation was defined as the average snow depth measured around each instrument, because this best represents the snow conditions influencing the thermal regime at the installation.

\subsection{Numerical simulations}

Numerical simulations of ground temperatures were conducted using TONE. TONE was used to obtain ground temperatures in simulations that accounted for the accumulation and ablation of a snow pack. The numerical simulations addressed objectives 2-4 of this chapter. It should be noted that the intent of the modelling was not to replicate specific points in the field, but rather to recreate general thermal conditions for sets of parameters representative of those on Peel Plateau.

\subsubsection{Ground materials and element spacing}

No detailed stratigraphic data were available from the study sites, but general substrate characteristics were observed during water-jet drilling, and during shallow core drilling elsewhere on Peel Plateau. Thus, a simplified model substrate profile was employed for most simulations, consisting of a $0.1 \mathrm{~m}$ thick layer of saturated peat underlain by $49.9 \mathrm{~m}$ of saturated, fine-grained mineral soil. The exception was a 
simulation of thermal conditions in the road centreline, which included a $2 \mathrm{~m}$ thick layer of low moisture content coarse-grained material overlying $48 \mathrm{~m}$ of fine-grained mineral soil. Thermal properties of materials are shown in Table 5.2. Temperaturedependent conductivity and unfrozen water content curves are presented in Figure 5.3. The frozen and unfrozen heat capacities were calculated using an arithmetic mean of soil constituent heat capacities (e.g., Burn, 2004, eq. 3.3.5), while temperaturedependent thermal conductivities were determined using an equation for composite ground material developed by Johansen (1977). Element spacing was $0.02 \mathrm{~m}$ near the surface and increased with depth to a maximum spacing of $2 \mathrm{~m}$ at $50 \mathrm{~m}$ depth the bottom of the simulation.

\subsubsection{Initial temperature profile}

The initial ground thermal profile was intended to represent conditions prior to construction of the Dempster Highway in the late 1970s (Figure 5.4). A 1000-year spin-up was run to establish an equilibrium ground temperature profile. The surface boundary condition was the median air temperature from three years of measurement at the DST site, modified by $n$-factors calculated from surface measurements at the DST-1 site (see Chapter 4). The Peel Plateau daily air temperatures were reduced slightly on a seasonal basis based on observed warming at Inuvik between 1950-80 and 1980-2010. This was to account for recent climate warming in the region. Differences in mean seasonal temperatures (summer, autumn, winter, spring) for the two time periods were subtracted from the measured daily air temperatures from Peel Plateau. Data from Inuvik were used for this correction because the records from Fort McPherson are insufficiently complete. No climate data have been collected from Peel Plateau 

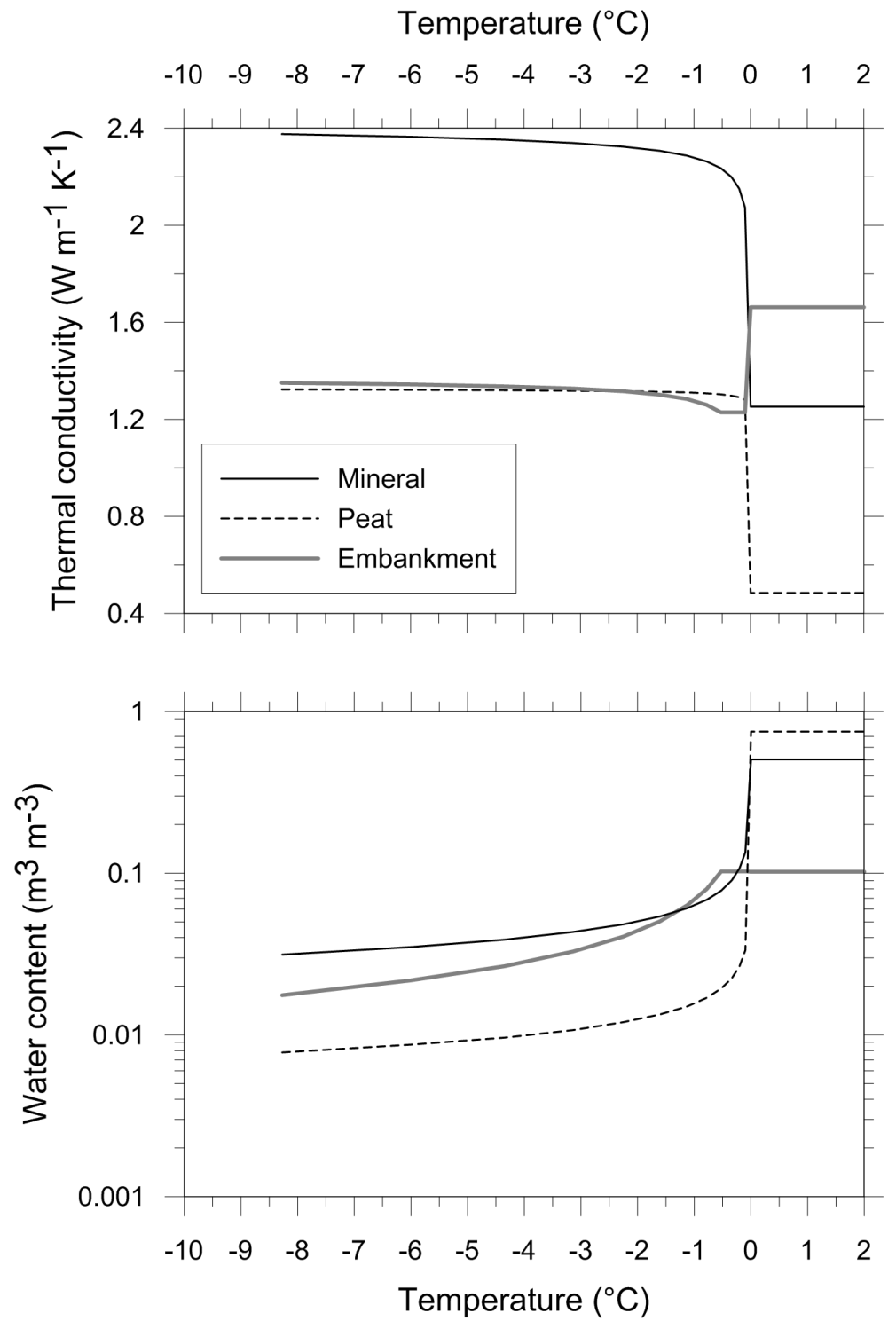

Figure 5.3: Thermal conductivity and unfrozen water content characteristic curves for the three materials in the simulations. The frozen thermal conductivity of the coarse embankment material is less than the unfrozen conductivity because of the very low moisture content (e.g., Farouki, 1981). 


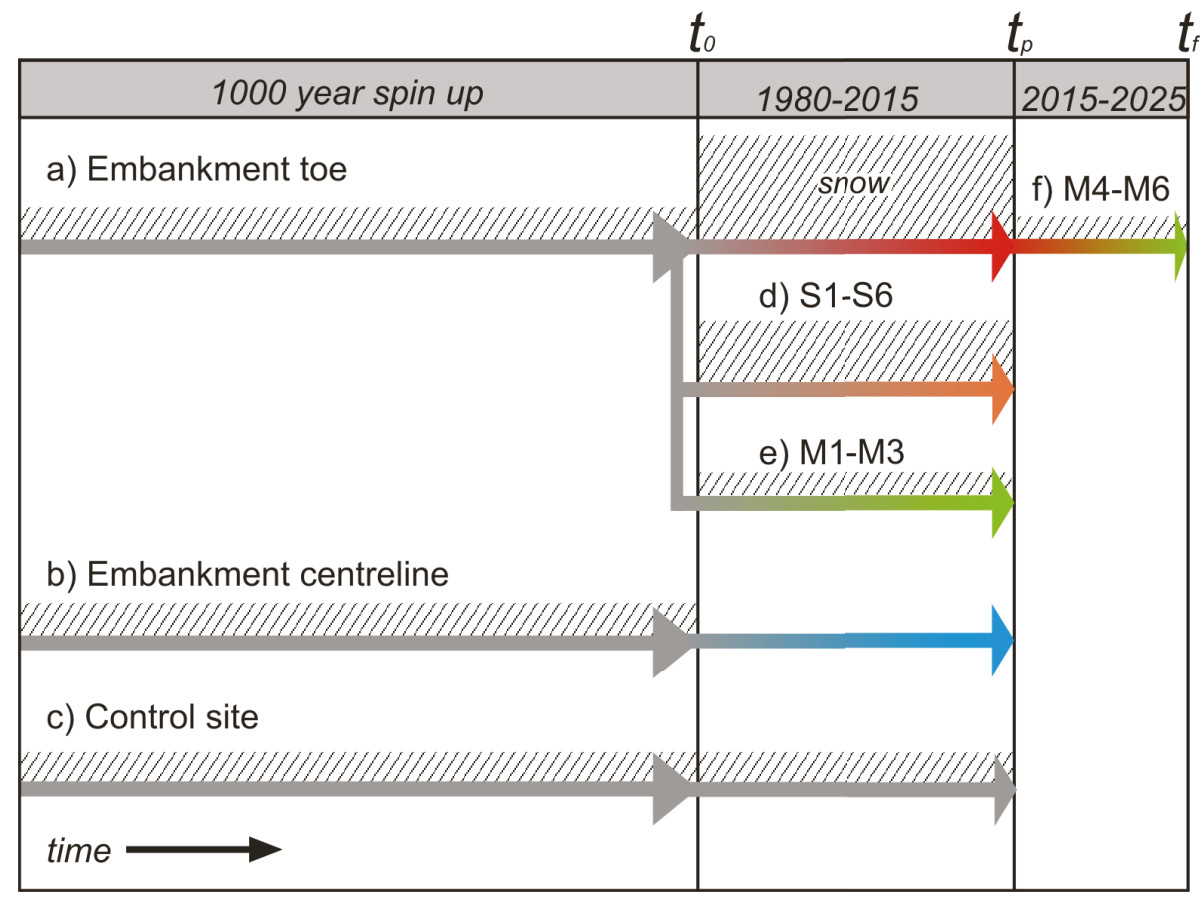

Figure 5.4: Schematic diagram of the numerical simulations showing timelines for (a) sites at the embankment toe, (b) the embankment centreline, (c) the DST control site, (d) the S1 to S6 simulations examining snow timing parameterizations, (e) the M1-M3 simulations examining long-term snow management since embankment construction, and (f) the 10-year M4-M6 simulations of snow management following 35 years of disturbance at the embankment toe. $t_{0}$ indicates embankment construction and the beginning of the transient simulations from the initial temperature profile (spin up), $t_{p}$ indicates the present, and $t_{f}$ the end of the M4-M6 simulations. Note that snow depth is different for each embankment toe site, and that the snow depths on the diagram are not to scale. 
Table 5.2: Properties of materials used in the simulations. $\lambda_{f}$ and $\lambda_{t}$ are the frozen and thawed thermal conductivities $\left(\mathrm{W} \mathrm{m}^{-1} \mathrm{~K}^{-1}\right.$ ) calculated using Kersten's method (e.g., Farouki, 1981) and an equation developed by Johansen (1977). $\theta_{v}$ is volumetric water content $\left(\mathrm{m}^{3} \mathrm{~m}^{-3}\right)$; the value for the mineral soil is the porosity for Mayo silty clay from Smith and Tice (1988), while the value for peat is from Smith and Riseborough (2010). The value for the embankment is representative of dry conditions within the coarse material. $C_{f}$ and $C_{t}$ are the frozen and thawed heat capacities $\left(\mathrm{J} \mathrm{m}^{-3} \mathrm{~K}^{-1}\right)$, and are based on an arithmetic mean of the soil constituent heat capacities (e.g., Burn, 2004, eq. 3.3.5).

\begin{tabular}{llllll}
\hline Material & $\lambda_{f}$ & $\lambda_{t}$ & $\theta_{v}$ & $C_{f}$ & $C_{t}$ \\
\hline Mineral & 2.4 & 1.3 & 0.51 & $1.9 \mathrm{E}+06$ & $3.0 \mathrm{E}+06$ \\
Peat & 1.3 & 0.5 & 0.75 & $1.9 \mathrm{E}+06$ & $3.6 \mathrm{E}+06$ \\
Embankment & 1.4 & 1.7 & 0.10 & $1.5 \mathrm{E}+06$ & $1.7 \mathrm{E}+06$ \\
\hline
\end{tabular}


prior to this study. All calculations were in daily time steps. The lower boundary condition was a constant heat flux of $0.05 \mathrm{~W} \mathrm{~m}^{-2}$.

\subsubsection{Transient simulations}

\section{Simulation initialization and boundary conditions}

Transient simulations aimed to reproduce (i) present thermal conditions in undisturbed tundra at the DST control site, (ii) disturbance observed at the five deep cables near the toe of the road embankment, and (iii) conditions at the road centreline. The model was run for 35 years to simulate the evolution of the thermal regime in 1980-2015.

For all simulations, the initial ground temperature profile was from Aug. 1 at the end of the 1000 year spin-up (Figure 5.4a-c). The ground or snow surface temperature was driven using the median of three years' air temperature measurements (2012-14) from the DST air temperature sensor described in Chapter 4. For (i) and (ii), snow cover was modelled using a linear accumulation with a constant density of $250 \mathrm{~kg} \mathrm{~m}^{-3}$. Snow density was based on average late-winter conditions measured in the field. Snow cover was initially specified to begin on the first day of freezing conditions (Sep. 24), however these values were adjusted slightly for each site to calibrate the resulting thaw depths and ground temperatures with field conditions (Table 5.3). The snow commencement dates used in the simulations are within the dates of snow arrival observed in the field, as described below.

The time to reach maximum snow depth at each site was specified from a minimum of 30 days (TST2) to a maximum of 120 days (DST1). These accumulation regimes correspond to maximum snow depths being reached between late-October and lateJanuary. The rapid accumulation at TST2 is reasonable for this environment, as 
O'Neill et al. (2015) observed deep snow accumulation within a few weeks of freezing temperatures near the snow fence and at the base of a steep tundra slope (see Chapter 4); the high embankment at TST2 is comparable to these settings. Snow cover is commonly assumed to accumulate over the freezing season with the square root of time (e.g., Zhang, 1993; Riseborough, 2007; Smith and Riseborough, 2010) so that the majority of the snow cover is established within the first few months of the freezing season. The linear accumulation specified for the sites in this study represents a similar regime, though snow cover is slightly lower early in the season in the linear case compared with a parabolic function.

The maximum snow depth for each site was specified as the median value of

three late-winter snow measurements from the field, rounded to the nearest $0.25 \mathrm{~m}$ (Table 5.3). For example, measured snow depths at DST1 were 1.24, 1.00, and 1.70 $\mathrm{m}$ in 2013, 2014, and 2015, respectively, so the maximum snow depth in the DST1 simulation was $1.25 \mathrm{~m}$. Snow ablation at the end of winter occurred at a rate of 1.5 kg m${ }^{-2}$ per degree-day (e.g., Smith and Riseborough, 2010).

When snow was absent, the ground surface freezing $n$-factor had a value of 1.0. A freezing $n$-factor of 0.9 was assigned to the embankment (e.g. Andersland and Ladanyi, 2004; Darrow, 2011). When present, the snow surface had an n-factor of 1.0. For each site in (i) and (ii), thawing-season $n$-factors were calculated using measured air temperatures, and ground temperatures recorded at $0.05 \mathrm{~m}$ depth at the shallow cables. The embankment was assigned a thawing $n$-factor of 1.1.

\section{Examining the effect of the snow accumulation regime at the embankment toe}

Additional 35-year transient conditions were simulated to examine the effect of the snow initiation date and the number of days taken to establish maximum snow cover 
for conditions representative of the embankment toe (Figure 5.4d). Maximum snow

depth was set as $1.0 \mathrm{~m}$ and the thawing $n$-factor to 0.7 for all cases to isolate the influence of the snow timing parameters. A $1.0 \mathrm{~m}$ snow pack was specified as this represents an intermediate value of snow accumulation measured at the embankment sites (Table 5.1). The parameters for each simulation are shown in Table 5.4.

\section{Snow management simulations}

Further transient simulations examined the effect of limiting snow depth and increasing snow density to mimic potential mechanical snow management at the embankment toe.

Three scenarios (M1-M3; Figure 5.4e) began with the initial (undisturbed) temperature profile and simulated ground temperatures over 35 years. These scenarios represent the effect of long-term snow management immediately following embankment construction. The maximum snow cover was set to $0.3 \mathrm{~m}$, and density varied to account for mechanical compaction during the snow removal process (Table 5.5). The maximum snow depth was set to $0.3 \mathrm{~m}$ to allow a base for machinery operation without significant disturbance to the ground surface. The maximum snow density simulated was $400 \mathrm{~kg} \mathrm{~m}^{-3}$, which is attainable after only two passes of a snow roller (Abele, 1990, Figure 51).

An additional three scenarios (M4-M6; Figure 5.4f) began with the disturbed conditions simulated at TST2 after 35 years, and the model was run for 10 years with the same snow depth and densities as M1-M3 (Table 5.5). These simulations represent the potential effect of future snow management activities at disturbed sites where significant permafrost degradation has already occurred. 
Table 5.3: Snow parameters and $n$-factors from field measurements used to simulate present ground thermal conditions at the embankment toe sites, undisturbed (control) tundra, and the road centreline. Snow initiation refers to the number of days between the onset of freezing surface temperatures and snow cover commencement.

\begin{tabular}{llllllll}
\hline & DST1 & DST2 & DST3 & TST1 & TST2 & DST control & Centreline \\
\hline Max snow (m) & 1.25 & 0.5 & 1.5 & 1 & 1.75 & 0.5 & 0 \\
Snow initiation & 7 & 7 & 7 & 10 & 0 & 7 & n/a \\
Days to max snow & 120 & 100 & 90 & 90 & 30 & 90 & n/a \\
$n_{t}$ & 0.62 & 0.78 & 0.67 & 0.77 & 0.70 & 0.70 & 1.1 \\
\hline
\end{tabular}


Table 5.4: Parameterizations for six snow accumulation simulations. Snow initiation refers to the number of days after freezing air temperatures that snow accumulation commences. Resulting $T_{g}$ (5 m depth), $T_{s}$, and thaw depths from year 35 of the simulations are also presented.

\begin{tabular}{lllllll}
\hline & $\mathrm{S} 1$ & $\mathrm{~S} 2$ & $\mathrm{~S} 3$ & $\mathrm{~S} 4$ & $\mathrm{~S} 5$ & $\mathrm{~S} 6$ \\
\hline Max snow $(\mathrm{m})$ & 1 & 1 & 1 & 1 & 1 & 1 \\
Snow initiation & 0 & 14 & 0 & 0 & 14 & 14 \\
Days to max snow & 30 & 30 & 90 & 120 & 90 & 120 \\
$n_{t}$ & 0.7 & 0.7 & 0.7 & 0.7 & 0.7 & 0.7 \\
\hline$T_{g}\left({ }^{\circ} \mathrm{C}\right)$ & -0.1 & -0.3 & -0.2 & -0.3 & -0.5 & -0.9 \\
$T_{s}\left({ }^{\circ} \mathrm{C}\right)$ & 1.9 & 1.5 & 1.6 & 1.4 & 1.0 & 0.4 \\
ALT $(\mathrm{m})$ & 4.4 & 2.6 & 3.2 & 2.1 & 1.2 & 1.1 \\
\hline
\end{tabular}


Table 5.5: Parameterizations for six snow management simulations that varied snow density $\left(\mathrm{kg} \mathrm{m}^{-3}\right)$. Snow initiation refers to the number of days after freezing air temperatures that snow accumulation commences. All $n_{t}$ values were 0.7 , as in S1-S6. The initial temperature profile for M1-M3 is from the undisturbed simulation (Und., Figure 5.7). Resulting $T_{g}$ (5 $\mathrm{m}$ depth), $T_{s}$, and active-layer thicknesses (ALT) from the final year of the simulations are also presented.

\begin{tabular}{lllllll}
\hline & M1 & M2 & M3 & M4 & M5 & M6 \\
\hline Simulation duration & 35 & 35 & 35 & 10 & 10 & 10 \\
Initial T profile & Und. & Und. & Und. & TST2 & TST2 & TST2 \\
Max. snow $(m)$ & 0.3 & 0.3 & 0.3 & 0.3 & 0.3 & 0.3 \\
Snow initiation & 0 & 0 & 0 & 0 & 0 & 0 \\
Snow density & 250 & 300 & 400 & 250 & 300 & 400 \\
Days to max snow & 30 & 30 & 30 & 30 & 30 & 30 \\
\hline$T_{g}\left({ }^{\circ} \mathrm{C}\right)$ & -2.2 & -3.7 & -5.7 & -0.3 & -1.9 & -4.1 \\
$T_{s}\left({ }^{\circ} \mathrm{C}\right)$ & -0.9 & -2.5 & -4.8 & -0.4 & -2.1 & -4.5 \\
ALT $(\mathrm{m})$ & 1.0 & 0.9 & 0.8 & 1.1 & 1.0 & 0.9 \\
\hline
\end{tabular}




\subsection{Results}

The results section is subdived into two parts: (1) field measurements and (2) simulation results. The field measurements section characterizes ground temperatures, thaw depths, and snow conditions at the instrumented sites. The simulation section presents the results of the spin-up, the simulations of present-day thermal conditions at the road embankment, and the scenarios in which the snow accumulation regime is manipulated.

\subsubsection{Field measurements}

\section{Ground temperatures}

Annual mean ground temperatures $\left(T_{g}\right)$ near $5 \mathrm{~m}$ depth at the road sites were between 0.5 and $2.5^{\circ} \mathrm{C}$ higher than at the control sites, except at DST2 (Table 5.6, Figure 5.5). $\mathrm{T}_{g}$ ranged from 0.0 to $-2.2{ }^{\circ} \mathrm{C}$ at the road sites, and were -1.8 and $-2.6{ }^{\circ} \mathrm{C}$ at the DST and TST control sites, respectively. $T_{g}$ at control sites were consistent with those measured by O'Neill et al. (2015). Annual mean ground temperature at DST2 was $-2.2{ }^{\circ} \mathrm{C}$, similar to the values for the control sites. Three of the road sites had $T_{g}>-$ $1.0^{\circ} \mathrm{C}$. Annual mean surface temperatures were $>0{ }^{\circ} \mathrm{C}$ at all road sites except DST2, and ranged from 1.3 to $2.1{ }^{\circ} \mathrm{C}$. At DST2, $T_{s}$ was $-1.6{ }^{\circ} \mathrm{C}$ (Table 5.6). Curvatures of the annual mean ground temperature envelopes indicate that permafrost is presently degrading at all road sites except DST2 (Figure 5.5).

\section{Thaw depths}

There was a large variation in thaw depth at road sites, from 0.9 to $5.3 \mathrm{~m}$, while at the DST and TST control sites, the ALTs were 0.7 and $0.6 \mathrm{~m}$, respectively (Table 

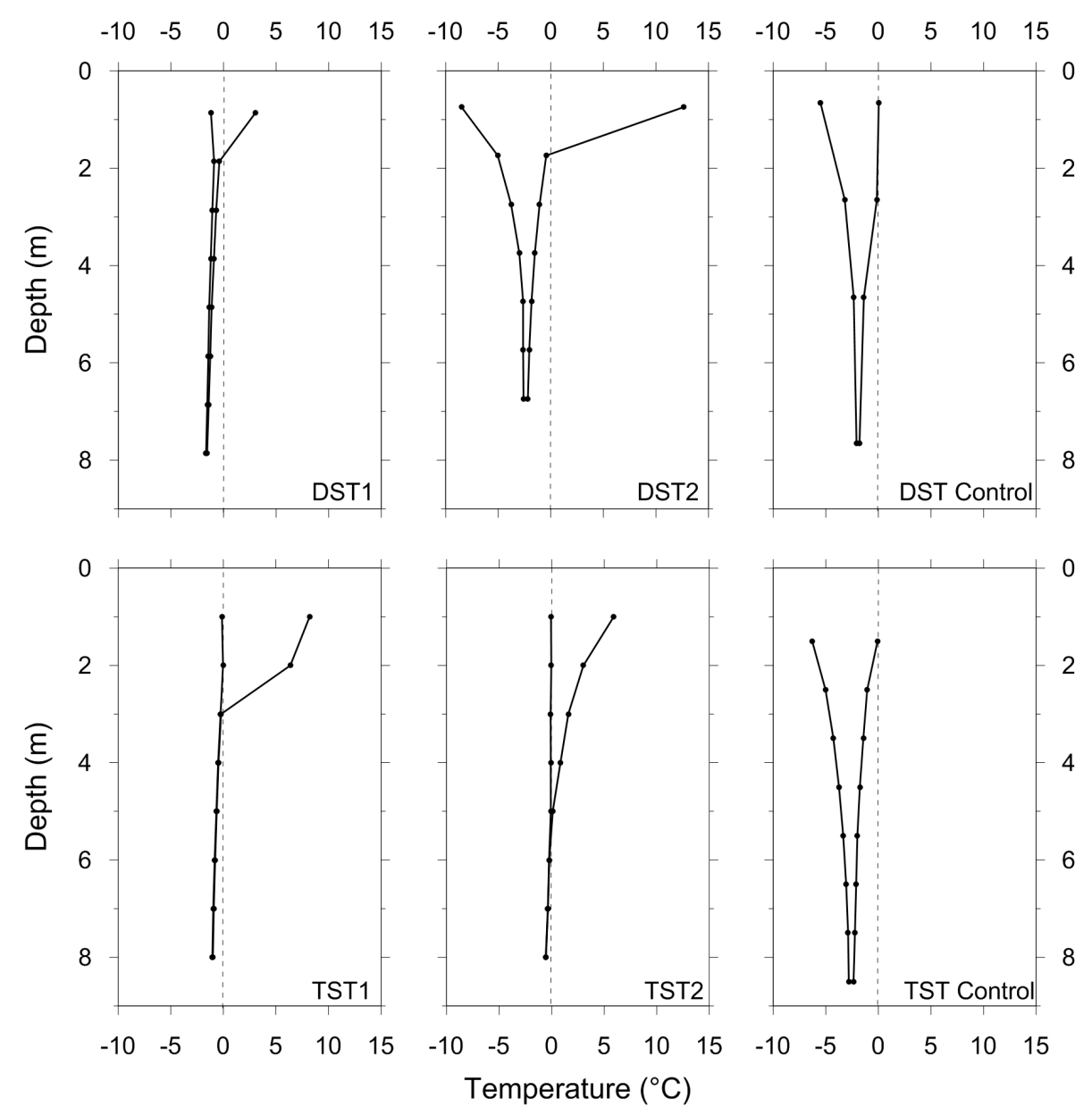

Figure 5.5: Temperature envelopes from the deep cables in 2013-14 at embankment toe sites and control sites. The dots on the lines indicate the position of thermistors. Note that DST3 is not plotted here. 
Table 5.6: Annual mean ground temperatures near $5 \mathrm{~m}$ depth $\left(T_{g}\right)$, at the surface $\left(T_{s}\right)$, and active-layer thickness (ALT) or thaw depth, late-winter snow depth (March), snow thermal resistance, and snow arrival dates (written as S/O dd; where $\mathrm{S}=$ Sept., $\mathrm{O}=$ Oct., dd = day) at the seven field sites. The $T_{s}$ ranges and snow arrival dates reported for the control sites are from nearby sites in undisturbed tundra (O'Neill et al., 2015), as there were no shallow cables at the control sites.

\begin{tabular}{|c|c|c|c|c|c|c|c|}
\hline & DST1 & DST2 & DST3 & DST Control & TST1 & TST2 & TST Control \\
\hline Distance from embankment (m) & 5 & 6 & 7 & 150 & 5 & 8 & 50 \\
\hline$T_{g}\left({ }^{\circ} \mathrm{C}\right)$ & -1.3 & -2.2 & -0.7 & -1.8 & -0.7 & 0 & -2.6 \\
\hline$T_{s}\left({ }^{\circ} \mathrm{C}\right)$ & 1.6 & -1.6 & 1.8 & -0.5 to -3.4 & 2.1 & 1.3 & -1.8 to -1.9 \\
\hline ALT/thaw depth $(\mathrm{m})$ & $1-1.7^{*}$ & 0.9 & $3.4^{*}$ & 0.7 & $3.0^{*}$ & $5.3^{*}$ & 0.6 \\
\hline Snow depth $(\mathrm{m})$ & $1.2-1.7$ & $0.4-0.8$ & $0.9-1.8$ & $0.4-0.8$ & $0.9-1.4$ & $1.1-2.2$ & $0.4-0.5$ \\
\hline Snow thermal resistance $\left(\mathrm{m}^{2} \mathrm{~K} \mathrm{~W}^{-1}\right)$ & $7-11$ & $4-5$ & $8-10$ & $4-7$ & $11-14$ & $10-13$ & $3-5$ \\
\hline \multirow{3}{*}{ Snow arrival date } & - & - & $\mathrm{O} 17^{2}$ & $\mathrm{O} 17^{2}$ & $\mathrm{~S} 11^{2}$ & $\mathrm{~S} 26^{2}$ & $\mathrm{O} 17^{2}$ \\
\hline & $\mathrm{S} 16^{3}$ & $\mathrm{~S} 17^{3}$ & $\mathrm{~S} 17^{3}$ & $\mathrm{~S} 17^{3}$ & $\mathrm{~S} 17^{3}$ & $\mathrm{~S} 17^{3}$ & $\mathrm{~S} 17^{3}$ \\
\hline & $\mathrm{S} 23^{4}$ & $\mathrm{~S} 23^{4}$ & - & $\mathrm{S} 23^{4}$ & $\mathrm{O} 4^{4}$ & - & $\mathrm{S} 23^{4}$ \\
\hline
\end{tabular}

*estimated from ground temperature envelope

$2,3,4$ indicate 2012,2013 , and 2014, respectively 
5.6). However, thaw depths at the control sites were probed on August 8 in 2014, so maximum thaw was likely not attained by that date. At these two sites, the maximum thaw depth attained in 2014 was not estimated using the deep cable temperature envelopes because the thermistor spacing was $1 \mathrm{~m}$, and the errors associated with such an estimate may be about 0.3-0.4 m (Riseborough, 2008, Figure 3). Thin frozen layers were encountered during probing in August 2014 between 0.5 and $0.6 \mathrm{~m}$ depth, and were underlain by unfrozen ground at several sites near the road embankment. These sites were at TST2, at a monitoring site on Peel Plateau described in Idrees et al. (2015), and at a snow fence near the embankment (see Chapter 6). This indicates that taliks have developed in some places near the embankment.

\section{Snow conditions}

Deep snow accumulated annually along the road embankment. Snow depths at all road sites except DST2 were commonly $>1 \mathrm{~m}$, and measured up to $2.2 \mathrm{~m}$. These depths are considerably greater than at control sites and DST2, which ranged from 0.4 to $0.8 \mathrm{~m}$ (Table 5.6$)$.

Snow thermal resistance was greater at road sites than at control sites, except at DST2 where the values were similar to those for control sites (Table 5.6). The median snow thermal resistance for all road site snow pits was $9.6 \mathrm{~m}^{2} \mathrm{~K} \mathrm{~W}^{-1}(\mathrm{n}=13)$. A Mann-Whitney U test indicated that the median at control sites was significantly lower $\left(4.5 \mathrm{~m}^{2} \mathrm{~K} \mathrm{~W}^{-1} ; \mathrm{n}=4, \mathrm{p}=0.02\right)$. The high thermal resistances at road sites were due to greater snow depths beside the embankment, as average snow pack densities for the road sites (230-350 $\mathrm{kg} \mathrm{m}^{-3}, \mathrm{n}=13$ ) were statistically indistinguishable (MannWhitney U) from those at the control sites $\left(230-270 \mathrm{~kg} \mathrm{~m}^{-3}, \mathrm{n}=4, \mathrm{p}=0.11\right)$.

The effect of the road embankment on snow accumulation in tundra is illustrated 
with the data collected along transects in 2015. In tundra, snow accumulation was enhanced between about 5 and $15 \mathrm{~m}$ from the roadside, and then decreased with distance from the embankment (Figure 5.6a). In contrast, there was no pronounced change in snow depth away from the embankment in forest, and snow depths were similar over the length of the transects, presumably due to a lack of wind redistribution (Figure 5.6b).

The annual start date of a continuous winter snow cover at road sites was estimated by examining ground temperatures from the thermistors at $0.05 \mathrm{~cm}$ depth. Snow was assumed to cover the ground when the diurnal variation in surface temperature dropped below $1^{\circ} \mathrm{C}$ and persisted below this value (Burn and Zhang, 2009; O'Neill et al., 2015). Snow cover began to accumulate at all the road sites between September 11 and October 17 in 2012-14 (Table 5.6).

\subsubsection{Simulation results}

The initial temperature profile from the spin-up conducted to establish conditions representative of undisturbed tundra in the 1970s is shown in Figure 5.7. The annual mean temperature at $5 \mathrm{~m}$ depth was $-2.9^{\circ} \mathrm{C}$, lower than measured at the control sites (DST control: $-1.8^{\circ} \mathrm{C}$; TST control: $-2.6{ }^{\circ} \mathrm{C}$ ).

\section{Reproducing conditions near the embankment}

The model generally reproduced present annual mean ground temperatures at the toe of the embankment, though the performance varied between sites and at different depths (Figure 5.8). The differences between measured and modeled $T_{g}$ values (5 m depth) were between $0.1{ }^{\circ} \mathrm{C}(\mathrm{TST} 2)$ and $0.9^{\circ} \mathrm{C}(\mathrm{DST} 1)$. The median difference between measured and modeled temperatures at all thermistor depths for the five 

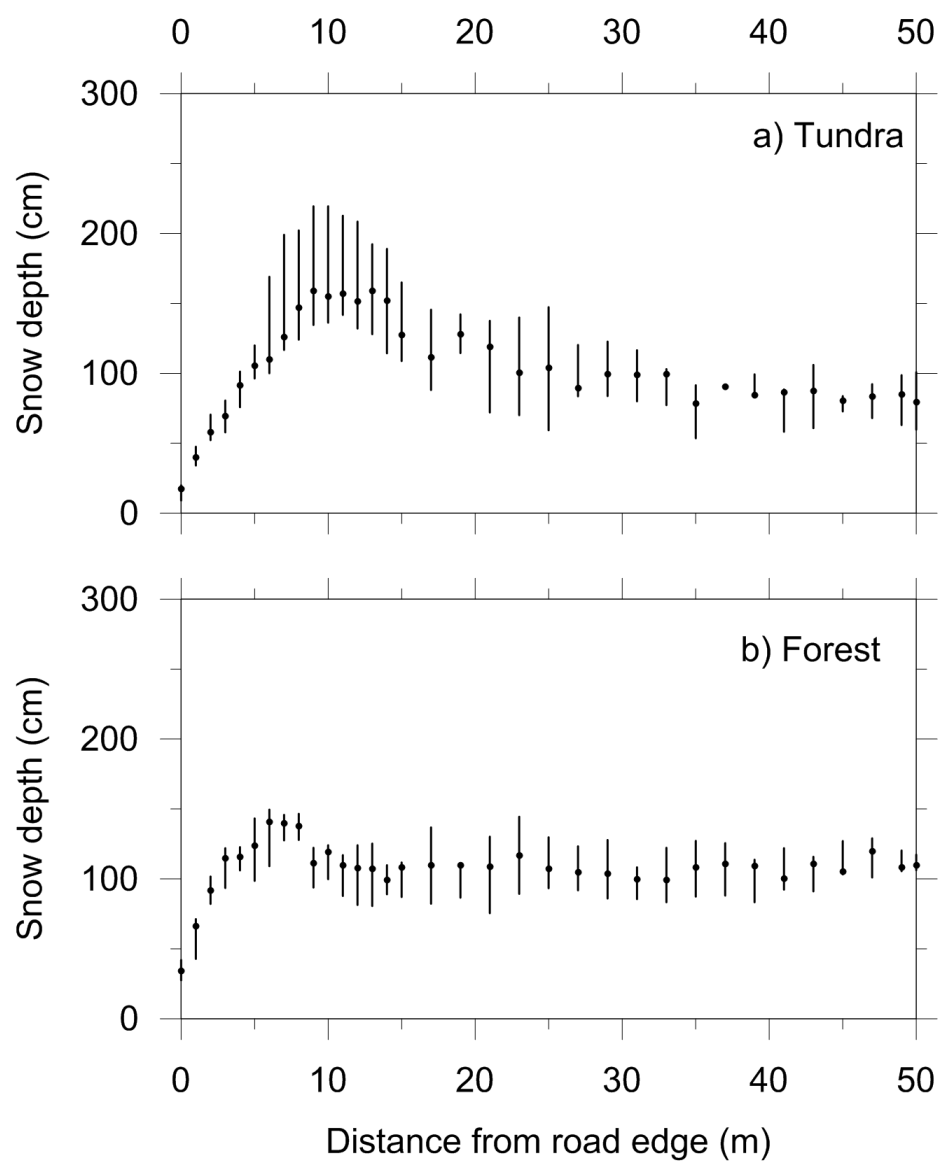

Figure 5.6: Snow accumulation measured in March 2015 at (a) six tundra and (b) six forest transects. The dots are the median depths from the transects, and the vertical lines represent the interquartile ranges. 


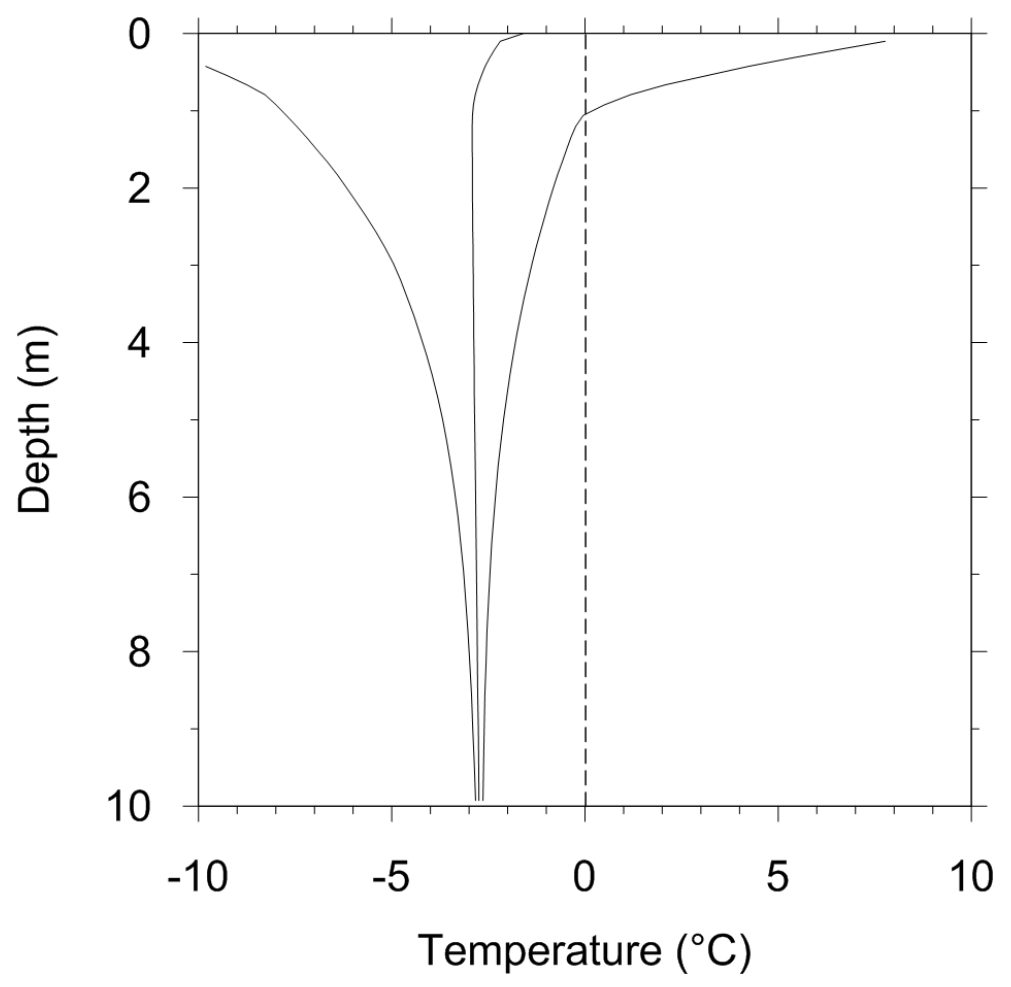

Figure 5.7: Temperature envelope for the equilibrium spin-up used as the initial condition in subsequent 35-year transient simulations. Measured air temperatures on Peel Plateau were reduced based on the record from Inuvik to represent cooler conditions in the late 1970s, when the road was constructed. The annual mean temperature at $5 \mathrm{~m}$ depth was $-2.9^{\circ} \mathrm{C}$, and thaw depth was $1.0 \mathrm{~m}$. 
embankment toe sites was between $0.1^{\circ} \mathrm{C}(\mathrm{TST} 2)$ and $0.9^{\circ} \mathrm{C}(\mathrm{DST} 1)$. In most cases, the differences in temperature decreased with depth, except for DST1 (Figure 5.8).

Temperatures from the road embankment centreline simulation were compared with measured values from the highway monitoring site on Peel Plateau presented in Idrees et al. (2015). Annual mean temperatures within the embankment were simulated reasonably well, with a median difference for the top four thermistors of $0.5^{\circ} \mathrm{C}$ (Figure 5.8f). Below $2 \mathrm{~m}$, the difference between measured and modeled values increased gradually with depth. This is likely due to lateral heat flow from the warm ground adjacent to the embankment, which is not accounted for in the 1-d simulation. Conditions at the DST control site were closely reproduced (Figure 5.8g), with the median difference between measured annual mean temperatures from all thermistor depths and modeled values being $0.1^{\circ} \mathrm{C}$.

Measured and modeled ground surface temperatures between 2012-15 (0.05 m depth) are presented for four sites in Figure 5.9. The influence of the lower snow depths in winter 2013-14 is apparent from the measured values at DST2. Modeled values do not capture the interannual variation as the snow conditions and air temperatures did not vary between years through the simulations. Thus, in some years the winter ground surface temperatures were reproduced closely (e.g. TST1 in 2013-14), while in others (DST2 in 2013-14) there were differences in daily surface temperatures of about $10^{\circ} \mathrm{C}$. However, at the four degrading sites at the embankment toe, winter ground surface temperatures were closely reproduced.

There are several systematic characteristics exhibited by the modeled ground surface temperatures. In particular, snow cover thawed later in the simulations than in the field at all sites in every year. This is apparent from the onset of positive surface 


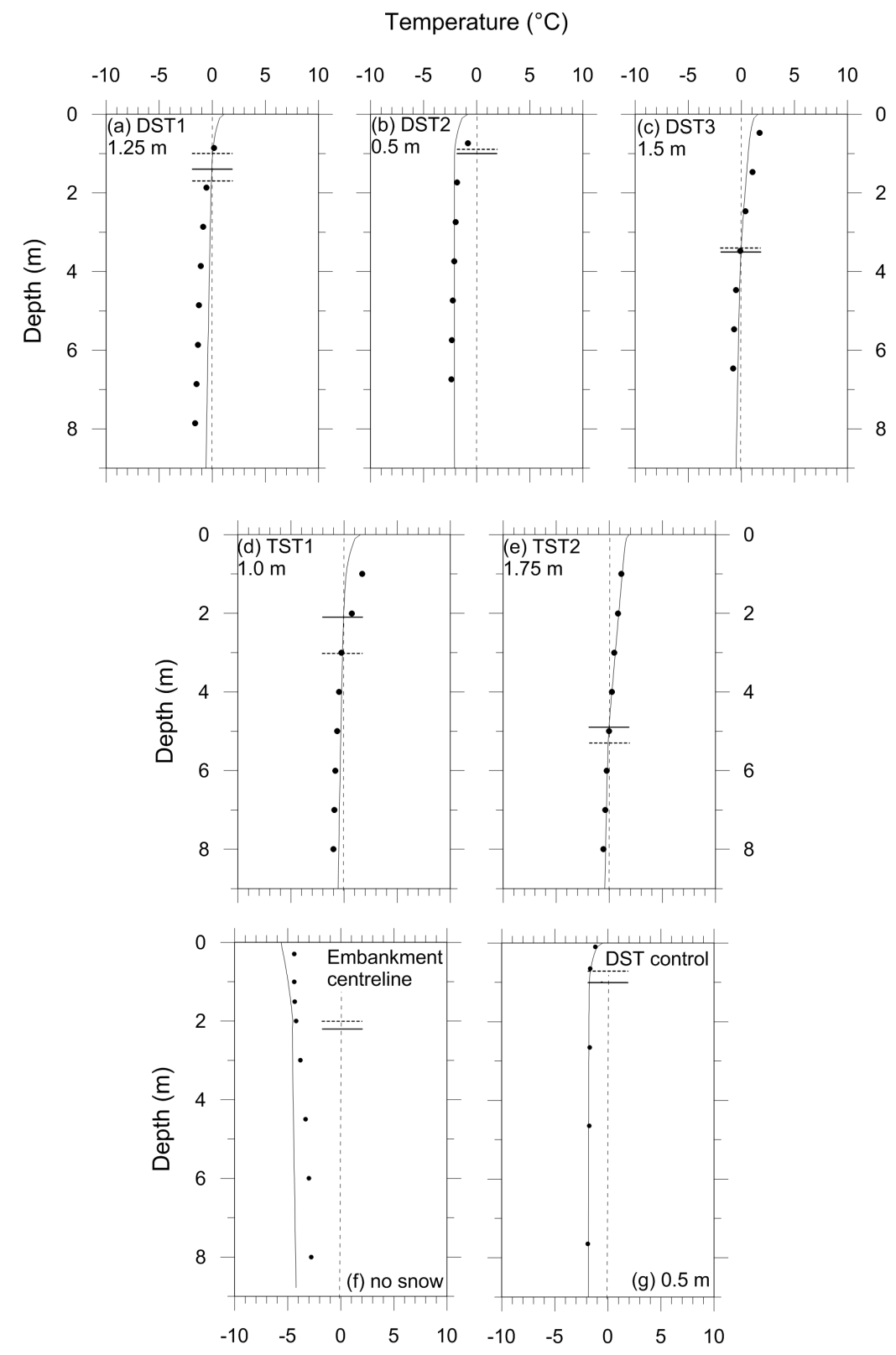

Figure 5.8: Measured (dots) and modeled (solid lines) annual mean ground temperatures for the five sites at the embankment toe (a to e), at the embankment centreline (f) (measured values from Idrees et al. (2015)), and for the DST control site $(\mathrm{g})$. The solid horizontal line is the modeled thaw depth after 35 years of disturbance, and the dashed horizontal lines are the measured values from Table 5.6. Maximum snow depths used in the simulations are shown under each site label. 

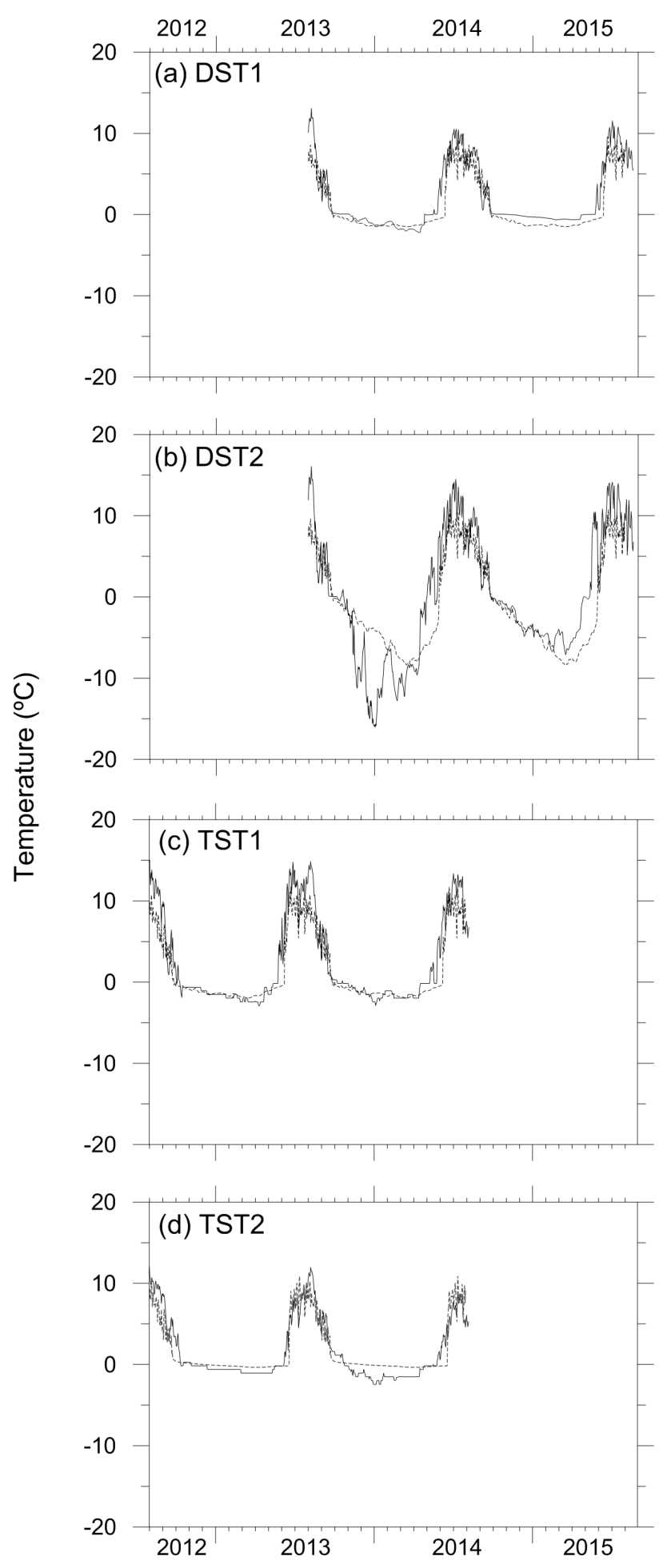

Figure 5.9: Measured (solid) and modeled (dashed) ground surface temperatures (0.05 m depth) between 2012-2015 for sites at the embankment toe. Note that DST3 is not plotted here. 
temperatures, which occurred between April and June depending on the snow depth (Figure 5.9). Modeled summer surface temperatures were also commonly lower than measured temperatures, by up to nearly $10{ }^{\circ} \mathrm{C}$, at DST1 and 2, and TST1.

There was some variation in the ability of the simulations to reproduce measured thaw depths (Figure 5.8). Among all sites, the median difference between measured and modeled thaw depth was $0.3 \mathrm{~m}$. There was a maximum difference of $0.9 \mathrm{~m}$ for TST1, and a minimum of $0.1 \mathrm{~m}$ for DST2 and DST3. In general, the simulations at sites with colder ground and little snow (DST2, Embankment centreline, DST control) best reproduced measured thaw depths, with a median difference of $0.2 \mathrm{~m}$ at these three sites (Figure 5.8). However, it should be noted again that thaw depth was probed on August 8 at DST2 and DST control, when thawing was likely not at a maximum, which may have contributed to some of the difference between measured and modeled values.

The implications of the differences between measured and modeled temperature and thaw depths are developed in the discussion below.

\section{Snow accumulation regime simulations}

The S1-S6 simulations examined the effect of changing the starting date for snow accumulation and its rate (see Table 5.4). S1 and S2 represented rapid snow drifting scenarios, S3 and S4 represented more gradual snow accumulation, and S5 and S6 represented delayed drifting scenarios with gradual snow accumulation. Results from year 35 of the simulations are shown in Figures 5.10-5.12.

$\mathrm{S} 1$ and S2 demonstrate the effect of a short delay in snow commencement on winter ground temperatures and, most notably, the resulting thaw depth. The two week delay in S2 allowed significant heat loss from the active layer, which is apparent from the initial cooling and persistence of lower surface temperatures throughout the 
freezing season (Figure 5.10a). A result of this heat loss early in the freezing season was reduced thaw depth by year 35 in S2 (2.6 m) compared to S1 (4.4 m) (Table 5.4). A talik nearly formed by year 35 in $\mathrm{S} 1$, indicated by the closing of the $0{ }^{\circ} \mathrm{C}$ isotherms just prior to downward thawing from the surface (Figure 5.10b). Freezeback in S1 took about 5 months longer than in S2. Summer thaw commenced at the same rate in $\mathrm{S} 1$ and $\mathrm{S} 2$, but as ground just below $0{ }^{\circ} \mathrm{C}$ was encountered between 1 and $4 \mathrm{~m}$ depth in $\mathrm{S} 1$, thawing progressed more rapidly. Differences in $T_{g}$ between $\mathrm{S} 1$ and $\mathrm{S} 2$ were small, because the greater heat extraction in S2 was occupied in phase change rather than in cooling by sensible heat (Figure 5.10, Table 5.4).

S3 and S4 demonstrate the influence of more gradual snow accumulation. The greater number of days to maximum snow depth had a relative effect of lowering ground surface temperatures and thaw depth. However, the difference in ground surface temperature between S3 and S4 occurred later in the freezing season than in $\mathrm{S} 1$ and $\mathrm{S} 2$, because snow initiated on the same day in the former scenarios. The thaw depth was $1.1 \mathrm{~m}$ thinner in S4 than in S3, and freezeback was completed about two months earlier (Figure 5.11, Table 5.4). Downward thaw from the surface in summer began at similar rates, but increased in July and August in S3 as warmer ground was encountered at depth (Figure 5.11b,c). As in S1 and S2, there was little difference in $T_{g}$ between $\mathrm{S} 3$ and $\mathrm{S} 4$ because heat exchange was mainly occupied by phase change in the near surface rather than in sensible heating or cooling.

S5 and S6 highlight the combined effects of a delayed snow commencement and longer snow accumulation. The primary difference between these scenarios and S1S4 is a more pronounced sensible cooling of the ground, both at the surface and at depth, and resulting shallower thaw depths (Figure 5.12). Surface temperatures reached near $-4{ }^{\circ} \mathrm{C}$ in $\mathrm{S} 6$, which facilitated significant winter heat loss as the latent 

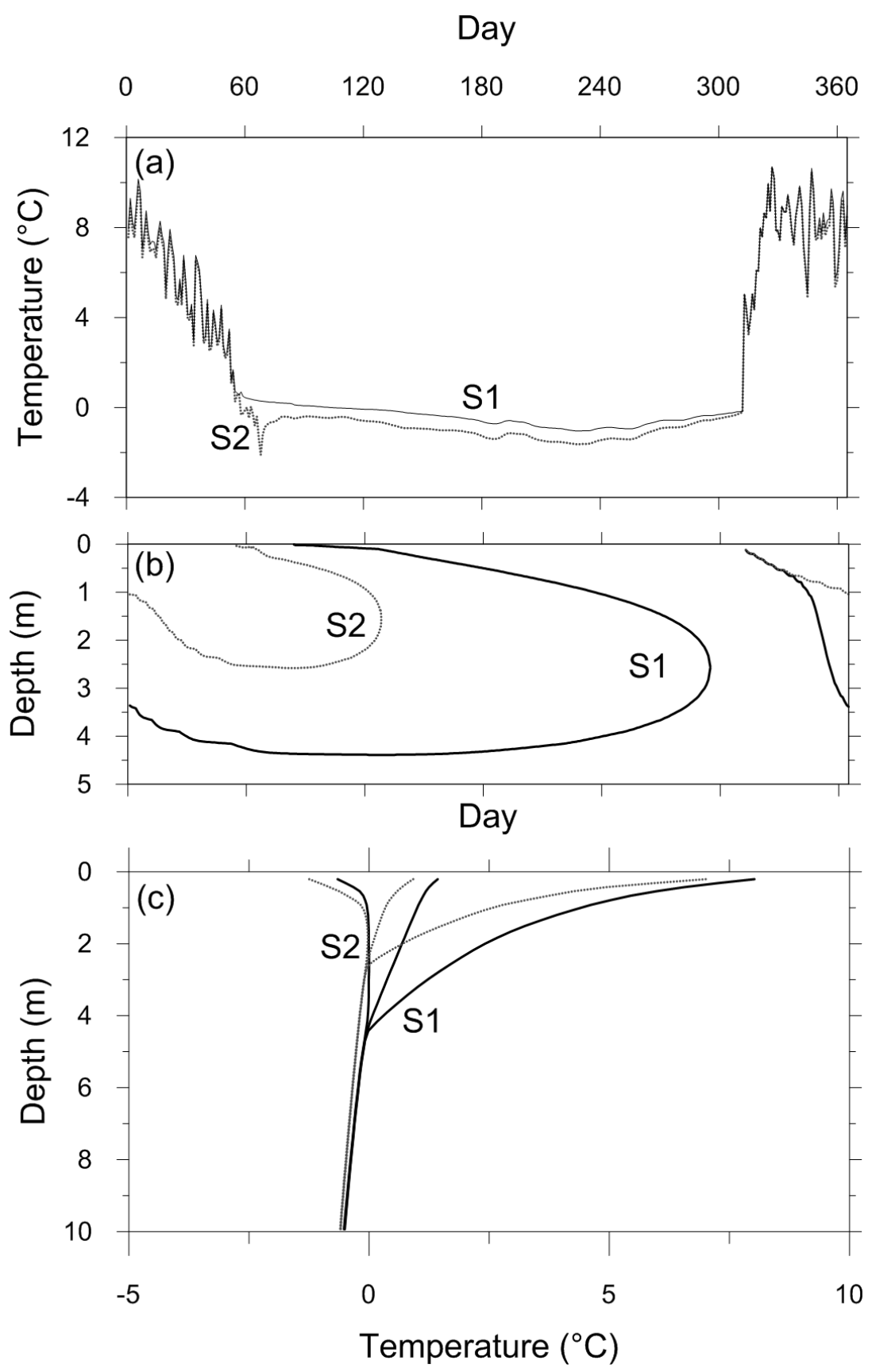

Figure 5.10: (a) simulated ground surface temperatures (0.05 $\mathrm{m}$ depth), (b) positions of the $0{ }^{\circ} \mathrm{C}$ isotherm, and (c) temperature envelopes for simulations $\mathrm{S} 1$ and $\mathrm{S} 2$. In $\mathrm{S} 1$, snow began to accumulate on the first day of freezing conditions; in S2, snow accumulation began 14 days after freezing conditions. In both simulations, snow reached its maximum depth $(1.0 \mathrm{~m})$ after 30 days of accumulation. The simulations commence on August 1 and results are shown for year 35. 


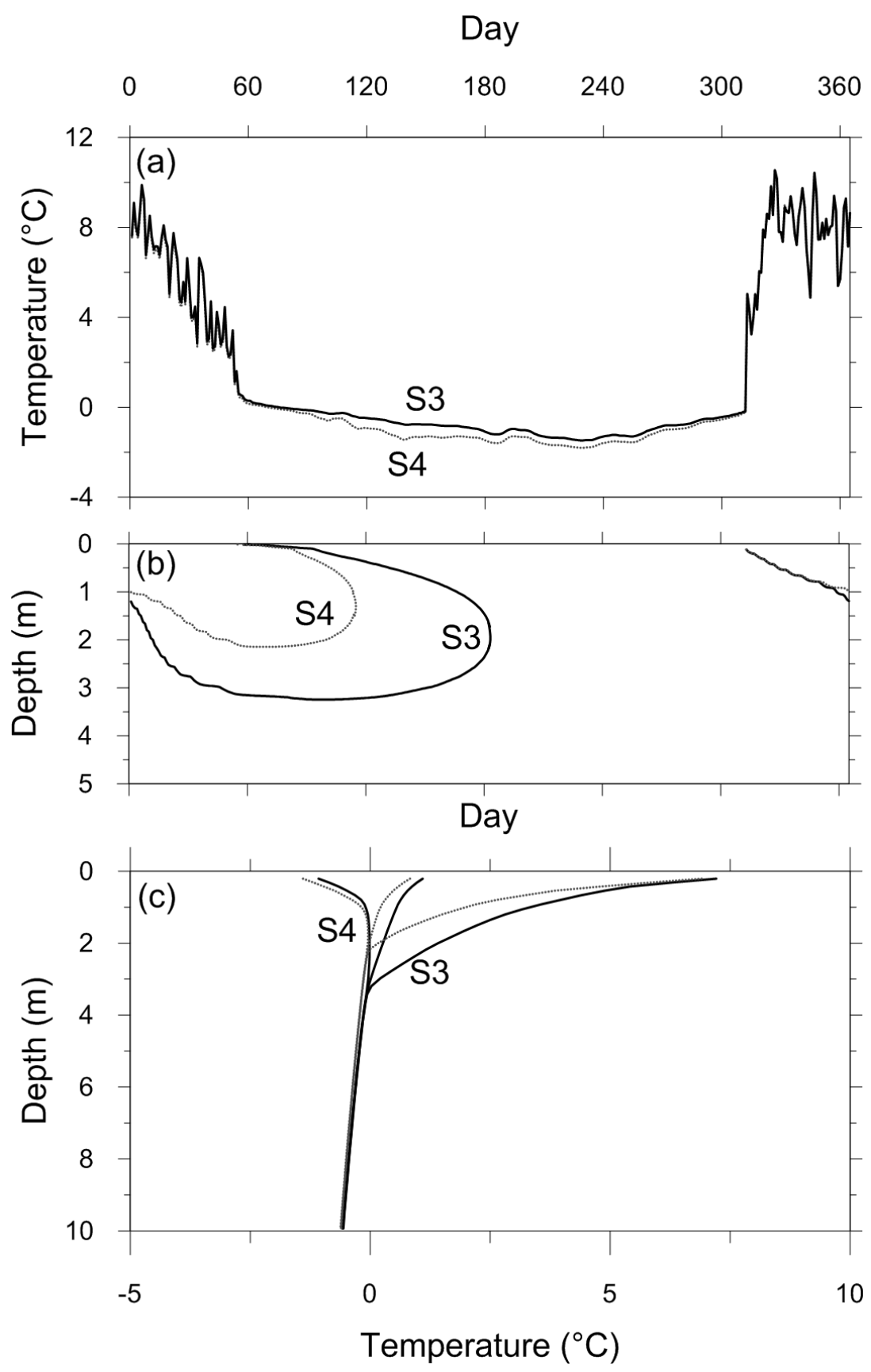

Figure 5.11: (a) simulated ground surface temperatures (0.05 $\mathrm{m}$ depth), (b) positions of the $0{ }^{\circ} \mathrm{C}$ isotherm, and (c) temperature envelopes for simulations S3 and $\mathrm{S} 4$. In $\mathrm{S} 3$, the maximum snow depth $(1.0 \mathrm{~m})$ is reached after 90 days; in $\mathrm{S} 4$, the maximum snow depth $(1.0 \mathrm{~m})$ is reached after 120 days. Snow commenced on the first day of freezing conditions in both simulations. The simulations commence on August 1 and results are shown for year 35. 
heat requirement, characterized by the unfrozen water content curve, was mostly satisfied (Figures 5.3, 5.12c). The sensible cooling of the ground in S5 and S6 caused ground thawing to be similar in both simulations, with little difference in thaw penetration timing or magnitude (Figure 5.12c). This is indicative of a threshold between simulations like S1-S4 and S5-S6 where thaw depths are controlled predominantly by the winter snow regime (S1-S4) rather than summer conditions (S5, S6).

\section{Snow manipulation simulations}

The M1-M6 simulations examined the effect of limiting the accumulation of snow at the embankment toe and increasing the snow pack density to simulate potential mechanical snow management. M1-M3 simulated 1980-2015 temperatures with three different snow densities, assuming snow depth was limited to $0.3 \mathrm{~m}$ each year for the 35 years since embankment construction. M4-M6 examined 10-year responses to depth and density manipulations of the disturbed thermal conditions simulated for TST2 after 35 years (e.g., 2015-2025) (see Table 5.5).

M1-M3 demonstrate the effect on ground temperatures of limiting snow accumulation and increasing snow density immediately following embankment construction (Figure 5.13). M1 resulted in ground temperatures slightly lower than the DST control site. When the density of the snow cover was increased to $400 \mathrm{~kg} \mathrm{~m}^{-3}$ in M3, mean annual ground temperature at $5 \mathrm{~m}$ depth was reduced to nearly $-5{ }^{\circ} \mathrm{C}$ after 35 years, compared to a value of $-1.8^{\circ} \mathrm{C}$ for the DST control simulation (Figure 5.13). The thaw depths after 35 years in M1-M3 were 1.0, 0.9, and 0.8, respectively, similar to values for undisturbed tundra.

M4-M6 demonstrate the response of disturbed conditions to snow management over 10 years. The M4-M6 manipulations rapidly decreased ground temperatures and 

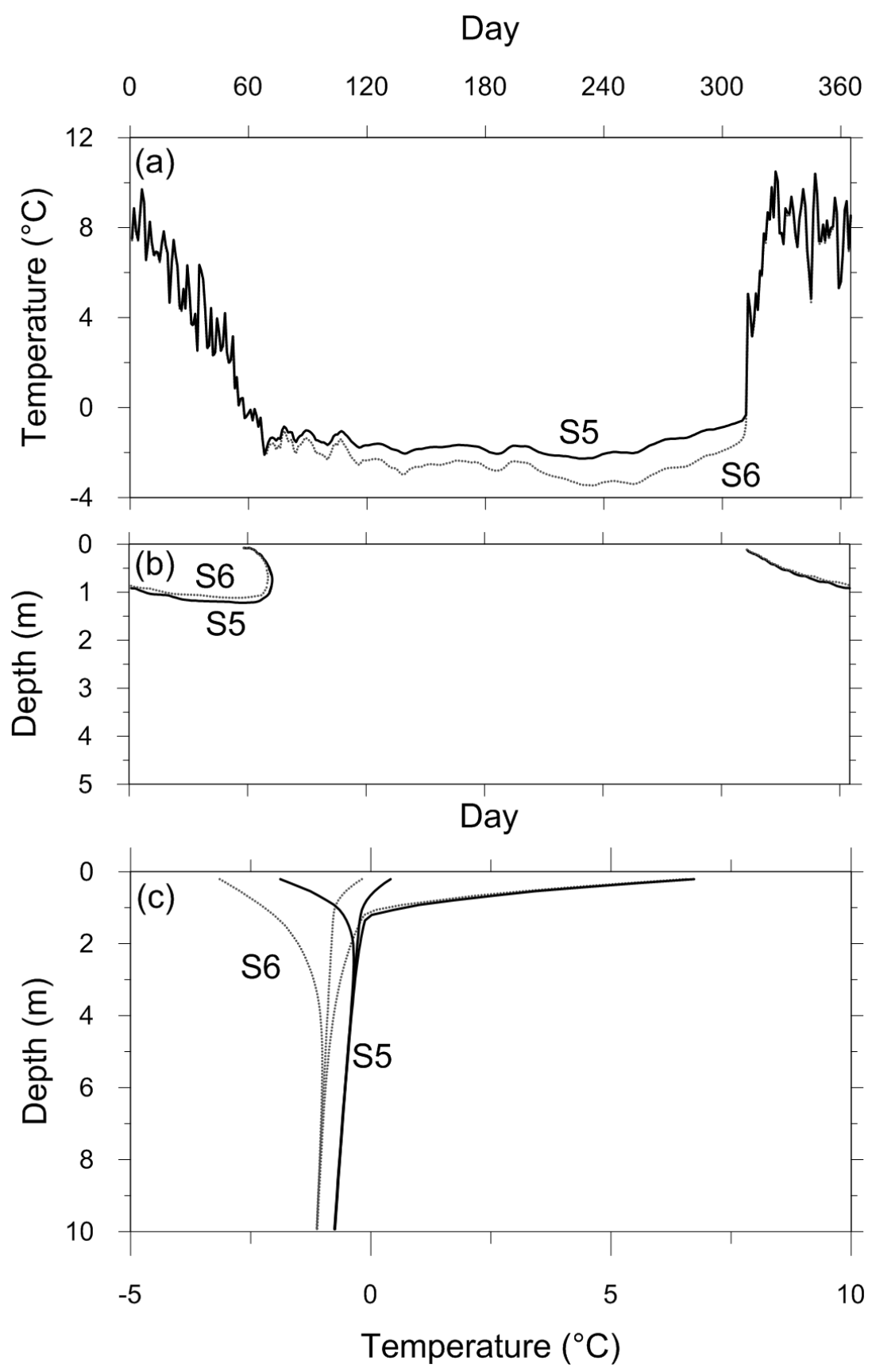

Figure 5.12: (a) simulated ground surface temperatures (0.05 $\mathrm{m}$ depth), (b) positions of the $0{ }^{\circ} \mathrm{C}$ isotherm, and (c) temperature envelopes for simulations $\mathrm{S} 5$ and S6. In these simulations, snow commenced 14 days following freezing conditions; in $\mathrm{S} 5$, the maximum snow depth $(1.0 \mathrm{~m})$ is reached after 90 days, and in S6, the maximum snow depth $(1.0 \mathrm{~m})$ is reached after 120 days. The simulations commence on August 1 and results are shown for year 35. 
thaw depths from the disturbed conditions simulated at TST2 (Figure 5.14, 5.16). After 10 years, $T_{g}$ was reduced by up to $4.2{ }^{\circ} \mathrm{C}$ (M6, Figure 5.14). The reduction in ground temperatures was rapid in the initial years following snow management. To illustrate, annual mean ground temperature profiles for years 2, 5, and 8 in M6 are plotted in Figure 5.15. Ground cooling reached about $4 \mathrm{~m}$ depth by the second year, $8 \mathrm{~m}$ by year 5 , and $17 \mathrm{~m}$ by year 8 . Thaw depth decreased from nearly $5.0 \mathrm{~m}$ in the first year to $<1.5 \mathrm{~m}$ in the second year of the M4-M6 simulations, and to about $1 \mathrm{~m}$ after 10 years (Figure 5.16), indicating the reduction in depth to permafrost.

The results from M1-M6 suggest that even shorter-term (e.g., several year) snow management efforts may serve to effectively cool near-surface ground temperatures, refreeze taliks, and prevent thaw of ice-rich permafrost at the embankment toe.

\subsection{Discussion}

\subsubsection{Field conditions}

Higher ground temperatures were observed near the toe of the road embankment than at control sites, except at DST2, where the embankment made little change in snow cover (Table 5.6). The thermal disturbance to permafrost is primarily associated with deeper snow cover resulting from wind deposition along the embankment (Figure 5.6). The average snow cover thermal resistance at road sites other than DST2 was 10.3 $\mathrm{m}^{2} \mathrm{~K} \mathrm{~W}^{-1}$, while at control sites it was $4.6 \mathrm{~m}^{2} \mathrm{~K} \mathrm{~W}^{-1}$, and $4.7 \mathrm{~m}^{2} \mathrm{~K} \mathrm{~W}^{-1}$ at DST2 (Table 5.6).

The increase in snow cover following embankment construction has resulted in increased thaw depth at all sites except DST2. For example, the measured thaw 


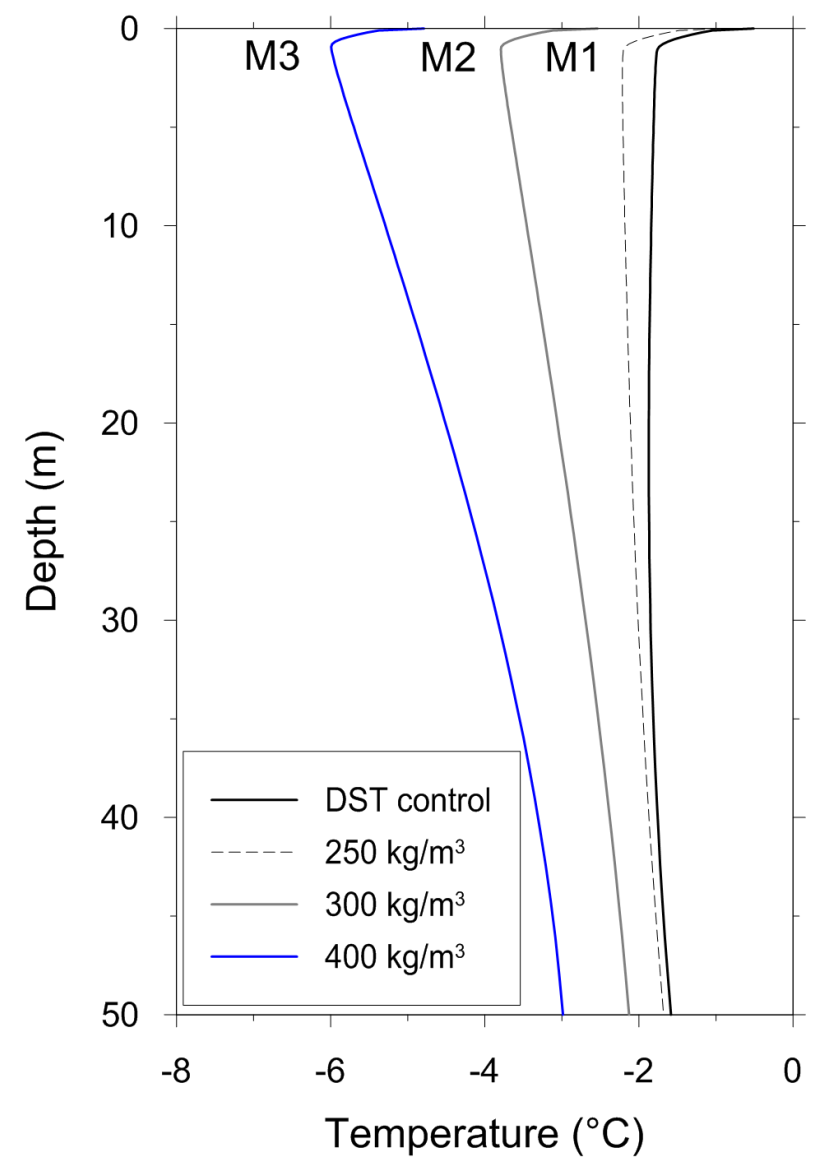

Figure 5.13: Simulated annual mean ground temperatures for year 35 of the M1-M3 snow manipulation scenarios (see Table 5.5). The initial temperature conditions in the simulations were the undisturbed conditions in Figure 5.7. The results are plotted with simulated conditions after 35 years for the DST control site (e.g., Figure 5.8g) 


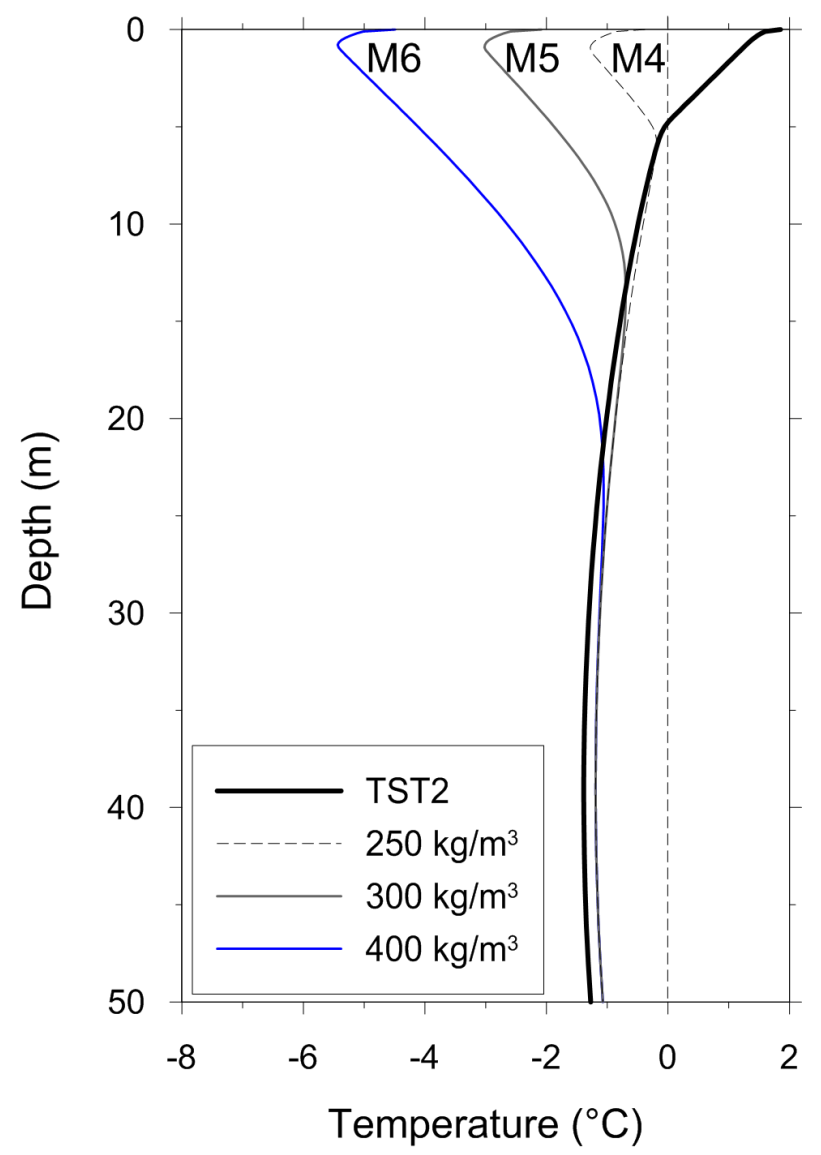

Figure 5.14: Simulated annual mean ground temperatures for year 10 of the M4-M6 snow manipulation scenarios (see Table 5.5). The initial temperature conditions in the simulations were from year 35 of the TST2 embankment toe simulation in Figure 5.8e 


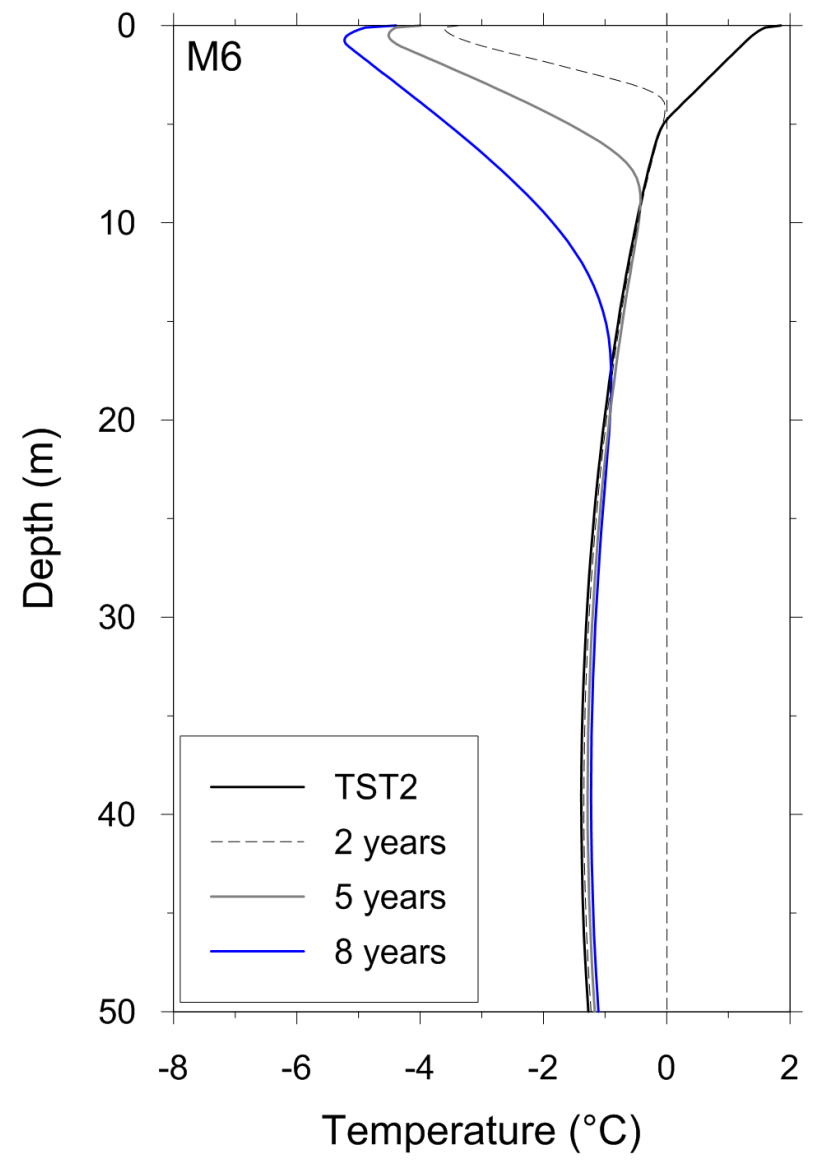

Figure 5.15: Simulated annual mean ground temperatures for years 2, 5, and 8 of the M6 snow manipulation scenario (see Table 5.5). The initial temperature conditions in the simulations were from year 35 of the TST2 embankment toe simulation in Figure $5.8 \mathrm{e}$ 


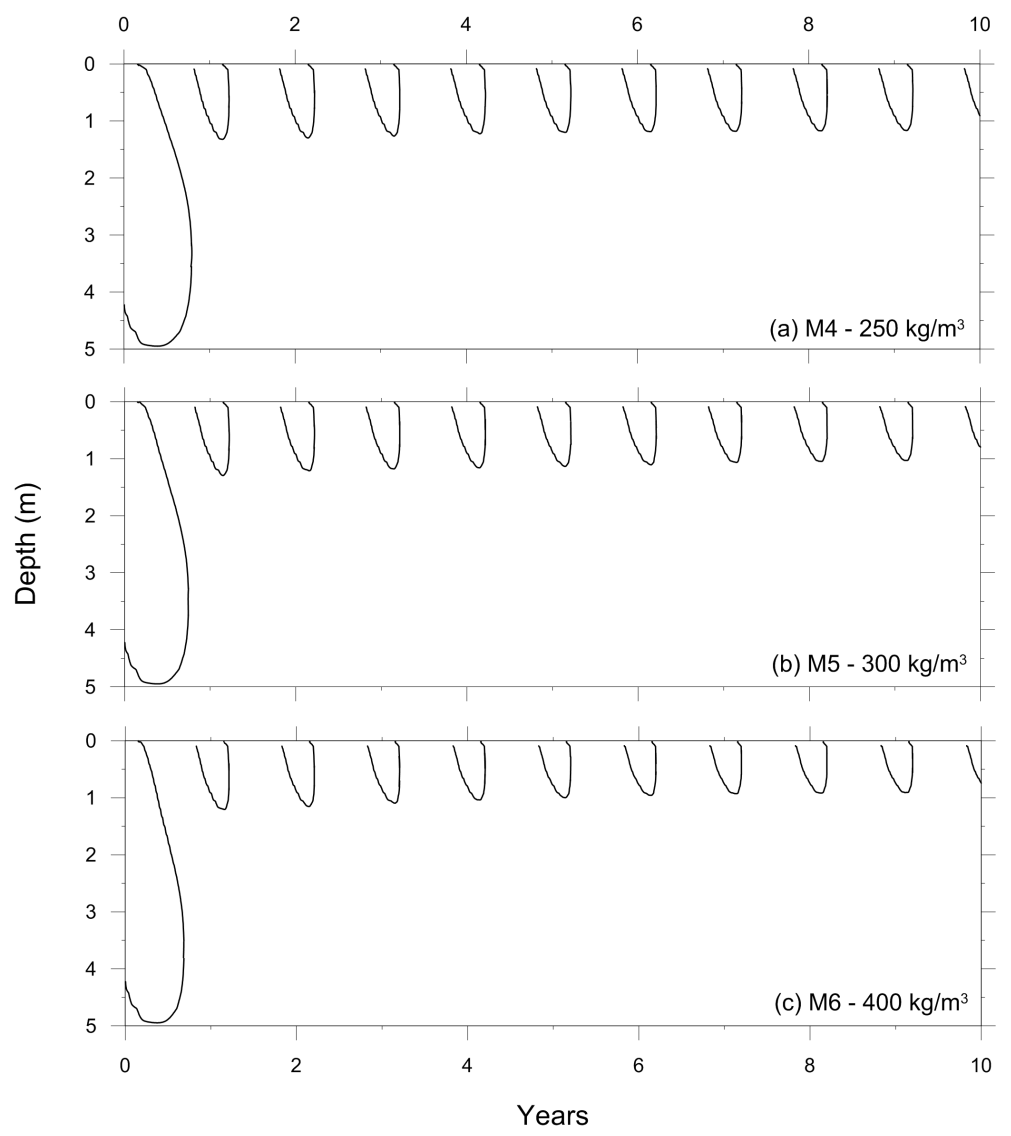

Figure 5.16: Simulated thaw depths $\left(0{ }^{\circ} \mathrm{C}\right.$ isotherm $)$ over ten years for the M4-M6 snow manipulation scenarios (see Table 5.5). The initial temperature conditions in the simulations were from year 35 of the TST2 embankment toe simulation in Figure 5.8e 
depths at control sites suggest that $>4 \mathrm{~m}$ of permafrost has degraded at TST2 (Table 5.6). The thaw of near-surface permafrost at four of the five road sites is corroborated by the temperature profiles, which are in disequilibrium (Figure 5.8), by probing, which indicated taliks at some locations near the road, and by $T_{s}$ values $>0{ }^{\circ} \mathrm{C}$.

Ground surface temperatures measured at the shallow cables were near $0{ }^{\circ} \mathrm{C}$ throughout the freezing season, indicating that winter ground cooling does not occur at the degrading road sites (Figure 5.9). The thermal data and deep surface thaw observed in this study help explain recent maintenance challenges along the embankment on Peel Plateau, where significant fill material has been placed beside the road to stabilize thawing. Ground thawing of several metres, as observed at TST2, may cause significant subsidence in this ice-rich environment and lead to such issues.

At DST2, snow cover was similar $(0.4$ to $0.8 \mathrm{~m})$ to that observed in undisturbed tundra on Peel Plateau (O'Neill et al., 2015). This is likely due to the embankment at this site being relatively low ( $1 \mathrm{~m}$ in height). The ground surface slopes upward away from the road, so that the site is exposed to the dominant northerly winter winds. Consequently, snow does not accumulate as at the other embankment toe sites, resulting in permafrost temperatures and thaw depths similar to control sites (Table 5.6). This finding indicates that site-specific topographic characteristics are important in determining susceptibility to permafrost degradation along linear transportation infrastructure in tundra terrain. The effects of site topography on disturbance at snow fences are investigated in Chapter 6.

\subsubsection{Simulations of field conditions}

In general, the 35-year disturbance simulations reproduced conditions observed in the

field. Modeled ground temperatures were similar to measured values at depths of 0-8 m (Figure 5.8). Simulated ground surface temperatures (0.05 $\mathrm{m}$ depth) after 35 years 
of disturbance closely matched measured values from the shallow cables, and reproduced seasonal patterns, particularly for the four sites with degrading permafrost. The largest absolute differences between measured and modeled ground surface temperatures on individual days occurred in the thawing season, except at DST2, where differences were also sometimes large in winter (Figure 5.17). The large differences in some freezing season surface temperatures at DST2 are attributable to the abnormally low snow accumulation in 2013-14. There was no interannual snow variation in the model, so in years with abnormal snow accumulation, differences at DST2 are pronounced due to the thin snow cover characteristic of the site. In contrast, the other road sites are less affected by seasonal differences in snow depth because the influence of changes in snow depth is diminished in snow packs more than $50 \mathrm{~cm}$ thick (Smith, 1975), and the surface temperature is constrained by the latent heat released during seasonal ground freezing.

Three indices of model performance for time series analyses are presented in Table 5.7 for the measured and modeled surface temperatures from Figure 5.17. The definitions and significance of these indices are widely reported in statistical source material (e.g., Adhikari and Agrawal, 2013). The indices are included to enrich the assessment of model performance in characterizing the ground surface thermal regime. Root mean square errors (RMSE) of modelled daily ground surface temperatures were between $1.5^{\circ} \mathrm{C}$ (TST2) and $4.2{ }^{\circ} \mathrm{C}$ (DST2), and mean absolute errors (MAE) were between 1.1 and $3{ }^{\circ} \mathrm{C}$ for the same sites, respectively (Table 5.7). The higher errors at DST2 are due to the interannual variation in snow depth causing significant differences in daily winter surface temperatures there. The RMSE values are higher than the MAE values because the statistic is weighted towards large errors. Mean error (ME) values were between $-0.1{ }^{\circ} \mathrm{C}(\mathrm{TST} 2)$ and $0.9^{\circ} \mathrm{C}(\mathrm{DST} 1)$. The positive MEs at DST1, DST2, and TST1 indicate that measured temperatures were typically 
higher than the simulated values, which is likely due to the systematically lower values produced by the model in summer (Figure 5.17). ME values are lower than MAE, particularly for DST2, because the statistic conceals large positive and negative errors by offsetting them.

Modeled thaw depths at sites with little snow were in close agreement with those measured in the field, and the presence of a talik, indicated by probing at TST2, was also simulated. There was general agreement regarding thaw depth at the embankment toe sites, with a median difference between modeled and measured values of 0.35 m. However, there were relatively large differences in measured and modeled thaw depths at TST1 $(0.9 \mathrm{~m})$ and TST2 $(0.4 \mathrm{~m})$. This is likely because ground temperatures at these sites were very close to $0{ }^{\circ} \mathrm{C}$, and thaw-depth prediction is made difficult under this condition because of the phase change associated with small changes in temperature (e.g., LeBlanc et al., 2014). This observation may limit the utility of such simulations for predicting the depth to permafrost in degrading permafrost.

\subsubsection{Simulation limitations}

Differences between measured and modeled values may be explained by a number of necessary simplifications in the simulations. First, no long-term air temperature record exists for Peel Plateau, and it was not possible to accurately produce a synthetic record using temperatures from Inuvik, because the long-term nature of the winter air temperature inversions between the plateau and lowlands is unknown (O'Neill et al., 2015). As a result, air temperatures were simulated using median values from three years' measurements, and these may not reflect air temperatures over the entire period of the transient simulation (1980-2015). For example, air temperatures in $2012-14$ at Inuvik were about $1{ }^{\circ} \mathrm{C}$ higher than in $1980-2015$. 


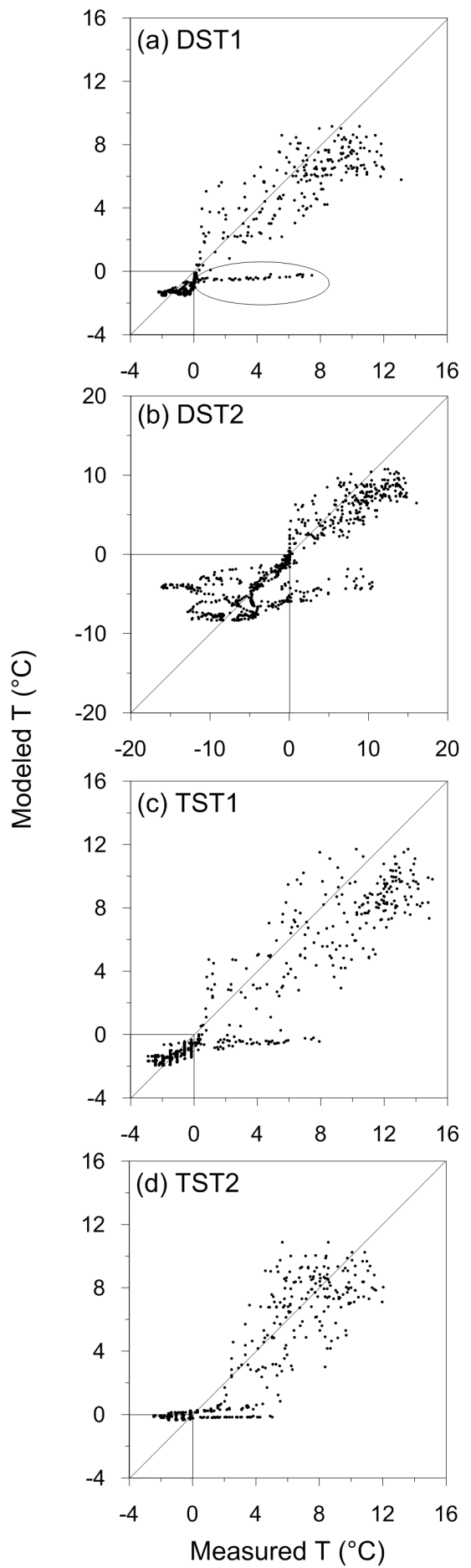

Figure 5.17: Modeled vs measured ground surface temperatures (0.05 m depth) at sites near the embankment toe between 2012-15 (same data as Figure 5.9). The ellipse in (a) encompasses values when the modeled snowpack was still ablating but the ground was free of snow in the field. Note that DST3 is not plotted here. 
Table 5.7: Root mean square error (RMSE, $\left.{ }^{\circ} \mathrm{C}\right)$, mean absolute error $\left(\mathrm{MAE},{ }^{\circ} \mathrm{C}\right)$, and mean error $\left(\mathrm{ME},{ }^{\circ} \mathrm{C}\right)$ of modeled daily ground surface temperatures $(0.05 \mathrm{~m}$ depth) at four sites at the Dempster Highway embankment toe. All indices are based on $n=730$ ( 2 years) daily measurements. The calculations were conducted using the hydroGOF package in R (http://www.rforge.net/hydroGOF/

\begin{tabular}{lllll}
\hline Statistic & DST1 & DST2 & TST1 & TST2 \\
\hline RMSE & 1.7 & 4.2 & 2.1 & 1.5 \\
MAE & 1.2 & 3.0 & 1.4 & 1.1 \\
ME & 0.9 & 0.8 & 0.9 & -0.1 \\
\hline
\end{tabular}


Second, the model assumed a constant snow accumulation regime, so any interannual effects or long term precipitation trends were not captured. Third, the site-specific $n_{t}$ values used characterized the present-day conditions at the shallow cables. These represent the best available information on the relation between air and ground surface temperatures in the thawing season. However, these do not account for interannual or shorter time scale variations in summer surface conditions that strongly control ground surface temperatures on a given day. In addition, proliferation of shrubs (Gill et al., 2014) and changes to soil moisture near the embankment toe (Cameron and Lantz, 2016) have likely caused an evolution of $n_{t}$ over time since embankment construction, which was not included in the model. Fourth, the initial equilibrium temperature profile was the same for all sites. This likely resulted in the differences in annual ground temperatures observed at DST1 (Figure 5.8). Nearsurface ground temperatures were reproduced closely, but differences increased with depth, where the measured values were lower than those simulated, suggesting that this site may have had lower initial ground temperatures than specified in the model. This point indicates that the assigned initial ground thermal profile is an important consideration, particularly if permafrost temperatures at depth are of interest. Earlier iterations of transient simulations with different initial ground temperatures indicated that thaw depths at the most disturbed sites are also sensitive to the initial thermal conditions. Fifth, material properties used in the simulation were a simplification of field conditions, and did not account for ground subsidence effects from the thaw of near-surface ground ice.

Finally, simulations did not include the effects of lateral heat flow. The ground thermal conditions near the road are the result of three-dimensional heat transfer processes (LeBlanc et al., 2014). This simplification was apparent in the simulation of 
temperatures at the road centreline, where modeled values were much lower at depth than measured in the field, because lateral heat flow from the warm ground at the embankment toe was not included (Figure 5.8). Nonetheless, the agreement between modeled and field conditions is remarkable and gives confidence in the simulations. The coincidence of the temperature profiles is due to the thermal inertia provided by the latent heat requirements of thawing permafrost. For transient conditions, the efficacy of latent heat in reducing variation in ground temperatures increases with depth due to reduction in amplitude of the annual temperature cycle.

\subsubsection{Snow cover simulation vs. the $n_{f}$ approach}

Simulations using a seasonal winter $n$-factor may underestimate ground surface temperatures early in the freezing season, because $n_{f}$ does not capture the decoupling of air and ground temperatures early in the freezing season under a snow pack. During this period, ground surface temperatures calculated from $n_{f}$ may be underestimated because the surface is maintained near $0{ }^{\circ} \mathrm{C}$ by latent heat released as the freezing front progresses downward (Hinkel et al., 2001) (Figure 5.9a,c,d), while air temperatures may be well below $0{ }^{\circ} \mathrm{C}$ (Karunaratne and Burn, 2003). The magnitude of this effect, in theory, varies with air temperature and the value of $n_{f}$ so that the lower the air temperature early in the freezeback period, and the higher the $n_{f}$, the greater the potential underestimation of ground surface temperature (e.g., Figure 5.18).

This theoretical consideration was examined by determining the freezing season RMSE, MAE, and ME between two years of measured ground surface temperatures, those simulated by TONE, and those obtained by applying site-specific seasonal $n_{f}$ values to the daily air temperatures used in the TONE simulations (Table 5.8). The error values support the relation shown in Figure 5.18. The three sites with deep snow accumulation had very low $n_{f}$ values (0.06-0.08). At these sites, the error indices for 
temperatures based on $n_{f}$ were within $0.2{ }^{\circ} \mathrm{C}$ of those for the TONE model simulations. This suggests that at sites with deep snow, the use of site-specific $n_{f}$ values closely approximates the ground surface thermal regime, and performs comparably with the TONE model. This is because the very low $n_{f}$ results in calculated ground surface temperatures near $0{ }^{\circ} \mathrm{C}$ (Figure 5.18), thus reproducing ground surface temperatures maintained by upward heat flow during freezeback. Howevever, $n_{f}$ at DST2 was 0.45 , and the associated error indices were greater than those calculated for the TONE simulations (Table 5.8). The ME for DST2 surface temperatures from TONE was $0.5^{\circ} \mathrm{C}$, compared with $-2.6^{\circ} \mathrm{C}$ for the $n_{f}$ method. This elevated negative ME value indicates a systematic underestimation in winter ground surface temperatures early in the freezing season, as indicated by the relation in Figure 5.18 for higher values of $n_{f}$.

Figure 5.18 and Table 5.8 suggest that the use of $n_{f}$ values from the literature (e.g., Table 3-6, Figure 3-4, Andersland and Ladanyi, 2004), rather than values derived for specific sites should be avoided. The $n_{f}$ value (0.33) for degrading permafrost in Table 3-6 of Andersland and Ladanyi (2004) is not representative of sites where deep snow accumulates as at an embankment. The degradation scenario presented in Andersland and Ladanyi (2004), originally reported by Linell (1973), was caused by clearing of the surface organic cover, and is thus reflected in a higher $n_{t}$. The $n_{f}$ values for embankment toe sites with deep snow in this study, and as reported by Flynn et al. (2016), are all $<0.1$. By using $n_{f}$ values from the literature to represent conditions at an embankment toe where deep snow accumulates, modeled daily winter ground temperatures may be up to $20^{\circ} \mathrm{C}$ lower than measured values (Darrow, 2011, p. 485).

Site-specific seasonal $n$-factors appear to perform well at sites with deep snow accumulation, and are an appropriate option if snow depths were not measured in 


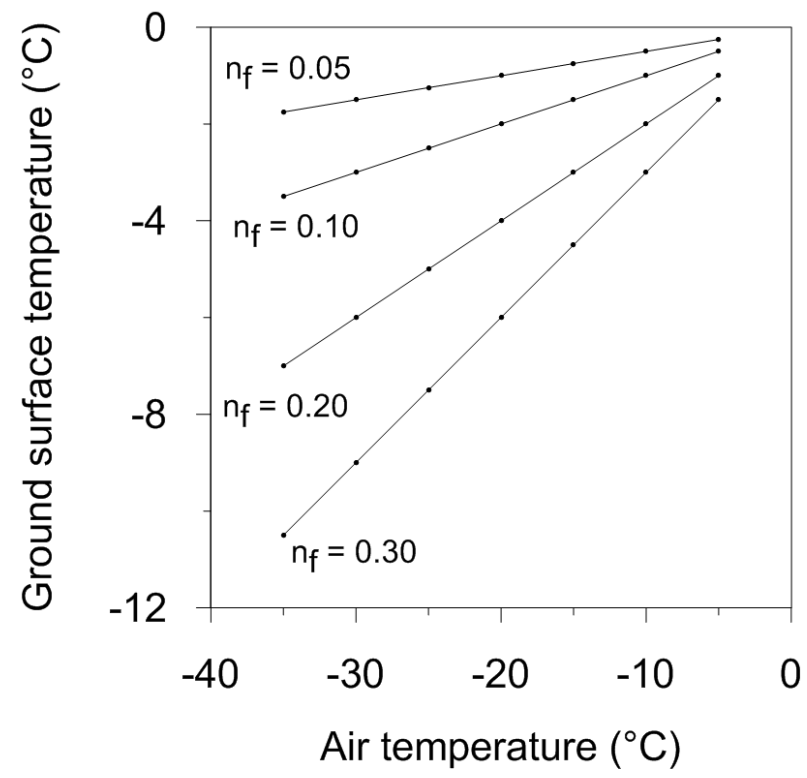

Figure 5.18: An example of air and calculated ground surface temperatures for four different $n_{f}$ values representative of different snow covers. As air temperature decreases and $n_{f}$ increases, lower ground surface temperatures are produced, which may underestimate ground temperatures during freezeback under a snow cover. 
Table 5.8: Root mean square error (RMSE, $\left.{ }^{\circ} \mathrm{C}\right)$, mean absolute error $\left(\mathrm{MAE},{ }^{\circ} \mathrm{C}\right)$, and mean error $\left(\mathrm{ME},{ }^{\circ} \mathrm{C}\right)$ between freezing season ground surface temperatures modeled by TONE and those measured in the field, and the same error indices (in brackets) for ground surface temperatures calculated using site-specific $n_{f}$ and those measured in the field. The indices were calculated for ground temperatures measured over 2 freezing seasons. The calculations were conducted using the hydroGOF package in R (http://www.rforge.net/hydroGOF/

\begin{tabular}{lllll}
\hline & DST1 & DST2 & TST1 & TST2 \\
\hline$n_{f}$ & 0.06 & 0.45 & 0.08 & 0.06 \\
RMSE & $0.7(0.8)$ & $4.0(4.3)$ & $0.6(0.8)$ & $1.1(0.9)$ \\
MAE & $0.6(0.7)$ & $2.7(3.4)$ & $0.4(0.6)$ & $0.8(0.7)$ \\
ME & $-0.5(-0.4)$ & $0.5(-2.6)$ & $-0.0(-0.1)$ & $0.6(-0.4)$ \\
\hline
\end{tabular}


the field. For sites with less snow (and so with higher $n_{f}$ ), the potential 'overcooling' effect early in winter may be mitigated by using $n_{f}$ values calculated over shorter time scales (e.g., monthly) rather than a seasonal value (LeBlanc et al., 2014). However, if ground surface temperatures are available, then the snow initiation date can be readily estimated (Burn and Zhang, 2009; O'Neill et al., 2015). This, combined with the measured end of winter snow depth, means that the snow accumulation regime is reasonably constrained, and that only the rate of accumulation need be estimated.

Model parameters are commonly fine-tuned to better reproduce field conditions, and the ability to define the nature of snow cover accumulation allows more flexibility, whereas adjustments of $n_{f}$ may lead to an improvement in some model outputs at the expense of others (Darrow, 2011). Here, minimal effort was spent manually adjusting parameters to yield temperature and ALT results similar to field conditions.

\subsubsection{Implications and future directions}

Measurements at the Dempster Highway embankment toe suggest permafrost is degrading in settings that are favourable to deep snow accumulation (Figure 5.5) (Darrow, 2011; Fortier et al., 2011; Lanouette et al., 2015). The thaw of ice-rich permafrost beside the Dempster Highway embankment on Peel Plateau is already an ongoing maintenance challenge, and future climate warming will exacerbate the problem. The agreement betweeen measured and modeled temperatures at the embankment toe allows future simulations to examine the effects of climate amelioration. The ground surface temperatures from the TONE model may be implemented as boundary conditions in two-dimensional simulations of permafrost conditions near infrastructure as in Smith and Riseborough (2010), using commercially available models such as 
TEMP/W. This would allow consideration of lateral heat flow between the embankment and surrounding terrain. The present literature on this topic has applied air temperature increases to the ground thermal regime using $n$-factors (Alfaro et al., 2009; Fortier et al., 2011; Flynn et al., 2016), but the TONE model also enables potential changes in precipitation (snow) to be considered explicitly. The $n$-factor approach during the freezing season may perform well for an embankment (no snow on driving surface, deep snow on side slopes) but not for surrounding undisturbed terrain.

Future investigations on permafrost near infrastructure embankments would benefit from a longer-term baseline dataset on snow accumulation regimes. Snow accumulation and ablation at the embankment may be monitored directly using time-lapse photography and snow stakes (Farinotti et al., 2010; Parajka et al., 2012), or inferred using thermistors mounted at increments above the ground surface (Lewkowicz, 2008; Lanouette et al., 2015). A robust catalogue of such data would allow increased confidence when assigning snow accumulation parameters in models, as interannual varibility over longer timespans could be quantified. Given the sensitivity of the modeled thaw depths to initial conditions and parameterization, modeling of future permafrost degradation at infrastructure could then employ a probabilistic approach based on measured distributions of field conditions. From a practical standpoint, the modelling in S1-S6 and M1-M6 suggests that snow management techniques that delay, limit, or densify snow accumulation near the embankment toe could be a maintenance option at sites where permafrost thaw threatens the embankment integrity. This would facilitate ground cooling during the critical freezeback period, resulting in a reduction in thaw depth and protection of underlying ice-rich ground. The short-term effects of snow manipulation on the thermal regime could be explored in the field by instrumenting a site and compacting snow cover at regular intervals, tracking snow depth 
and density changes over the winter. Snow compaction may have a double effect of facilitating conductive heat loss through the snow pack, and limiting ground thaw in summer due to a longer snow ablation period (e.g., Keller et al., 2004).

\subsection{Summary and conclusions}

The measurement and modelling of permafrost conditions near the Dempster Highway road embankment on Peel Plateau has lead to the following conclusions:

(1) Permafrost is degrading at four of five study sites near the toe of the embankment. Annual mean ground temperatures near $5 \mathrm{~m}$ depth at the degrading sites were between -1.3 and $0.0{ }^{\circ} \mathrm{C}$, in comparison with -1.8 and $-2.6{ }^{\circ} \mathrm{C}$ at two control sites in undisturbed tundra. A talik was measured at the site with the deepest snow by probing in summer, and simulated with a 1-dimensional numerical model.

(2) High ground temperatures are associated with a thick, insulating snow cover that accumulates along the embankment.

(3) Enhanced snow accumulation near the embankment toe is pronounced in both dwarf- and tall-shrub tundra, due to wind redistribution, but not where the road passes through forest.

(4) A one-dimensional numerical model that incorporated the accumulation and ablation of a snow pack closely reproduced ground temperatures following 35 years of disturbance at embankment toe sites. Thaw depths were reasonably reproduced, but differences were larger at sites with ground temperatures near $0{ }^{\circ} \mathrm{C}$, highlighting 
the difficulty of modeling thaw depth precisely in degrading permafrost.

(5) A delay in the onset of deep $(1 \mathrm{~m})$ snow accumulation for a short period (e.g. two weeks) and/or an extension in the duration of snow accumulation allows the evacuation of latent heat from the active layer, facilitates sensible cooling of the ground, and significantly decreases thaw depth in the following summer.

(6) Limiting the depth and increasing the density of snow cover at the embankment toe significantly reduced temperatures and thaw depths in modelling simulations of the most disturbed site. Active snow management should be further explored as a potential maintenance activity along thaw sensitive sections of northern transportation infrastructure. 


\section{Chapter 6}

\section{Permafrost degradation at snow fences}

\section{Modified from the manuscripts:}

O'Neill H.B., and Burn C.R. (Early view online: 16 June 2016), Talik formation at a snow fence in continuous permafrost, western Arctic Canada. Permafrost and Periglacial Processes, DOI: 10.1002/ppp.1905

and:

O'Neill, H.B., and Burn, C.R. (2015), Permafrost degradation adjacent to snow fences along the Dempster Highway, Peel Plateau, NWT. Paper 219. Proceedings, 68th Canadian Geotechnical Conference and 7th Canadian Permafrost Conference, 21-23 September 2015, Québec City, QC. Available at: http://carleton.ca/permafrost/canadian-permafrost-conference/

\subsection{Introduction}

Snow fences upwind of infrastructure lower wind velocity and promote snow deposition, reducing snow accumulation and increasing visibility at nearby installations. The fences also alter the ground thermal regime, as the accumulated snow limits ground heat loss and prolongs active-layer freeze back. Consequently, near-surface 
ground temperatures in winter are considerably higher near snow fences than beneath the surrounding snow pack (Mackay, 1978, 1993; Burn et al., 2009). Such warming may cause subsidence at sites with ice-rich permafrost (e.g., Hinkel and Hurd, 2006).

Snow cover is the most important local control on ground temperatures in the continuous permafrost zone (Mackay and MacKay, 1974; Zhang, 2005). A second important variable is the moisture (latent heat) content of the active layer, which influences the freezeback period and resulting permafrost temperatures. Complex relations exist between snow cover, ground thermal conditions, active-layer moisture content, and vegetation in tundra environments (e.g., Sturm et al., 2001a; Morse et al., 2012). Past research has shown the ground thermal effects of enhanced snow accumulation at fences over several years following their construction (Mackay, 1978; Hinkel and Hurd, 2006; Burn et al., 2009; Johansson et al., 2013; Lafrenière et al., 2013). However, to our knowledge, no studies have examined multi-decadal thermal effects of snow fences. This topic should be explored near highways because the snow fences, erected to improve visibility for drivers, may initiate thermokarst processes close to the road embankment.

The objectives of this chapter are to: (1) report ground thermal effects of a snow fence constructed in the early 1980s beside the Dempster Highway on Peel Plateau, west of Fort McPherson, NWT (Figure 6.1); (2) simulate numerically the effects of the fence over time; and (3) describe resulting active-layer thicknesses and vegetation near this fence, and at three additional snow fences in the region. This is important to investigate as it allows a temporal and spatial characterization of thermokarst initiation and associated ALT and vegetation responses from disturbances in the region. The results may also apply more broadly to tundra in other areas of the continuous permafrost zone. 


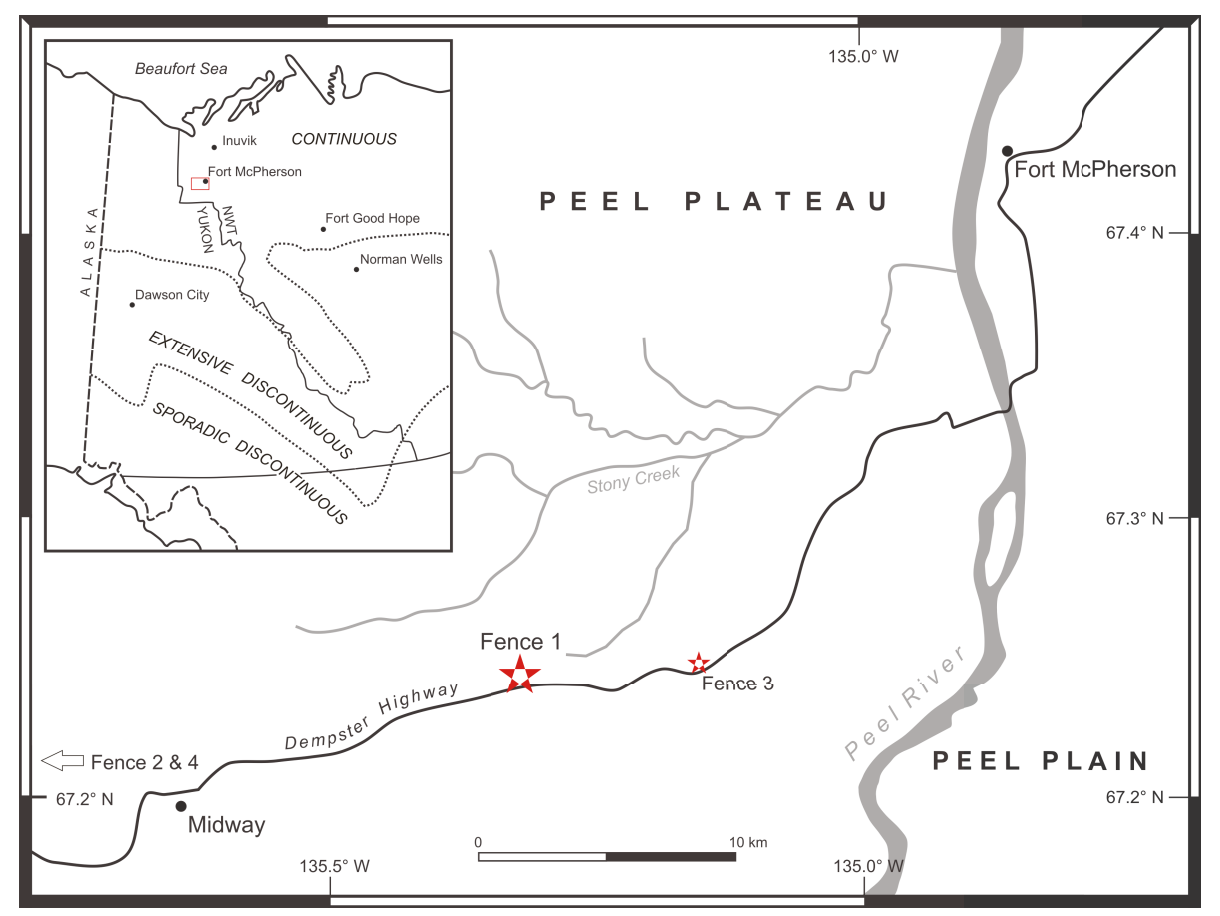

Figure 6.1: Location of study sites. Fences 2 and 4 are at $67.18^{\circ} \mathrm{N} 135.78^{\circ} \mathrm{W}$ and 67.10N 136.10W, respectively, in Richardson Mountains. Permafrost zones of northwest Canada are shown in the inset. 


\subsection{Study design and sites}

In 2012-15, snow depth, ALT, shallow ground temperatures, ground surface topography, and vegetation were examined at a snow fence (Fence 1; Figure 6.2) located on Peel Plateau, at the Midway emergency airstrip. ALT and vegetation heights were measured at three other snow fences (Fences 2-4) in the region, to capture these conditions in a range of topographic settings. Fence 1 was in a poorly-drained peatland (Figure 6.2). Sedges dominated the vegetation cover near the fence where the ground was saturated. Fence 2 was on a $20^{\circ}$, well-drained tundra slope in Richardson Mountains. Fence 3 was in relatively flat, shrubby ground, but was well drained in comparison with Fence 1. Fence 4 was on a tundra slope $\left(5^{\circ}\right)$ in Richardson Mountains. The fences were erected in the early 1980s, and are approximately $1 \mathrm{~m}$ high.

\subsection{Field measurements and analyses}

Snow depths were measured at Fence 1 by probing in March 2013, 2014, and 2015 every $2 \mathrm{~m}$ along a 40-m transect normal to the fence (Figure 6.2). Thaw depths were measured along the transect in August 2012-15 with 1-cm diameter probes either 1.5 or $1.75 \mathrm{~m}$ long. The $1.75 \mathrm{~m}$ probe was not long enough to reach the frost table in 2013, so in 2015 a probe of $3 \mathrm{~m}$ length was used. ALTs were also estimated by probing at fences 2-4 in 2014, typically every $2 \mathrm{~m}$ along transects that ran $50 \mathrm{~m}$ from either site of the structures. Some transects were shorter than $50 \mathrm{~m}$ because of the proximity of the fences to the road embankment. Two transects were established at Fence 4 because of the structure's considerable length.

Ground temperatures were recorded in 2012-15 with shallow thermistor arrays at three locations at Fence 1, to compare conditions near the fence with those in 


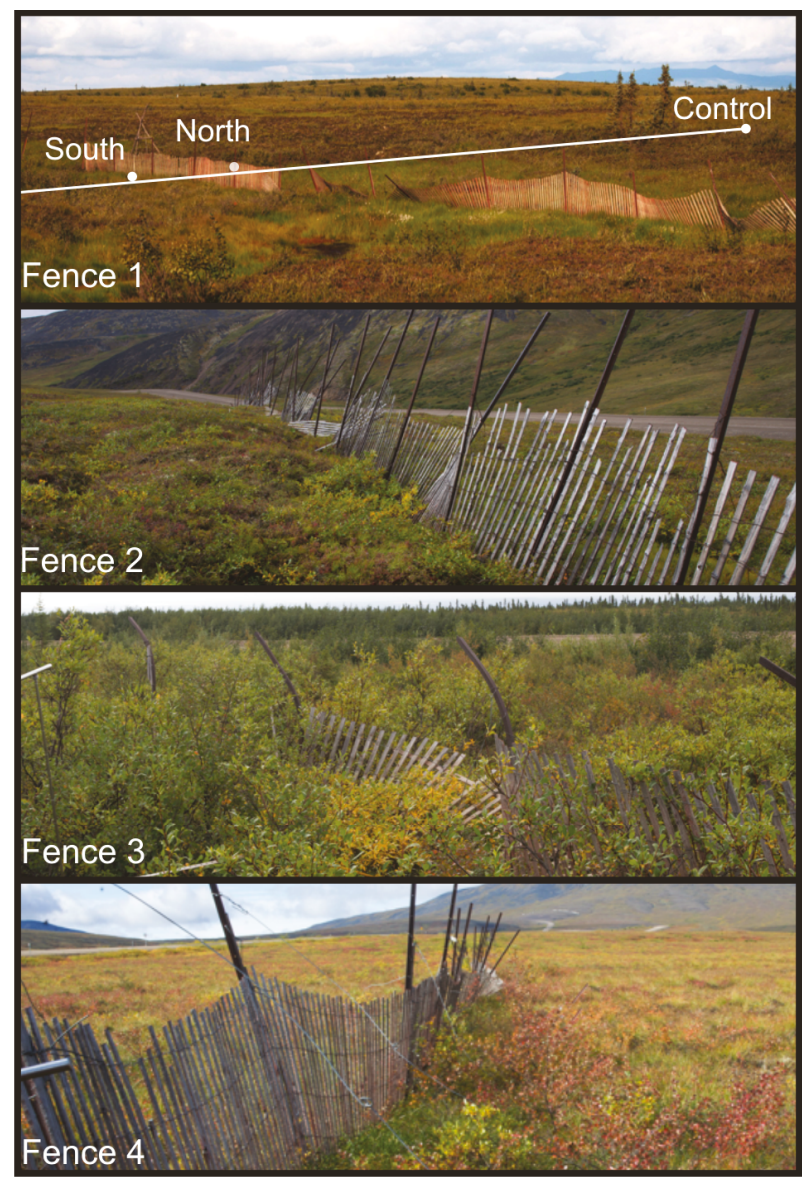

Figure 6.2: Field sites in summer 2014. Locations of the transect (line) and shallow thermistor arrays (dots) are shown for Fence 1. 
undisturbed terrain. Thermistors (HOBO TMC6-HA/D, Onset Computer Corp., Bourne, MA) were placed at 0.05 and 1-m depth at each location. The south and north sites were beside the fence in saturated ground. The control site was $25 \mathrm{~m}$ upwind of the fence. The thermistors were attached to data loggers (HOBO H08006-04), which recorded soil temperatures every two hours. The thermistors have a reported accuracy of $0.25^{\circ} \mathrm{C}$ over a measurement range of -40 to $50{ }^{\circ} \mathrm{C}$, and a resolution of about $0.45^{\circ} \mathrm{C}$ with the logger used. The ground surface profile along the transect was surveyed in summer 2012 with an optical level.

Core samples were retrieved from undisturbed permafrost in a borehole drilled approximately $5 \mathrm{~m}$ from the control site to characterize near-surface ground ice content and determine potential ground subsidence. The samples were retrieved using a hand-held drilling unit attached to a concrete corer (Calmels et al., 2005). The core samples comprised the top $0.85 \mathrm{~m}$ of permafrost. Samples were described and bagged

in the field, and excess-ice content was determined in the lab by allowing the samples to thaw in covered beakers. Excess-ice content (\%) was estimated for each sample.

Vegetation heights were measured in summer 2014 along the transects at fences 24 to examine the effect of the fences on shrub vegetation. Vegetation heights were not measured at Fence 1 because low sedges, not shrubs, dominated there. The Spearman rank correlation test was used to examine associations between ALT and vegetation height and distance from the snow fences. All statistical tests were conducted at the 0.05 significance level.

\subsection{Numerical simulations}

Numerical simulations of ground temperatures near Fence 1 were conducted using TEMP/W. The objective was to simulate the evolution of the ground thermal regime 
under the disturbed thermal conditions measured in the field.

The horizontal extent of the simulation was $40 \mathrm{~m}$, the same length as the field transect (Figure 6.2). As near-surface conditions were of interest, the vertical extent was limited to 50-m depth. Mesh size and element spacing increased incrementally from $0.05 \mathrm{~m}$ near the surface to $2 \mathrm{~m}$ beyond $20-\mathrm{m}$ depth.

The simplified model substrate profile consisted of a 0.8 m-thick layer of saturated peat underlain by saturated silty clay. The thermal properties of the materials are given in Table 6.1 and the temperature-dependent conductivity and unfrozen water content curves are shown in Figure 6.3. The frozen and unfrozen heat capacities were calculated using a weighted arithmetic mean of soil constituent heat capacities (e.g., Burn, 2004, eq. 3.3.5). The unfrozen water content curve of the mineral soil was that of Mayo silty clay, reported in Smith and Tice (1988), while values for peat are after Smith and Riseborough (2010). Mayo silty clay has a grain-size distribution similar to the fine-grained sediments on Peel Plateau. Temperature-dependent thermal conductivities were determined using an equation for composite ground material developed by Johansen (1977).

Ground surface temperatures were assigned as the upper boundary condition first in a (spin-up) simulation to establish an equilibrium temperature profile. The surface boundary condition for the spin-up was obtained by (1) reducing the median of three years of air temperatures (2012-14) measured on Peel Plateau based on the warming observed between 1951-1980 and 1981-2010 at Inuvik (similar data are not available from Fort McPherson), (2) calculating freezing and thawing season n-factors for the control site, and (3) from (1) and (2), estimating ground surface temperatures representative of conditions in 1951-1980 for the control site (Figure 6.5a). A geothermal heat flux of $0.05 \mathrm{~W} \mathrm{~m}^{-2}$ was assigned as the lower boundary condition in the simulations. The time step for calculations was 1 day. 
Next, the measured 2013-14 ground surface temperatures near the fence at the south instrument (i.e., disturbed conditions; Figure 6.5b) were imposed as a step change in a second (transient) simulation, from 14 to $32 \mathrm{~m}$ along the transect, coincident with the saturated, sedge-dominated ground observed in the field (Figure 6.2). Present-day (2013-14) conditions at the control site were assigned to the remainder of the transect. The disturbance was simulated for a 35-year period, about the age of the fence. The respective ground surface temperatures were looped each year for the duration of the two simulations, i.e., spin-up and disturbance.

\subsection{Results}

\subsubsection{Fence 1}

\section{Snow depths}

Although March snow depths varied between the three years of measurement, they were consistently greater near the fence than in adjacent tundra. Snow depths near the fence were up to $1.5 \mathrm{~m}$ in 2013 , while further from the structure they were $<1 \mathrm{~m}$. In 2014, there was less snow on Peel Plateau than in 2013 (O'Neill et al., 2015), and depths near the fence were about $1 \mathrm{~m}$. At either end of the transect, snow depths ranged from about 0.3 to $0.8 \mathrm{~m}$ (Table 6.2; Figure 6.4). In 2015, snow cover was up to $1.8 \mathrm{~m}$ thick near the fence, $<1 \mathrm{~m}$ near the control instrument, and thicker than in other years at the south end of the transect $(\sim 1.5 \mathrm{~m}$, Table 6.2$)$. 

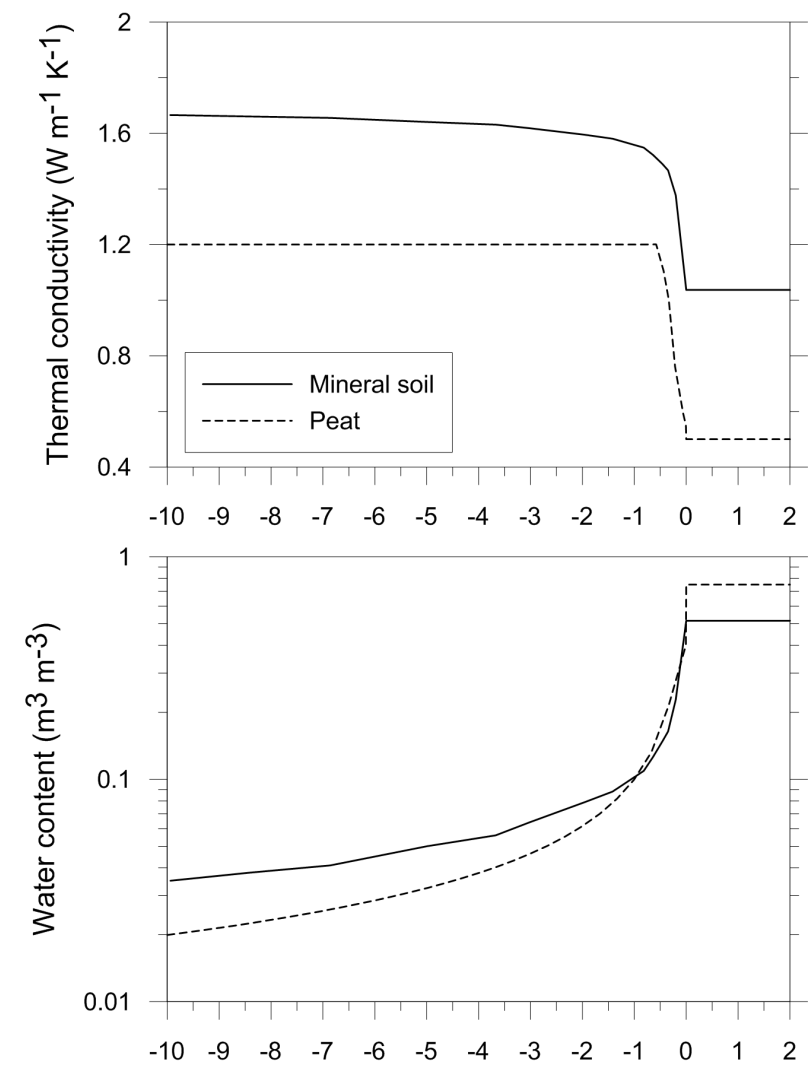

Figure 6.3: Thermal conductivity and unfrozen water content characteristic curves for mineral and peat used in modeling simulations. 
Table 6.1: Properties of peat and silty clay used in model simulations.

\begin{tabular}{lll}
\hline Description & Peat & Silty clay \\
\hline Volumetric water content $\left(\mathrm{m}^{3} \mathrm{~m}^{-3}\right)$ & 0.75 & 0.52 \\
Unfrozen heat capacity $\left(\mathrm{J} \mathrm{m}^{-3}{ }^{\circ} \mathrm{C}^{-1}\right)$ & $3.77 \mathrm{E}+06$ & $3.14 \mathrm{E}+06$ \\
Frozen heat capacity $\left(\mathrm{J} \mathrm{m}^{-3}{ }^{\circ} \mathrm{C}^{-1}\right)$ & $2.09 \mathrm{E}+06$ & $2.22 \mathrm{E}+06$ \\
\hline
\end{tabular}


Table 6.2: Late-summer thaw depth and late-winter snow depths along the transect at the fence, 2012-15. The + symbols indicate when the maximum length of the probe was attained, or when friction prevented the probe from reaching the frost table. Locations of the control $(\mathrm{C})$, north $(\mathrm{S})$, and south $(\mathrm{S})$ instruments are indicated in the distance column.

\begin{tabular}{|c|c|c|c|c|c|c|c|}
\hline \multirow{3}{*}{ Dist. (m) } & \multicolumn{4}{|c|}{ Thaw depth (m) } & \multicolumn{3}{|c|}{ Snow depth (m) } \\
\hline & $16-A u g$ & 14-Aug & 08-Aug & 22-Aug & 19-Mar & 25-Mar & 19-Mar \\
\hline & 2012 & 2013 & 2014 & 2015 & 2013 & 2014 & 2015 \\
\hline $0(\mathrm{C})$ & 0.61 & 0.44 & 0.49 & 0.54 & 0.74 & 0.72 & 0.83 \\
\hline 2 & 0.50 & 0.47 & 0.52 & 0.59 & 0.92 & 0.70 & 0.82 \\
\hline 4 & 0.60 & 0.43 & 0.45 & 0.52 & 1.02 & 0.71 & 0.75 \\
\hline 6 & 0.67 & 0.61 & 0.37 & 0.61 & 1.05 & 0.72 & 0.93 \\
\hline 8 & 0.63 & 0.77 & 0.40 & 0.74 & 1.16 & 0.89 & 0.93 \\
\hline 10 & 0.78 & 0.90 & 0.50 & 1.02 & 1.37 & 0.89 & 0.93 \\
\hline 12 & 0.88 & 1.00 & 0.60 & 1.25 & 1.45 & 1.07 & 0.94 \\
\hline 14 & 0.97 & 1.20 & 0.92 & 1.28 & 1.50 & 0.96 & 0.98 \\
\hline 16 & 1.14 & 1.30 & 1.05 & 1.35 & 1.42 & 0.97 & 1.33 \\
\hline 18 & 1.10 & 1.55 & $1.50+$ & 1.45 & 1.43 & 1.01 & 1.40 \\
\hline 20 & $1.50+$ & $1.75+$ & $1.50+$ & 1.20 & 1.43 & 0.97 & 1.45 \\
\hline $22(\mathrm{~N})$ & 1.00 & $1.75+$ & $1.50+$ & 1.40 & 1.40 & 1.00 & 1.72 \\
\hline 24 & $1.50+$ & $1.75+$ & 1.32 & 1.30 & 1.39 & 1.06 & 1.81 \\
\hline 26 & $1.50+$ & $1.75+$ & $\begin{array}{c}-\mathrm{Fe} \\
1.50+\end{array}$ & $1.50+$ & 1.41 & 1.01 & 1.48 \\
\hline $28(\mathrm{~S})$ & 1.30 & 1.25 & $1.50+$ & $1.60+$ & 1.39 & 1.00 & 1.48 \\
\hline 30 & 1.40 & 1.40 & $1.50+$ & $1.50+$ & 1.38 & 0.85 & 1.54 \\
\hline 32 & 1.10 & 1.28 & 1.33 & 1.30 & 1.35 & 0.48 & 1.52 \\
\hline 34 & 0.80 & 1.29 & 0.60 & $1.60+$ & 0.95 & 0.38 & 1.45 \\
\hline 36 & 0.62 & 0.41 & 0.57 & 0.51 & 0.90 & 0.33 & 1.48 \\
\hline 38 & 0.70 & 0.66 & 0.50 & 0.75 & 0.88 & 0.33 & 1.48 \\
\hline 40 & 0.55 & 0.70 & 0.48 & 0.80 & 0.87 & 0.38 & 0.83 \\
\hline
\end{tabular}




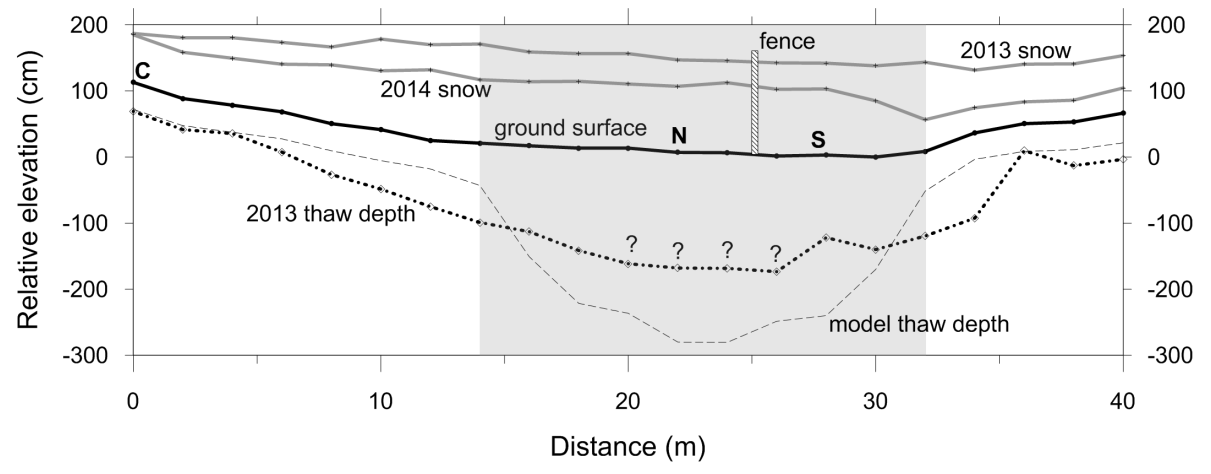

Figure 6.4: Cross-section of Fence 1 transect showing late-winter snow depths, ground relief, and August thaw depths from 2013 field measurements and the numerical simulation. The 2013 thaw depth data are shown because this is when the deepest probing near the fence was possible. Capital letters indicate the instrument locations. The shaded area represents wet, sedge-dominated ground, which prescribed the disturbed conditions in the simulation. 


\section{Ground temperatures}

Annual mean ground temperatures $\left(T_{g}\right)$, determined from August to August, were higher near the fence than at the control site in each year (Table 6.3). On the south side, $T_{g}$ at $1-\mathrm{m}$ depth was $0.6^{\circ} \mathrm{C}$ in $2012-13$, but the instrument was flooded in 2014 and 2015, and so values for these years could not be determined. On the north side, $T_{g}$ at 1 -m depth were $0.1,0.0$, and $-0.2{ }^{\circ} \mathrm{C}$ in $2012-13,2013-14$, and $2014-15$, respectively. This instrument was also inundated in 2015, but data were recorded until May, and so the annual value for 2014-15 was calculated from May-May at the site. Winter ground temperatures at $0.05-\mathrm{m}$ depth remained high $\left(>-2{ }^{\circ} \mathrm{C}\right)$ beside the fence, but dropped to considerably lower values $\left(<-8{ }^{\circ} \mathrm{C}\right)$ at the control site (Figure $\left.6.5 \mathrm{~b}\right)$. The $0.05 \mathrm{~m}$ ground temperatures at the control site were also consistently lower than at the sites beside the fence in summer.

\section{Late-summer thaw depth and ground subsidence}

Late-summer thaw depths were greater near the fence than near the ends of the transect (Figure 6.4; Table 6.2). In 2012-14, the thaw depth near the fence extended below the maximum length of the measurement probes. In 2015, when the $3 \mathrm{~m}$ probe was used, friction prevented penetration beyond $1.6 \mathrm{~m}$. Therefore, maximum thaw depth was not measured in the field.

During probing in August 2014, a thin (0.05-0.1 m) frozen layer was encountered at several locations near the fence at a depth of about $0.5 \mathrm{~m}$, i.e., within peat. This frozen layer was penetrated with the probe, and underlain by unfrozen ground, indicating a talik.

The ground around the fence had subsided noticeably as a result of the disturbed 


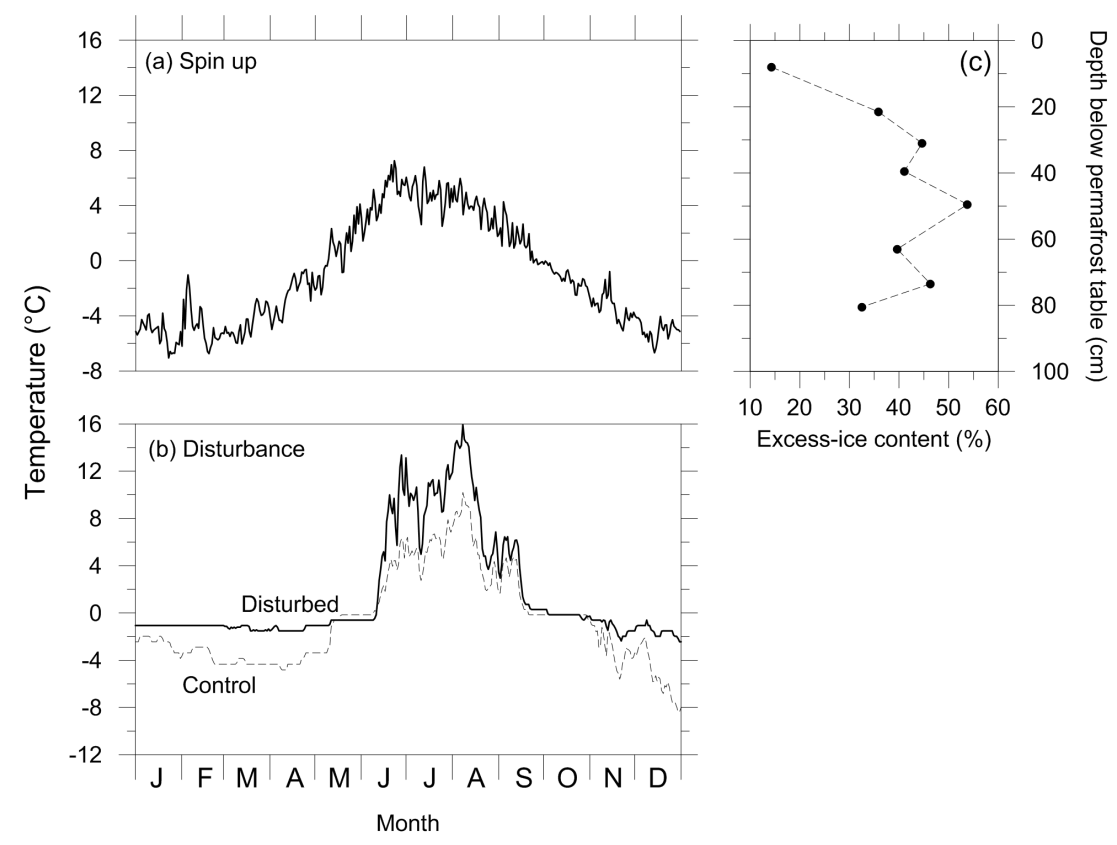

Figure 6.5: (a) Ground surface temperatures for the control site at Fence 1 calculated from air temperatures on Peel Plateau corrected to account for the cooler 1951-80 climate (see text), and n-factors for the site $\left(\mathrm{n}_{f}=0.21 ; \mathrm{n}_{t}=0.36\right)$ used for the model spin up; (b) measured temperatures in 2013-14 at 0.05-m depth near the fence (south instrument) and at the control site, used as the surface boundary conditions in the disturbance simulation; and (c) excess-ice contents from the core drilled near the control site in undisturbed tundra. The symbols represent the average depth of the retrieved core sections. 
Table 6.3: Annual mean ground temperatures $\left(T_{g}\right)$ at 0.05 and $1 \mathrm{~m}$ at the snow fence and control site in 2012-15. Minimum temperatures are shown in brackets beside the annual means. Annual period for most data begins near 15 August. For values marked with asterisks, the annual period begins on 1 May.

\begin{tabular}{llll|lll}
\hline Instrument & \multicolumn{3}{c|}{$\mathbf{T}_{\mathbf{g}(\mathbf{0 . 0 5})}\left({ }^{\circ} \mathrm{C}\right)$} & \multicolumn{3}{c}{$\mathbf{T}_{\mathbf{g}(\mathbf{1 . 0})}\left({ }^{\circ} \mathrm{C}\right)$} \\
& 2012-13 & 2013-14 & $2014-15$ & 2012-13 & 2013-14 & 2014-15 \\
\hline South & $2.2(-1.4)$ & n/a $(-2.4)$ & n/a & $0.6(-0.2)$ & n/a $(-0.6)$ & n/a \\
North & $1.8(-1.5)$ & $1.3(-2.4)$ & $1.9^{*}(-1.1)$ & $0.1(-0.6)$ & $0.0(-0.6)$ & 0.12 \\
Control & $-0.2(-4.8)$ & $-1.3(-8.9)$ & $0.9(-2.9)$ & $-0.8(-1.5)$ & $-1.1(-3.4)$ & $-0.6(-0.6)$ \\
\hline
\end{tabular}


thermal conditions and active-layer thickening. We estimate the subsidence to be about $0.5 \mathrm{~m}$ based on the ground surface profile surveyed in 2012 (Figure 6.4).

\section{Simulation results}

The talik formed under the snow fence after 25 years of disturbance. Talik configuration after 35 years is presented in Figure 6.6a, and summer thawing is shown in Figure 6.6b. In the first four years of disturbance, the rate of increase in late-summer thaw depth declined while thaw was restricted to the $0.8 \mathrm{~m}$ peat layer (Figure 6.6c). The rate increased as thaw penetrated into the mineral substrate. The talik rapidly increased in width following its initiation (Figure 6.6d). After 35 years, the talik was $1.3 \mathrm{~m}$ thick in its centre and about $11 \mathrm{~m}$ wide (Figure 6.6a,b). Similar results were obtained from a simulation with a vertical domain of $20 \mathrm{~m}$ and warmer initial ground conditions that had not been corrected for recent climate warming. These results indicate that, in general, the model is insensitive to such changes in geometry or small differences in initial surface conditions. The boundary conditions of the disturbance therefore largely control the timing of talik initiation and resulting thaw depths.

Annual increases in thaw depth under the fence declined when the bowl-shaped talik appeared in year 25 (Figure 6.6c). At that stage, the talik preferentially widened and the thaw depth under the fence remained relatively stable for several years. Lateral flow dominated the heat flux into frozen ground around the talik due to steeper temperature gradients in the horizontal dimension, because ground beneath the talik had warmed for several years before the talik formed. Lateral thaw caused the bottom of the talik to flatten out. However, as the horizontal gradient declined over time, thaw depth again increased (Figure 6.6c, year 30), and the thawed zone became more bowl-shaped (Figure 6.6b). The difference between talik thickness (July 
1) and thaw depth (Sept 1) is due to upfreezing from the top of permafrost, seasonal freezing at the surface, and thaw (May-July) at the base of the seasonally frozen ground (Figure 6.6c).

The simulated thaw depths after 35 years of disturbance were up to about $3 \mathrm{~m}$ (Figures 6.4 and 6.6). The deepest thaw could not be determined in the field due to friction along the probe, and so the difference between the measured and modeled values was not determined. The disturbance was simulated for an additional 165 years (total disturbance of 200 years). By this time, thaw depth on September 1 reached $5.6 \mathrm{~m}$, and was still increasing slowly. The closed talik was $15.5 \mathrm{~m}$ wide and $5.3 \mathrm{~m}$ thick on July 1 at the end of the simulation.

\subsection{Active-layer thickness and topography}

There was a significant negative correlation $(\rho=-0.20, \mathrm{p}<0.01, \mathrm{n}=164)$ between ALT and the distance from Fences 1-4 (Figure 6.7). However, the effect of the snow fences on the active layer was not consistent among the fences, but varied with topography. ALTs at the flattest sites (Fences 1 and 3) were statistically associated with distance from the fences $(\rho=-0.59, \mathrm{p}<0.01, \mathrm{n}=47)$, but not at sites on sloping ground (Fences 2 and 4, Figure 6.7) $(\rho=-0.13, \mathrm{p}=0.15, \mathrm{n}=117)$.

\subsection{Vegetation}

Two distinct vegetation responses were observed near the snow fences. First, the vegetation community has changed at Fence 1 from shrub-tundra species to wetland vegetation (Figure 6.2). At the control site in undisturbed tundra, cloudberry 

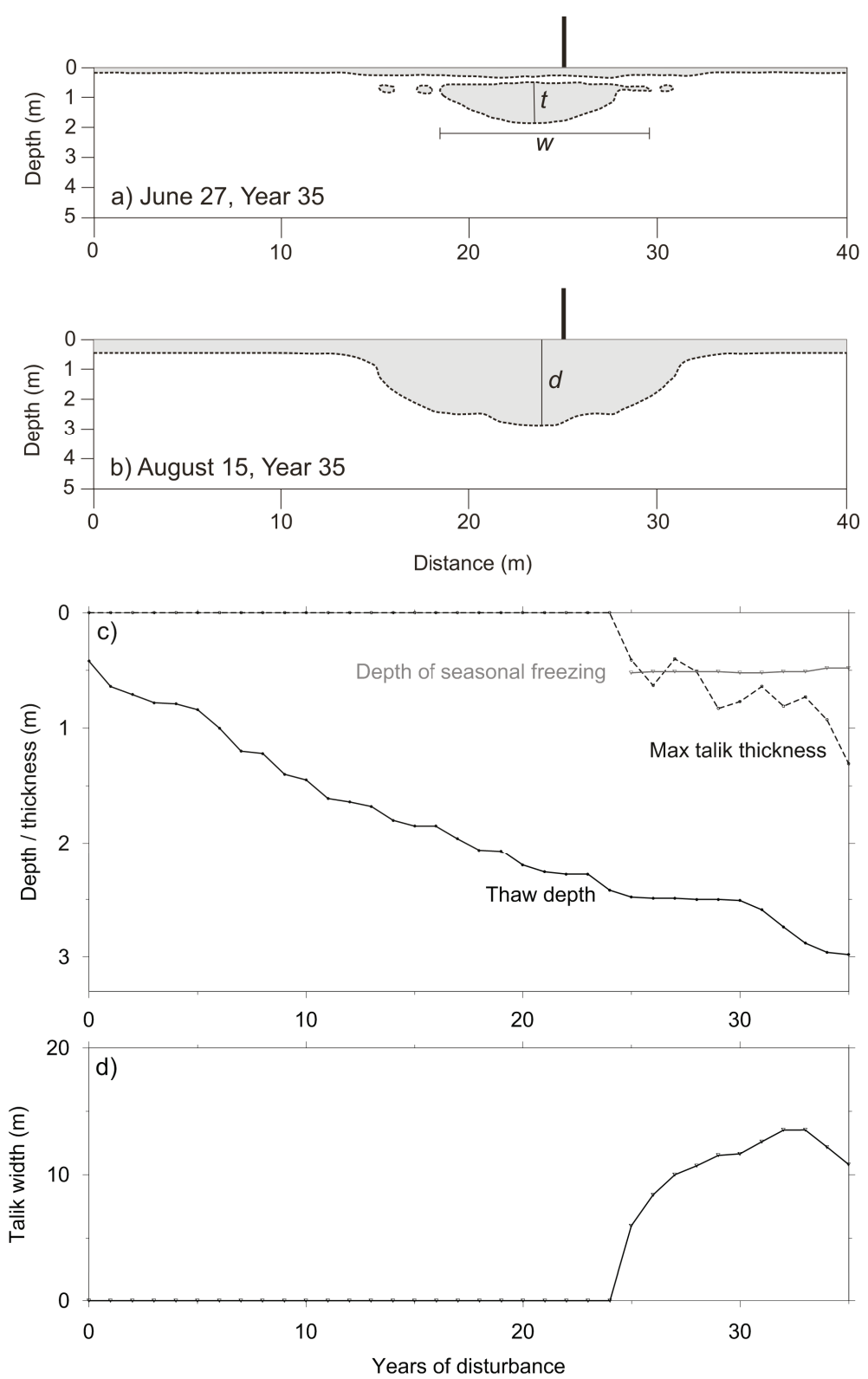

Figure 6.6: Numerical simulation of: (a) ground below $0{ }^{\circ} \mathrm{C}$ (white) and thawed ground (grey) at the end of June of year 35; maximum talik thickness $(t)$ is determined at this point, after winter upfreezing has ceased; $w=$ talik width; (b) late-summer thaw depth; $d=$ maximum thaw depth; (c) depth of seasonal freezing (on 1 May) above the talik, maximum talik thickness on 1 July (see a) and maximum thaw depth on 1 September (see b). The scalloped-shaped progression in the simulation of thaw depth is discussed by Riseborough (2008). (d) Talik width on 1 July (see a). Talik width was the maximum horizontal extent of the main thaw bulb. Isolated thawed zones adjacent to the main bulb were excluded. 


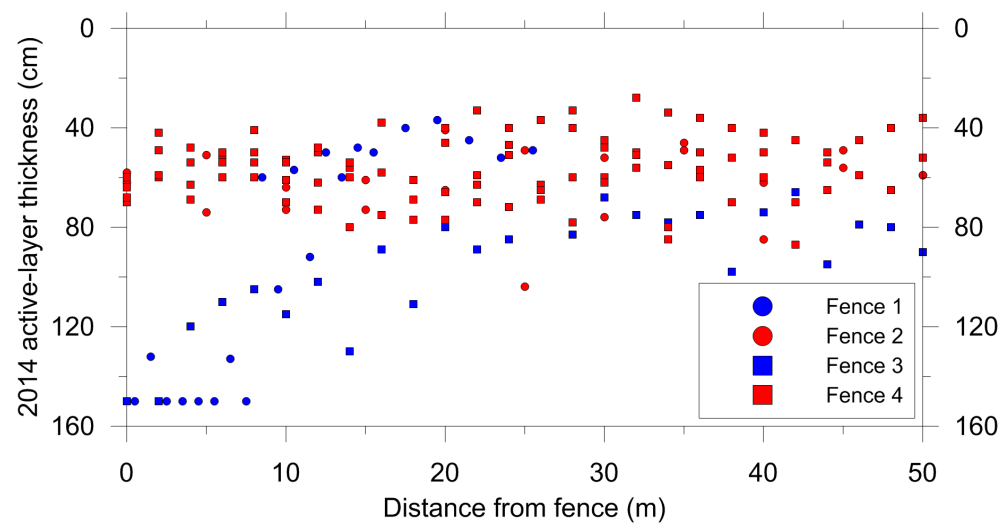

Figure 6.7: Active-layer thicknesses along transects at all fences in 2014. The blue data points are from sites on flat ground and the red points are from sites on slopes. 
(Rubus chamaemorus) and mosses dominated vegetation cover, with some low-lying shrubs such as dwarf-birch (Betula glandulosa), cranberry (Vaccinium vitis-idaea), and Labrador tea (Rhododendron subarcticum) also present. However, vegetation beside the fence consisted mostly of moisture-tolerant sedges (Carex spp.), with limited cover of cloudberry, dwarf-birch, mosses, and willows (Salix spp.). The second vegetation response observed was a change in shrub structure at Fences 2-4. Pooled data of vegetation height were significantly and negatively correlated $(\rho=-0.22, \mathrm{p}<0.01$, $\mathrm{n}=142$ ) with the distance from the fences (Figure 6.8), indicating that tundra shrubs have increased in height near Fences 2-4.

\subsection{Discussion}

\subsubsection{Long-term permafrost degradation at Fence 1}

Ground surface temperatures were higher near Fence 1 in winter due to snow accumulation and in summer due to the thermal properties of the saturated organic material. Considerable snow cover was present in late winter at the fence, and an iButton array indicated that deep $(>0.9 \mathrm{~m})$ snow accumulated there by early November 2012 , limiting heat loss in the freezing season (O'Neill et al., 2015). As a result, measured ground temperatures were higher near the fence than at the control site, and above $0{ }^{\circ} \mathrm{C}$ on an annual basis. In summer, ground temperatures at $0.05-\mathrm{m}$ depth were also typically higher near the fence than at the control site, because the saturated ground near the fence has a higher thermal diffusivity than the drier organic material at the control site (Burn, 2004; Johansson et al., 2013). There was no appreciable cooling effect from the persistence of the snow bank in summer as observed by Hinkel and Hurd (2006) at Barrow, because the smaller fence on Peel Plateau trapped less snow, 


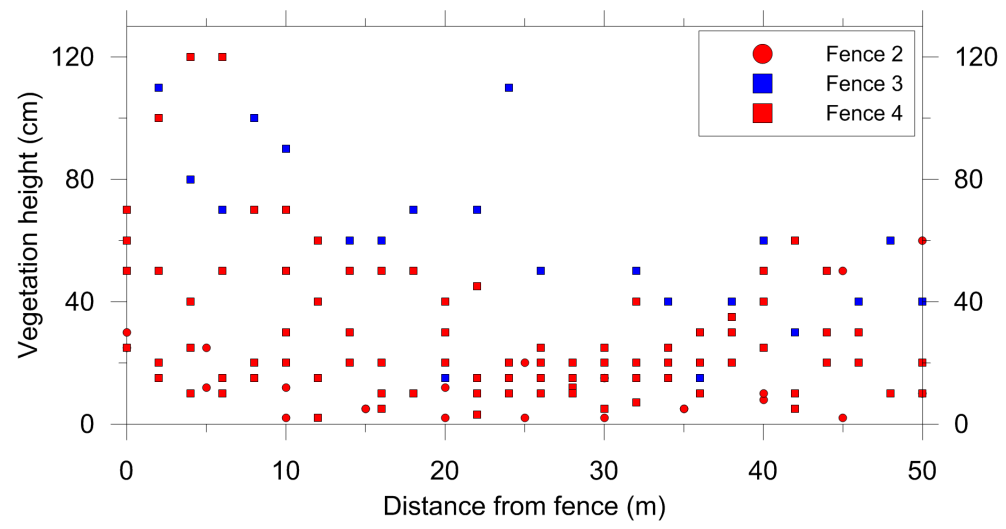

Figure 6.8: Vegetation heights along transects at Fences 2-4. The blue data are from the sites in flat ground and the red data are from sites on slopes. 
which melted by June 10, early in the thawing season.

Thaw depth was greater near the fence than at the control site, and appears to have increased by at least $1.25 \mathrm{~m}$. The mean excess-ice content of the retrieved core was $39 \%$ (Figure 6.5c), which, in conjunction with the increase in thaw depth of at least $1.25 \mathrm{~m}$, accounts for the $0.5 \mathrm{~m}$ subsidence observed (see subsidence potential, Equation 3.6).

The long-term consequence of the snow fence is significant ground warming (Figure 6.9) and development of a closed talik, indicated by probing in summer 2014, and replicated in the numerical simulation. This result is similar to the simulation by Fortier et al. (2011) of talik development over about 20 years beside a road embankment in northern Québec where deep snow cover develops. The simulation suggests that permafrost thaw will continue at the fence and that the talik will grow in the coming decades before equilibrium is established. However, it is difficult to suggest when or if this might occur because equilibrium conditions are predicated on climatic and surface boundary conditions that are, themselves, changing (Kennedy, 1992). The permafrost degradation at Fence 1 is demonstrative of the effect that saturated organic matter, and the associated high latent heat content, plays in delaying freezeback and acting as a catalyst for thermokarst initiation (Kokelj et al., 2014)

The model overestimated thaw depth between 15 and $30 \mathrm{~m}$ along the transect and underestimated it between about 5-15 $\mathrm{m}$ and 30-40 $\mathrm{m}$ (Figure 6.4). This is primarily due to the binary assignment of boundary conditions along the transect, with ground either under a disturbed or undisturbed thermal regime. In reality, a continuum of ground surface temperature regimes exists, with thermal disturbance likely decreasing with distance from the fence. The use of the most disturbed site conditions (south) in the simulation likely contributed to the deeper thaw depths near the fence, while 


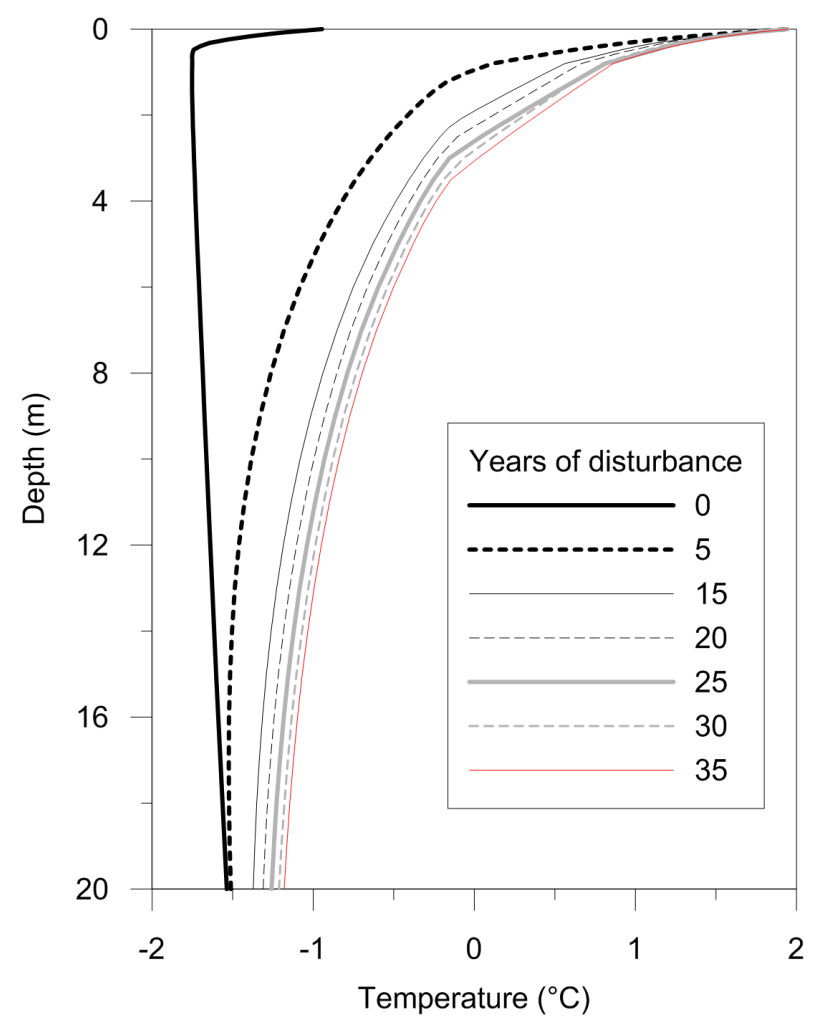

Figure 6.9: Simulated annual mean ground temperature profiles during the 35-year disturbance. 
the sharp distinction between disturbed and undisturbed conditions contributed to the underestimation further from the fence.

The modeled patches of thawed ground in Figure 6.6a and apparent inter-annual fluctuations in talik thickness seen in Figure 6.6c are likely a result of the unfrozen water content characteristic of the fine-grained substrate. These oscillating positions of the $0{ }^{\circ} \mathrm{C}$ isotherm should not be considered as a change in a discrete physical boundary, because they are caused by slight changes in temperature. Effects due to node spacing likely also account for some of the inter-annual oscillation in talik thickness, and for the scalloped shape of the thaw depth trace (Figure 6.6c, see Riseborough, 2008, Figure 1)

In summary, the thermal disturbance from increased snow cover at Fence 1 has caused permafrost degradation and substantial ground subsidence. The case study is an example of anthropogenic disturbance initiating thermokarst and the effects of snow fences on undisturbed terrain near linear transportation infrastructure. The modeling allowed the spatial and temporal boundaries of permafrost degradation to be examined, and demonstrated the evolution of ground thermal conditions in two dimensions during thermokarst initiation.

\subsection{Active-layer thickness, topography, and vege- tation response}

At Fences 1 and 3, in relatively flat ground, ALTs were thicker near the fences than at other sites surveyed. No similar systematic effects were observed in sloping terrain at sites 2 and 4 (Figure 6.7). This may be because water, either from thawed ground ice or precipitation, is able to drain away and does not increase the latent heat content 
of the active layer that must dissipate during freeze back. However, this should be investigated further, as the number of fences examined was limited, and ground ice conditions were unknown at Fences 2-4. There appeared to be some ground subsidence at Fences 2-4, though not to the extent observed in the wet environment at Fence 1.

Higher shrubs were observed in proximity to the structures at Fences 2-4 (Figures 6.2 and 6.8). This suggests that the snow fences enhance shrub growth, likely due primarily to protection from wind abrasion in winter within the snow pack, and to changed ground thermal, active layer, moisture, and nutrient conditions (e.g Sturm et al., 2001a). However, at Fence 1, the significant depression around the fence and associated saturated conditions has instead caused establishment of sedge vegetation. Therefore, it appears that the disturbance from snow fences in well-drained terrain is generally an anthropogenically-induced source of shrub enhancement for tundra, but where the ground becomes saturated, a shift in vegetation community may occur. The observation of shrub enhancement near infrastructure in the region is similar to that observed by Gill et al. (2014) beside the Dempster Highway embankment.

\subsection{Conclusions}

(1) A snow fence in operation (Fence 1) for about 35 years alongside the Dempster Highway has caused deep snow accumulation, leading to permafrost degradation. Probing in summer indicated a talik near the fence. Numerical simulations support the development of a talik under the thermal conditions measured at the site within the timespan of snow fence operation.

(2) Although thaw depths at the site were not measured at Fence 1 in the 1980s, when it was constructed, field measurements in 2013-15 at disturbed and undisturbed 
sites and the results in the numerical simulation suggest that the thaw depth has increased from about 0.5 to $>1.75 \mathrm{~m}$. A numerical simulation indicated thaw depths of up to $3 \mathrm{~m}$ after 35 years of disturbance. Thaw of the ice-rich top of permafrost has resulted in ground subsidence of $\sim 0.5 \mathrm{~m}$ at Fence 1 . Active-layer thicknesses are significantly greater near fences in flat ground, but were similar to undisturbed tundra at fences on slopes, presumably because water is able to drain away in sloped areas.

(3) The numerical simulation of Fence 1 suggests that permafrost degradation at the site may continue for many decades, as the thermal regime at the snow fence did not reach equilibrium after 200 years of disturbance.

(4) Vegetation has responded to disturbed conditions near snow fences. Increased shrub growth has occurred at well-drained sites, while sedges now dominate the vegetation cover at a poorly-drained site. 


\section{Chapter 7}

\section{Conclusions}

\section{$7.1 \quad$ Introduction}

This thesis has provided an improved understanding of relations between vegetation, snow, ground temperatures, and anthropogenic disturbance in areas of warm, continuous permafrost. The effect of air temperature inversions on continuous permafrost was also explored for the first time. Overall, this thesis has resulted in a baseline characterization of ground thermal conditions on Peel Plateau, Northwest Territories, a region of significant interest in recent literature.

Ground temperatures were recorded in undisturbed terrain across the alpine tree line between forest of the Peel Plain lowlands and tundra near the top of Peel Plateau. Permafrost conditions were also characterized in disturbed tundra vegetation near the Dempster Highway road embankment where deep snow accumulation has altered the ground surface energy balance and caused permafrost to degrade. The thermal influence of changing snow characteristics (depth, density, timing) on the ground thermal regime in the region was explored using one-dimensional numerical simulations. Finally, a detailed case study of permafrost degradation was conducted at a long-standing snow fence on Peel Plateau. Two-dimensional numerical simulations were used to investigate the timing and geometry of talik formation, and to simulate future degradation at the fence. Active-layer thicknesses and vegetation conditions 
were also recorded at three other snow fences near the embankment to examine their response to increased snow depths in different topographical settings.

The following sections briefly recount the main research objectives, summarize key conclusions and relevance, and suggest directions for future research.

\subsection{Key findings}

\subsubsection{Permafrost conditions across treeline on Peel Plateau}

The first objective of this research was to characterize ground temperatures across treeline in undisturbed terrain characteristic of Peel Plateau. Initially, it was anticipated that ground temperatures may not decline as much as across the forest tundra ecotone as at the nearby latitudinal treeline north of Inuvik, because of winter air temperature inversions between Peel Plateau and the surrounding lowlands.

Field measurements indicated that near-surface ground temperatures generally increased across treeline between Peel Plain and Peel Plateau. The annual mean temperature at the permafrost surface $\left(T_{p s}\right)$ in mineral soils increased with elevation from about $-2.5^{\circ} \mathrm{C}$ in lowland forest to about $-1.5^{\circ} \mathrm{C}$ in dwarf-shrub tundra. Twelve of fourteen $T_{p s}$ values from tundra on Peel Plateau were higher than values from lowland spruce forest on Peel Plain. The increase in $T_{p s}$ with elevation coincided with higher winter air temperatures over tundra due to strong atmospheric inversions, and earlier snow accumulation at tundra sites. Daily surface lapse rates during air temperature inversions were up to $3.5^{\circ} \mathrm{C} 100 \mathrm{~m}^{-1}$. The overall difference in air freezing degree-days between Peel Plain and Peel Plateau was equivalent in magnitude to a southern shift in latitude of nearly $200 \mathrm{~km}$.

This thesis has provided the first systematic examination of permafrost temperatures on Peel Plateau, a region that has attracted significant recent attention in the 
literature (Kokelj et al., 2013; Gill et al., 2014; Lacelle et al., 2015; Cameron and Lantz, 2016). This body of work provides a fundamental baseline of thermal data in the region and is a foundation for studies seeking to evaluate landscape changes in this sensitive landscape. The results contribute to understanding the interactions between air temperatures, vegetation, and snow in upland permafrost terrain. The higher $T_{p s}$ in alpine tundra on Peel Plateau compared to lowland forest in Peel Plain contrasts with the northward decrease in $T_{p s}$ across latitudinal treeline elsewhere in the western Canadian Arctic (Palmer et al., 2012). An increase in $T_{p s}$ with elevation may be common in Arctic mountain environments due to the prevalence of atmospheric temperature inversions in winter (Burns, 1973). In such contexts, although vegetation

characteristics are governed by summer climate (Walker, 2000), permafrost conditions are critically influenced by the winter regime. The permafrost on Peel Plateau is considerably warmer and, hence, more sensitive to disturbance than other tundra settings in the continuous permafrost zone.

\subsubsection{The anthropogenic thermal regime: permafrost condi- tions at the Dempster Highway road embankment}

The second objective was to characterize the ground thermal regime in disturbed ground near the toe of the Dempster Highway road embankment, where thick snow accumulates annually. It was hypothesized that the increased snow accumulation at the roadway has caused taliks to develop at some locations. One-dimensional numerical simulations that incorporated the accumulation and ablation of a snow pack were used to examine permafrost conditions near the road embankment and the effect of the snow accumulation regime and snow density on ground temperatures.

Measured annual mean ground temperatures at five sites near the embankment 
toe were between -2.2 and $0.0{ }^{\circ} \mathrm{C}$, and were -1.8 and $-2.6{ }^{\circ} \mathrm{C}$ at two control sites in undisturbed tundra. Permafrost was actively degrading near four of the five embankment sites, in association with deep $(>1 \mathrm{~m})$ snow accumulation. Late-summer thaw depths were $<1 \mathrm{~m}$ at the control sites, but up to $>5 \mathrm{~m}$ beside the road embankment; a talik was present at the most disturbed site.

Numerical simulations using the one-dimensional TONE model accurately reproduced ground thermal conditions in undisturbed tundra, near the embankment toe, and at the road centreline. This allowed subsequent simulations that examined the ground thermal response to manipulated snow conditions. These simulations indicated that limiting snow depth and increasing snow density may significantly reduce ground temperatures and prevent the thaw of ice-rich permafrost near the embankment toe.

This section of the thesis led to an understanding of the thermal disturbance caused by deep snow accumulation along linear infrastructure in tundra of the continuous permafrost zone. The research is of practical relevance as it characterized the consequences of permafrost degradation at the road, and suggested a method that may contribute to the effective management of infrastructure in permafrost regions. The results add to a growing body of literature on the disturbance to permafrost from northern infrastructure (e.g., Wu and Zhang, 2008; Bommer et al., 2010; Darrow, 2011; Streletskiy et al., 2012), and specifically in the western Canadian Arctic (Kokelj et al., 2010; Idrees et al., 2015; Burn et al., 2015).

\subsubsection{Permafrost degradation at snow fences}

The third objective was to simulate, in two dimensions, the long-term disturbance to permafrost from snow accumulation near the Dempster Highway. This involved a field-based case study from 2012-15 of ground temperatures, snow depths, and thaw 
depths at a snow fence near the highway embankment; the structure has been in place for about 35 years. Field data were used to parameterize a two-dimensional finiteelement thermal model to characterize the timing and geometry of talik formation at the site. Active-layer thicknesses and vegetation conditions were also measured at three other snow fences in the region to examine multi-decadal response to the increase in snow cover in different topographic settings.

Annual mean ground temperatures $\left(T_{g}\right)$ from two instruments near the fence was much higher than at a nearby control site in each year. $T_{g}$ at 1-m depth near the fence were between -0.2 and $0.6^{\circ} \mathrm{C}$, while at the control site $T_{g}$ was between -0.6 and -1.1 in 2012-15. Winter ground surface temperatures (0.05-m depth) remained high $\left(>-2{ }^{\circ} \mathrm{C}\right)$ beside the fence, but dropped to below $-8^{\circ} \mathrm{C}$ at the control site. The increased snow accumulation and associated ground warming has caused thaw depths to increase near the fence by at least $1.25 \mathrm{~m}$, resulting in thaw subsidence of about $50 \mathrm{~cm}$. A talik was indicated near the fence by probing in summer, and reproduced in a two-dimensional numerical simulation. The change in surface boundary conditions at the fence caused a talik to form after 25 years of disturbance in the numerical simulation. Thaw depths continued increasing into the future in the simulation for over 100 years, indicating the long-term nature of the disturbance. Active-layer thickness measurements from the three other fences in the region indicated that structures placed on slopes or on convex surfaces limit the thaw of permafrost, likely because water is able to drain away rather than accumulate in thaw depressions.

The snow fence case study demonstrated the effect of anthropogenic disturbance initiating thermokarst in undisturbed terrain near linear transportation infrastructure. The study is of practical relevance and may inform future snow fence placement along new infrastructure projects, like the Inuvik-Tuktoyaktuk highway. The results indicated that snow fences should be placed in topographical settings that facilitate 
drainage, and thus limit the thermal disturbance and prevent thermokarst initiation.

\subsection{Peel Plateau evolution}

The three results chapters have together provided valuable information on the thermal state of permafrost on Peel Plateau. Based on this information, future conditions in the region may be hypothesized; this section briefly describes potential thermal/physical changes on Peel Plateau.

The results in Chapter 4 identified that permafrost temperatures on Peel Plateau are typically $>-2{ }^{\circ} \mathrm{C}$. The warm ground combined with ice-rich sediments make Peel Plateau sensitive to disturbance that alters the surface energy balance. The effects of surface disturbance were explored in Chapters 5 and 6 ; increases in snow depth at infrastructure initiated talik formation within 30 years of the disturbance. The modelling at the snow fence site in Chapter 6 indicated that the thaw depth may continue to increase for many decades to come before equilibrium is established. The flat ground at this site facilitated thermokarst initiation, and the associated thaw settlement and inhibited drainage caused a shift to wetland vegetation.

The anticipated future climate warming may exacerbate present disturbances near infrastructure on Peel Plateau, and initiate thermokarst processes in presently unaffected ground. As the results in Chapter 6 indicated, the greatest disturbance will likely occur in flat or concave topographical settings, where thaw subsidence causes moisture to accumulate. These settings may be limited in the rolling natural terrain on Peel Plateau. On sloping terrain, increasing thaw depths in the future may result in differential settlement as near-surface ground ice melts, changing the local topography.

The concave topography formed by the road embankment has already caused 
thermokarst depressions, ponding, and related shifts in vegetation (Gill et al., 2014; Cameron and Lantz, 2016). The ground adjacent to the highway will likely continue being the most prone to future thermokarst development due to the deep snow that accumulates there annually. Further atmospheric forcing may cause these disturbances to enlarge, initiating feedbacks that lead to more extensive disturbance near the road (e.g., Gill et al., 2014). In contrast, modelling in Chapter 5 suggested that active snow management (i.e. the mechanical removal or compaction of snow) may effectively prevent future permafrost degradation in particularly vulnerable areas.

In addition to thermokarst development, the growth of large retrogressive-thaw slumps will likely continue in the region (e.g., Lacelle et al., 2015). Further increases in rainfall may contribute to greater slump activity (Kokelj et al., 2015). Therefore,

the future landscape on Peel Plateau could become more heterogeneous in terms of topography, vegetation, and moisture conditions as active and stabilized slumps scar the landscape, thermokarst depressions and ponds develop, and vegetation communities in and around these features shift.

\subsection{Directions for future research}

This thesis has characterized ground thermal conditions and their controlling factors on Peel Plateau, and quantified the disturbance to permafrost from infrastructure. Potential future research directions were identified through these investigations, and are outlined below. 


\subsubsection{Permafrost across treeline}

There are several topics that could be explored in future investigations of permafrost conditions on Peel Plateau. Since Chapter 4 was the first characterization of permafrost temperatures across the treeline in the region, the number of sites, particularly in forest settings, was limited. Additional ground temperature sensors could be installed to obtain a distribution of conditions in each vegetation type (e.g., Lin et al., 2015). This would enrich the results from this thesis, and enable probabilistic modelling to examine the ground thermal response to future climate warming in this environment of warm, ice-rich, and thus sensitive permafrost.

In this thesis, ground and air temperature measurements were collected between the lowlands of Peel Plain and the top of Peel Plateau. This elevational transect could be extended into Richardson Mountains, and long-term installations used to gain further insight into relations between air temperature, snow, and vegetation. This would contribute to the presently sparse data available from mountainous regions of North America (Gruber et al., 2015; Mountain Research Initiative EDW Working Group, 2015), and would be a unique monitoring network within the continuous permafrost zone.

\subsubsection{Infrastructure}

While numerous passive techniques exist to cool ground around infrastructure on permafrost (e.g., air convection embankments, heat drains, snow sheds, thermosyphons), this thesis has identified the potential for active snow management by mechanical means to reduce ground temperatures and limit thaw depths. This could be explored in a field test to determine the effectiveness and economy of mechanical snow compaction as a management strategy at sensitive portions of the highway. 
The simulations of conditions at the road embankment were limited to onedimension in this thesis. However, ground surface temperatures determined with TONE, which account for the accumulation and ablation of a snow pack, could be used to drive two-dimensional simulations that account for lateral heat flow (Smith and Riseborough, 2010). Climate change scenarios could be implemented in the onedimensional simulations to examine long-term effects of warming air temperatures or increases in precipitation (snow) on permafrost conditions.

Chapter 5 included a brief comparison of the freezing n-factor approach of determining ground surface temperatures and that of simulating a snow pack. The results suggested that the freezing season n-factor approach works reasonably well under a deep snow pack, but may underestimate ground surface temperatures early in the freezing season when less snow is present. However, this should be examined more formally in simulations designed specifically to determine differences between the two methods in generating key outputs such as thaw depths and annual mean ground temperatures.

\subsubsection{Thermokarst initiation}

The Dempster Highway on Peel Plateau offers an opportunity to study the early stages of thermokarst initiation. Numerous small ponds have formed adjacent to the embankment due to the formation of thaw depressions and infilling from rain and/or melt water. Permafrost degradation under shallow water during the early stages of thermokarst initiation remains poorly understood (Roy-Léveillée, 2014, p. 193). Recent studies from near the highway on Qinghai-Tibet Plateau have investigated this topic, albeit under very different environmental conditions ( Lin et al., 2010, 2016). In

addition to examining the thermal implications of these features, such studies near the Dempster Highway could be coupled with greenhouse gas flux measurements. This 
would help quantify the potentially important role of new ponds in the permafrostcarbon cycle (e.g., Laurion et al., 2010; Abnizova et al., 2012). 


\section{Bibliography}

Abele, G. (1990), Snow roads and runways, Cold Regions Research and Engineering Laboratory Monograph 90-3, Hanover, NH.

Abnizova, A., J. Siemens, M. Langer, and J. Boike (2012), Small ponds with major impact: The relevance of ponds and lakes in permafrost landscapes to carbon dioxide emissions, Global biogeochemical cycles, 26(2), 1-9.

Adhikari, R., and R. Agrawal (2013), An introductory study on time series modeling and forecasting, Lambert Academic Publishing, Germany.

Alfaro, M. C., G. A. Ciro, K. J. Thiessen, and T. Ng (2009), Case study of degrading permafrost beneath a road embankment, Journal of cold regions engineering, 23(3), 93-111.

Andersland, O. B., and B. Ladanyi (2004), Frozen ground engineering, John Wiley \& Sons, Hoboken, NJ.

Anisimov, O., and S. Reneva (2006), Permafrost and changing climate: the Russian perspective, Ambio: a journal of the human environment, 35(4), 169-175.

Auerbach, N. A., M. D. Walker, and D. A. Walker (1997), Effects of roadside disturbance on substrate and vegetation properties in Arctic tundra, Ecological applications, 7(1), 218-235.

Blok, D., M. M. P. D. Heijmans, G. Schaepman-Strub, A. V. Kononov, T. C. Maximov, and F. Berendse (2010), Shrub expansion may reduce summer permafrost thaw in Siberian tundra, Global change biology, 16(4), 1296-1305.

Bommer, C., M. Phillips, and L. U. Arenson (2010), Practical recommendations for planning, constructing and maintaining infrastructure in mountain permafrost, Permafrost and periglacial processes, 21(1), 97-104.

Bonnaventure, P. P., and A. Lewkowicz (2013), Impacts of mean annual air temperature change on a regional permafrost probability model for the southern Yukon and northern British Columbia, Canada, The cryosphere, 7, 935-946. 
Brown, J., O. J. Ferrians Jr, J. A. Heginbottom, and E. S. Melnikov (1997), Circum-Arctic map of permafrost and ground-ice conditions, U.S. Geological Survey Circum-Pacific Map Series CP-45, scale 1:10,000,000, Washington, DC.

Brown, J., K. M. Hinkel, and F. E. Nelson (2000), The circumpolar active layer monitoring (CALM) program: research designs and initial results, Polar geography, $24(3), 166-258$.

Brown, R. (1966), Influence of vegetation on permafrost, in Proceedings, Permafrost International Conference, 11-15 November 1963, Lafayette, IN, pp. 20-25, National Academy of Science - National Research Council, Washington, DC.

Brown, R. (1969), Factors influencing discontinuous permafrost in Canada, in The periglacial environment, past and present, edited by T. Péwé, pp. 11-53, McGillQueen's University Press, Montreal, QC.

Brown, R., and T. Péwé (1973), Distribution of permafrost in North America and its relationship to the environment; a review 1963-1973, in Proceedings, permafrost: North American contribution to The Second International Conference, 13-28 July 1973, Yakutsk, USSR, pp. 71-100, National Academies of Science, Washington, DC.

Burgess, M. M., and S. L. Smith (2000), Shallow ground temperatures, in The physical environment of the Mackenzie Valley, Northwest Territories: a base line for the assessment of environmental change, edited by L. Dyke and G. Brooks, pp. 89103, Natural Resources Canada, Ottawa, ON.

Burn, C. R. (1993), Comments on "Detection of climatic change in the western North American Arctic using a synoptic climatological approach", Journal of climate, $6(7), 1473-1475$.

Burn, C. R. (1994), Permafrost, tectonics, and past and future regional climate change, Yukon and adjacent Northwest Territories, Canadian journal of earth sciences, 31(1), 182-191.

Burn, C. R. (1997), Cryostratigraphy, paleogeography, and climate change during the early Holocene warm interval, western Arctic coast, Canada, Canadian journal of earth sciences, 34(7), 912-925.

Burn, C. R. (1998a), The response (1958-1997) of permafrost and near-surface ground temperatures to forest fire, Takhini River valley, southern Yukon Territory, Canadian journal of earth sciences, 35(2), 184-199.

Burn, C. R. (1998b), The active layer: two contrasting definitions, Permafrost and periglacial processes, $9(4), 411-416$. 
Burn, C. R. (2004), The thermal regime of cryosols, in Cryosols: permafrost-affected soils, edited by J. M. Kimble, pp. 391-413, Springer, Berlin Heidelberg.

Burn, C. R., and S. V. Kokelj (2009), The environment and permafrost of the Mackenzie Delta area, Permafrost and periglacial processes, 20(2), 83-105.

Burn, C. R., and C. A. S. Smith (1988), Observations of the "thermal offset" in near-surface mean annual ground temperatures at several sites near Mayo, Yukon Territory, Canada, Arctic, 41(2), 99-104.

Burn, C. R., and Y. Zhang (2009), Permafrost and climate change at Herschel Island (Qikiqtaruq), Yukon Territory, Canada, Journal of geophysical research, $114(\mathrm{~F} 2)$, $1-16$.

Burn, C. R., and Y. Zhang (2010), Sensitivity of active-layer development to winter conditions north of treeline, Mackenzie delta area, western Arctic coast, in Proceedings of the 6th Canadian Permafrost Conference, 12-16 September 2010, Calgary, Canada, pp. 12-16, Canadian Geotechnical Society, Richmond, BC.

Burn, C. R., J. R. Mackay, and S. V. Kokelj (2009), The thermal regime of permafrost and its susceptibility to degradation in upland terrain near Inuvik, N.W.T., Permafrost and periglacial processes, 20(2), 221-227.

Burn, C. R., J. L. Moore, H. B. O’Neill, D. H. Hayley, J. R. Trimble, F. Calmels, S. Orban, and M. Idrees (2015), Permafrost characterization for the Dempster Highway, in Proceedings, 68th Canadian Geotechnical Conference and 7th Canadian Permafrost Conference, 21-23 September 2015, Quebec City, QC, p. 8, Canadian Geotechnical Society, Richmond, BC.

Burns, B. M. (1973), The climate of the Mackenzie Valley-Beaufort Sea, 24, Environment Canada, Toronto, ON.

Burton, I. (1963), The quantitative revolution and theoretical geography, The Canadian geographer, 7(4), 151-162.

Calmels, F., O. Gagnon, and M. Allard (2005), A portable earth-drill system for permafrost studies, Permafrost and periglacial processes, 16(3), 311-315.

Cameron, E. A., and T. C. Lantz (2016), Drivers of tall shrub proliferation adjacent to the Dempster Highway, Northwest Territories, Canada, Environmental research letters, $11(4), 1-11$.

Carslaw, H., and J. Jaeger (1959), Heat conduction in solids, Oxford University Press, Oxford, UK. 
Chasmer, L., W. Quinton, C. Hopkinson, R. Petrone, and P. Whittington (2011), Vegetation canopy and eadiation controls on permafrost plateau evolution within the discontinuous permafrost zone, Northwest Territories, Canada, Permafrost and periglacial processes, 22(3), 199-213.

Christensen, T. R., T. Johansson, H. J. Åkerman, M. Mastepanov, N. Malmer, T. Friborg, P. Crill, and B. H. Svensson (2004), Thawing sub-arctic permafrost: effects on vegetation and methane emissions, Geophysical research letters, 31(4).

Church, M. (2013), Refocusing geomorphology: field work in four acts, Geomorphology, 200, 184-192.

Collins, M., R. Knutti, J. Arblaster, J. Dufresne, T. Fichefet, P. Friedlingstein, X. Gao, W. Gutowski, T. Johns, and G. Krinner (2013), Long-term climate change: projections, commitments and irreversibility, in Climate change 2013: the physical science basis. Contribution of Working Group I to the Fifth Assessment Report of the Intergovernmental Panel on Climate Change, edited by T. Stocker, D. Qin, G.K. Plattner, M. Tignor, S. Allen, D. J., A. Nauels, Y. Xia, V. Bex, and P. Midgley, pp. 1029-1136, Cambridge University Press, Cambridge, UK.

Darrow, M. M. (2011), Thermal modeling of roadway embankments over permafrost, Cold regions science and technology, 65(3), 474-487.

Darrow, M. M., and D. D. Jensen (2016), Modeling the performance of an air convection embankment (ACE) with thermal berm over ice-rich permafrost, Lost Chicken Creek, Alaska, Cold Regions Science and Technology, 130, 43-58.

de Grandpré, I., D. Fortier, and E. Stephani (2012), Degradation of permafrost beneath a road embankment enhanced by heat advected in groundwater, Canadian journal of earth sciences, 49(8), 953-962.

Doré, G., F. Niu, and H. Brooks (2016), Adaptation of transportation infrastructure built on degrading permafrost. Permafrost and Periglacial Processes, Permafrost and Periglacial Processes, 27, 1-13.

Driver, F. (2000), Editorial: field-work in geography, Transactions of the Institute of British Geographers, 25(3), 267-268.

Duk-Rodkin, A., and O. L. Hughes (1992), Surficial geology, Fort McPherson-Bell River, Yukon-Northwest Territories, Geological Survey of Canada Map 1745A, scale 1:250,000, Ottawa, ON.

Dumais, S., and G. Doré (2016), An albedo based model for the calculation of pavement surface temperatures in permafrost regions, Cold Regions Science and Technology, 123, 44-52. 
Elliott-Fisk, D. (2000), The taiga and boreal forest, in North American terrestrial vegetation, edited by M. Barbour and B. MD, pp. 41-74, Cambridge University Press, Cambridge, UK.

Environment Canada (2014), Climate normals and averages. http://climate.weather. gc.ca/climate_normals/index_e.html [March 14, 2014].

Farinotti, D., J. Magnusson, M. Huss, and A. Bauder (2010), Snow accumulation distribution inferred from time-lapse photography and simple modelling, Hydrological processes, 24 (15), 2087-2097.

Farouki, O. (1981), Thermal properties of soils, Cold Regions Research and Engineering Laboratory Monograph 81-1, Hanover, NH.

Flynn, D., D. Kurz, M. Alfaro, J. Graham, and L. U. Arenson (2016), Forecasting ground temperatures under a highway embankment on degrading permafrost, Journal of cold regions engineering, p. 04016002.

Fortier, R., A.-M. LeBlanc, and W. Yu (2011), Impacts of permafrost degradation on a road embankment at Umiujaq in Nunavik (Quebec), Canada, Canadian geotechnical journal, 48(5), 720-740.

Fulton, R. J. (1995), Surficial materials of Canada: materiaux superficiels du Canada, Geological Survey of Canada "A" Series Map 1880a, scale 1:5,000,000, Ottawa, ON.

Georges, C., and G. Kaser (2002), Ventilated and unventilated air temperature measurements for glacier-climate studies on a tropical high mountain site, Journal of geophysical research: atmospheres, 107(D24), 1-10.

Gill, G. (1983), Comparison testing of selected naturally ventilated solar radiation shields, Report to NOAA Data Buoy Office for Development Contract NA-82-OAA-266, NOAA, St. Louis, MO.

Gill, H. K., T. C. Lantz, H. B. O’Neill, and S. V. Kokelj (2014), Cumulative impacts and feedbacks of a gravel road on shrub tundra ecosystems in the Peel Plateau, Northwest Territories, Canada, Arctic, Antarctic, and alpine research, 46 (4), 947961.

Goodrich, L. E. (1982a), The influence of snow cover on the ground thermal regime, Canadian geotechnical journal, 19(4), 421-432.

Goodrich, L. E. (1982b), An introductory review of numerical methods for ground thermal regime calculations, Division of Building Research Paper No. 1061, National Research Council Canada, Ottawa, ON. 
Gruber, S., C. R. Burn, L. Arenson, M. Geertsema, S. Harris, S. L. Smith, P. Bonnaventure, and B. Benkert (2015), Permafrost in mountainous regions of Canada, in Proceedings, 68th Canadian Geotechnical Conference and 7th Canadian Permafrost Conference, 21-23 September 2015, Quebec City, QC, p. 8, Canadian Geotechnical Society, Richmond, BC.

Harazono, Y., M. Yoshimoto, and A. Miyata (1995), Micrometeorological data and their characteristics over the Arctic tundra at Barrow, Alaska during the summer of 1993, Miscellaneous publication of the National Institute of Agro-Environmental Sciences (Japan).

Harris, S. A., H. M. French, J. Heginbottom, G. H. Johnston, B. Ladanyi, D. Sego, and R. van Everdingen (Eds.) (1988), Glossary of permafrost and related groundice terms, Technical Memorandum no. 142, National Research Council of Canada, Ottawa, ON.

Heginbottom, J. A., M. A. Dubeuil, and P. T. Harker (1995), Canada - permafrost, in National Atlas of Canada, Fifth Edition, Natural Resources Canada map Plate 2.1 MCR 4177, scale 1:7,500,000, Ottawa, ON.

Henry, K., and M. Smith (2001), A model-based map of ground temperatures for the permafrost regions of Canada, Permafrost and periglacial processes, 12 (4), 389-398.

Hinkel, K. M., and J. K. Hurd, Jr. (2006), Permafrost destabilization and thermokarst following snow fence installation, Barrow, Alaska, U.S.A., Arctic, Antarctic, and alpine research, 38(4), 530-539.

Hinkel, K. M., F. Paetzold, F. E. Nelson, and J. G. Bockheim (2001), Patterns of soil temperature and moisture in the active layer and upper permafrost at Barrow, Alaska: 1993-1999, Global and planetary change, 29(3-4), 293-309.

Huculak, N. A., J. W. Twach, R. S. Thomson, and R. D. Cook (1978), Development of the Dempster Highway north of the Arctic Circle, in Proceedings, 3rd International Conference on Permafrost, 10-13 July 1978, Edmonton, AB, pp. 798-805, National Research Council of Canada, Ottawa, ON.

Idrees, M., C. R. Burn, J. L. Moore, and F. Calmels (2015), Monitoring permafrost conditions along the Dempster Highway, in Proceedings, 68th Canadian Geotechnical Conference and 7th Canadian Permafrost Conference, 21-23 September 2015, Quebec City, QC, p. 8, Canadian Geotechnical Society, Richmond, BC.

Johansen, O. (1977), Thermal conductivity of soils, Cold Regions Research and Engineering Laboratory Draft Translation 637, Hanover, NH.

Johansson, M., T. V. Callaghan, J. Bosiö, H. J. Åkerman, M. Jackowicz-Korczynski, and T. R. Christensen (2013), Rapid responses of permafrost and vegetation to 
experimentally increased snow cover in sub-arctic Sweden, Environmental research letters, 8(3), 035,025.

Johnston, G. H. (1981), Permafrost engineering design and construction, National Research Council of Canada, Ottawa, ON.

Jorgenson, M. T., V. E. Romanovsky, J. Harden, Y. Shur, J. O’Donnell, E. A. G. Schuur, M. Kanevskiy, and S. Marchenko (2010), Resilience and vulnerability of permafrost to climate change, Canadian journal of forest research, 40(7), 12191236.

Kane, D. L., K. M. Hinkel, D. J. Goering, L. D. Hinzman, and S. I. Outcalt (2001), Non-conductive heat transfer associated with frozen soils, Global and planetary change, 29(3-4), 275-292.

Kanigan, J. C. N., C. R. Burn, and S. V. Kokelj (2009), Ground temperatures in permafrost south of treeline, Mackenzie Delta, Northwest Territories, Permafrost and periglacial processes, 20(2), 127-139.

Karunaratne, K. C., and C. R. Burn (2003), Freezing n-factors in discontinuous permafrost terrain, Takhini River, Yukon Territory, Canada, in Proceedings of the 8th International Conference on Permafrost, 20-25 July 2003, Zurich, Switzerland, edited by W. Haeberli and D. Brandova, pp. 519-524, Swets and Zeitlinger, Lisse.

Keller, T., C. Pielmeier, C. Rixen, F. Gadient, D. Gustafsson, and M. Stähli (2004), Impact of artificial snow and ski-slope grooming on snowpack properties and soil thermal regime in a sub-alpine ski area, Annals of glaciology, 38(1), 314-318.

Kennedy, B. A. (1992), Hutton to Horton: views of sequence, progression and equilibrium in geomorphology, Geomorphology, 5(3-5), 231-250.

Kirkby, M. J., P. S. Naden, T. P. Burt, and D. P. Butcher (1987), Computer simulation in physical geography, John Wiley and Sons Ltd., Chichester, UK.

Kokelj, S. V., and C. R. Burn (2003), Ground ice and soluble cations in near-surface permafrost, Inuvik, Northwest Territories, Canada, Permafrost and periglacial processes, $14(3), 275-289$.

Kokelj, S. V., M. F. J. Pisaric, and C. R. Burn (2007), Cessation of ice-wedge development during the 20th century in spruce forests of eastern Mackenzie Delta, Northwest Territories, Canada, Canadian journal of earth sciences, 44(11), 15031515 .

Kokelj, S. V., D. W. Riseborough, R. Coutts, and J. C. N. Kanigan (2010), Permafrost and terrain conditions at northern drilling-mud sumps: Impacts of vegetation and climate change and the management implications, Cold regions science and technology, 64(1), 46-56. 
Kokelj, S. V., D. Lacelle, T. C. Lantz, J. Tunnicliffe, L. Malone, I. D. Clark, and K. S. Chin (2013), Thawing of massive ground ice in mega slumps drives increases in stream sediment and solute flux across a range of watershed scales, Journal of geophysical research: earth surface, 118(2), 681-692.

Kokelj, S. V., T. C. Lantz, S. A. Wolfe, J. C. Kanigan, P. D. Morse, R. Coutts, N. Molina-Giraldo, and C. R. Burn (2014), Distribution and activity of ice wedges across the forest-tundra transition, western Arctic Canada, Journal of geophysical research: earth surface, 119(9), 2032-2047.

Kokelj, S. V., J. Tunnicliffe, D. Lacelle, T. C. Lantz, K. S. Chin, and R. Fraser (2015), Increased precipitation drives mega slump development and destabilization of icerich permafrost terrain, northwestern Canada, Global and planetary change, 129, $56-68$.

Lacelle, D., M. St-Jean, B. Lauriol, I. D. Clark, A. Lewkowicz, D. G. Froese, S. C. Kuehn, and G. Zazula (2009), Burial and preservation of a 30,000 year old perennial snowbank in Red Creek valley, Ogilvie Mountains, central Yukon, Canada, Quaternary science reviews, 28(27), 3401-3413.

Lacelle, D., A. Brooker, R. H. Fraser, and S. V. Kokelj (2015), Distribution and growth of thaw slumps in the Richardson Mountains-Peel Plateau region, northwestern Canada, Geomorphology, 235, 40-51.

Lachenbruch, A. H., T. T. Cladouhos, and R. Saltus (1988), Permafrost temperature and the changing climate, in Proceedings of the Fifth International Conference on Permafrost, 2-5 August 1988, Trondheim, Norway, vol. 3, edited by K. Senneset, pp. 9-17, Tapir Publishers Trondheim, Norway.

Lafrenière, M. J., E. Laurin, and S. F. Lamoureux (2013), The impact of snow accumulation on the active layer thermal regime in high Arctic soils, Vadose zone journal, 12(1).

Lanouette, F., G. Dore, D. Fortier, and C. Lemieux (2015), Influence of snow cover on the ground thermal regime along an embankment built on permafrost: In-situ measurements, in Proceedings, 68th Canadian Geotechnical Conference and 7th Canadian Permafrost Conference, 21-23 September 2015, Quebec City, QC, p. 7, Canadian Geotechnical Society, Richmond, BC.

Lantz, T. C., S. E. Gergel, and S. V. Kokelj (2010), Spatial heterogeneity in the shrub tundra ecotone in the Mackenzie Delta region, Northwest Territories: implications for Arctic environmental change, Ecosystems, 13(2), 194-204.

Lantz, T. C., P. Marsh, and S. V. Kokelj (2013), Recent shrub proliferation in the Mackenzie Delta uplands and microclimatic implications, Ecosystems, 16(1), 4759. 
Laurion, I., W. F. Vincent, S. MacIntyre, L. Retamal, C. Dupont, P. Francus, and R. Pienitz (2010), Variability in greenhouse gas emissions from permafrost thaw ponds, Limnology and oceanography, 55(1), 115-133.

LeBlanc, A. M., G. A. Oldenborger, W. E. Sladen, and M. Allard (2014), Infrastructure and climate warming impacts on ground thermal regime, Iqaluit International Airport, southern Baffin Island, Nunavut, in Summary of activities 2014, pp. 119132, Canada-Nunavut Geoscience Office.

Leffingwell, E. d. K. (1915), Ground-ice wedges: the dominant form of ground-ice on the north coast of Alaska, The journal of geology, 23(7), 635-654.

Lepage, J.-M., and G. Doré (2010), Experimentation of mitigation techniques to reduce the effects of permafrost degradation on transportation infrastructures at Beaver Creek experimental road site (Alaska Highway, Yukon), in Proceedings of the 6th Canadian Permafrost Conference, 12-16 September 2010, Calgary, Canada, pp. 526-533, Canadian Geotechnical Society, Richmond, BC.

Lepage, J.-M., G. Doré, and D. Fortier (2012), Thermal effectiveness of the mitigation techniques tested at Beaver Creek Experimental road site based on a heat balance analysis (Yukon, Canada), in Cold Regions Engineering 2012: Sustainable Infrastructure Development in a Changing Cold Environment, pp. 42-51, ASCE Publications.

Lewkowicz, A. G. (2008), Evaluation of miniature temperature-loggers to monitor snowpack evolution at mountain permafrost sites, northwestern Canada, Permafrost and periglacial processes, 19(3), 323-331.

Lewkowicz, A. G., and P. P. Bonnaventure (2011), Equivalent elevation: a new method to incorporate variable surface lapse rates into mountain permafrost modelling, Permafrost and periglacial processes, 22(2), 153-162.

Lewkowicz, A. G., P. P. Bonnaventure, S. L. Smith, and Z. Kuntz (2012), Spatial and thermal characteristics of mountain permafrost, northwest Canada, Geografiska annaler: series A, physical geography, 94(2), 195-213.

Li, L., and J. W. Pomeroy (1997), Estimates of threshold wind speeds for snow transport using meteorological data, Journal of applied meteorology, 36(3), 205213.

Lin, Z., F. Niu, Z. Xu, J. Xu, and P. Wang (2010), Thermal regime of a thermokarst lake and its influence on permafrost, Beiluhe Basin, Qinghai-Tibet Plateau, Permafrost and periglacial processes, 21 (4), 315-324. 
Lin, Z., C. R. Burn, F. Niu, J. Luo, M. Liu, and G. Yin (2015), The thermal regime, including a reversed thermal offset, of arid permafrost sites with variations in vegetation cover density, Wudaoliang Basin, Qinghai-Tibet Plateau, Permafrost and periglacial processes, 26(2), 142-159.

Lin, Z., J. Luo, and F. Niu (2016), Development of a thermokarst lake and its thermal effects on permafrost over nearly $10 \mathrm{yr}$ in the Beiluhe Basin, Qinghai-Tibet Plateau, Geosphere, 12(2), 632-643.

Linell, K. (1973), Long-term effects of vegetative cover on permafrost stability in an area of discontinuous permafrost, in Proceedings, Permafrost: North American Contribution [to The] Second International Conference, 13-28 July 1973, Yakutsk, USSR, pp. 699-693, National Academies of Science, Washington, DC.

Lounsbury, J., and F. Aldrich (1986), Introduction to geographic field methods and techniques, Charles E Merrill Publishing, Columbus, $\mathrm{OH}$.

Lunardini, V. J. (1981), Heat transfer in cold climates, Van Nostrand Reinhold Company, New York, NY.

Luthin, J. N., and G. L. Guymon (1974), Soil moisture-vegetation-temperature relationships in central Alaska, Journal of hydrology, 23, 233-246.

Mackay, J. (1963), The Mackenzie Delta area, Queen's Printer and Controller of Stationery, Ottawa, ON.

Mackay, J. R. (1967), Permafrost depths, lower Mackenzie Valley, Northwest Territories, Arctic, 20(1), 21-26.

Mackay, J. R. (1977), Probing for the bottom of the active layer, in Geological Survey of Canada Paper 77, pp. 327-328, Geological Survey of Canada, Ottawa, ON.

Mackay, J. R. (1978), The use of snow fences to reduce ice-wedge cracking, Garry Island, Northwest Territories, in Current Research, Part A, Scientific and Technical Notes, Geological Survey of Canada Paper 78, pp. 523-524, Geological Survey of Canada, Ottawa, ON.

Mackay, J. R. (1993), Air temperature, snow cover, creep of frozen ground, and the time of ice-wedge cracking, western Arctic coast, Canadian journal of earth sciences, 30(8), 1720-1729.

Mackay, J. R. (1995), Active layer changes (1968 to 1993) following the forest-tundra fire near Inuvik, N.W.T., Canada, Arctic and alpine research, 27(4), 323-336.

Mackay, J. R., and C. R. Burn (2002), The first 20 years (1978-1979 to 1998-1999) of active-layer development, Illisarvik experimental drained lake site, western Arctic coast, Canada, Canadian journal of earth sciences, 39(11), 1657-1674. 
Mackay, J. R., and C. R. Burn (2011), A century (1910-2008) of change in a collapsing pingo, Parry Peninsula, western Arctic coast, Canada, Permafrost and periglacial processes, 22(3), 266-272.

Mackay, J. R., and D. K. MacKay (1974), Snow cover and ground temperatures, Garry Island, N.W.T., Arctic, $27(4), 287-296$.

McGregor, R., D. Hayley, G. Wilkins, E. Hoeve, E. Grozic, V. Roujanski, A. Jansen, and G. Dore (2010), Guidelines for development and management of transportation infrastructure in permafrost regions, Transportation Association of Canada report, Ottawa, ON.

Morse, P. D. (2013), Near-surface permafrost conditions, Kendall Island Bird Sanctuary, western Arctic coast, Canada, Ph.D. thesis, Carleton University, Ottawa, ON.

Morse, P. D., C. R. Burn, and S. V. Kokelj (2012), Influence of snow on near-surface ground temperatures in upland and alluvial environments of the outer Mackenzie Delta, Northwest Territories, Canadian journal of earth sciences, 49(8), 895-913.

Mountain Research Initiative EDW Working Group (2015), Elevation-dependent warming in mountain regions of the world, Nature climate change, 5(5), 424-430.

Natali, S. M., E. A. Schuur, E. E. Webb, C. E. H. Pries, and K. G. Crummer (2014), Permafrost degradation stimulates carbon loss from experimentally warmed tundra, Ecology, 95(3), 602-608.

Nauta, A. L., M. M. Heijmans, D. Blok, J. Limpens, B. Elberling, A. Gallagher, B. Li, R. E. Petrov, T. C. Maximov, J. van Huissteden, et al. (2015), Permafrost collapse after shrub removal shifts tundra ecosystem to a methane source, Nature climate change, 5(1), 67-70.

Nelson, F. E., O. A. Anisimov, and N. I. Shiklomanov (2001), Subsidence risk from thawing permafrost, Nature, 410(6831), 889-890.

Nelson, F. E., O. A. Anisimov, and N. I. Shiklomanov (2002), Climate change and hazard zonation in the circum-Arctic permafrost regions, Natural hazards, 26(3), 203-225.

Niu, F., J. Luo, Z. Lin, M. Liu, and G. Yin (2014), Morphological characteristics of thermokarst lakes along the Qinghai-Tibet engineering corridor, Arctic, Antarctic, and alpine research, $46(4), 963-974$.

Norris, D. K. (1984), Geology of the northern Yukon and northwestern District of Mackenzie, Geological Survey of Canada Map 1581A, scale 1:500 000, Ottawa, $\mathrm{ON}$. 
Odell, N. E. (1943), The geomorphology and glaciology of north-east greenland: review, The geographical journal, 101, 33-40.

Oelke, C., T. Zhang, M. C. Serreze, and R. L. Armstrong (2003), Regional-scale modeling of soil freeze/thaw over the Arctic drainage basin, Journal of geophysical research: atmospheres, $108(\mathrm{D} 10)$.

Oke, T. (1978), Boundary layer climates., Methuen and Co. Ltd., London, UK.

O’Neill, H. B., C. R. Burn, S. V. Kokelj, and T. C. Lantz (2015), 'Warm' tundra: atmospheric and near-surface ground temperature inversions across an alpine treeline in continuous permafrost, western Arctic, Canada, Permafrost and periglacial processes, 26(2), 103-118.

Osterkamp, T. E., and V. E. Romanovsky (1997), Freezing of the active layer on the coastal plain of the Alaskan Arctic, Permafrost and periglacial processes, 8(1), $23-44$.

Outcalt, S. I., F. E. Nelson, and K. M. Hinkel (1990), The zero-curtain effect: heat and mass transfer across an isothermal region in freezing soil, Water resources research, 26(7), 1509-1516.

Palmer, M. J., C. R. Burn, and S. V. Kokelj (2012), Factors influencing permafrost temperatures across tree line in the uplands east of the Mackenzie Delta, 2004-2010, Canadian journal of earth sciences, 49(8), 877-894.

Parajka, J., P. Haas, R. Kirnbauer, J. Jansa, and G. Blöschl (2012), Potential of time-lapse photography of snow for hydrological purposes at the small catchment scale, Hydrological processes, 26(22), 3327-3337.

Patterson, D. E., and M. W. Smith (1981), The measurement of unfrozen water content by time domain reflectometry: results from laboratory tests, Canadian geotechnical journal, 18(1), 131-144.

Phillips, M. R., C. R. Burn, S. A. Wolfe, P. D. Morse, A. J. Gaanderse, H. B. O’Neill, D. H. Shugar, and S. Gruber (2015), Improving water content description of ice-rich permafrost soils, in Proceedings, 68th Canadian Geotechnical Conference and 7th Canadian Permafrost Conference, 21-23 September 2015, Quebec City, QC, p. 7, Canadian Geotechnical Society, Richmond, BC.

Qin, Y., and J. Zhang (2013), A review on the cooling effect of duct-ventilated embankments in China, Cold Regions Science and Technology, 95, 1-10.

Richards, K. (1996), Samples and cases: generalisation and explanation in geomorphology, in Scientific Nature of Geomorphology: Proceedings of the 27th Binghamton Symposium in Geomorphology, September, 1996, Binghampton, USA, edited 
by B. Rhoads and C. Thorn, pp. 171-190, John Wiley and Sons Ltd., Chichester, UK.

Riseborough, D. W. (1990), Soil latent heat as a filter of the climate signal in permafrost, in Proceedings of the Fifth Canadian Permafrost Conference, 6-10 June 1990, Québec, QC, vol. 54, pp. 199-205, Centre d'études nordiques, Université Laval, Québec.

Riseborough, D. W. (2004), Exploring the parameters of a simple model of the permafrost-climate relationship, Ph.D. thesis, Carleton University, Ottawa, ON.

Riseborough, D. W. (2007), The effect of transient conditions on an equilibrium permafrost-climate model, Permafrost and periglacial processes, 18(1), 21-32.

Riseborough, D. W. (2008), Estimating active layer and talik thickness from temperature data: implications from modeling results, in Proceedings of the 9th International Conference on Permafrost, 28 June - 3 July 2008, Fairbanks, Alaska, USA, edited by D. L. Kane and K. M. Hinkel, pp. 1487-1492, Institute of Northern Engineering, Fairbanks, AK.

Riseborough, D. W., N. Shiklomanov, B. Etzelmüller, S. Gruber, and S. Marchenko (2008), Recent advances in permafrost modelling, Permafrost and periglacial processes, 19(2), 137-156.

Romanovsky, V. E., and T. E. Osterkamp (2000), Effects of unfrozen water on heat and mass transport processes in the active layer and permafrost, Permafrost and periglacial processes, $11(3)$, 219-239.

Roy-Léveillée, P. (2014), Permafrost and thermokarst lake dynamics in the Old Crow Flats, Northern Yukon, Canada, Ph.D. thesis, Carleton University Ottawa.

Roy-Léveillée, P., C. R. Burn, and I. D. McDonald (2014), Vegetation-permafrost relations within the forest-tundra ecotone near Old Crow, Northern Yukon, Canada, Permafrost and periglacial processes, 25(2), 127-135.

Schuur, E., A. McGuire, C. Schädel, G. Grosse, J. Harden, D. Hayes, G. Hugelius, C. Koven, P. Kuhry, D. Lawrence, et al. (2015), Climate change and the permafrost carbon feedback, Nature, 520(7546), 171-179.

Schuur, E. A. G., J. Bockheim, J. G. Canadell, E. Euskirchen, C. B. Field, S. V. Goryachkin, S. Hagemann, P. Kuhry, P. M. Lafleur, H. Lee, G. Mazhitova, F. E. Nelson, A. Rinke, V. E. Romanovsky, N. Shiklomanov, C. Tarnocai, S. Venevsky, J. G. Vogel, and S. A. Zimov (2008), Vulnerability of permafrost carbon to climate change: implications for the global carbon cycle, BioScience, 58(8), 701-714. 
Serreze, M. C., J. E. Walsh, F. S. Chapin III, T. E. Osterkamp, M. Dyurgerov, V. E. Romanovsky, W. C. Oechel, J. Morison, T. Zhang, and R. G. Barry (2000), Observational evidence of recent change in the northern high-latitude environment, Climatic change, 46(1-2), 159-207.

Shur, Y. L., and M. T. Jorgenson (2007), Patterns of permafrost formation and degradation in relation to climate and ecosystems, Permafrost and periglacial processes, 18(1), 7-19.

Simpson, G. G. (1963), Historical science, in The fabric of geology, edited by C. C. Albritton, pp. 24-48, Addison-Wesley Publishing, Reading, MA.

Smith, C. A. S., C. R. Burn, C. Tarnocai, and B. Sproule (1998), Air and soil temperature relations along an ecological transect through the permafrost zones of northwestern Canada, in Proceedings of the Seventh International Conference on Permafrost, 23-27 June 1998, Yellowknife, Canada, edited by A. G. Lewkowicz and M. Allard, pp. 23-26, Université Laval, Centre d'études nordiques, Québec.

Smith, M. W. (1975), Microclimatic influences on ground temperatures and permafrost distribution, Mackenzie Delta, Northwest Territories, Canadian journal of earth sciences, 12(8), 1421-1438.

Smith, M. W., and D. W. Riseborough (2002), Climate and the limits of permafrost: a zonal analysis, Permafrost and periglacial processes, 13(1), 1-15.

Smith, M. W., and A. R. Tice (1988), Measurement of the unfrozen water content of soils: comparison of NMR (nuclear magnetic resonance) and TDR (time domain reflectometry) methods, Cold Regions Research and Engineering Laboratory Report 88-18, Hanover, NH.

Smith, S. L., and M. M. Burgess (2000), Ground temperature database for northern Canada, Geological Survey of Canada Open File 3954.

Smith, S. L., and D. W. Riseborough (2010), Modelling the thermal response of permafrost terrain to right-of-way disturbance and climate warming, Cold regions science and technology, 60(1), 92-103.

Smith, S. L., V. E. Romanovsky, A. G. Lewkowicz, C. R. Burn, M. Allard, G. D. Clow, K. Yoshikawa, and J. Throop (2010), Thermal state of permafrost in North America: a contribution to the international polar year, Permafrost and periglacial processes, $21(2), 117-135$.

Streletskiy, D. A., N. I. Shiklomanov, and F. E. Nelson (2012), Permafrost, infrastructure, and climate change: a GIS-based landscape approach to geotechnical modeling, Arctic, Antarctic, and alpine research, 44(3), 368-380. 
Sturm, M., J. Holmgren, M. König, and K. Morris (1997), The thermal conductivity of seasonal snow, Journal of glaciology, 43(143), 26-41.

Sturm, M., J. Holmgren, J. P. McFadden, G. E. Liston, F. S. Chapin, and C. H. Racine (2001a), Snow-shrub interactions in Arctic tundra: a hypothesis with climatic implications, Journal of climate, $14(3), 336-344$.

Sturm, M., C. Racine, and K. Tape (2001b), Climate change: increasing shrub abundance in the Arctic, Nature, 411(6837), 546-547.

Tabler, R. (1991), Snow fence guide, Strategic Highway Research Program, Report SHRPW/FR-91-106, National Research Council, Washington, DC.

Tarnocai, C., J. G. Canadell, E. A. G. Schuur, P. Kuhry, G. Mazhitova, and S. Zimov (2009), Soil organic carbon pools in the northern circumpolar permafrost region, Global biogeochemical cycles, 23(2).

Taylor, A. E., M. Nixon, J. Eley, M. Burgess, and P. Egginton (1998), Effect of atmospheric temperature inversions on ground surface temperatures and discontinuous permafrost, Norman Wells, Mackenzie Valley, Canada, in Proceedings of the Seventh International Conference on Permafrost, 23-27 June 1998, Yellowknife, Canada, edited by A. G. Lewkowicz and M. Allard, pp. 1043-1048, Université Laval, Centre d'études nordiques, Québec.

Thompson, C., J. Beringer, F. S. Chapin III, A. D. McGuire, and J. Franklin (2004), Structural complexity and land-surface energy exchange along a gradient from arctic tundra to boreal forest, Journal of vegetation science, 15(3), 397-406.

Timoney, K. P., G. H. La Roi, S. C. Zoltai, and A. L. Robinson (1992), The high subarctic forest-tundra of northwestern Canada: position, width, and vegetation gradients in relation to climate, Arctic, pp. 1-9.

Viereck, L. A. (1982), Effects of fire and firelines on active layer thickness and soil temperatures in interior Alaska, in Proceedings of the 4th Canadian permafrost conference, 2-6 March 1981, Calgary, AB, edited by H. M. French, pp. 123-135, National Research Council of Canada, Ottawa, ON.

Wahl, H. E., D. B. Fraser, R. C. Harvey, and J. B. Maxwell (1987), Climate of Yukon, 233 pp., Climatological Studies Number 40, Atmospheric Environment Service, Environment Canada, Ottawa, ON.

Walker, D. A. (2000), Hierarchical subdivision of Arctic tundra based on vegetation response to climate, parent material and topography, Global change biology, $6(\mathrm{~S} 1)$, $19-34$.

Williams, P. J. (1982), The surface of the earth: an introduction to geotechnical science, Longman Group, London, UK. 
Williams, P. J., and M. W. Smith (1989), The frozen earth: fundamentals of geocryology, Cambridge University Press, Cambridge, UK.

Withers, C. W. (2011), Geography's narratives and intellectual history, in The Sage Handbook of Geographical Knowledge, edited by J. Agnew and D. Livingstone, pp. 39-50, Sage: Los Angeles, CA.

Wu, Q., and T. Zhang (2008), Recent permafrost warming on the Qinghai-Tibetan Plateau, Journal of geophysical research: atmospheres, 113(D13).

Yu, S., Z. Jianming, L. Yongzhi, and W. Jingmin (2002), Thermal regime in the embankment of Qinghai-Tibetan Highway in permafrost regions, Cold regions science and technology, 35(1), 35-44.

Yukon Ecoregions Working Group (2004), Peel River Plateau, in Ecoregions of the Yukon Territory: biophysical properties of Yukon landscapes, edited by C. A. Smith, C. F. Roots, and J. C. Meikle, pp. 75-82, Agriculture and Agri-Food Canada, PARC Technical Bulletin No. 04-01, Summerland, BC.

Zazula, G. D., G. MacKay, T. D. Andrews, B. Shapiro, B. Letts, and F. Brock (2009), A late Pleistocene steppe bison (Bison priscus) partial carcass from Tsiigehtchic, Northwest Territories, Canada, Quaternary science reviews, 28(25), 2734-2742.

Zhang, T. (1993), Climate, seasonal snow cover and permafrost temperatures in Alaska north of the Brooks Range, Ph.D. thesis, University of Alaska Fairbanks.

Zhang, T. (2005), Influence of the seasonal snow cover on the ground thermal regime: An overview, Reviews of geophysics, 43(4). 


\title{
Appendix A
}

\section{Signed co-author statements}

\author{
STATEMENT OF CO-AUTHORSHIP
}

I, Christopher R. Burn, as co-author of "“Warm' Tundra: Atmospheric and Near-Surface Ground Temperature Inversions Across an Alpine Treeline in Continuous Permafrost, Western Arctic, Canada", published in the peer-reviewed journal Permafrost and Periglacial Processes, of "Talik Formation at a Snow Fence in Continuous Permafrost, Western Arctic Canada" published in Permafrost and Periglacial Processes, of "Permafrost degradation adjacent to snow fences along the Dempster Highway, Peel Plateau, NWT", in the Proceedings of the 68th Canadian Geotechnical Conference and 7th Canadian Permafrost Conference, 21-23 September 2015, Quebec City, QC, and of "Field measurements of permafrost conditions beside the Dempster Highway embankment, Peel Plateau, NWT", in the Proceedings of the 68th Canadian Geotechnical Conference and 7th Canadian Permafrost Conference, 21-23 September 2015, Quebec City, QC, acknowledge Hugh Brendan O'Neill as the lead contributing author of these manuscripts. Brendan designed and performed the field studies, obtained and analyzed all data, and wrote and revised the manuscripts.

I, Christopher R. Burn, have contributed to the published papers in this thesis as supervisor of Hugh Brendan O'Neill during the doctoral program in Geography. This has entailed suggestions, discussion, criticism, advice, and editorial contributions to the design, field investigations, analysis, and writing of this thesis. These activities are entirely consistent with the role of thesis supervisor.

Christopher R. Burn $28 \mathrm{Sept} 2016$ 


\title{
STATEMENT OF CO-AUTHORSHIP
}

\begin{abstract}
I, Steve V. Kokelj, as co-author of "'Warm' Tundra: Atmospheric and Near-Surface Ground Temperature Inversions Across an Alpine Treeline in Continuous Permafrost, Western Arctic, Canada" and "Field measurements of permafrost conditions beside the Dempster Highway embankment, Peel Plateau, NWT", acknowledge Hugh Brendan O'Neill as the manuscripts' lead contributing author. Brendan designed and performed the studies, obtained and analyzed all data, and wrote and revised the manuscripts.
\end{abstract}

I, Steve V. Kokelj, have contributed to the published papers in the role of thesis committee member and principal investigator in the Northwest Territories Cumulative Impacts Monitoring Program (NWT CIMP) project, the community-driven research programme to which the papers in this thesis contribute. This involvement has included contributions to the design and implementation of field data collection, the supply of field instrumentation, discussion, criticism, and editorial revisions of the manuscripts. These activities have been entirely consistent with the roles of thesis committee member and principal investigator of the NWT CIMP project.

Steve V. Kokelj
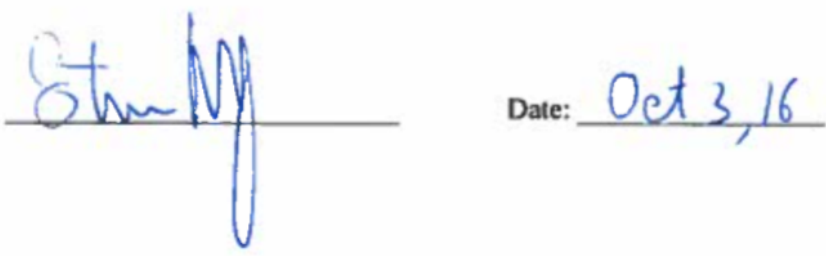
STATEMENT OF CO-AUTHORSHIP

I, Trevor C. Lantz, as co-author of " Warm' Tundra: Atmospheric and Near-Surface Ground Temperature Inversions Across an Alpine Treeline in Continuous Permafrost, Western Arctic, Canada", acknowledge Hugh Brendan O'Neill as the manuscript's lead contributing author. Brendan designed and performed the study, obtained and analyzed all data, and wrote and revised the manuscript.

I, Trevor C. Lantz, have contributed to the published paper in the role of a research partner and an investigator in the NWT CIMP project. This involvement has included assistance in the field, discussion, editorial revisions of the manuscript, and the contribution of ten data points to Figure 4.8 in the thesis (Figure 8 in the published paper). These activities have been entirely consistent with the roles of a research partner and investigator in the NWT CIMP project. 


\section{Appendix B}

\section{Other publications and presentations related to this research}

The following are refereed and non-refereed publications and presentations associated with this thesis.

\section{Journal articles}

Gill, H.K., T.C. Lantz, H.B. O’Neill, and S.V. Kokelj (2014), Cumulative Impacts and Feedbacks of a Gravel Road on Shrub Tundra Ecosystems in the Peel Plateau, Northwest Territories, Canada, Arctic, Antarctic, and Alpine Research, 46(4), 947961.

\section{Conference proceedings}

Burn, C.R., J.L. Moore, H.B. O’Neill, D.W. Hayley, J.R. Trimble, F. Calmels, S.N. Orban, and M. Idrees (2015), Permafrost characterization for the Dempster Highway, in Proceedings, 68th Canadian Geotechnical Conference and 7th Canadian Permafrost Conference, 21-23 September 2015, Quebec City, QC, Canadian Geotechnical Society, Richmond, BC. 8 p.

Phillips, M.R., C.R. Burn, S.A. Wolfe, P.D. Morse, A.J. Gaanderse, H.B. O'Neill, D.H. Shugar, and S Gruber (2015), Improving water content description of ice-rich permafrost soils., in Proceedings, 68th Canadian Geotechnical Conference and 7th Canadian Permafrost Conference, 21-23 September 2015, Quebec City, QC, Canadian Geotechnical Society, Richmond, BC. 7 p.

These conference proceedings are both available for download at: http://carleton.ca/permafrost/canadian-permafrost-conference/

\section{Selected conference presentations}


O’Neill, H.B., C.R. Burn, and S.V. Kokelj, (2016), Thermal conditions of permafrost on Peel Plateau, Northwest Territories, Canada. Oral presentation at the XI International Conference on Permafrost, 20-24 June 2016, Postdam, Germany.

O’Neill, H.B., and C.R. Burn, (2015), Permafrost degradation adjacent to snow fences along the Dempster Highway, Peel Plateau, NWT. Oral presentation at the 68th Canadian Geotechnical Conference and 7th Canadian Permafrost Conference, 21-23 September 2015, Québec City, Canada.

O'Neill, H.B., C.R. Burn, and S.V. Kokelj, (2015), Field measurements of permafrost conditions beside the Dempster Highway embankment, Peel Plateau, NWT. Oral presentation at the 68th Canadian Geotechnical Conference and 7th Canadian Permafrost Conference, 21-23 September 2015, Quebec City, Canada.

O'Neill, H.B., C.R. Burn, and S.V. Kokelj, (2014), Permafrost conditions across an Arctic alpine tree line in the continuous permafrost zone, NWT, Canada. Poster presentation at the 4 th European Conference on Permafrost, 18-21 June 2014, Évora, Portugal.

O'Neill, H.B., and C.R. Burn (2013), Permafrost conditions along the Dempster Highway, Peel Plateau, NWT. Oral presentation at the 4th Annual Workshop of the Network of Expertise on Permafrost, 5-8 June 2013, Fairbanks, Alaska.

\section{Other presentations}

O’Neill, H.B. (2014), Challenges on the Dempster Highway: permafrost conditions and environmental feedbacks. Oral presentation to The Arctic Circle club, 14 January 2014, Ottawa, Canada. 


\section{Appendix C}

\section{Copyright permissions}

Chapters 4 and 6 were published in the journal Permafrost and Periglacial Processes (PPP). John Wiley \& Sons, Inc. holds the copyright for most figures within these chapters. Permission for figure reproduction within this thesis was granted and the licenses are attached below. 


\section{JOHN WILEY AND SONS LICENSE TERMS AND CONDITIONS}

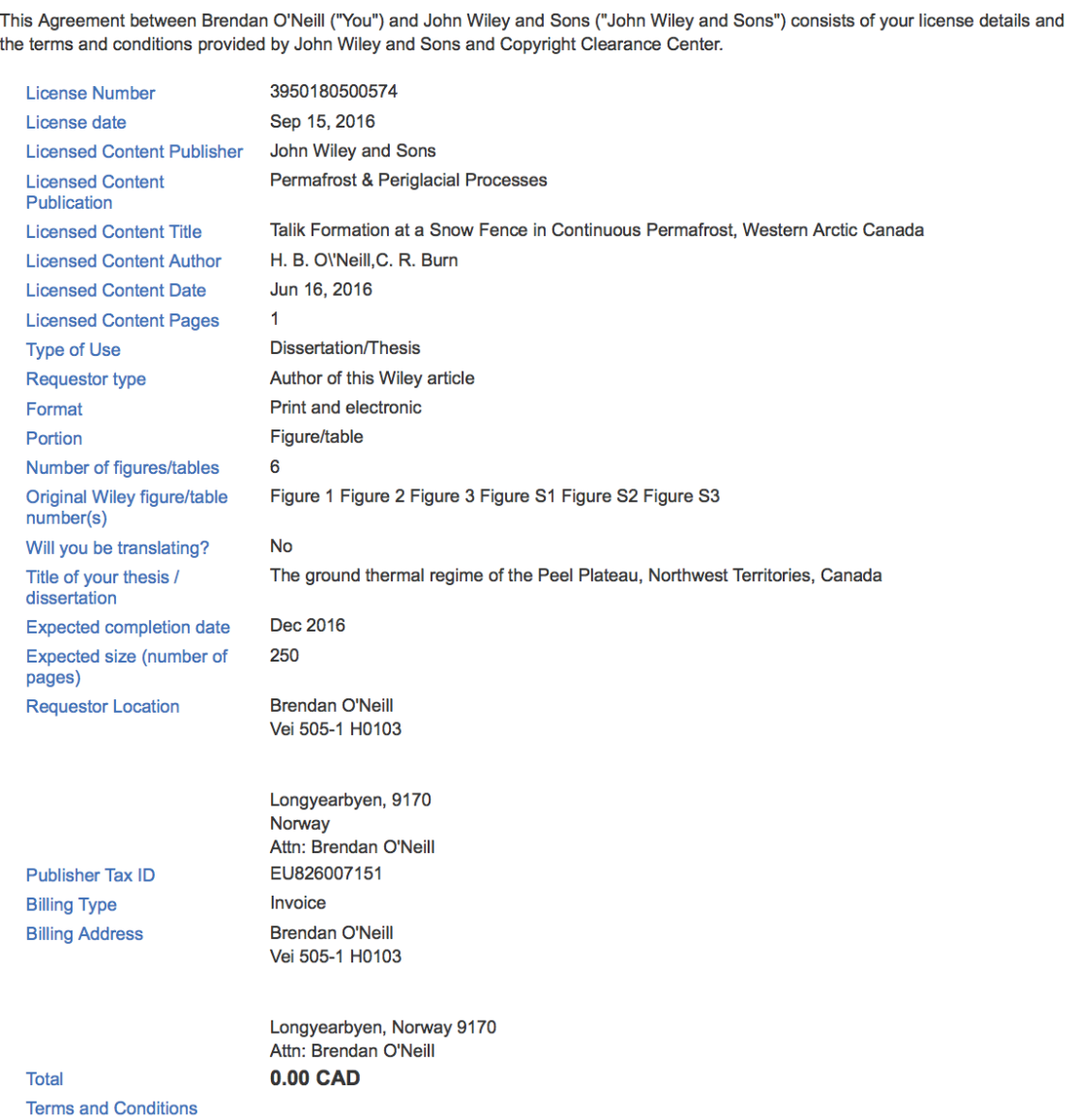


9/15/2016

RightsLink - Your Account

\section{JOHN WILEY AND SONS LICENSE TERMS AND CONDITIONS}

This Agreement between Brendan O'Neill ("You") and John Wiley and Sons ("John Wiley and Sons") consists of your license details and the terms and conditions provided by John Wiley and Sons and Copyright Clearance Center.

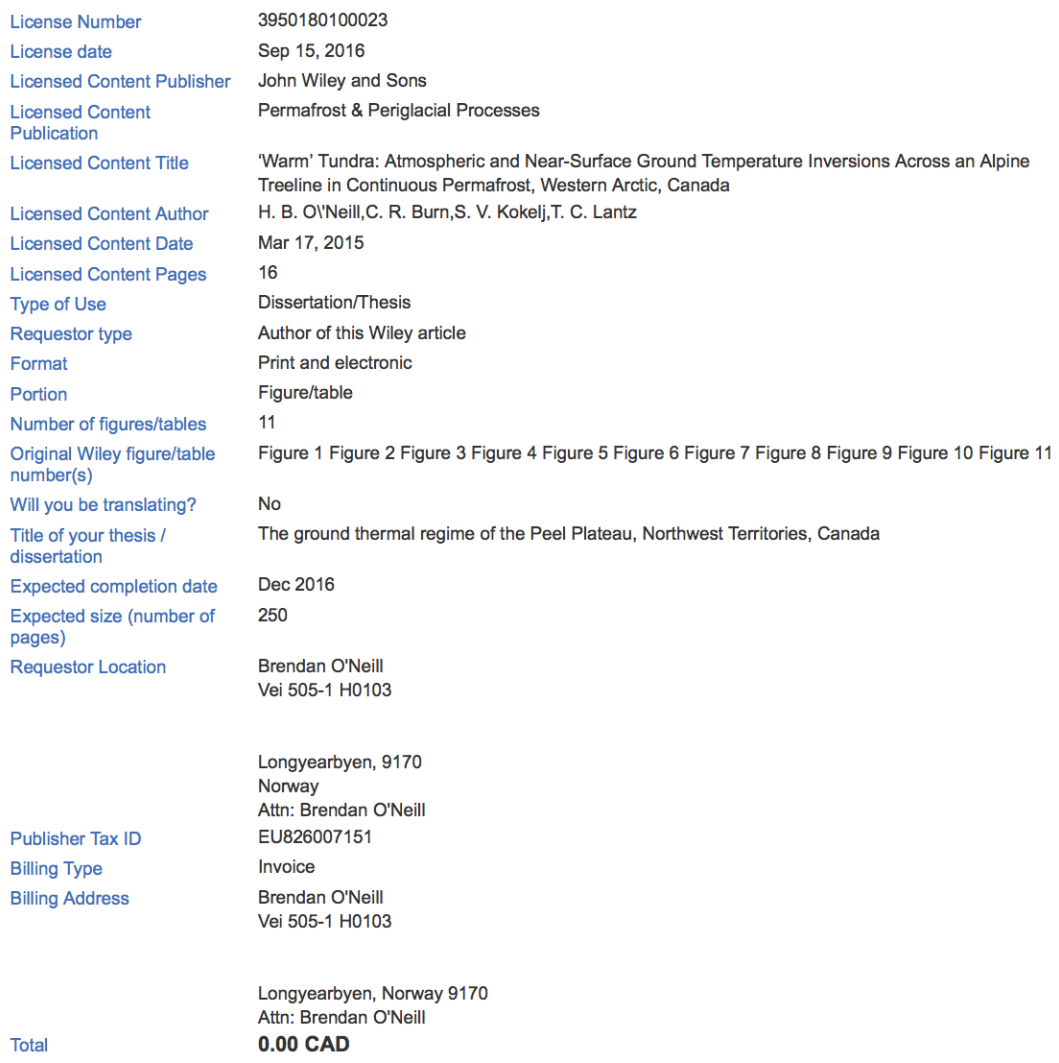

